Michael Fernandes de Almeida

\title{
Efeitos do exercício físico moderado sobre o tráfego de neurotrofinas e seus receptores no sistema nervoso central de ratos idosos
}

\author{
Dissertação apresentada à Faculdade de Medicina da \\ Universidade de São Paulo para obtenção do título de \\ Mestre em Ciências. \\ Programa de Fisiopatologia Experimental. \\ Orientadora: Profạ . Merari de Fátima Ramires Ferrari
}

São Paulo 

Michael Fernandes de Almeida

\title{
Efeitos do exercício físico moderado sobre o tráfego de neurotrofinas e seus receptores no sistema nervoso central de ratos idosos
}

\author{
Dissertação apresentada à Faculdade de Medicina da \\ Universidade de São Paulo para obtenção do título de \\ Mestre em Ciências. \\ Programa de Fisiopatologia Experimental. \\ Orientadora: Profạ . Merari de Fátima Ramires Ferrari
}

São Paulo 


\section{Dados Internacionais de Catalogação na Publicação (CIP)}

Preparada pela Biblioteca da

Faculdade de Medicina da Universidade de São Paulo

$$
\text { Creprodução autorizada pelo autor }
$$

Almeida, Michael Fernandes de

Efeitos do exercício físico moderado sobre o tráfego de neurotrofinas e seus receptores no sistema nervoso central de ratos idosos / Michael Fernandes de Almeida. -- São Paulo, 2015.

Dissertação(mestrado)--Faculdade de Medicina da Universidade de São Paulo.

Programa de Fisiopatologia Experimental.

Orientador: Merari de Fátima Ramires Ferrari.

Descritores: 1.Transporte axonal 2.Fatores de crescimento neural 3.Receptor TrkB 4.Exercício 5.Teste de esforço 6.Ratos 7.Neurodegeneração neural 


\section{DEDICATÓRIA}

Dedico o presente trabalho a minha mãe, Vanderléia Fernandes de Almeida, por toda sua luta, dedicação e carinho, por ter cuidado e cuidar de mim, me dando forças para superar todos os obstáculos,e por me ensinar o verdadeiro significado da vida. 


\section{AGRADECIMENTO}

Primeiramente agradeço a Deus, por me guardar e guiar todos os dias, hoje e sempre.

Agradeço aos meus familiares, em especial meus irmãos Diogo e Ana Carolina, que junto aos demais membros, e não menos importantes, são os pilares de minha vida e conquistas.

Agradeço minha orientadora Prof ${ }^{a}$. Dra ${ }^{a}$. Merari de Fátima Ramires Ferrari por não apenas ter permitido a realização deste trabalho, mas por abrir as portas e me impulsionar em um mundo, até então, distante ao meus olhos.

Ao Prof. Dr. Renato de Sousa Almeida por toda orientação, ajuda, paciência, dedicação, consideração e em especial por sua verdadeira amizade.

Aos professores, mestres, e meus grandes amigos! Em especial Enrique, Totó, Maurício e Helton por me ensinar os caminhos da aprendizagem, por me estimularem a busca por conhecimento e pela amizade.

Aos companheiros de laboratório, Rodrigo Chaves e Karen Farizatto, com quem nesses últimos anos passamos mais tempo comparado a qualquer outra pessoa de nosso convívio. Gostaria de agradecer a todos pela ajuda, pelo companheirismo, pelos esforços em todos os momentos.

Aos professores que gentilmente forneceram espaço físico e apoio intelectual para realização deste trabalho, em especial à Profáa Drạ. Débora Rejane Fior Chadi, pelo fornecimento da esteira de treinamento dos animais; à Prof ${ }^{a}$. Dra ${ }^{\text {a }}$. Edilamar Menezes de Oliveira, pelo auxilio no ensaio da enzima citrato-sintase.

Ao aluno Tiago Fernandes pela disponibilidade e auxílio para a realização do ensaio da enzima citrato-sintase. Também agradeço à aluna Carolliny Moura da Silva pelo auxílio na criação e treinamento dos animais. 
Aos amigos que trago comigo desde infância, aos que tive o prazer de conhecer durante a graduação e pós-graduação, e os que conheci ao longo de minha trajetória, meu muito obrigado.

A todos que direta ou indiretamente colaboraram com a realização deste trabalho, em especial os professores que permitiram a realização do mesmo em suas equipes e as pessoas que colaboraram com as coletas.

A todos, meus sinceros agradecimentos, eu não seria nada sem vocês, muito obrigado! 


\section{EPÍGRAFE}

"Não há garantia de que o universo se resigna às nossas predisposições. Mas não vejo como poderemos tratar com o universo - tanto o universo exterior como o interior - sem estudálo. A melhor maneira de evitar abusos é que a população em geral seja cientificamente educada, para compreender as implicações de tais investigações. Em troca da liberdade de investigação, os cientistas estão obrigados a explicar seus trabalhos. Se a ciência é considerada um sacerdócio fechado, muito difícil e elitista para a compreensão da pessoa média, os perigos de abuso são maiores. Mas se a ciência é um tópico de interesse e preocupação geral - se tanto suas coisas boas como suas conseqüências sociais forem discutidas regular e competentemente nas escolas, na imprensa, e nas mesas familiares teremos aumentado enormemente nossas possibilidades de entender como é realmente 0 mundo, e como melhorar a ele e a nós mesmos."

(Carl Sagan)

"Não sei como termina, mas sei por que começou". (autoria desconhecida) 


\section{NORMAS}

Este texto está de acordo com a seguintes normas em vigor no momento desta publicação:

Referências: Apresentadas de acordo com as normas da Associação Brasileira de Normas Técnicas (ABNT). Abreviaturas dos títulos dos periódicos de acordo com Listo of Journals Indexed in Index Medicus.

Estrutura Textual: desenvolvida de acordo com o disposto em: Universidade de São Paulo. Faculdade de Medicina. Divisão de Biblioteca e Documentação. Guia de apresentação de dissertações, teses e monografias. Elaborado por: Anneliese Carneiro da Cunha, Maria Julia de A. L. Freddi, Maria F. Crestana, Marinalva de Souza Aragão, Suely Campos Cardoso, Valéria Vilhena. $3^{a}$ ed. 2011. São Paulo: Divisão de Biblioteca e Documentação. 


\section{APOIO FINANCEIRO}

Fundação de Amparo à pesquisa do estado de São Paulo - FAPESP

Processos: 2011/15281-0 (bolsa de mestrado - beneficiário: Michael Fernandes de Almeida, período de 03/2012 a 02/2014), 2011/064347 (auxílio à pesquisa regular - responsável: Prof ${ }^{\mathrm{a}}$ Merari F.R. Ferrari) e 2012/15495-2 (auxílio à pesquisa regular - responsável:Profa Merari F.R. Ferrari).

Conselho Nacional de Desenvolvimento Científico e Tecnológico - CNPq

Processos: 471779/2010-5 e 471999/2013-0 (Editais Universais - responsável: Prof ${ }^{a}$ Merari F.R. Ferrari).

Coordenação de Aperfeiçoamento de Pessoal de Nível Superior - CAPES Bolsa de mestrado (período de 06/2014 a 09/2015). 


\section{SUMÁRIO}

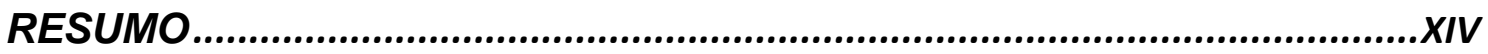

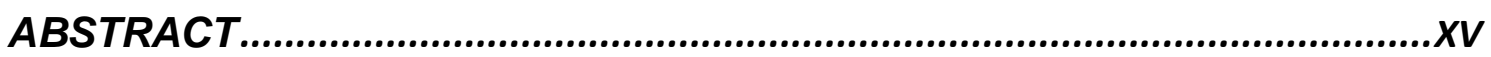

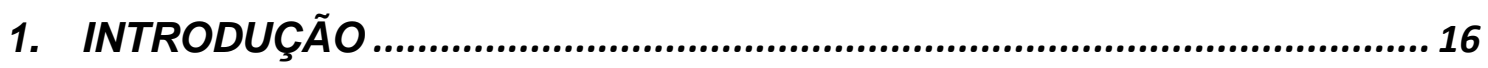

1.1. Envelhecimento e doenças neurodegenerativas ........................................................16

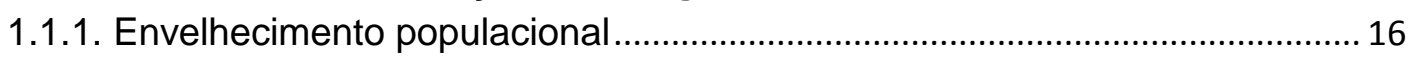

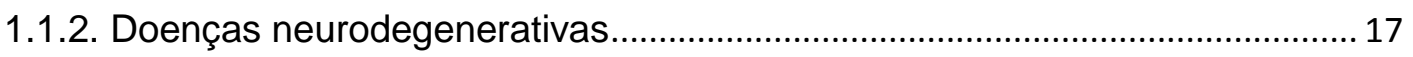

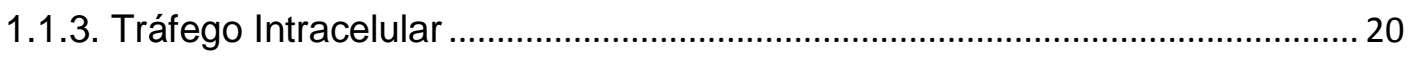

1.2. Exercício físico e doenças neurodegenerativas ...............................................................21

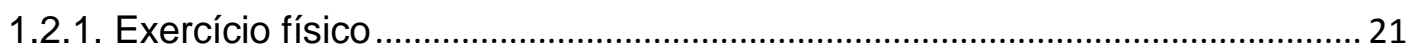

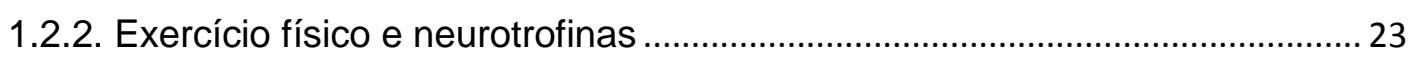

1.2.3. Neurotrofinas e seus receptores ...................................................................... 24

1.2.4. Tráfego de neurotrofinas e seus receptores ..................................................... 25

1.3. Modelo de neurodegeneração .........................................................................................27

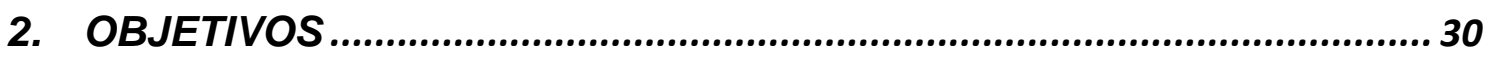

2.1. Objetivo geral ..........................................................................................................

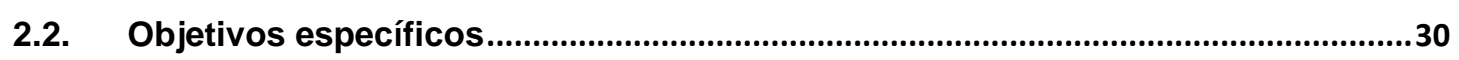

3. MATERIAIS E MÉTODOS..................................................................... 31

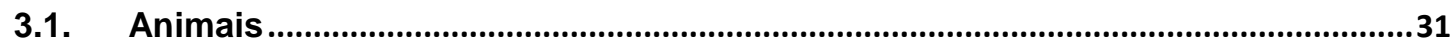

3.2. Exposição à rotenona ................................................................................................

3.3. Grupos experimentais..................................................................................................

3.4. Protocolo de exercício físico forçado …………............................................................

3.5. Coleta de material para análise ………….........................................................................35

3.6. Expressão de proteínas do tráfego intracelular por western blot ...........................38

3.7. Análise da atividade da enzima citrato-sintase .............................................................40

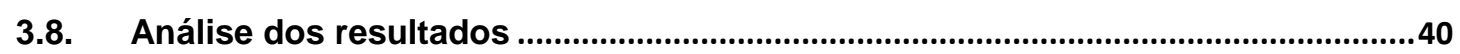

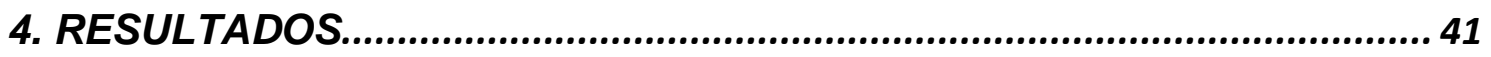

4.1. Variação da massa corporal durante protocolo de exposição à rotenona $e$ exercício físico forçado de intensidade moderada.

4.2. Efeitos do protocolo de exercício forçado, com intensidade moderada sobre a capacidade física

4.3. Atividade da citrato sintase no sóleo após exercício forçado, com intensidade moderada 


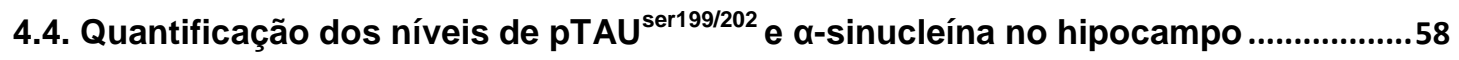

4.5. Quantificação dos níveis das isoformas de TrkB no hipocampo ...............................60

4.6. Níveis de proteínas do tráfego anterógrado de receptores TrKB no hipocampo ....63

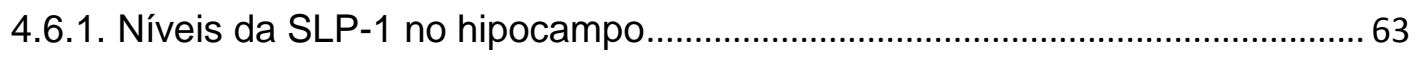

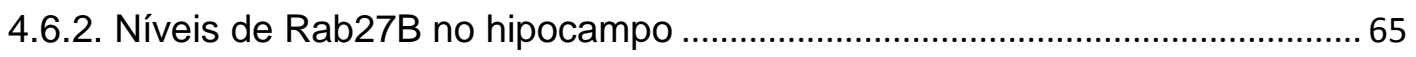

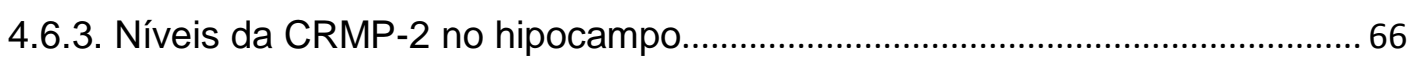

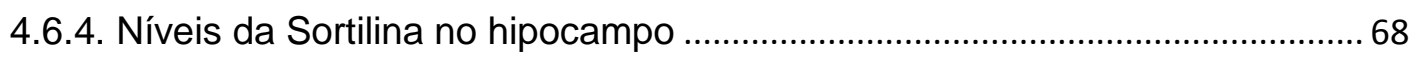

4.7. Níveis de proteínas do tráfego retrógrado de receptores TrKB no hipocampo ........71

4.7.1. Níveis de expressão da EDH-4 no hipocampo ............................................. 71

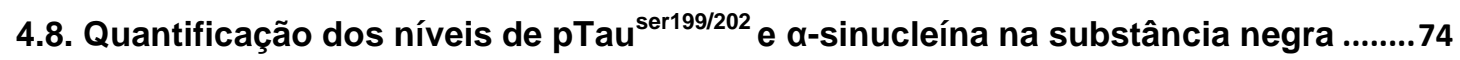

4.9. Quantificação dos níveis das isoformas de TrkB na substância negra.......................76

4.10. Níveis de proteínas do tráfego anterógrado de receptores TrkB na substância negra.

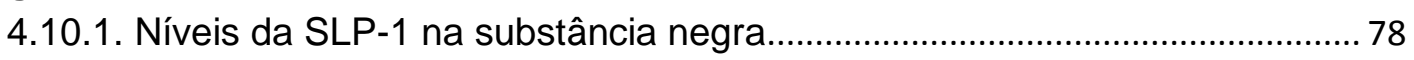

4.10.2. Níveis de Rab27B na substância negra ........................................................ 79

4.10.3. Níveis da CRMP-2 na substância negra ...................................................... 80

4.11. Quantificação dos níveis $\alpha$-sinucleína na medula cervical e torácica ........................84

4.12. Quantificação dos níveis de expressão das isoformas de TrkB na medula cervical

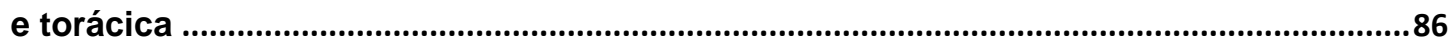

4.13. Níveis de proteínas do tráfego anterógrado de receptores TrkB na medula cervical e torácica ......................................................................................................................90

4.13.1. Níveis da SLP-1 na medula cervical e torácica ............................................ 90

4.13.2. Níveis da CRMP-2 na medula cervical e torácica.......................................... 90

4.13.3. Níveis da Sortilina na medula cervical e torácica ......................................... 92

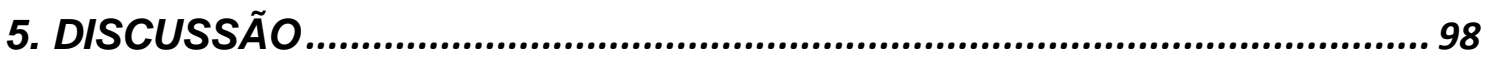

5.1. Tratamento com baixas doses de rotenona altera massa corporal de forma independente do treinamento físico

5.2. Exercício físico moderado aumentou a capacidade física independente do tratamento.

5.3. O protocolo de exercício físico elevou os níveis de atividade da enzima citratosintase no músculo sóleo e gastrocnêmio

5.4. Exposição a baixas doses de rotenona como modelo anterior a formação dos agregados proteicos.

5.5. Aumento nos níveis de expressão da TrkB em resposta a exposição à rotenona e à prática de exercício físico.

5.6. Exposição a baixas doses de rotenona e a expressão de proteínas envolvidas no tráfego de neurotrofinas e seus receptores 
7. REFERÊNCIAS BIBLIOGRÁFICAS..................................................... 119

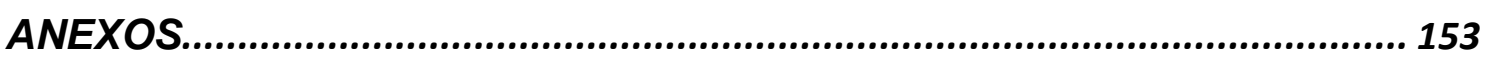

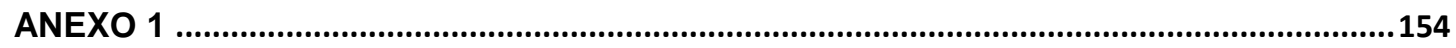

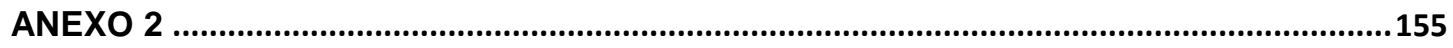

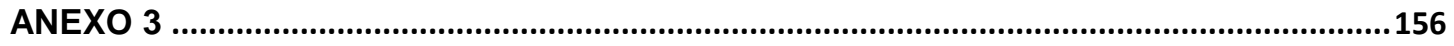




\section{RESUMO}

Almeida MF. Efeitos do exercício físico moderado sobre o tráfego de neurotrofinas e seus receptores no sistema nervoso central de ratos idosos [Dissertação]. São Paulo: "Faculdade de Medicina, Universidade de São Paulo"; 2015.

O exercício físico pode atenuar os efeitos do envelhecimento sobre o sistema nervoso central, por meio do aumento da expressão de neurotrofinas, tais como fator neurotrófico derivado do cérebro (BDNF), o qual promove a ramificação dendrítica e melhora da maquinaria sináptica, pela interação com seu receptor TrkB. Receptores TrkB são produzidos no corpo da célula e transportados aos terminais axonais, por meio de SLP1, CRMP2, Rab27B e Sortilina onde são ancorados para realizar seu papel fisiológico. Sabendo que a relação entre o tráfego de receptores de neurotrofinas e o treinamento físico ainda é pouco conhecida, o objetivo do presente trabalho é analisar os níveis do receptor TrkB, bem como de seus transportadores anterógrados e retrógrados, no sistema nervoso central de ratos idosos, modelos de neurodegeneração, expostos a diferentes protocolos de treinamento físico moderado. Os ratos do primeiro grupo experimental foram expostos a $1 \mathrm{mg} / \mathrm{kg} / \mathrm{dia}$ de Rotenona ou DMSO durante 4 semanas, depois, juntamente com a exposição à rotenona, realizaram treinamento físico moderado em esteira, 5 vezes por semana, durante 40 minutos; ou permaneceram em repouso. Os ratos do segundo grupo experimental realizaram 6 semanas de treinamento, sendo em seguida expostos à rotenona por 4 semanas, e subdividos em dois grupos, um que continuou o exercício e outro que ficou sedentário. Os resultados encontrados sugerem que o treinamento físico parece reverter ou prevenir de maneira geral os danos presentes na neurodegeneração considerando as proteínas do tráfego de BDNF e seu receptor, e ainda, que a magnitude e direção destas alterações está diretamente relacionada ao protocolo de treinamento físico, bem como, a região do sistema nervoso central analisada.

Descritores: transporte axonal; fatores de crescimento neural; receptor TrkB; exercício; teste de esforço; ratos, neurodegeneração neural. 


\begin{abstract}
Almeida MF. Effects of moderate physical exercise upon intracellular trafficking of neurotrophins and their receptors in the central nervous system of aged rats [Dissertation]. Sao Paulo: "Faculdade de Medicina, Universidade de Sao Paulo"; 2015.

Physical exercise can attenuate the effects of aging on the central nervous system by increasing the expression of neurotrophins such as brainderived neurotrophic factor (BDNF), which promotes dendritic branching and enhances synaptic machinery, through interaction with its receptor TrkB. TrkB receptors are synthesized in the cell body and are transported to the axonal terminals, through SLP1, CRMP2, Sortilin and Rab27B, to where receptors are anchored to perform its physiological role. However, the aspects of the neurotrophin receptors traffic after physical training is still a matter of investigation. Thus, the present study aims to analyze the expression levels of TrkB receptor and their anterograde carriers in aged Lewis rats, model of neurodegeneration, and its relationship with moderate exercise training. Rats from the first experimental group were exposed to $1 \mathrm{mg} / \mathrm{kg} / \mathrm{day}$ of Rotenone (ROT) or DMSO for 4 weeks, and then subjected or not to moderate exercise running on treadmill, five days a week, 40 minutes a day, combined with the drug. Rats from the second experimental group were trained for 6 weeks, followed by exposure to rotenone during 4 weeks, rats were then subdivided into two groups, one that continued the exercise and the other became sedentary. Results suggest that exercise training appears to reverse or prevent the impairment related to neurodegeneration considering the proteins involved in BDNF signaling, and also that the magnitude and direction of these changes in directly related to the physical training protocol, as well as the area of the central nervous system analyzed.
\end{abstract}

Descriptors: axonal transport; nerve growth factors; receptor TrkB; exercise; exercise teste; rats; nerve neurogeneration. 


\section{INTRODUÇÃO}

\subsection{Envelhecimento e doenças neurodegenerativas}

Diante do iminente aumento na expectativa de vida da população mundial, aliado à diminuição da taxa de mortalidade e de natalidade, o número de pessoas idosas tem aumentado de forma exponencial. Tal processo de envelhecimento da população pode ser atribuído aos avanços científicos, especialmente na área de medicina e controle de doenças infecto-contagiosas. Paralelamente, pode-se observar o aumento na incidência de doenças relacionadas à idade, como as doenças neurodegenerativas. Desta forma, entender o processo de envelhecimento e as doenças neurodegenerativas torna-se imprescindível no processo de melhora da qualidade de vida da população.

\subsubsection{Envelhecimento populacional}

O envelhecimento populacional é tendência e realidade mundial, particularmente nos países em desenvolvimento. A diminuição da taxa de mortalidade e aumento na expectativa de vida indica que futuramente o número de pessoas idosas será superior ao de crianças. Paralelo às perspectivas de envelhecimento, o número de pessoas acometidas por doenças relacionadas à idade tem aumentado expressivamente, despertando a atenção da comunidade científica e política.

Dados revelados pelas Nações Unidas ${ }^{1}$ estimou que em 2050 a população idosa será de aproximadamente 2 bilhões de pessoas, perspectivas que aumentam em três vezes os números atuais. Para o Brasil, a expectativa é que o número de pessoas com mais de 60 anos aumente em 3,5 vezes em relação aos valores atuais.

A população idosa irá aumentar mais que qualquer outra faixa etária nos próximos anos, sendo que, de acordo com o último "Relatório sobre a situação 
da população mundial", elaborado pelo Fundo de Populações das Nações Unidas (UNFPA) ${ }^{2}$, a expectativa de vida nas últimas seis décadas aumentou cerca de 11 anos em países desenvolvidos e 26 anos em países em desenvolvimento, afirmando ainda que essa tendência deve permanecer nas próximas décadas.

O Instituto Brasileiro de Geografia e Estatística IBGE, ${ }^{3}$, estimou, a partir dos valores obtidos no Censo realizado em 2010, que o número de idosos no Brasil em 2060 representará mais de $25 \%$ da população brasileira, que atualmente esta mesma faixa etária corresponde a 7\%.

Outro dado que merece destaque é em relação à população com 80 anos ou mais, esta faixa etária deve aumentar em torno de $6 \%$ em toda população mundial, e aproximadamente $8 \%$ no Brasil ${ }^{1}$. Ressalta-se que o envelhecimento é um processo natural e que seus efeitos degenerativos são de ordem fisiológica, psíquica e social ${ }^{4 ;}$. Tal processo configura-se pela diminuição das funções do organismo entre os 30 e 70 anos de vida e é agravado a partir dos 70 anos, tornando esses indivíduos mais susceptíveis a doenças relacionadas à idade, como as neurodegenerativas.

Com o declínio das funções do organismo, o indivíduo senil começa a ficar mais susceptível às doenças, o que pode levar ao estresse, à depressão, diminuição da autoestima, afastamento dos grupos sociais, falta de motivação para realizar atividades de lazer e até as atividades cotidianas ${ }^{4}$.

Pode-se ainda associar esses prejuízos fisiológicos a danos funcionais e estruturais dos diversos órgãos que compõem os diferentes sistemas, incluindo o sistema nervoso central. Nesse sentido, vale destacar as doenças neurodegenerativas, tais como doença de Alzheimer (AD) e Parkinson (PD), que têm dentre os principais fatores de risco, o envelhecimento.

\subsubsection{Doenças neurodegenerativas}

As doenças neurodegenerativas estão entre as que mais acometem pessoas idosas em todo mundo. Embora a causa primária dessas doenças não esteja definida, o envelhecimento pode ser considerado o principal fator de risco. 
Dados epidemiológicos apontam que mais de 25 milhões de pessoas no mundo são afetadas por demência, sendo a doença de Alzheimer a mais comum dentre todas. Estes mesmos dados revelam ainda que a proporção de pessoas afetadas se correlaciona diretamente com 0 processo de envelhecimento (Figura 1$)^{6}$.

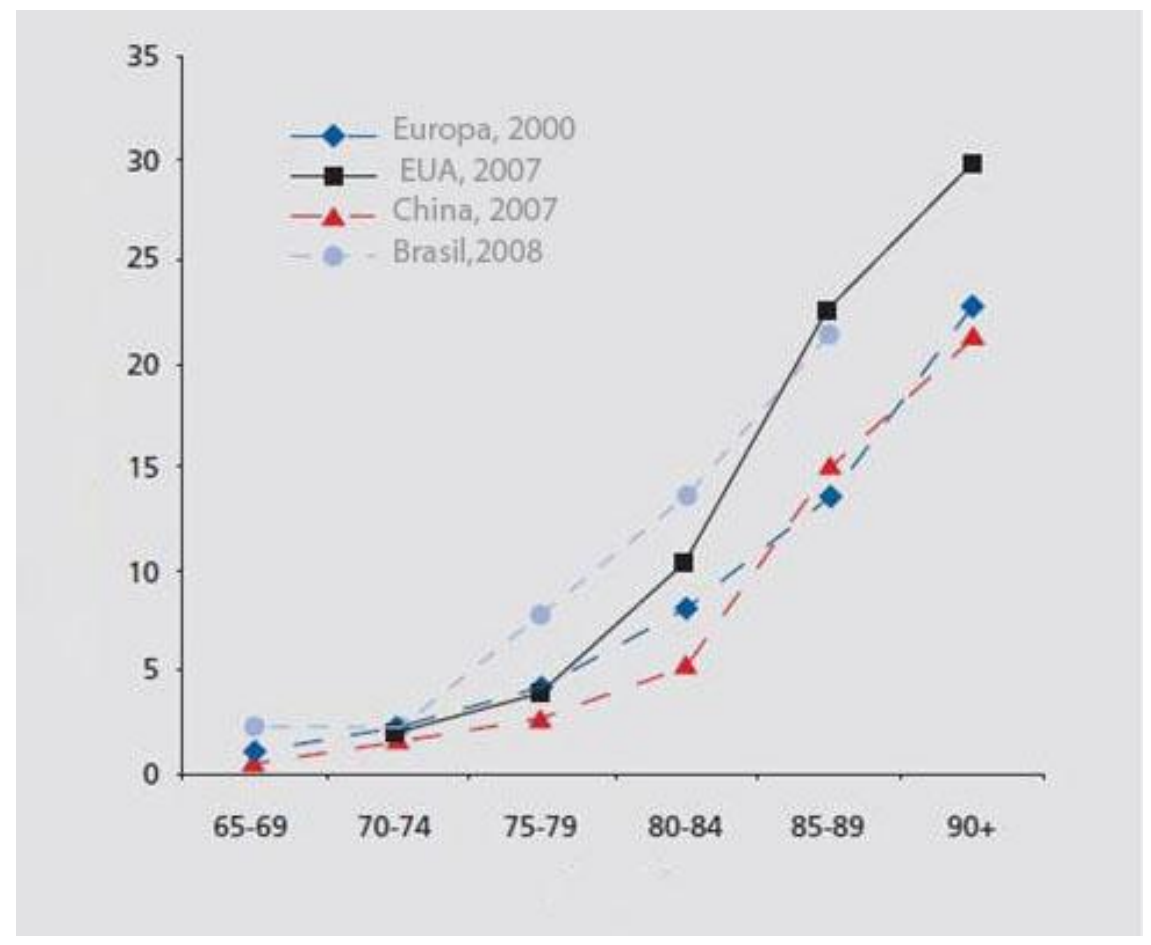

FIGURA 1 - Prevalência idade-específica da doença de Alzheimer (por 100 habitantes). Adaptado de Qiu e colaboradores ${ }^{6}$.

No Brasil, dados correspondentes a idosos numa comunidade de São Paulo apontam que a prevalência de demência varia de $2 \%$ entre indivíduos com idade entre 65 e 69 anos a $40 \%$ entre aqueles com idade superior a 84 anos $^{7}$. Nos Estados Unidos da América (EUA), 4\% dos indivíduos até os 65 anos, $6 \%$ entre os 65 e 70 anos, $44 \%$ entre 75 e 84 anos e $46 \%$ com 85 anos ou mais são acometidos pela doença de Alzheimer ${ }^{8}$. Sendo ainda que a estimativa para 2050 é que esse número seja quadruplicado ${ }^{9}$.

Para a doença de Parkinson, Mayeux ${ }^{10}$ revela que, de maneira geral, $1 \mathrm{a}$ $3 \%$ dos indivíduos com 50 anos ou mais e 5 a 18\% com 80 anos ou mais são acometidos pela doença. No Brasil, poucos são os dados epidemiológicos sobre esta questão, sendo que a maioria dos estudos se baseia em dados de países desenvolvidos ou a partir de estudos em comunidades. Nesse sentido, 
Barbosa e colaboradores ${ }^{11}$ em estudo realizado na cidade de Bambuí, estado de Minas Gerais, revelaram que o nível de acometidos pela doença é de 7,2\% em pessoas com mais de 64 anos de idade.

A correlação entre envelhecimento e doenças neurodegenerativas, pode ser compreendida pelo fato de que o processo de envelhecimento é a acompanhado da formação de placas senis distribuídas por todo o sistema nervoso central, que podem estar relacionadas à morte celular natural e ao comprometimento do organismo. Neste contexto, o aparecimento de agregados de proteínas podendo gerar disfunções e/ou morte celular são considerados características marcantes da neurodegeneração.

O processo de formação de placas senis está associado à agregação de proteínas no meio intra e extracelular em todo o sistema nervoso central. Esses agregados são considerados marcadores de doenças neurodegenerativas como a de Alzheimer ${ }^{12 ; 13}$ e a de Parkinson ${ }^{14}$. Em contrapartida, Dayan ${ }^{15}$ relata a existência dessas placas senis em indivíduos não acometidos por doenças neurodegenerativas.

$\mathrm{Na}$ doença de Alzheimer esses agregados proteicos são compostos primordialmente pelo peptídeo beta amiloide $(A B)$ no meio extracelular, oriundos de clivagem anormal da proteína precursora amiloide ${ }^{16}$, e intracelularmente por emaranhados neurofibrilares formados pela hiperfosforilação da proteína Tau no hipocampo, cerebelo, locus coeruleus e córtex ${ }^{17}$.

A presença de inclusões insolúveis contendo alfa-sinucleína ( $\alpha$ sinucleína), chamados de corpos de Lewy, são comumente encontrados na substância negra, cerebelo, hipotálamo e sistema nervoso autônomo de pacientes com a doença de Parkinson ${ }^{18 ; 19 ; 20 ; 21 . ~}$

Estudos mais recentes, têm encontrado que formas intermediárias da proteína tau hiperfosforilada ${ }^{22}$ ou oligômeros de B-amiloide e $\alpha$-sinucleína ${ }^{23}$ teriam maior nível de toxicidade que os agregados de proteínas em si.

A disfunção celular em decorrência da agregação de proteínas está relacionada, dentre outras coisas, ao prejuízo do tráfego de organelas e vesículas $24 ; 25 ; 26$. 
Muito embora a causa primária da neurodegeneração ainda não possa ser definitivamente esclarecida por causa de seu caráter multifatorial, a deficiência na comunicação celular deve ser considerada um dos principais mecanismos desencadeadores da morte celular, especialmente durante 0 envelhecimento.

\subsubsection{Tráfego Intracelular}

A coordenação dos eventos encefálicos depende da neurotransmissão que é promovida essencialmente por fatores intracelulares responsáveis pelo transporte de organelas e moléculas sinalizadoras até seus locais de ação, assim como a organização do citoplasma, secreção, endocitose e os diversos processos celulares. O prejuízo do tráfego intracelular e, consequentemente, da comunicação intercelular contribui para 0 desencadeamento da neurodegeneração.

O transporte axonal em neurônios é essencial devido ao tamanho celular e a polaridade celular, permitindo uma comunicação eficiente entre o corpo celular e terminal axonal, como por exemplo, mantendo estes abastecidos com proteínas, lipídeos e mitocôndria, reciclando ou degradando proteínas mal enoveladas evitando que elas se agreguem. Além de seu papel no metabolismo neuronal, o transporte axonal é crucial para a neurotransmissão permitindo que o neurônio responda corretamente aos sinais tróficos ou ao estresse $^{27}$.

Os microtúbulos, estruturas do citoesqueleto, são as principais vias por onde o transporte axonal ocorre em ambos os sentidos por meio de proteínas motoras, sendo estas especificas de cada carga ${ }^{28}$.

Diversos estudos têm relatado alterações no transporte axonal como uma característica das doenças neurodegenerativas, esse prejuízo no tráfego pode, por exemplo, acumular componentes do citoesqueleto e organelas, mantendo-os ancorados e impossibilitando de realizar seu papel na homeostase celular ${ }^{29} ; 30 ; 31 ; 32 ; 33 ; 34$.

Assim sendo, pode-se dizer que o tráfego intracelular e a comunicação intercelular são essenciais para o funcionamento do sistema nervoso central, e 
que danos nesses processos podem ser fatores de risco para a neurodegeneração, visto que podem comprometer não apenas o funcionamento intracelular, mas também interromper a comunicação entre as células.

\subsection{Exercício físico e doenças neurodegenerativas}

O exercício físico parece estar entre os métodos mais eficazes de garantir a qualidade de vida, visto que, quando praticado de maneira regular pode resultar em múltiplos benefícios para o indivíduo, inclusive diante de doenças. Atualmente pode-se encontrar inúmeros trabalhos, com as mais variadas populações comprovando e reforçando o benefícios da prática de exercício físico regular. Ainda, o exercício físico pode contribuir para que o processo de envelhecimento ocorra de maneira menos agressiva ao organismo, minimizando as perdas e disfunções. Desta maneira, é de suma importância compreender os mecanismos sobre os quais o exercício físico atua e sua relação em prevenir e tratar as doenças neurodegenerativas.

\subsubsection{Exercício físico}

Os benefícios gerados pela prática regular de exercícios físicos podem ser físicos, mentais e sociais, ou seja, existe uma relação direta entre exercício físico e qualidade de vida. A utilização do exercício físico ultrapassou a barreira do lazer, se transformando em uma forma de tratamento, não farmacológico, para diversas doenças, especialmente as modernas, como obesidade, hipertensão e diabetes.

De maneira geral, o exercício físico parece gerar adaptações nos sistemas cardiovascular e muscular, na composição corporal, na flexibilidade, aptidão neuromotora, entre outras, podendo diminuir até mesmo o risco de morte $35 ; 36$.

Vários trabalhos relatam que quanto melhores os níveis de aptidão cardiorrespiratória e muscular menores são os riscos de problemas de saúde ${ }^{37}$; 
38; 39; 40; 41; 42; 43; 44 . Em indivíduos com doença pré-existente a diminuição do risco de eventos clínicos também está associada com maior aptidão cardiorrespiratória ${ }^{39 ; 45 ; 46 ; 47 ; ~} 48$.

De acordo com a literatura, pode-se afirmar que o exercício físico regular reduz o risco de desenvolver inúmeras doenças, podendo ainda ser recomendado como intervenção terapêutica para o tratamento e controle de muitas doenças crônicas, tais como hipertensão ${ }^{49 ; 50}$, diabetes tipo $2^{51 ;} 52$, obesidade $^{53 ; 54}$ e osteoporose ${ }^{55 ; 56}$.

Além disso, diretrizes de prática clínica também identificaram o papel da atividade física no tratamento e controle de doenças como depressão e transtornos de ansiedade ${ }^{57}$, demência ${ }^{58 ; 59 ; 60}$, acidente vascular cerebral $^{61}$, entre outras.

Os exercícios físicos podem ser classificados de diversas maneiras, como por exemplo, em aeróbio e anaeróbio, considerando a tarefa metabólica; em cíclico ou acíclico, considerando a tarefa motora, longo ou curto, de acordo com tempo; em baixo, moderado ou alto, de acordo com a intensidade, dentre outras.

Os efeitos dos exercícios físicos variam de acordo com características individuais e do programa de exercício ${ }^{62 ; 63 ; 64 ; 65 .}$

Em idosos, a deterioração estrutural e funcional ocorre na maioria dos sistemas fisiológicos, mesmo na ausência de doença. Os declínios na capacidade aeróbia máxima e o desempenho do músculo esquelético com o avançar da idade são dois exemplos de envelhecimento fisiológico que podem afetar as atividades da vida diária e a preservação da independência física ${ }^{66}$.

A atividade física também diminui o impacto do envelhecimento por meio da restauração da capacidade funcional em idosos, visto que após praticar protocolo de exercício aeróbio e resistido houve aumento da capacidade aeróbica e força muscular em 20 a 30\%, respectivamente, em adultos mais velhos $^{67 ; 68}$.

A intensidade do exercício físico deve ser considerada para que se obtenha efeitos benéficos ao sistema nervoso central. O exercício físico vigoroso pode amplificar a excitotoxicidade levando a aumento do incremento de cálcio intracelular em neurônios motores e subsequente morte celular. No 
entanto, protocolos de exercício físico de baixa a moderada intensidade são indicados em modelos murinos de esclerose lateral amiotrófica, enquanto exercício de alta intensidade implicam em efeitos deletérios nesses camundongos ${ }^{69}$.

Assim sendo, pode-se sugerir que o exercício físico é essencial para um envelhecimento saudável. No entanto, os mecanismos pelos quais esses benefícios ocorrem ainda não estão totalmente esclarecidos.

\subsubsection{Exercício físico e neurotrofinas}

Estudos do envelhecimento humano mostram que a prática de atividade física protege contra o declínio cognitivo. O exercício aumenta a atenção e o desempenho em tarefas cognitivas tanto em humanos quanto em outros primatas. Em modelo murino de acidente vascular cerebral, o exercício aeróbico promoveu ramificações dendríticas e aumento das habilidades motoras $^{70}$.

O exercício físico pode atenuar os efeitos do envelhecimento sobre o sistema nervoso central por meio de alguns mecanismos já descritos, como: aumento da angiogênese e da saturação de oxigênio no sistema nervoso central $^{71}$ melhora da eficiência da neurotransmissão, como a serotonérgica e noradrenérgica, o que facilita o processamento da informação ${ }^{72 ; 73}$; melhora do metabolismo ${ }^{74}$; diminuição da inflamação ${ }^{75}$; proteção contra a perda de volume encefálico ${ }^{76}$; aumento da expressão de neurotrofinas como o fator neurotrófico derivado do cérebro (BDNF), aumento do fator de crescimento semelhante à insulina I (IGF-I) e do fator de crescimento básico do fibroblasto (bFGF).

A prática de atividade física aumenta a expressão do BDNF, bem como de genes que são membros da maquinaria de tráfego de vesículas e porções das vias de sinalização cuja atividade afetam a função sináptica ${ }^{77}$. Particularmente no hipocampo, o aumento da expressão do BDNF pela atividade física protege os neurônios dos diversos insultos, promove neurogênese no adulto e aumenta a eficácia das sinapses ${ }^{78}$, sendo um componente essencial do mecanismo molecular pelo qual o exercício melhora a neuroplasticidade. Entretanto, considerando a ampla relevância e 
abrangência fisiológica da atividade física, é provável que múltiplos sistemas estejam envolvidos na neuroproteção decorrente do exercício.

Com relação a isso, Molteni e colaboradores ${ }^{77}$ descreveram alterações, por microarray, na expressão de RNAm de diversos componentes do sistema de neurotrofinas (BDNF, NGF e Trk), além de sistemas de neurotransmissão (Glutamato e GABA), vias de sinalização e transdução de sinal (sintaxina, sinaptotagmina e MAPK) e fatores de transcrição (CREB) no hipocampo após exercício físico.

Pode-se dizer que um dos mecanismos pelo qual o exercício físico age diante da neurodegeneração é por meio da renovação celular e neuroplasticidade, alterando os níveis de neurotrofinas e seus receptores. Ou seja, o efeito benéfico do exercício físico, considerando a neurodegeneração, pode se dar pela melhora da maquinaria de neurogênese e comunicação celular.

\subsubsection{Neurotrofinas e seus receptores}

A grande família das neurotrofinas é composta, atualmente, por 6 membros: fator neurotrófico derivado do cérebro (BDNF), fator de crescimento do nervo (NGF), neurotrofina-3 (NT-3), neurotrofina-4 (também denominada neurotrofina-5) (NT-4 ou NT-5), neurotrofina-6 (NT-6) e neurotrofina-7 (NT-7), os quais interagem com receptores do tipo Trk (TrkA, TrkB e TrkC) ou p $75^{79}$.

As neurotrofinas regulam genes-alvo que podem codificar proteínas estruturais, enzimas ou neurotransmissores que resultam em modificação da morfologia e função neuronal. Essa habilidade em melhorar a plasticidade neuronal permite a formação e retenção de memória e aprendizagem em todas as dimensões: espacial, cognitiva, motora.

O BDNF é um mediador importante da neuroplasticidade no hipocampo. A sinalização sináptica e a responsividade apresentam-se aumentadas em segundos após a administração de BDNF em neurônios do hipocampo de ratos. Esse fator neurotrófico também aumenta a ramificação axonal no córtex, o que aumenta os sítios sinápticos em potencial ${ }^{80 ; 81}$. Quando bloqueada a expressão do BDNF, ocorre deficiência de memória e aprendizagem ${ }^{82}$. 
Durante o envelhecimento há declínio da expressão de BDNF bem como dos receptores de fatores neurotróficosTrk ${ }^{83 ; 84 ; 85 ; 86}$, o que está associado a disfunção hipocampal, prejuízo da memória e aumento do risco para depressão por diminuir a neurotransmissão serotonérgica ${ }^{87}$, enquanto o aumento do BDNF pelo exercício físico aparentemente diminui a atrofia do hipocampo, melhora a memória e reduz a depressão ${ }^{88}$.

Aparentemente a atividade física voluntária induz a produção de fatores neurotróficos, cuja quantidade está associada a melhora da plasticidade, da memória, da potenciação de longo prazo e aumento do número de novas células no hipocampo ${ }^{89}$. O aumento da expressão de BDNF no hipocampo após 2, 6 e 12 horas de corrida espontânea em roda aumentou a resistência do cérebro a danos e neurodegeneração durante o envelhecimento ${ }^{90}$.

Carro e colaboradores ${ }^{91}$ demonstraram que exercício moderado (1 km/dia) melhora a recuperação funcional e previne a morte de neurônios em diversos modelos murinos de neurodegeneração, como a degeneração hipocampal, injúria do tronco encefálico e degeneração cerebelar hereditária. Em animais que corriam antes de sofrerem a lesão houve melhora da função neuronal, e aqueles que correram durante 5 semanas após a lesão, essa melhora alcançou $90 \%$ dos valores controles ${ }^{70}$.

Com relação ao tempo de treinamento, Ploughman e colaboradores ${ }^{92}$ demonstraram que os níveis de BDNF e outros marcadores da neuroplasticidade se mantinham elevados até 2 horas após o exercício prolongado, de intensidade moderada e voluntário. A implicação para a reabilitação clínica é que o exercício frequente de baixa intensidade e intermitente pode aumentar os níveis de BDNF no hipocampo criando um meio neuroplástico favorável durante a recuperação de células nervosas.

\subsubsection{Tráfego de neurotrofinas e seus receptores}

O transporte axonal ocorre via microtúbulos e é realizado por proteínas motoras. De forma generalizada, o transporte é realizado por um complexo formado por proteínas motoras e auxiliares, sendo que alterações na sua expressão podem afetar todo o tráfego. E que, cada carga tem seu conjunto 
transportador específico. Desta forma, é essencial compreender quais a proteínas responsáveis pelo transporte de neurotrofinas e seus receptores.

As proteínas Rab estão relacionadas ao transporte de vesículas, e sabese que alteração nestas proteínas está intimamente relacionada ao distúrbio da formação de vesículas, mobilidade entre os compartimentos celulares, ancoramento e transporte de organelas ${ }^{93}$.

Dentre as proteínas Rab, destaca-se a Rab27 que participa do tráfego de fatores neurotróficos e seus receptores. Para o tráfego anterógrado, os receptores TrkB ligam-se à proteína semelhante à sinaptotagmina (SLP1) pela cauda citoplasmática de forma dependente de Rab27B, e proteína mediadora da resposta à colapsina-2 (CRMP-2) conecta SLP1 a cinesina-1, que é a proteína motora associada aos microtúbulos e que leva a carga em direção aos terminais axonais ${ }^{94}$. Ressalta-se que alterações conformacionais, estruturais e do estado de fosforilação da CRMP-2 também têm sido relacionadas à agregação proteica presente na neurodegeneração ${ }^{\text {95; 96; } 97}$ (Figura 2).

Em adição, a proteína associada a huntintina-1 (HAP-1) e a sortilina participam do transporte anterógrado e estabilização do precursor do BDNF (proBDNF) para a periferia celular ${ }^{98}$. A proteína HAP1 também interage com diversas outras proteínas incluindo o receptor $\mathrm{GABA}_{A}{ }^{99 ; 100}$ e os receptores para fatores neurotróficos ${ }^{101 ; 102}$. A sortilina encontra-se expressa em altos níveis nos neurônios ${ }^{103}$, e está preferencialmente localizada na rede trans-Golgi ${ }^{104}$ onde parece estar envolvida no direcionamento do proBDNF para a via secretora regulada ${ }^{105 ;} 106$.

$\mathrm{Na}$ via retrógrada, a internalização dos receptores TrkB é mediada por proteínas Pincher (chaperona pinocítica), também denominadas EHD4 ou PAST4, as quais localizam-se próximo à membrana plasmática e participam da sinalização retrógrada por endossomos em neurônios, bem como pela proteína $\operatorname{Rab5} 5^{107 ; 108 ; 109}$.

Uma das categorias da sinalização retrógrada envolve a formação de corpos multivesiculares em que moléculas exógenas ou endógenas, incluindo fatores neurotróficos e seus receptores são transportados até o corpo celular. A formação desses corpos multivesiculares tem a participação de complexos ESCRT e proteínas Rab. Esses corpos multivesiculares podem sequestrar 
proteínas "mal dobradas" protegendo a célula dos efeitos deletérios da agregação proteica que está presente em diversas condições neurodegenerativas e durante o envelhecimento. De fato, neurônios expostos a situações de hipóxia mostram aumento no número e tamanho desses corpos multivesiculares tornando-os indicadores gerais de estresse celular já que são dinâmicos no tamanho e frequência.

Com isso, postula-se que alterações nos corpos multivesiculares estão associadas a diversas doenças do sistema nervoso. Foi observado acúmulo de corpos multivesiculares em neurônios de animais idosos semelhante ao que ocorre em doenças neurodegenerativas próprias do envelhecimento indicando que alterações estruturais do sistema de endocitose podem ocorrer de forma concomitante à neurodegeneração durante o processo de envelhecimento 0 que é a base das doenças neurodegenerativas ${ }^{110}$.

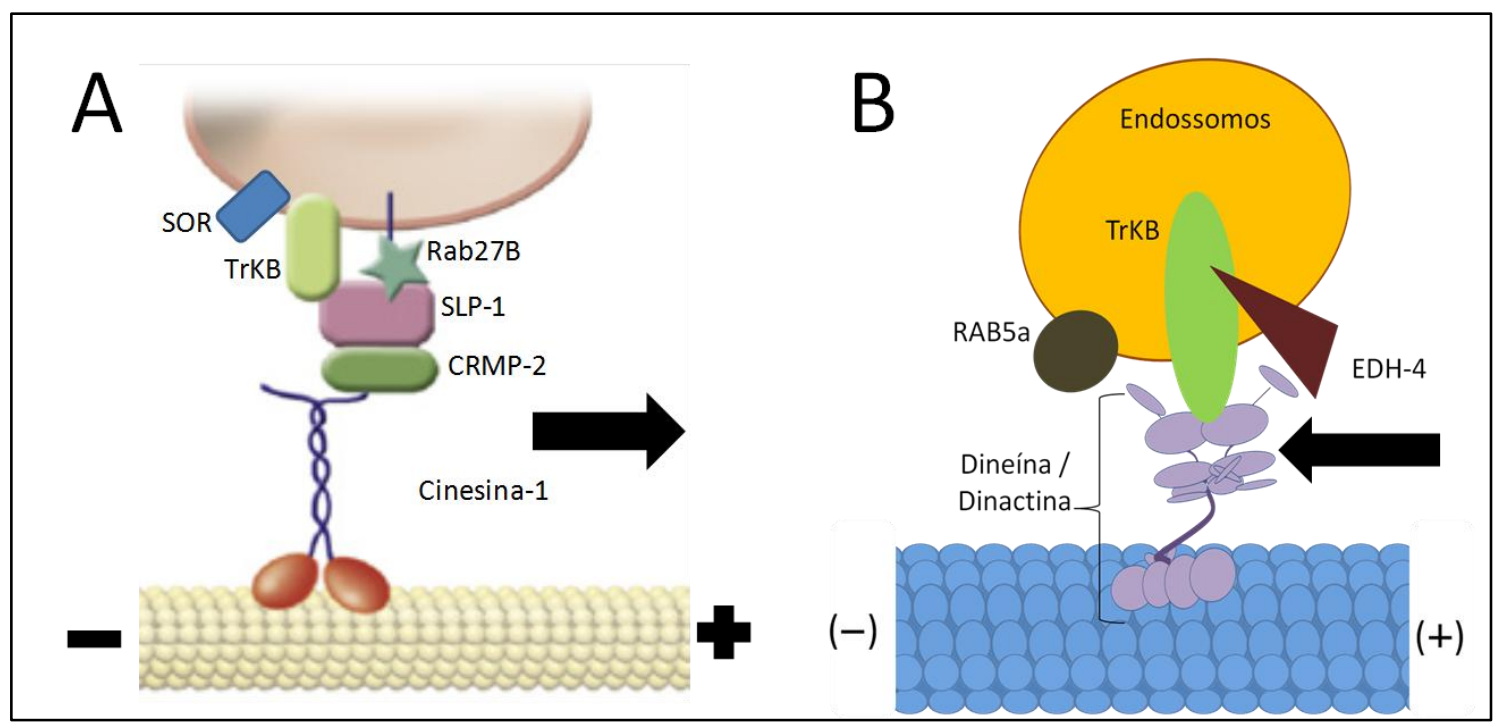

FIGURA 2 - Imagem representativa da formação do complexo de proteínas responsáveis pelo tráfego axonal, sentido anterógrado $(A)$ e retrógrado $(B)$, de TrkB via microtúbulo. Adaptado de Hirokawa e colaboradores ${ }^{111}$.

\subsection{Modelo de neurodegeneração}

O presente estudo utiliza exposição à rotenona para a indução de agregados proteicos in vivo ${ }^{112 ; 113 ; 114}$. A rotenona é um pesticida natural e um inibidor específico do complexo I da cadeia respiratória mitocondrial, o que leva a aumento do estresse oxidativo mimetizando o que ocorre durante o processo 
de envelhecimento. $O$ efeito da rotenona mais bem caracterizado é sobre 0 complexo I, mas também inibe o proteassomo, promove disfunção no GAPDH, age também sobre células gliais ${ }^{112 ; 115 ; 116 ; 117}$, e atua diretamente sobre 0 citoesqueleto ${ }^{118}$.

Esse modelo mostra-se adequado, pois exposição crônica à droga induz formação de agregados proteicos contendo alfa-sinucleína, tau hiperfosforilada e beta-amiloide em células do hipocampo, substância negra, estriado e locus coeruleus $^{112 ; 113 ; 114 ; 119}$. Apesar de ter sido primeiramente descrita pelo envolvimento na doença de Parkinson em agricultores que utilizavam pesticidas à base de rotenona, esse xenobiótico é hoje melhor caracterizado e exerce seus efeitos também em células do hipocampo ${ }^{120}$.

Nosso grupo demonstrou que a exposição à rotenona promove a formação de agregados proteicos contendo a-sinucleína, tau hiperfosforilada e $\beta$-amiloide em células do hipocampo, substância negra, e locus coeruleus ${ }^{121}$ sendo adequado para o presente estudo. Demonstramos a agregação proteica em cultura de células bem como no hipocampo, substância negra e locus coeruleus de ratos idosos, no entanto, a presença de agregação na medula espinhal está sendo investigada no presente momento.

Além disso, nossos experimentos anteriores confirmaram a ação da rotenona em alterar a expressão de proteínas motoras de mitocôndrias antes da formação desses agregados ${ }^{121}$ na expressão gênica e na mobilidade mitocondrial ${ }^{34}$, indicando que alterações do tráfego intracelular ocorrem antes da formação de agregados proteicos, podendo ser estes sinais iniciais da neurodegeneração.

Dados em fase de publicação, demonstram que a exposição à 2 $\mathrm{mg} / \mathrm{kg} / \mathrm{dia}$ de rotenona em ratos Lewis idosos promove a agregação do peptídeo ß-amiloide, a-sinucleína e tau hiperfosforilada no hipocampo, substância negra e locus coeruleus. Por outro lado, em concentrações menores $(1 \mathrm{mg} / \mathrm{kg} / \mathrm{dia})$ de exposição à rotenona não há formação destes agregrados, bem como não há alteração dos níveis de proteína carbonilada, um marcador de estresse oxidativo.

No entanto, alterações do tráfego de neurotrofinas e seus receptores, aliados aos efeitos do exercício físico não estão esclarecidas. Desta forma, o 
presente estudo pretende contribuir para o avanço do conhecimento sobre a regulação do tráfego de fatores neurotróficos e de seus receptores a fim de estabelecer a correlação dos eventos de transporte intracelular com a formação de agregados no sistema nervoso central e a neurodegeneração com 0 envelhecimento. 


\section{OBJETIVOS}

\subsection{Objetivo geral}

Analisar o nível das proteínas envolvidas no tráfego intracelular do BDNF e do receptor TrkB na medula espinhal, hipocampo e substância negra de ratos expostos a rotenona e submetidos ao exercício físico forçado de baixa a moderada intensidade.

\subsection{Objetivos específicos}

1) Analisar o efeito do exercício físico forçado de baixa a moderada intensidade, por meio da corrida em esteira, sobre a massa corporal e agregação de proteínas em ratos idosos submetidos a $1 \mathrm{mg} / \mathrm{kg} /$ dia de rotenona.

2) Estudar o efeito do exercício físico forçado, de baixa a moderada intensidade, sobre o nível das proteínas Rab27, CRMP-2, SIp1, HAP-1 e sortilina, as quais estão envolvidas no tráfego anterógrado de BDNF e seu receptor TrkB, por Western Blot, na medula espinhal, hipocampo e substância negra de ratos idosos submetidos a $1 \mathrm{mg} / \mathrm{kg} / \mathrm{dia}$ de rotenona.

3) Analisar a expressão da proteína EDH-4, a qual participa do tráfego retrógrado de neurotrofinas e seus receptores, por Western Blot, na medula espinhal, hipocampo e substância negra de ratos idosos submetidos ao exercício físico forçado, de baixa a moderada intensidade, e expostos a $1 \mathrm{mg} / \mathrm{kg} / \mathrm{dia}$ de rotenona. 


\section{MATERIAIS E MÉTODOS}

\subsection{Animais}

Foram utilizados ratos (Rattus norvegicus) da linhagem Lewis (68 animais), machos, com 8 ou 9 meses de idade obtidos da Universidade de Campinas e criados no Departamento de Genética e Biologia Evolutiva do Instituto de Biociências da Universidade de São Paulo. Esta linhagem foi escolhida por ser suscetível à agregação de proteínas constitutivas após tratamento com rotenona.

Os experimentos propostos estão em conformidade com todos os aspectos éticos de experimentação animal recomendados pelo Concea, bem como de acordo com a lei federal No. 11.794, e foram aprovados pelo comitê de ética em experimentação animal do Instituto de Biociências (138/2011) (Anexo 1) e da Faculdade de Medicina (451/11) (Anexo 2), ambas unidades da Universidade de São Paulo.

Os animais foram mantidos em ciclo claro/escuro de 12 horas e tiveram ração apropriada e água ad libitum.

\subsection{Exposição à rotenona}

Os ratos foram submetidos à exposição à rotenona (ROT) (Sigma) administrada subcutaneamente por meio de mini bombas osmóticas (Alzet, cód. 4ML2) durante 4 ou 8 semanas. As mini bombas foram implantadas por meio de uma pequena incisão na pele da região dorsal dos animais sob anestesia (cetamina e xilazina). A concentração de rotenona infundida foi de $1 \mathrm{mg} / \mathrm{kg} / \mathrm{dia}$.

Do total de animais utilizados inicialmente, aproximadamente $20 \%$ desses morreram durate o processo de implantação da bomba osmótica, possívelmente devido a condição de envelhecimento.

Os ratos envolvidos neste experimento tinham inicialmente 8 ou 9 meses meses de idade, pois é sabido que ratos idosos são mais sensíveis que jovens 
aos efeitos centrais da rotenona, apresentando maior formação de agregados proteicos insolúveis, sem que haja grandes efeitos periféricos decorrentes de intoxicação pela droga ${ }^{122}$, o que condiz com a etiologia das doenças neurodegenerativas.

As mini bombas osmóticas foram preparadas conforme recomendação do fabricante e foram preenchidas com solução estéril de rotenona diluída em DMSO e polietilenoglicol (1:1) de acordo com o peso de cada animal de forma a receberem $1 \mathrm{mg} / \mathrm{kg} / \mathrm{dia}$ infundidos a uma velocidade de fluxo de aproximadamente $2,5 \mu \mathrm{l} /$ hora. Os animais controles receberam solução de DMSO e polietilenoglicol (1:1) infundida por mini bombas idênticas às dos animais do grupo experimental.

Os animais foram pesados antes da implantação das mini bombas e semanalmente até o final do protocolo experimental, com o intuito de identificar possíveis efeitos tóxicos exacerbados periféricos da rotenona e para assegurar o bem-estar animal.

\subsection{Grupos experimentais}

Os animais foram divididos em grupos experimentais com relação ao tratamento ao qual foram submetidos, DMSO ou ROT de maneira aleatória. $O$ protocolo experimental do presente trabalho apresenta dois grupos distintos, Grupo 1 (G1) e Grupo 2 (G2), sendo que G1 possibilita a análise do treinamento físico como tratamento, enquanto G2 possibilita analisar o efeito de prevenção e manutenção considerando o quadro de neurodegeneração.

O G1 é composto por ratos que foram submetidos ao tratamento crônico com rotenona e seu respectivo controle aos nove meses de idade. Após 30 dias corridos, este mesmo grupo realizou a troca da bomba osmótica, visando garantir a eficiência na exposição à droga, iniciando conjuntamente o protocolo de treinamento físico forçado (Figura 3). Nesta fase os animais foram subdividos em grupos dentro do tratamento, DMSO ou ROT, e de acordo com a condição física, sendo sedentário (SED) ou treinado (EXE). 
Para $\circ$ G2, os ratos iniciaram o protocolo de treinamento físico forçado aos oito meses e meio de idade, permanecendo por seis semanas. $\mathrm{Na}$ sequência, foram submetidos ao tratamento com DMSO ou ROT, e subdividos em grupos de maneira similar ao G1 (Figura 3). A Tabela 1 apresenta a distribuição dos grupos, bem como o número amostral pertencente a cada um deles.

TABELA 1 - Caracterização dos grupos, número amostral e média da massa corporal no início do protocolo, em relação ao tratamento e a condição física proposto pelo protocolo experimental.

TRATAMENTO/CONDIÇÃO FÍSICA

\begin{tabular}{ccccc} 
& $D M S O / S E D$ & $R O T / S E D$ & $D M S O / E X E$ & $R O T / E X E$ \\
\hline $\begin{array}{c}\text { MC inicial } \\
(\mathbf{k g})\end{array}$ & $0,42 \pm 0,08$ & $0,42 \pm 0,06$ & $0,43 \pm 0,09$ & $0,43 \pm 0,08$
\end{tabular}

G1

$\begin{array}{lllll}\text { “n” Amostral } & 05 & 06 & 05 & 06\end{array}$

G2 $\quad \begin{array}{lllll}\mathbf{( k g}) & 0,31 \pm 0,05 & 0,31 \pm 0,04 & 0,31 \pm 0,05 & 0,31 \pm 0,04\end{array}$

\begin{tabular}{ccccc} 
"n" Amostral & 05 & 06 & 05 & 05 \\
\hline G1 - Grupo 1; G2 - Grupo 2; MC - massa corporal; "n" - Número amostral;
\end{tabular} DMSO - controle; ROT - rotenona; SED - sedentário; EXE - treinado 


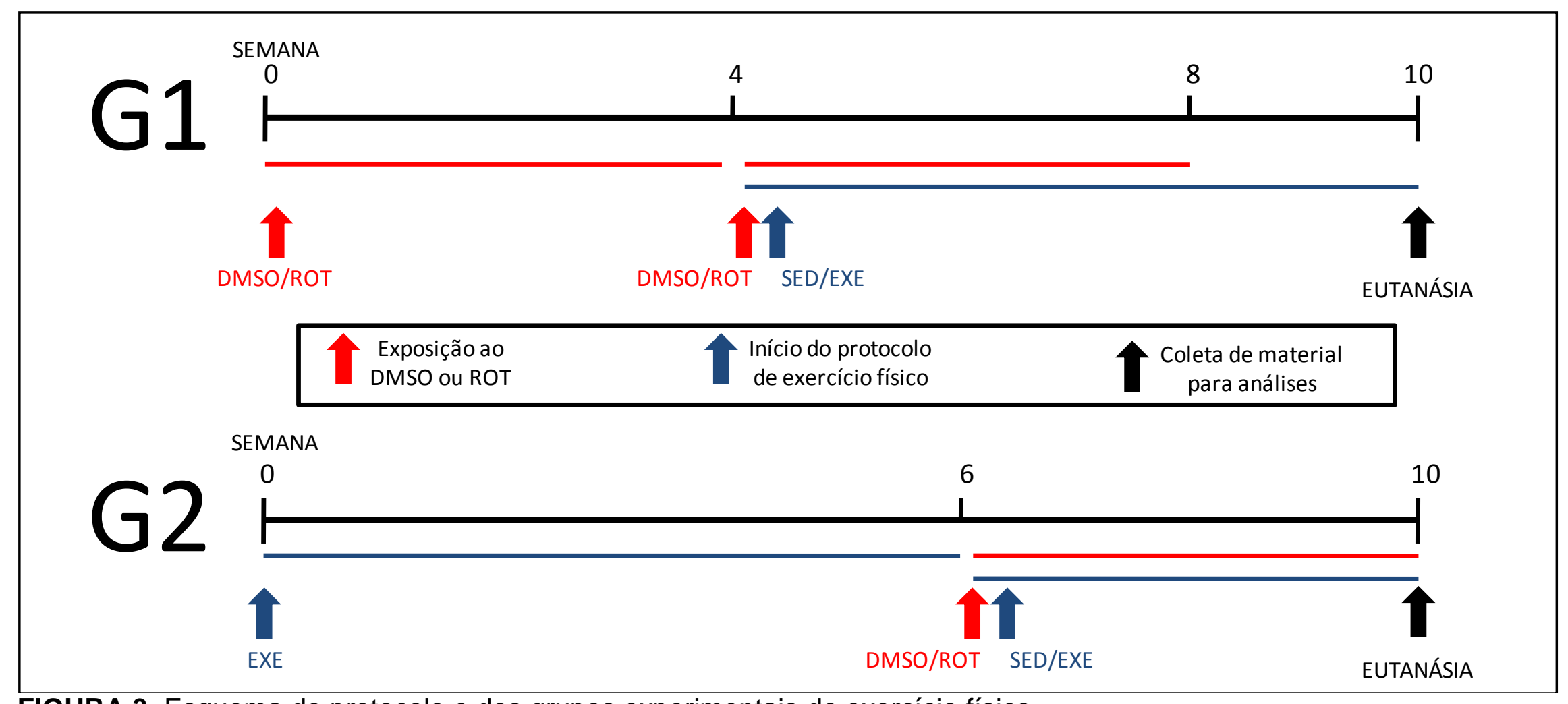

FIGURA 3. Esquema do protocolo e dos grupos experimentais do exercício físico. 


\subsection{Protocolo de exercício físico forçado}

Inicialmente todos os animais foram pré-selecionados de acordo com sua habilidade de correr na esteira, adaptada para animais, durante 15 sessões para familiarização, em velocidades de 0,1 a $0,5 \mathrm{~km} / \mathrm{h}$, duração de 10 a 30 minutos por dia, com $0 \%$ de inclinação. Vale ressaltar que $22 \%$ do total de animais (68) foram excluídos por não apresentarem aptidão para a corrida.

Após o período de adaptação, os animais foram selecionados em dois grupos: sedentário e treinamento. Antes de iniciar o protocolo de treinamento todos realizaram o teste de exercício máximo (teste de exercício gradativo na esteira iniciado a velocidade de $0,3 \mathrm{~km} / \mathrm{h}$ com incrementos de $0,3 \mathrm{~km} / \mathrm{h}$ a cada 3 minutos até a exaustão) para determinar a capacidade máxima individual e determinar as velocidades equivalentes ao protocolo de treinamento.

O protocolo de treinamento foi adaptado de Amaral e colaboradores ${ }^{123} \mathrm{e}$ consistiu em treinos de intensidade moderada, com velocidade de aproximadamente $50-60 \%$ da capacidade máxima individual, durante 5 dias por semana, 40 minutos por dia, durante 6 ou 10 semanas de acordo com 0 protocolo experimental (Figura 3).

Os animais que pertenciam aos grupos sedentários também eram manuseados até a esterira de corrida, onde esses permaneciam pelo mesmo tempo dos animais do grupo treinamento, contudo com a esteira em velociade zero (parada), afim de reproduzir o mesmo estrese a todos animais.

O teste de capacidade individual foi repetido a cada duas semanas no grupo treinamento, para ajustes da velocidade diante do proposto pelo protocolo, e no final, em ambos os grupos, para permitir comparação com o teste inicial.

\subsection{Coleta de material para análise}

Após finalizar o protocolo experimental, os ratos foram decapitados, e seus encéfalos extraídos para dissecar-mos as áreas de interesse. Foram dissecadas as seguintes áreas: hipocampo, substância negra, medula cervical e toráxica (Figura 4). Todas as áreas foram submersas em $400 \mu \mathrm{L}$ de tampão 
de lise ( $1 \%$ NP40, 0,5\% deoxicolato de sódio, 1\% SDS, $1 \mathrm{mM}$ EDTA, $1 \mathrm{mM}$ EGTA e $1 \%$ coquetel inibidor de proteases (Sigma)) e congeladas a $-70^{\circ} \mathrm{C}$. 


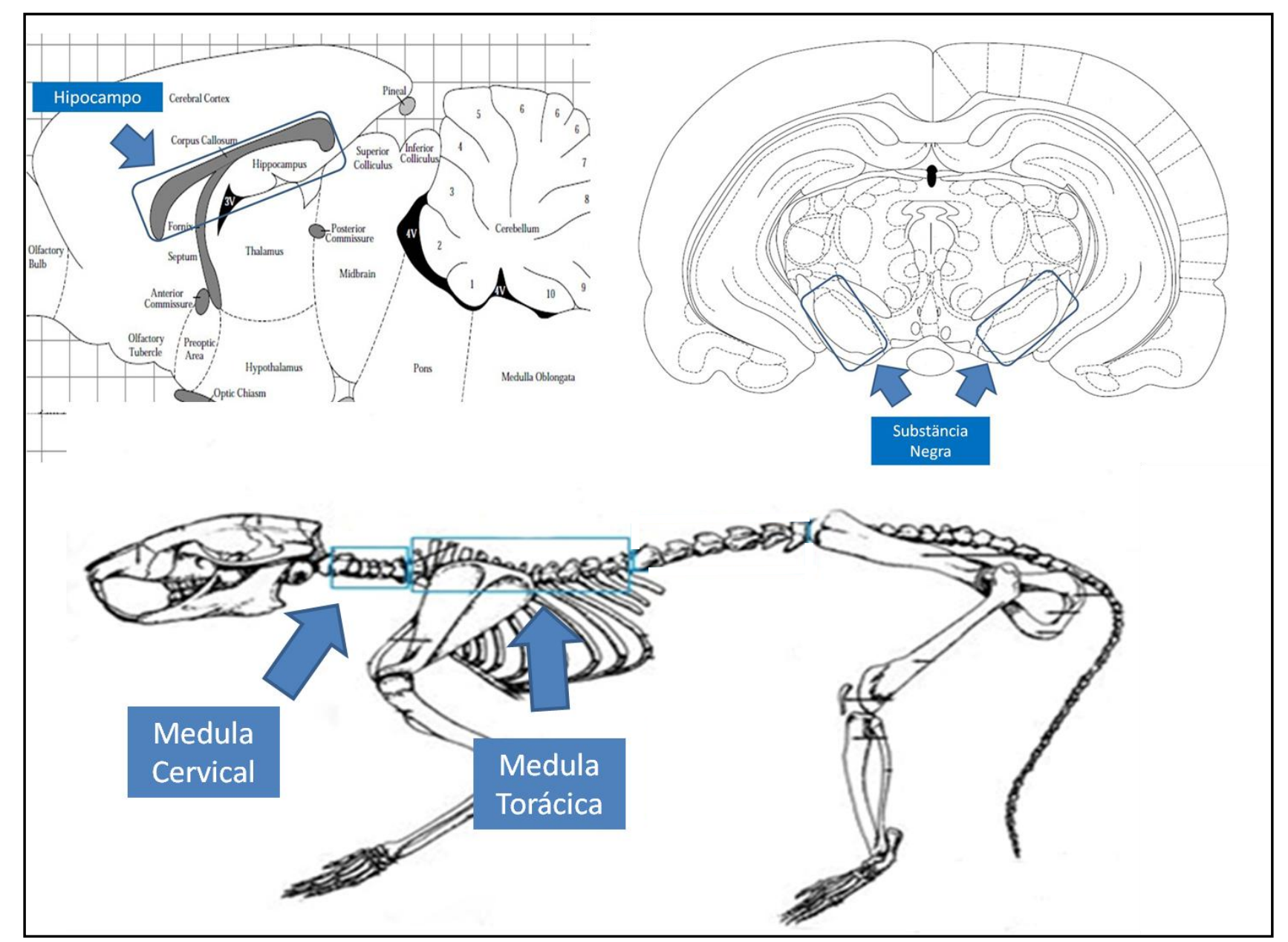

FIGURA 4 - Imagens representativas de secções do encéfalo e áreas da medula de ratos contendo as regiões extraídas para a análise. Hipocampo; Substância Negra; Medula Cervical e Medula Torácica. Modificado de Paxinos e Watson ${ }^{124}$. 


\subsection{Expressão de proteínas do tráfego intracelular por western blot}

O tecido foi lisado e homogeneizado na mesma solução em que se encontrava no congelamento. A quantidade de proteína foi acessada pelo método de Bradford ${ }^{125}$. A curva de calibração foi feita utilizando-se albumina em quantidade de 0 a $32 \mu \mathrm{g}$ de proteína por poço.

As amostras $(70 \mu \mathrm{g})$ foram desnaturadas à $100^{\circ} \mathrm{C}$ durante 3 minutos e aplicadas às canaletas do gel de poliacrilamida a $12 \%$ para fracionamento. Em uma das canaletas foi aplicado o marcador de peso molecular (Full Range Rainbow $^{\mathrm{TM}}$, GE). O tampão de corrida foi preparado com $250 \mathrm{mM}$ trizma, $960 \mathrm{mM}$ glicina e 1\% SDS, as proteínas foram separadas através de aplicação de 150 volts durante 1 hora.

Após a corrida, as proteínas foram transferidas para membrana de nitrocelulose e bloqueada com leite 5\% TBS-T ou BSA 5\% TBS-T durante 1 ou 2 horas à temperatura ambiente, seguida de incubação com os anticorpos primários, diluídos em TBS-T contendo leite $3 \%$ ou BSA 1\%: anti-SLP1 (sc136480, Santa Cruz) (1/2000), anti-CRMP-2 (C2993, Sigma) (1/7000), antiSortilina (ab16640, Abcam) (1/1000), anti-TrkB (H-181, sc-8316, Santa Cruz) (1/1000), anti- $\alpha$-sinucleína (C-20-R, sc-7011-R, Santa Cruz) (1/500), anti-Rab27 (R-4655, Sigma) (1/1000) anti-EDH4 (NBP1-54873, Novus) (1/1000) e antipTau (Ser199/202,T6819, Sigma) (1/1000). A incubação com o anticorpo secundário (anti-mouse 1/6000 ou anti-rabbit 1/10000, diluído em TBS-T contendo leite $3 \%$ ou BSA $1 \%$ ), conjugado a uma peroxidase (HRP), foi realizada à temperatura ambiente durante 1 hora.

A normalização para a análise destas proteínas foi realizada pela incubação do anticorpo primário anti-ß-actina (sc-47778, Santa Cruz) (1/1000) e anticorpo secundário anti-mouse conforme descrito anteriormente. A tabela 2 e 3 apresentam resumidamente as descrição da aplicação dos anticorpos deste trabalho. 
TABELA 2 - Descrição do protocolo de aplicação dos anticorpos primários usados para detecção dos níveis de proteína por meio da técnica de western blot.

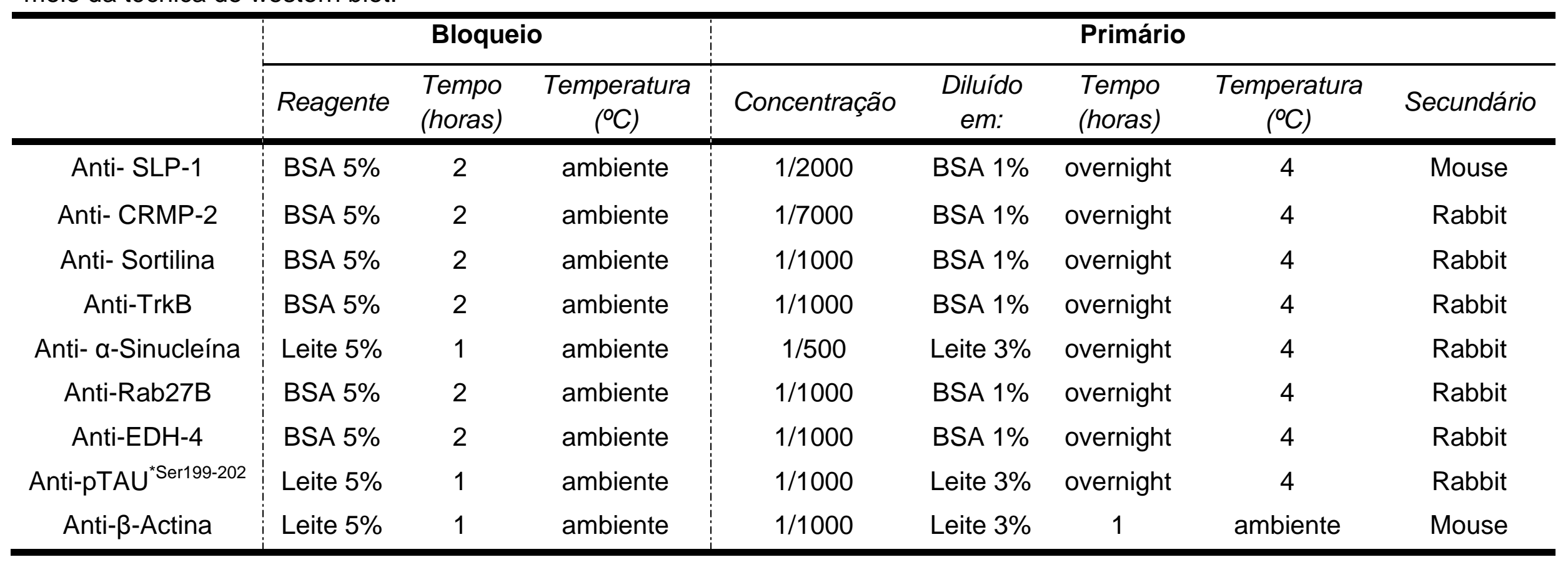

TABELA 3 - Caracterização dos anticorpos secundários usados para detecção dos níveis de proteína por meio da técnica de western blot.

\begin{tabular}{ccccc}
\hline & Concentração & Diluído em: & Tempo (horas) & Temperatura (으) \\
\hline Anti- Mouse & $1 / 6000$ & BSA 1\% ou Leite 3\% & 1 & ambiente \\
Anti-Rabbit & $1 / 10000$ & BSA 1\% ou Leite 3\% & 1 & ambiente \\
\hline
\end{tabular}




\subsection{Análise da atividade da enzima citrato-sintase}

A análise da atividade da enzima citrato sintase foi realizada no homogeneizado dos músculos sóleo e gastrocnêmio dos animais, em espectrofotômetro conforme descrito por Srere ${ }^{126}$. Os músculos sóleo e gastrocnêmio foram homogeneizados com tampão fosfato (PBS) na proporção de $1: 10$ ( $1 \mathrm{~g}$ de tecido para $10 \mathrm{ml}$ de PBS). As amostras foram centrifugadas a $1.500 \mathrm{~g}$, durante 10 minutos a $4^{\circ} \mathrm{C}$. O sobrenadante foi retirado e utilizado para medida da atividade enzimática.

A cinética enzimática foi realizada em espectrofotômetro e foi determinada pela quantificação da intensidade de cor formada pela reação entre a coenzima $A(C \circ A)$ e o ácido oxalacético na presença do ácido 5,5'ditiobis 2 nitrobenzoico (DTNB). A leitura foi realizada a $25^{\circ} \mathrm{C}$, durante um intervalo de 160 segundos, em $412 \mathrm{~nm}$. A atividade da enzima foi determinada pela diferença entre a absorbância inicial e a final, dividida pela diferença de tempo

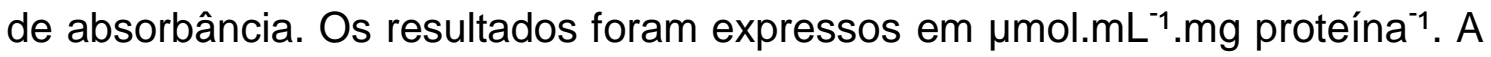
quantidade de proteína por reação foi determinada pelo método de Bradford utilizando como padrão uma curva de albumina bovina (BSA).

\subsection{Análise dos resultados}

Os resultados foram avaliados usando o programa GraphPadPrism (versão 4.03,GraphPad Software, San Diego, California, USA). Sendo adotado o nível de significância de $5 \%(p \leq 0,05)$.

O Teste " $\mathrm{t}$ " de Student e Anova de medidas repetidas, com post hoc Bonferroni, foram empregados para valores atingidos no teste de capacidade máxima do Grupo 1 e Grupo 2, respectivamente. A massa corporal dos animais também foi vericados por meio do teste do anova de medidas repetidas.

Anova de duas vias, com post hoc Bonferroni, foi empregado para atividade da enzima citrato-sintase e níveis de expressão de proteínas. 


\section{RESULTADOS}

\subsection{Variação da massa corporal durante protocolo de exposição à rotenona e exercício físico forçado de intensidade moderada}

A aferição da massa corporal foi feito por pesagens realizadas uma vez por semana durante todo o protocolo experimental, e analisado pela diferença de cada semana com a semana inicial (delta da massa corporal). Inicialmente a massa corporal dos animais tanto do $\mathrm{G} 1$ como do $\mathrm{G} 2$ não diferiam entre os diferentes grupos experimentais.

A massa corporal durante o protocolo experimental do G1 (Figura 5), grupo que é submetido a exposição a rotenona e seguido de treinamento físico ou não e seus respectivos controles, diminuiu quando analisados apenas os efeitos da exposição à rotenona (DMSOsed vs ROTsed). Sendo que, esses resultados parecem indicar que a rotenona tende a promover diminuição significativa na massa corporal após 4 semanas de exposição à rotenona (Semana 1 vs Semana 5) bem como ao final das 11 semanas (Semana 1 vs Semana 11; Semana 5 Vs Semana 11). Ao fim do protocolo experimental, os animais do grupo controle (DMSO) também apresentaram diminuição da massa corporal (Semana 1 vs Semana 11; Semana 5 vs Semana 11).

Considerando o treinamento de seis semanas aliado à exposição à rotenona, a massa corporal não se altera com o treinamento físico (DMSOsed vs DMSOexe), ou na condição de sedentarismo (DMSOsed, Semana 1 vs Semana 5; Semana 1 vs Semana 11; Semana 5 vs Semana 11 ) (Figura 5).

Quando o treinamento físico foi realizado após um mês de exposição à rotenona, seguido de treinamento físico (6 semanas) sem interrupção da liberação contínua da ROT por quatro semanas, também encontrou-se diminuição da massa corporal (ROTsed vs ROTexe) (Figura 5). Sugerindo, que o processo de envelhecimento é quem determina as alterações da massa corporais e não o treinamento físico em ratos Lewis idosos. 


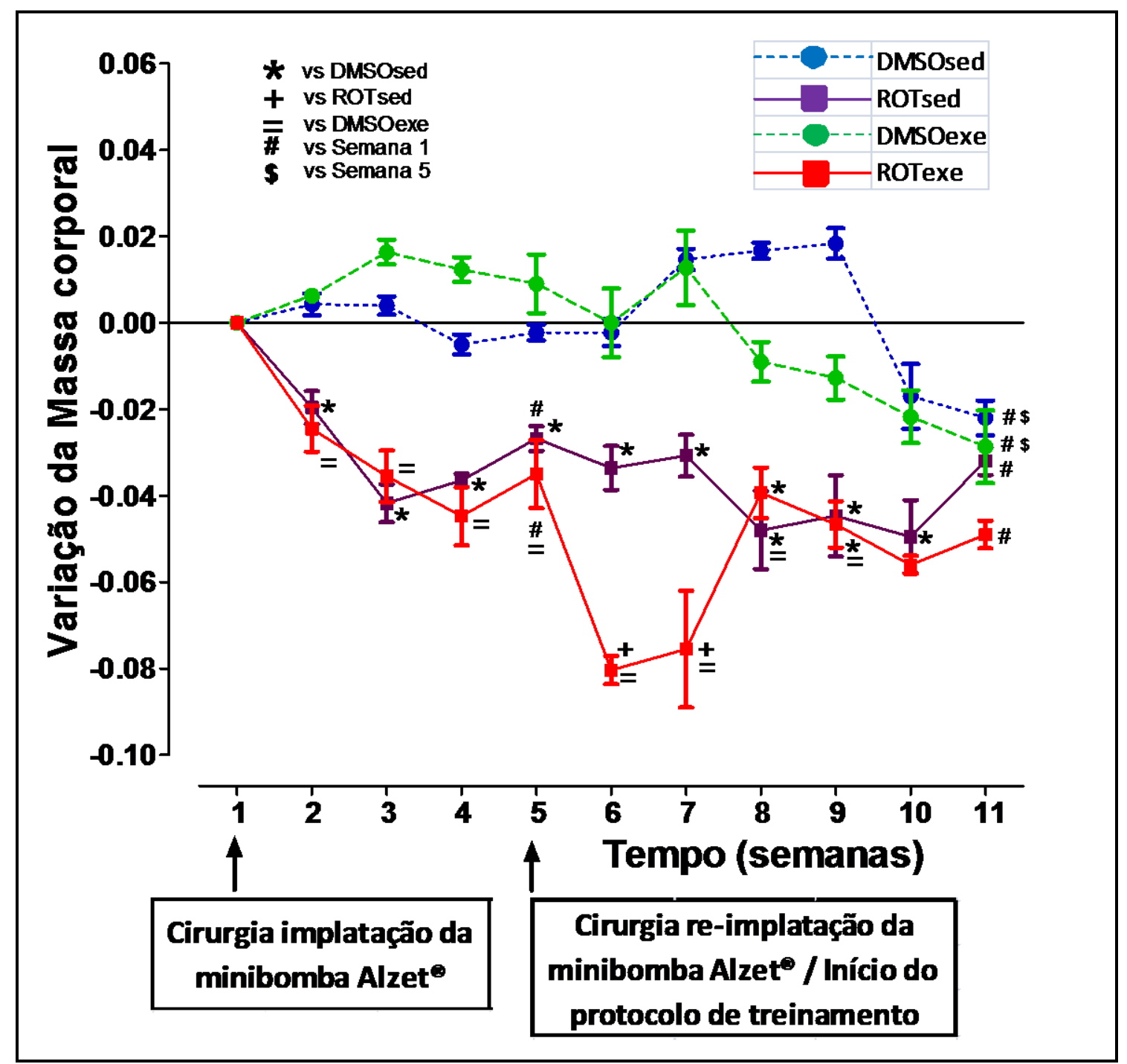

FIGURA 5 - Variação da Massa corporal, em quilogramas, dos ratos submetidos ao protocolo experimental G1. Pesagens realizadas semanalmente. Os valores são apresentados em média \pm erro padrão da média segundo a análise de medidas repetidas (ANOVA), acompanhado do pós-teste de Bonferroni ( $p \leq 0,05)$.

No G2, grupo em que inicialmente todos os animais foram submetidos ao treinamento físico por seis semanas, os resultados demonstram não haver alterações da massa corporal neste período (EXE - Semana 1 vs Semana 7) (Figura 6).

Após esse período em que todos os animais treinaram por seis semanas, os ratos foram dividos em 4 grupos, de acordo com descrito nos materiais e métodos, e verificou-se que a ROT diminui significamente a massa corporal, mesmo quando ela é precedida de treinamento físico (DMSOsed vs ROTsed; ROTsed- Semana 1 vs Semana 11) (Figura 6). 
O treinamento físico também não alterou a massa corporal, bem como não se diferiu dos achados na condição de sedentário (DMSOsed vs DMSOexe) (Figura 6).

Da mesma forma, o treinamento físico não foi capaz de reverter ou minimizar a perda de massa corporal devido à exposição à rotenona (ROTsed vs ROTexe) (Figura 6).

Também encontramos que o tempo, envelhecimento, influencia significativamente a massa corporal dos animais do G2, aumentando para os grupos DMSO e diminuindo para os grupos rotenona, quando comparados os estados inicial ao final (Figura 6). Dados semelhantes aos achados para G1.

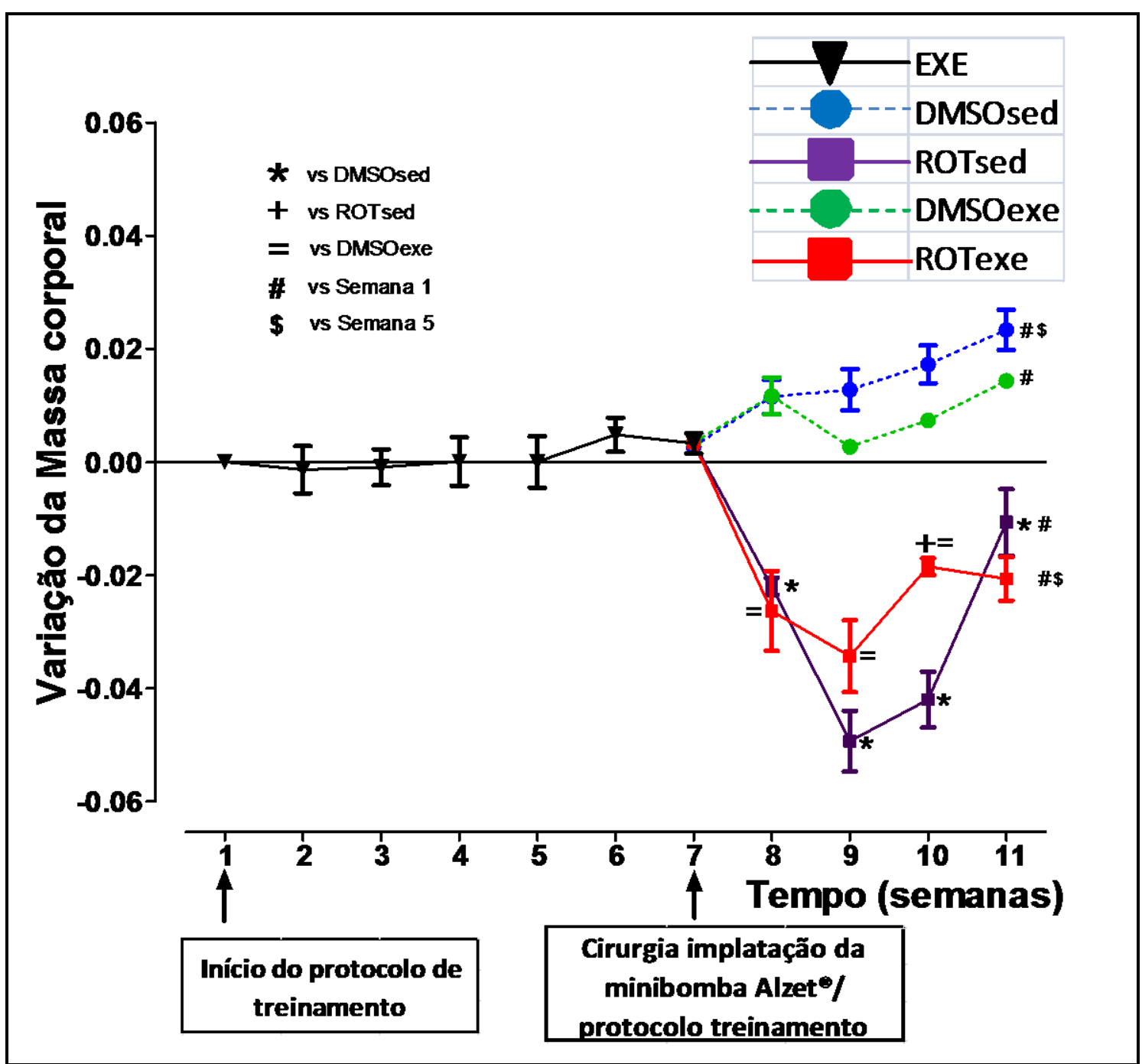

FIGURA 6 - Variação da massa corporal, em quilogramas, dos ratos submetidos ao protocolo experimental G2. Pesagens realizadas semanalmente. Os valores são apresentados em média \pm erro padrão da 
média segundo a análise de variância (ANOVA) de duas vias, seguido do pósteste de Bonferroni ( $p \leq 0,05)$.

Tais achados sugerem que o processo natural de envelhecimento e a exposição à rotenona alteram significativamente a massa corporal de maneira independente do treinamento físico moderado para ratos Lewis idosos (Figura 7).

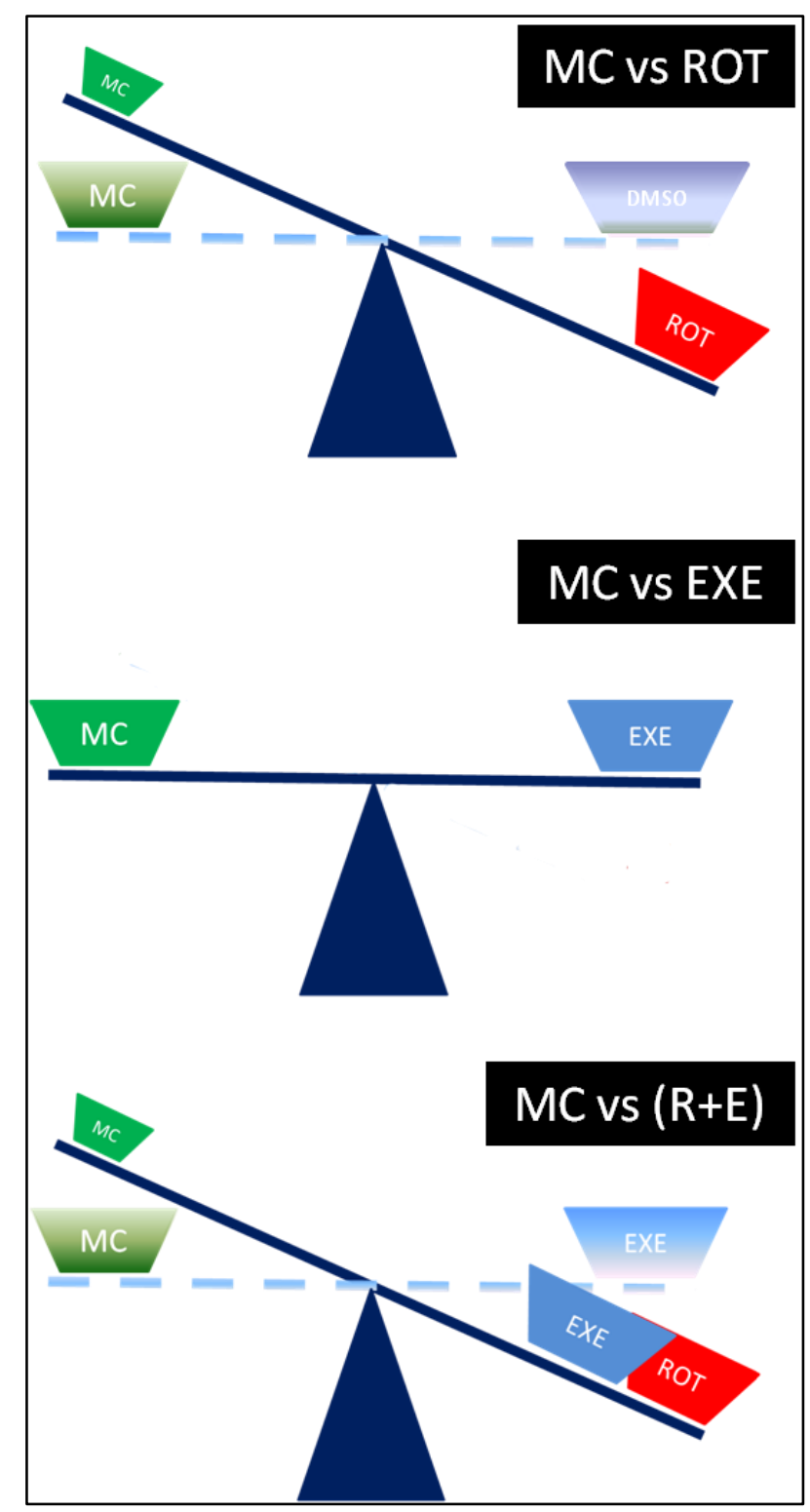

FIGURA 7 - Esquema ilustrativo das alterações da massa corporal de ratos Lewis idosos expostos a baixas doses de rotenona e submetidos ao treinamento físico, e seus representativos controles. A rotenona dimunui a massa corporal de maneira independente do treinamento físico. Onde, MC corresponde a massa corporal, ROT a rotenona, DMSO ao solvente de rotenona, EXE ao treinamento físico, $(\mathrm{R}+\mathrm{E})$ a rotenona mais treinamento físico. 


\subsection{Efeitos do protocolo de exercício forçado, com intensidade}

moderada sobre a capacidade física

O protocolo de exercício físico forçado, corrida em esteira com intensidade moderada (50-60\% capacidade máxima individual), é avaliado e garantido por meio do teste de capacidade máxima antes, durante e após aplicação do treinamento físico proposto.

O resultado do teste de capacidade física pode ser analisado por meio das variáveis: tempo de corrida e distância percorrida, representando o tempo e a distância total atingidos ao final de cada teste, respectivamente. Sendo que, quanto maiores os valores para o tempo e distância atingidos melhores são as condições físicas do indivíduo, considerando que ele consegue suportar uma maior sobrecarga.

Inicialmente, não se verificaram diferenças significativas nos valores iniciais tanto para tempo como para a distância. No entanto, no teste final observa-se um aumento significativo para os grupos que realizaram 0 treinamento físico (DMSOexe e ROTexe), bem como diminuição significativa destes parâmetros nos grupos que não realizaram treinamento físico (DMSOsed e ROTsed) (Figura 8A-B).

Os achados para G1 indicam que o treinamento físico aumenta as variáveis tempo de corrida (Figura 8A) e distância percorrida (Figura 8B), em relação ao estado inicial. Para os valores obtidos nos testes pré (inicial) e pós (final) protocolo de treinamento físico, tem-se que o treinamento físico aumentou em 39\% e 77\% o tempo e a distância final (DMSOexe - Início vs Final). Confirmando os efeitos de melhora da capacidade física com o treinamento físico, tem-se que na ausência do treinamento o tempo de corrida decresce em $46 \%$ e a distância em $50 \%$ considerando o estado inicial e final (DMSOsed - Inicial vs Final) (Figura 8A-B).

Quando analisados os efeitos da rotenona sobre a capacidade física, os achados indicam aumento dos valores de tempo (43\%) e de distância (95\%) para o grupo treinado (ROTexe - Inicial vs Final); e diminuição para de $30 \%$ e $43 \%$ para tempo e distância, respectivamente, para o grupo sedentário exposto a rotenona (Inical vs Final) (Figura 8A-B). 


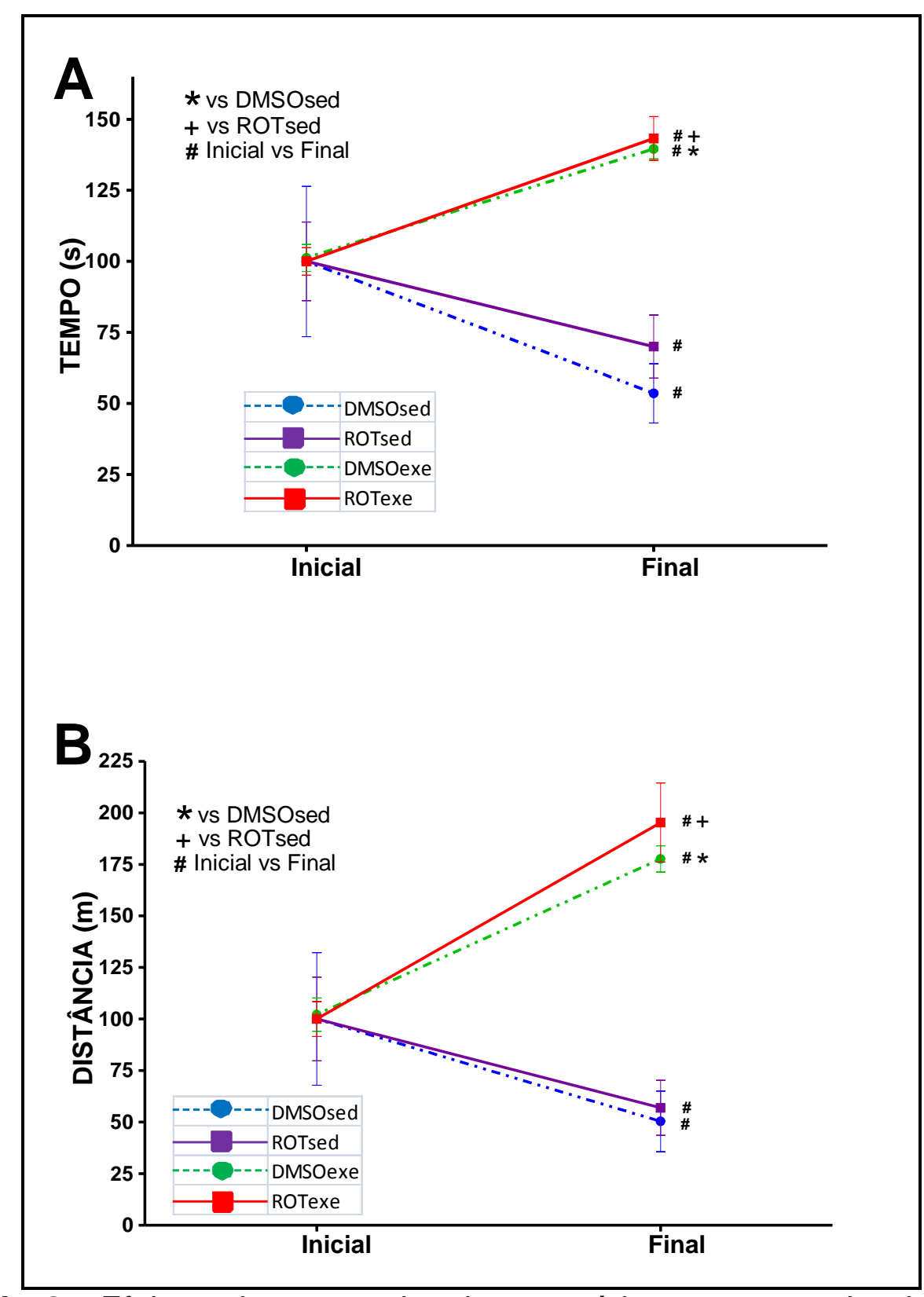

FIGURA 8- Efeitos do protocolo de exercício em ratos Lewis idosos pertencentes ao grupo que realizou 6 semanas de exercício físico forçado, de intensidade baixa a moderada, depois da exposição à droga, Grupo 1 (G1). Valores relativos ao tempo de corrida (A) e distância percorrida (B) obtidos para os grupos controle (DMSO) ou rotenona (ROT), sedentários (sed) ou treinados (exe). Testes realizados pós-adaptação e ao final do protocolo de exercício forçado, 6 semanas. Valores apresentados em porcentagem relativa ao controle. DMSOsed $(n=5)$, ROTsed $(n=6)$, DMSOexe $(n=5)$ e ROTexe $(n=6)$. Anova de medidas repetidas, pós-teste Bonferroni $(p \leq 0,05)$.

Desta maneira, pode-se sugerir que seis semanas de treinamento físico moderado, por meio da corrida em esteira, foram suficientes não apenas para 
recuperar a diminuição gradativa da capacidade física em consequência do sedentarismo e/ou envelhecimento, mas também sendo capaz de aumentar a condição física dos animais treinados. Além disso, tais alterações são independentes do possível estresse celular causado pela exposição à rotenona, já que os animais expostos ao xenobiótico apresentaram desempenho semelhante aos animais controles. A figura 9 representa um resumo dos achados em relação aos efeitos do treinamento físico.

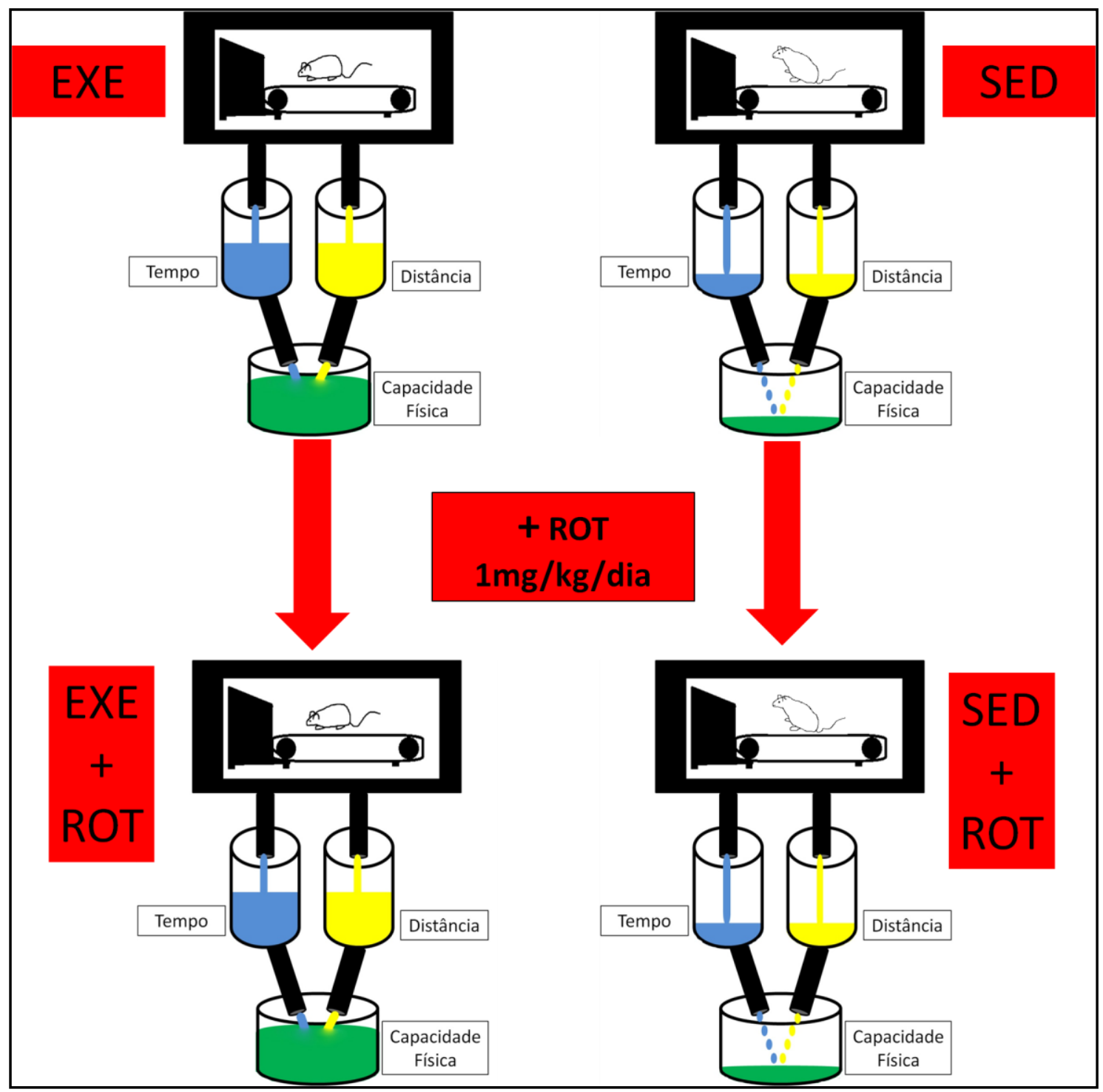

FIGURA 9 - Esquema ilustrativo das alterações da capacidade física de ratos Lewis idosos expostos a baixas doses de rotenona e submetidos ao treinamento físico após e durante período de exposição, e seus representativos controles (Grupo 1). O treinamento físico aumenta a capacidade física de maneira independente a exposição a rotenona. Onde, EXE corresponde ao treinamento físico, SED ausência de treinamento físico e ROT a rotenona. 
Os animais que realizaram o treinamento físico moderado, por meio de corrida em esteira, os quais posteriormente foram divididos em quatro subgrupos, sendo dois que permaneceram em treinamento físico (EXE) e dois que se tornaram sedentários (SED), apresentaram melhoras significativas considerando o tempo de corrida (Figura 10A) e distância percorrida (Figura 10B). Para tal, obteve-se aumento de $40 \%$ para o tempo e de $68 \%$ para a distância (EXE - Inicial vs Final). Como descrito anterioremente, deve-se considerar tempo e distância como parâmetros de alterações da capacidade física (Figura 10A e B).

Desta maneira, pode-se sugerir que, de acordo com 0 teste de capacidade física, 6 semanas foram suficientes para melhorar significativamente a condição física dos animais.

Posteriormente a esta fase de treinamento físico e subdivisão dos grupos, os dados obtidos para tempo e distância no teste de capacidade física final comparados com estes últimos indicam que (Figura 10A e B):

- a interrupção total do treinamento físico por 4 semanas, diminui o tempo e a distância em $41 \%$ e 55\%, respectivamente, nos animais DMSOsed 6 semanas comparados com a condição final.

- em contrapartida, a continuação do treinamento físico, por 4 semanas em intensidade moderada, proporciona aumento de $11 \%$ e $26 \%$ para tempo e distância, respectivamente nos animais DMSOexe -6 semanas comparados com a condição final.

- quando considerada a exposição a $1 \mathrm{mg} / \mathrm{kg} / \mathrm{dia}$ de rotenona por 4 semanas sem a continuidade do treinamento físico, observa-se uma diminuição do tempo de $52 \%$ e da distância de $70 \%$ nos animais ROTsed- 6 semanas comparados com a condição final.

- e, quando a exposição à mesma dose de rotenona é acompanhada pelo treinamento físico, tem-se uma diminuição menos acentuda do tempo (14\%) e da distância (17\%) nos animais ROTexe- 6 semanas comparados com a condição final.

Comparando-se os resultados do teste de capacidade física final ao resultado do teste inicial, obtém-se que a paralisação do treinamento físico não leva a alteração significativa relativa ao estado inicial para as variáveis do teste 
(tempo e distância) (DMSOsed - Inicial vs Final). Da mesma maneira que, a exposição à rotenona sem a continuidade não se difere dos valores iniciais (ROTsed- Inicial vs Final).

A continuidade do treinamento físico aumenta em $56 \%$ o tempo e $112 \%$ a distância (DMSOexe), além de manter os valores para tempo e distância quando o treinamento físico aconteceu simultaneamente à exposição a $1 \mathrm{mg} / \mathrm{kg} / \mathrm{dia}$ de rotenona (ROTexe- Inicial vs Final) (Figura 10A-B).

Assim sendo, pode-se sugerir que 6 semanas de treinamento físico moderado, por meio de corrida em esteira, foi suficiente para aumentar o tempo de corrida e a distância percorrida no teste de capacidade física. Ainda, mesmo após aumento na capacidade física, a interrupção total do treinamento físico diminuiu tal capacidade de maneira acentuada.

Pode-se sugerir, baseado nos achados, que a rotenona interfere no ganho de capacidade física, entretanto não há perda de condicionamento, já que os níveis de tempo de corrida e distância percorrida são mantidos após as 6 primeiras semanas de treinamento. Todos esses resultados estão representados na Figura 11. 


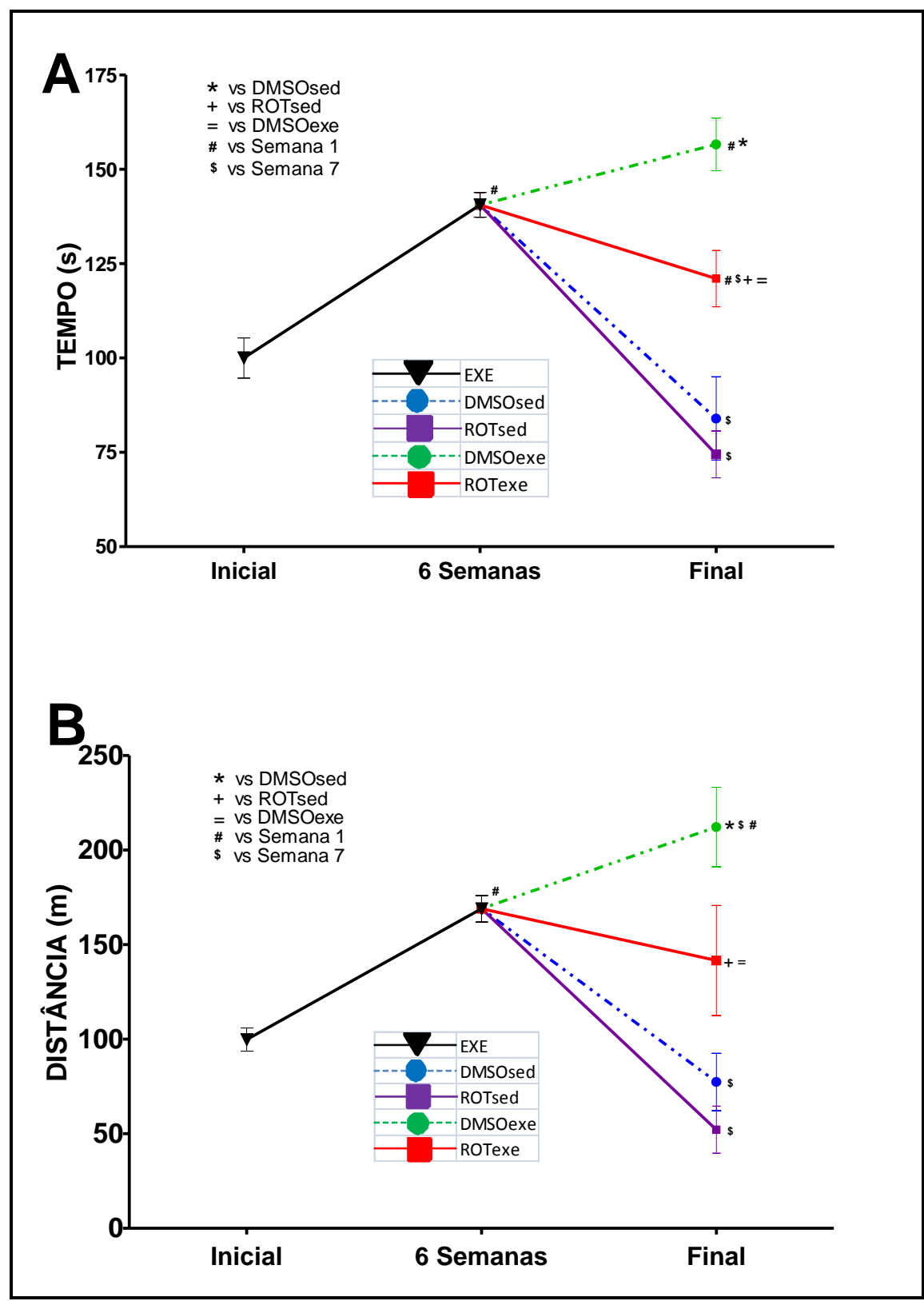

FIGURA 10 - Efeitos do protocolo de exercício em ratos Lewis idosos pertencentes ao grupo que realizou 6 semanas de exercício, de intensidade baixa a moderada, seguidas da exposição a droga simultaneamente a mais 4 semanas de treinamento físico ou não, Grupo 2 (G2). Valores relativos ao tempo (A) e distância (B). Valores apresentados em porcentagem relativa ao controle. EXE $(n=21)$ subdividido após seis semanas em: DMSOsed $(n=5)$, ROTsed $(n=6)$, DMSOexe $(n=5)$ e ROTexe $(n=5)$. Anova de medidas repetidas, pós-teste Bonferroni $(p \leq 0,05)$. 


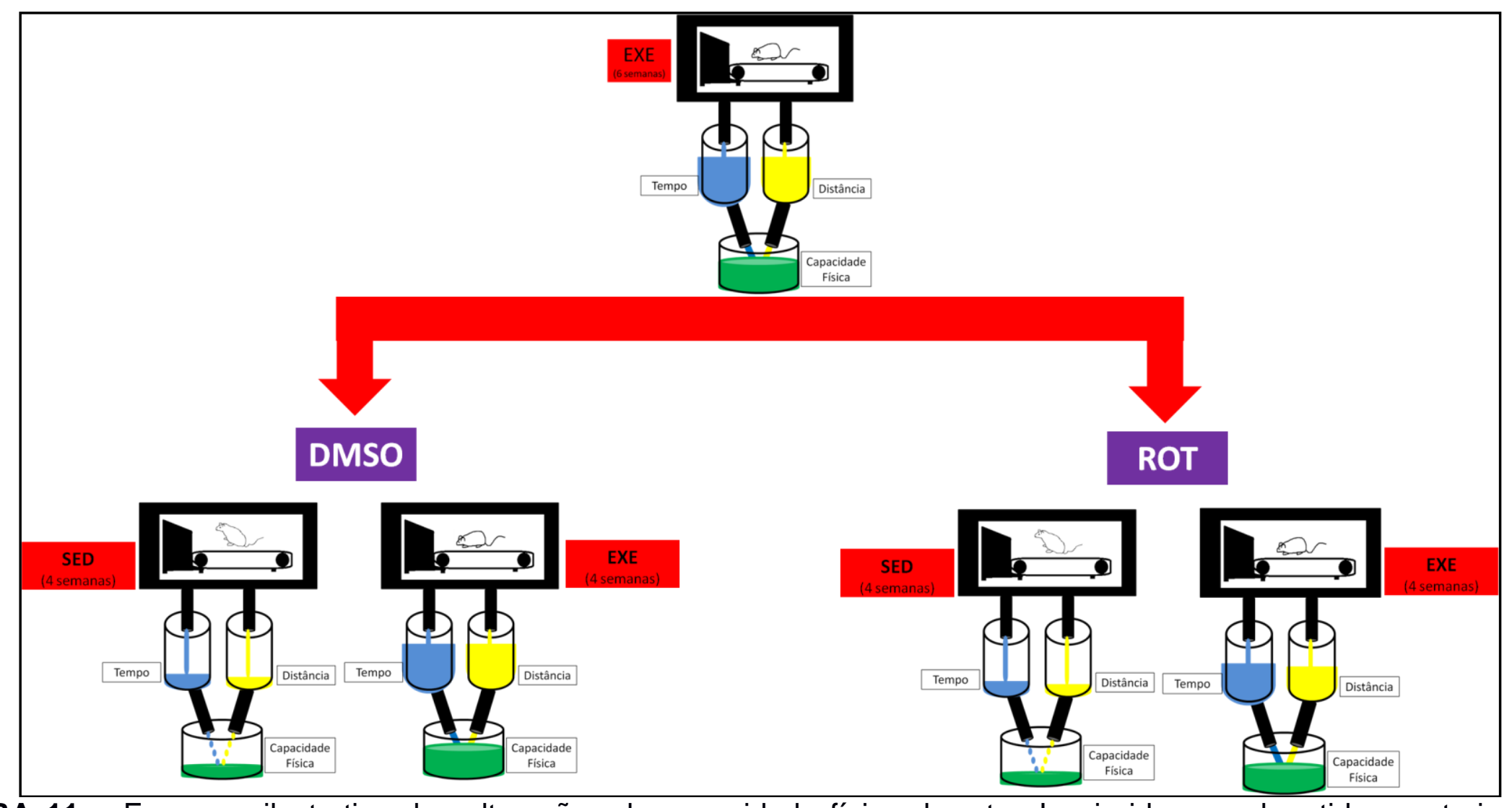

FIGURA 11 - Esquema ilustrativo das alterações da capacidade física de ratos Lewis idosos submetidos ao treinamento físico moderado por 6 semanas, seguido de exposição a rotenona simultaneamente a continuidade do treinamento físico por mais 4 semanas, e seus respetivos controles (G2). O treinamento físico aumenta a capacidade física de maneira significativa, sendo mantida em varoles maiores com a continuidade do treinamento físico. A interrupção do treinamento por 4 semanas reverte o ganho gerado anteriormente (6 semanas). A exposição à rotenona interfere negativamente nos efeitos benéficos do treinamento físico em ratos treinados, entretanto não piora a capacidade física se comparado com estado inicial. EXE corresponde ao treinamento físico, SED ausência de treinamento físico e ROT à rotenona. 


\subsection{Atividade da citrato sintase no sóleo após exercício forçado, com intensidade moderada}

Sabendo que o treinamento físico foi capaz de aumentar o tempo de corrida e a distância atingidos pelo teste de capacidade física, representando uma possível melhora da condição física, fez-se necessário verificar se isso se correlacionava com alterações celulares.

Utilizou-se a atividade da enzima citrato sintase $(C S)^{127}$ nos músculos sóleos e gastrocnêmios para verificar possíveis alterações no metabolismo celular. Visto que, alteração em sua atividade pode dar subsídios para caracterizar em qual nível o metabolismo aeróbio está sendo ativado, comparando assim o grupo sedentário ao treinado.

Os valores obtidos no presente trabalho para G1 mostram um aumento significativo de $90 \%$ na atividade da CS no músculo sóleo em resposta a exposição a rotenona (DMSOsed Vs ROTsed). Em resposta ao protocolo de treinamento físico, a atividade da CS mostrou-se aumentar significativamente em $39 \%$ para o grupo DMSO (DMSOsed vs DMSOexe). Sendo que este aumento da atividade da CS é mantido quando os animais foram submetidos ao treinamento físico e expostos à rotenona simultaneamente (ROTsed vs ROTexe) (Figura 12).

Desta forma, pode-se sugerir que tanto a exposição a rotenona quanto 0 treinamento físico, independentemente, bem como a associação entre 0 treinamento físico e a exposição à rotenona, aumentam a atividade da citrato sintase. 


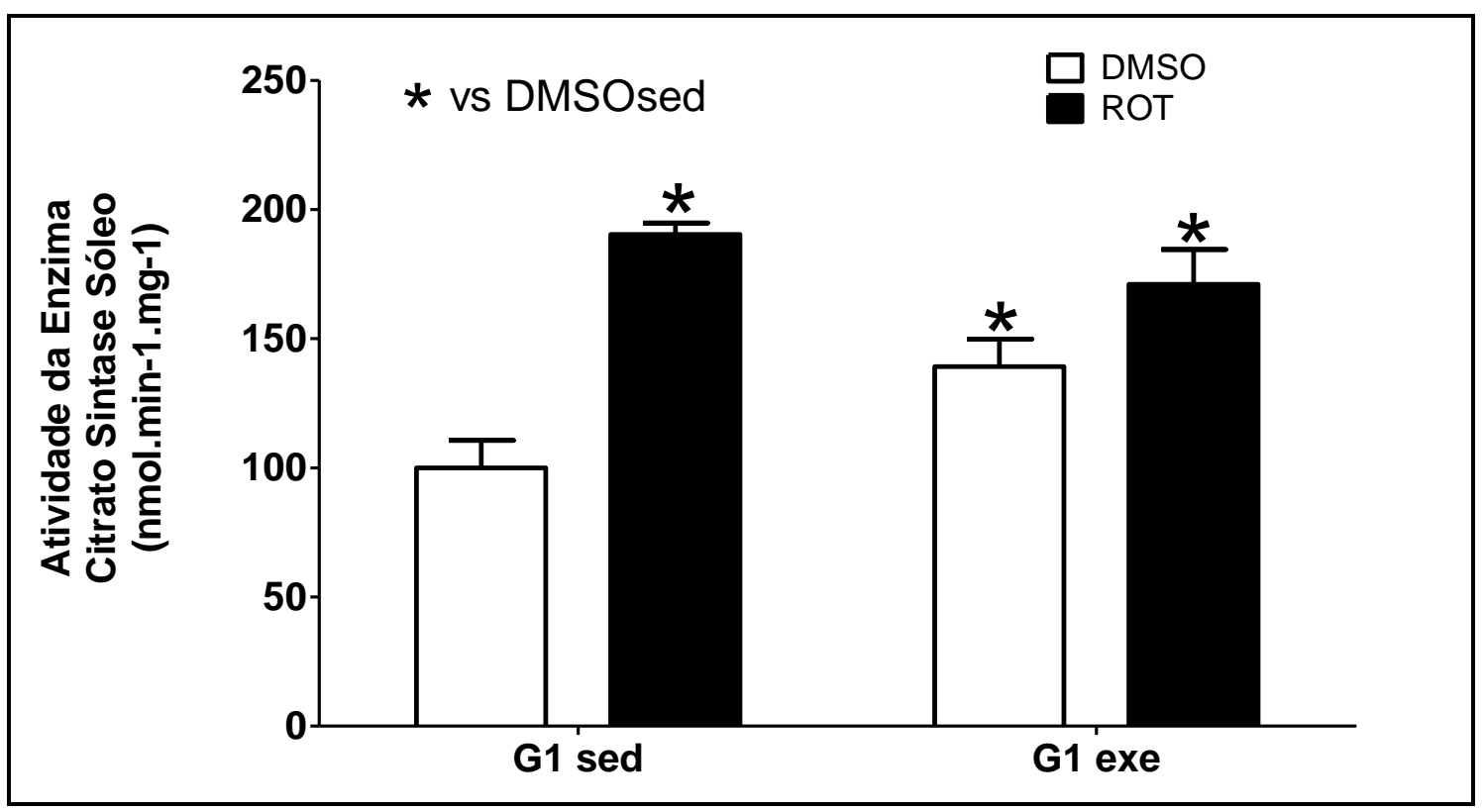

FIGURA 12- Atividade da enzima citrato-sintase no músculo sóleo de ratos idosos submetidos a exposição à rotenona (ROT) ou seu solvente (DMSO) e ao protocolo de exercício físico forçado (exe), de intensidade moderada, por 6 semanas (G1). Valores expressos em porcentagem do controle. DMSOsed $(n=5)$, ROTsed $(n=4)$, DMSOexe $(n=5)$ e ROTexe $(n=5)$. Anova duas vias, pósteste Bonferroni $(p \leq 0,05)$.

Para o G2, também no músculo sóleo, obteve-se diminuição significativa, equivalente a $51 \%$ da atividade da CS em resposta ao tratamento com rotenona (DSMOsed vs ROTsed). Em contrapartida, quando analisados os efeitos do treinamento físico, a atividade da CS encontra-se significativamente aumentada, equivalente a 84\% (DMSOsed vs DMSOexe) (Figura 13).

Já na condição em que se aliam o treinamento e a exposição à rotenona não se verificaram alterações em relação ao controle (DMSOsed vs ROTexe). Portanto, tanto o efeito de diminuição causado pela exposição à rotenona, quanto o aumento causado pelo treinamento físico na atividade da CS são neutralizados na condição ROTexe (Figura 13). 


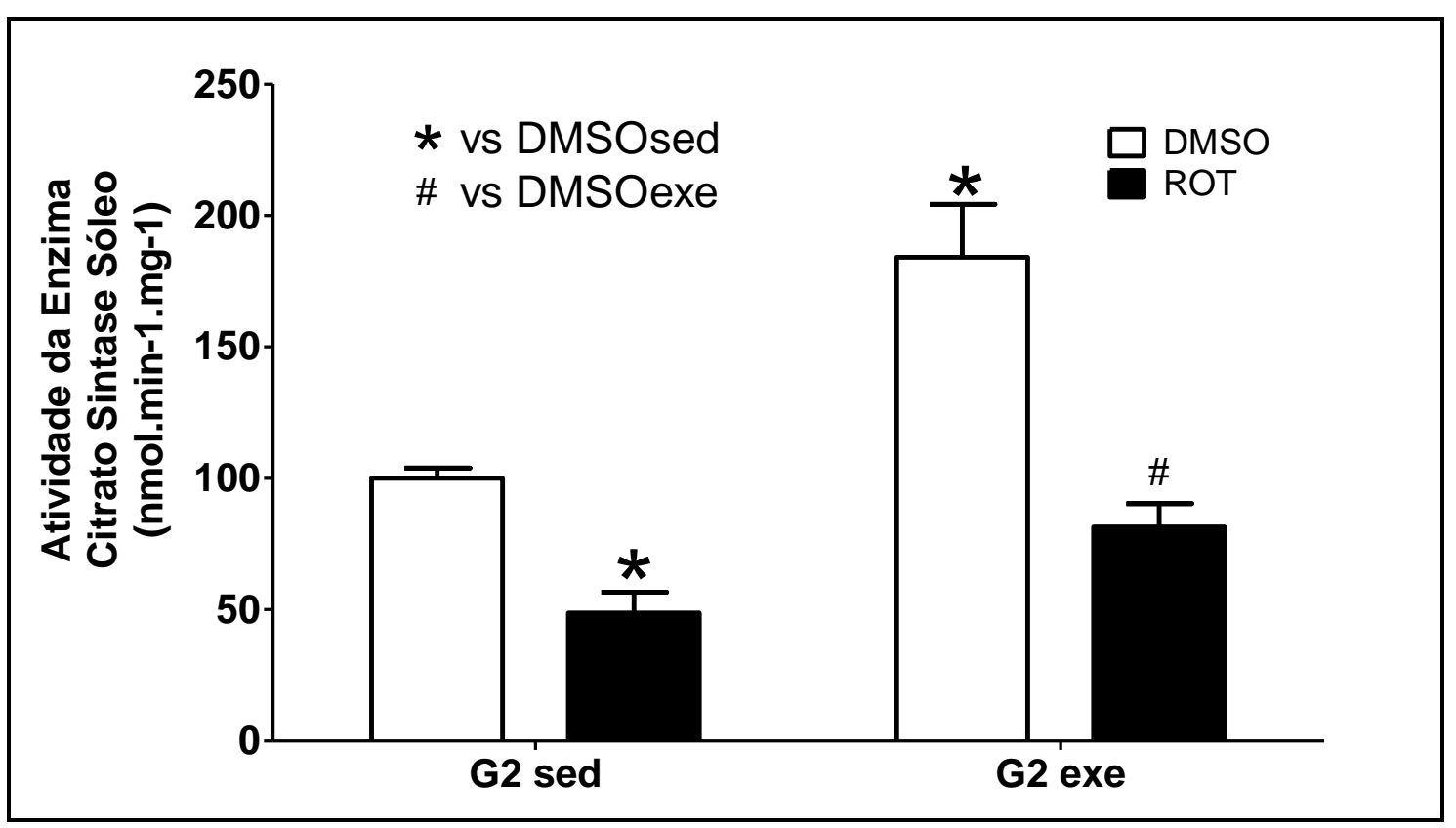

FIGURA 13 - Atividade da enzima citrato-sintase no músculo sóleo de ratos idosos submetidos a exposição à rotenona (ROT) ou seu solvente (DMSO), e ao protocolo de exercício físico forçado, de intensidade moderada, iniciado antes da exposição à rotenona (G2). Valores expressos em porcentagem do controle. DMSOsed $(n=3)$, ROTsed $(n=4)$, DMSOexe $(n=5)$ e ROTexe $(n=5)$. Anova de medidas repetidas, pós-teste Bonferroni $(p \leq 0,05)$.

No músculo gastrocnêmio, os animais do G1 mostraram uma diminuição significativa de 55\% em resposta a exposição à rotenona (DMSOsed vs ROTsed). Com o treinamento físico verificou-se aumento de aproxidamente $62 \%$ na atividade da CS (DMSOsed vs DMSOexe). Quando o treinamento físico foi realizado simultaneamente à exposição à rotenona não se verificaram alterações significativas (DMSOsed vs ROTexe), sugerindo que em conjunto (rotenona + treinamento físico) impedem os efeitos isolados de ambos (Figura 14). 


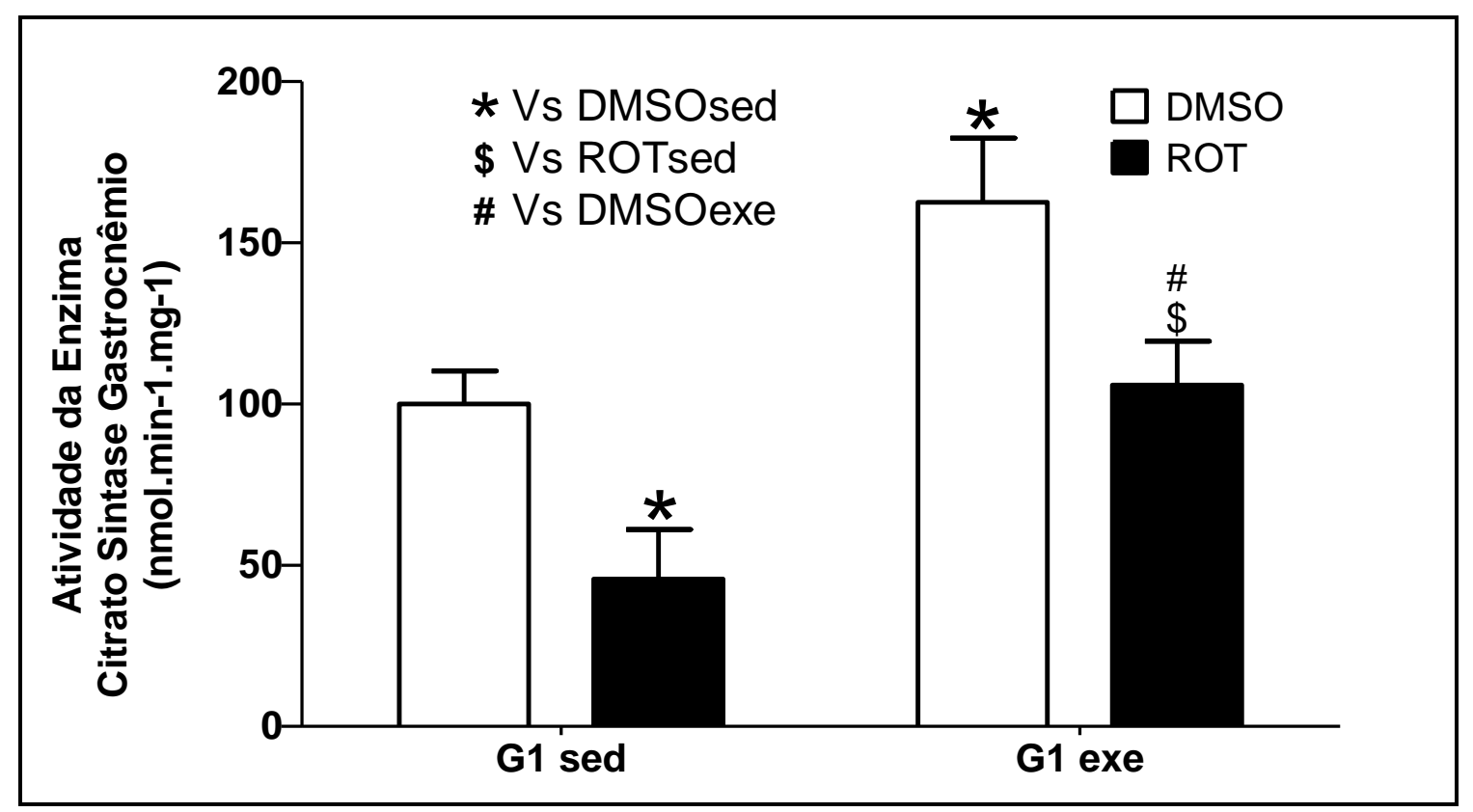

FIGURA 14- Atividade da enzima citrato-sintase no músculo gastrocnêmio de ratos idosos submetidos a exposição à rotenona (ROT) ou seu solvente (DMSO) e ao protocolo G1 de exercício físico forçado (exe), de intensidade moderada, por 6 semanas.Valores expressos em porcentagem do controle. DMSOsed $(n=5)$, ROTsed $(n=5)$, DMSOexe $(n=5)$ e ROTexe $(n=5)$. Anova de medidas repetidas, pós-teste Bonferroni $(p \leq 0,05)$.

Para os animais que compuseram o G2, tem-se que a atividade da CS não se altera com à exposição a $1 \mathrm{mg} / \mathrm{kg} / \mathrm{dia}$ de rotenona (DMSOsed vs ROTsed). O mesmo ocorre para o treinamento físico, seja quando aplicado isoladamente (DMSOsed vs DMSOexe), ou em conjunto a exposição à rotenona (ROTsed VS ROTexe) (Figura 15). 


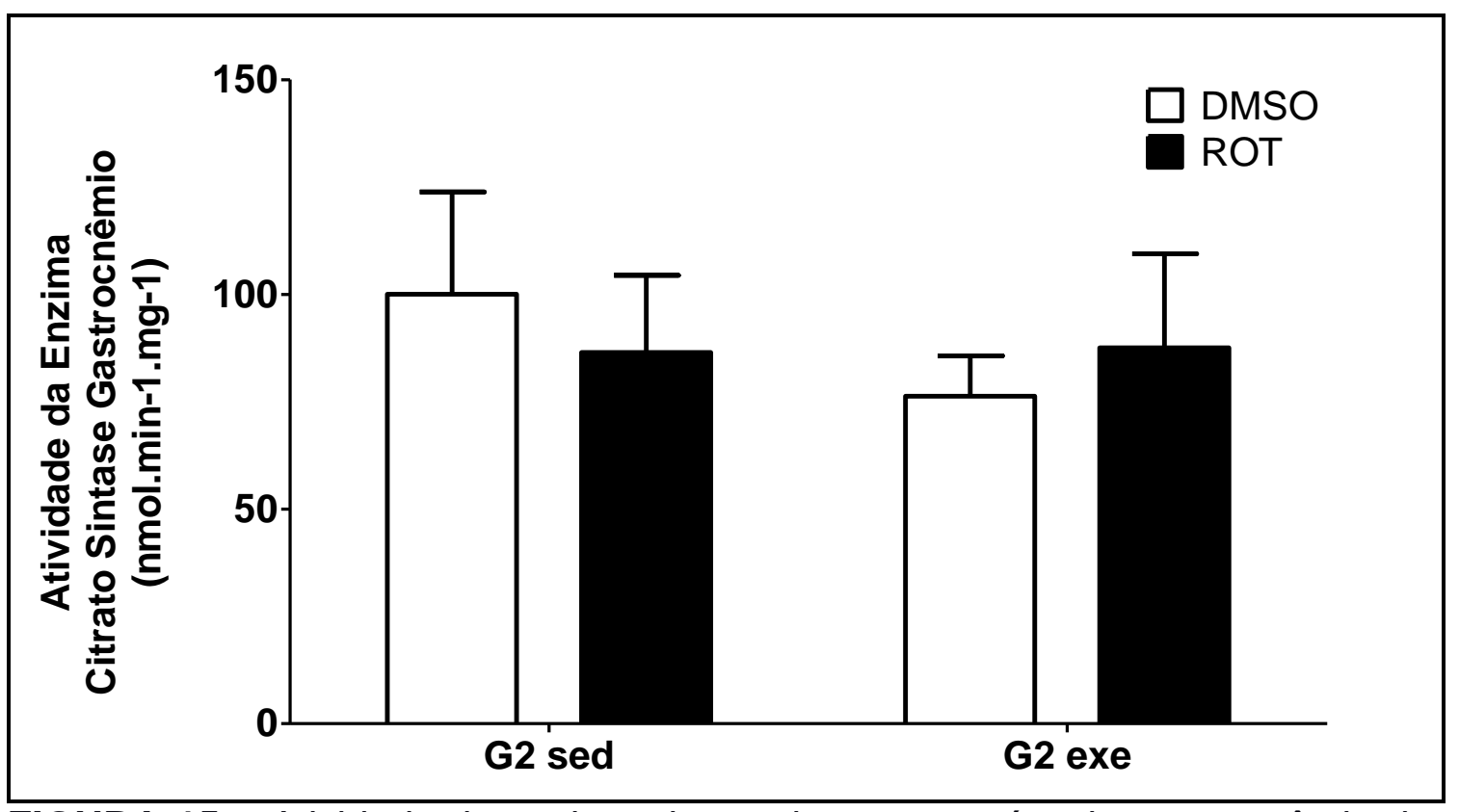

FIGURA 15 - Atividade da enzima citrato-sintase no músculo gastrocnêmio de ratos idosos submetidos a exposição à rotenona (ROT) ou seu solvente (DMSO) e ao protocolo de exercício físico forçado, de intensidade moderada, iniciado antes da exposição à rotenona (G2). Valores expressos em porcentagem do controle. DMSOsed $(n=5)$, ROTsed $(n=5)$, DMSOexe $(n=5)$ e ROTexe $(n=5)$.

Conforme os achados descritos anteriormente pode-se sugerir que a atividade da enzima CS é regulada tanto pela exposição à rotenona quanto pelo treinamento físico. Além disso, observou-se que o treinamento físico promoveu aumento da atividade da enzima CS, como esperado, exceto para o G2 no gastrocnêmio. Assim sendo, é possível pressumir que além das alterações do treinamento físico sobre a capacidade física, foi possível identificar as alterações equivalentes no metabolismo celular. A figura 16 ilustra a variação da atividade da enzima citrato sintase diante da exposição à rotenona e ao treinamento físico de maneira isolada ou em conjuto. 


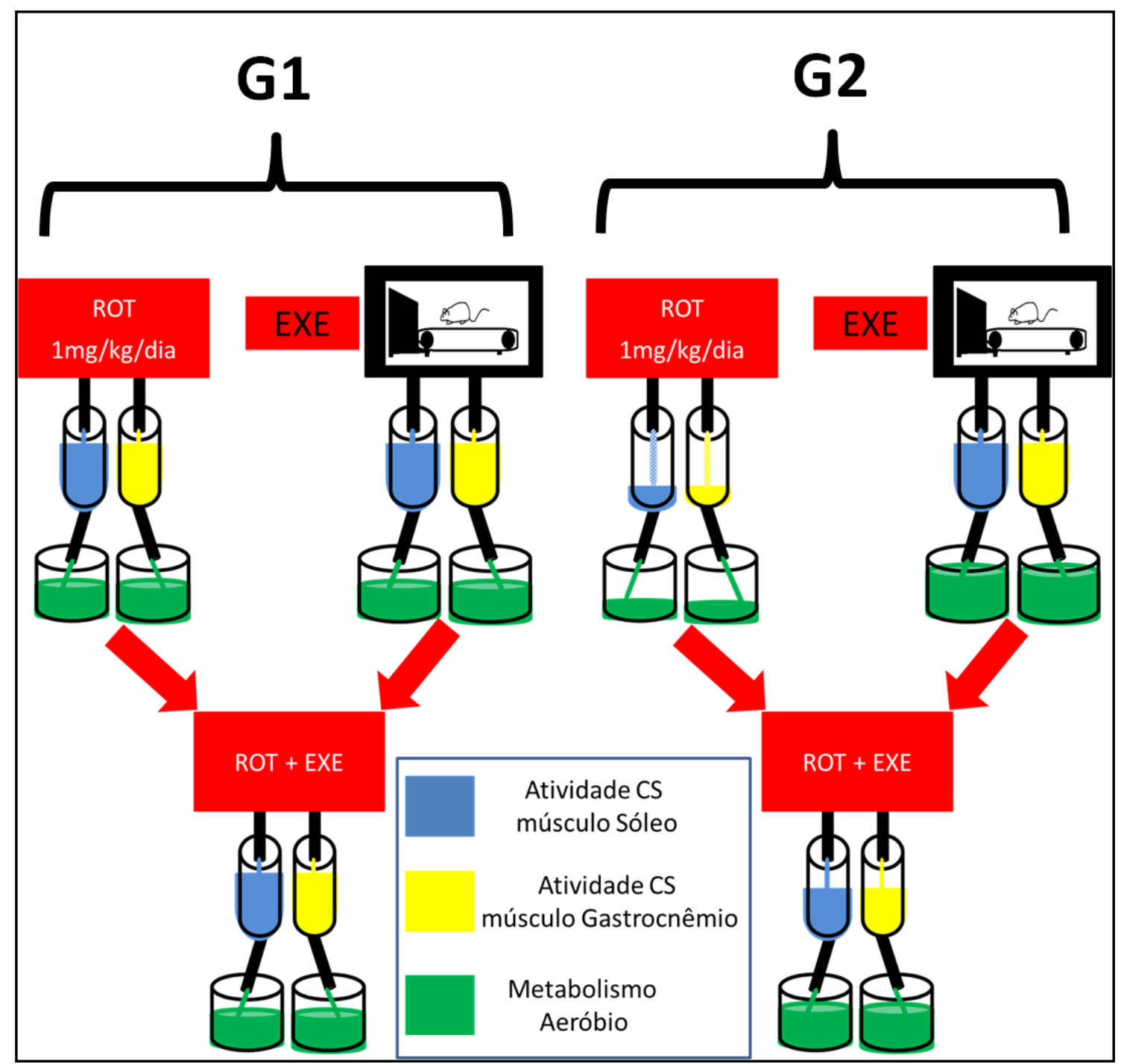

FIGURA 16 - Esquema ilustrativo das alterações da atividade da enzima citrato sintase (CS) nos músculos sóleo e gastrocnêmio de ratos Lewis idosos expostos a $1 \mathrm{mg} / \mathrm{kg} / \mathrm{dia}$ de rotenona e/ou submetidos ao treinamento físico moderado, e seus respetivos controles para os grupos de acordo com protocolo experimental (G1 e G2). A atividade da enzima citrato sintase aumenta tanto com exposição à rotenona quanto pelos efeitos do treinamento físico (6 semanas) para o G1. Para o G2, a atividade da CS diminuiu com a exposição a rotenona, e em contrapartida aumenta com o treinamento físico. Onde, G1 corresponde ao grupo que foi exposto à rotenona seguido de treinamento físico (EXE) e persistência à exposição à rotenona (ROT); o G2 ao corresponde aos grupo que realizou treinamento físico e posteriormente foi submetido a exposição a rotenona com ou sem continuidade do treinamento. 


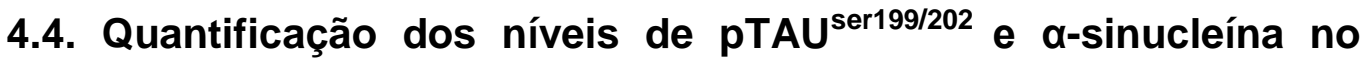
hipocampo

A hiperfosforilação da proteína pTau e o aumento da a-sinucleína, favorecendo a agregação dessas, são considerados marcadores padrões da doença de Alzheimer e Parkinson, respectivamente. Entretanto, anteriormente à agregação de proteínas é possível verificar alterações celulares afetando a comunicação celular. Desta maneira, verificou-se a expressão das proteínas pTau ${ }^{\text {ser199/202 }}$ e a-sinucleína no hipocampo de ratos Lewis expostos a $1 \mathrm{mg} / \mathrm{kg} / \mathrm{dia}$ de rotenona e/ou treinamento físico e seus respectivos controles.

Observou-se que a exposição a $1 \mathrm{mg} / \mathrm{kg} / \mathrm{dia}$ de rotenona não alterou os níveis de pTau ${ }^{\text {ser199/202 }}$ em relação ao controle (G1, DMSOsed vs ROTsed). O mesmo ocorreu quanto analisado diante dos efeitos do treinamento físico forçado (G1, DMSOsed vs DMSOexe), e quando aliado à exposição à rotenona simultaneamente ao treinamento físico (G1, ROTsed vs ROTexe) (Figura 17A).

Para os animais do G2, não se observaram alterações dos níveis de pTau ${ }^{\text {ser199/202 }}$ com a exposição à rotenona (DMSOsed vs ROTsed). Contudo, o treinamento físico (DMSOsed vs DMSOexe), bem como o efeito da rotenona aliada aos efeitos do treinamento físico (ROTsed vs ROTexe) promoveram diminuição da hiperfosforilaração da pTau ${ }^{\text {ser199/202 }}$ de $29 \%$ e $31 \%$, respectivamente (Figura 17B).

Referente aos níveis de a-sinucleína, não se observou alteração após exposição à rotenona (G1, DMSOsed vs ROTsed). Em contrapartida, o treinamento físico forçado, por seis semanas, aumentou em $49 \%$ os níveis de a-sinucleína (G1, DMSOsed vs DMSOexe). Ainda, a exposição à rotenona seguida de treinamento físico, com continuidade da exposição à rotenona durante 4 semanas de treinamento físico, levou a aumento de aproximadamente $40 \%$ dos níveis de a-sinucleína comparado aos efeitos da rotenona somente (G1, ROTsed vs ROTexe) (Figura 17C).

Para o grupo que foi inicialmente submetido ao treinamento físico, G2, verificou-se que a exposição a $1 \mathrm{mg} / \mathrm{kg} / \mathrm{dia}$ de rotenona elevou os níveis de $\alpha$ sinucleína (187\%, G2 DMSOsed vs ROTsed), bem como a continuidade do treinamento físico durante o período de 4 semanas aliado ou não com a 
exposição a rotenona (232\%, DMSOsed vs DMSOexe; ROTsed - $287 \%$ e ROTexe-280\%) (Figura 17D).

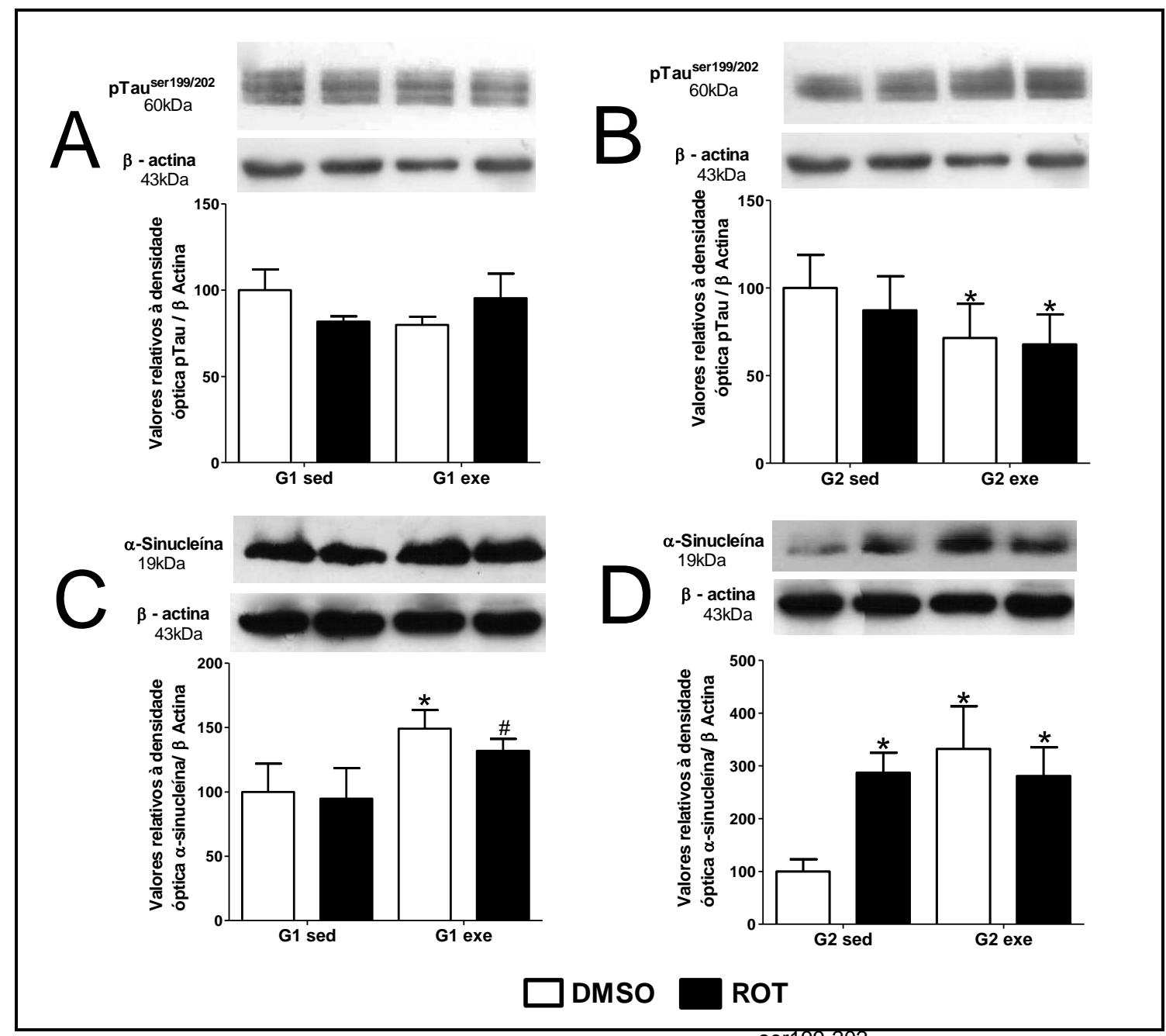

FIGURA 17 - Quantificação dos níveis de pTau ${ }^{\text {ser199-202 }}$ (60kDa, A-B) e $\alpha$ sinucleína (19kDa, C-D) no hipocampo de ratos idosos expostos a DMSO ou rotenona (ROT $1 \mathrm{mg} / \mathrm{kg} / \mathrm{dia}$ ) submetidos ao treinamento físico, conforme descrito para G1 (A e C) e G2 (B e D). Imagens representativas das bandas de Western Blot correspondentes a pTau ${ }^{\text {ser199-202, }}$ a-sinucleína e $B$-actina (utilizada para normalização). Valores apresentados em porcentagem do controle. $(p<0,05)$ * vs DMSOsed, \# vs ROTsed segundo a análise de variância (ANOVA) de duas vias seguido do pós-teste de Bonferroni. ( $n=5)$.

Desta maneira, pode-se sugerir que a exposição a baixas doses de rotenona parecem não alterar os níveis de hiperfosforilação da pTau ${ }^{\text {ser199/202 em }}$ ratos Lewis idosos, independente da realização do treinamento físico moderado anterior ou posteriormente à exposição. Contudo, quando o treinamento físico 
foi realizado antes, durante e depois da exposição, o mesmo parece agir de maneira independente da rotenona diminuindo os níveis de hiperfosforilação da pTau ${ }^{\text {ser199/202. }}$.

Pode-se ainda sugerir que, a exposição à rotenona não altera os níveis de $\alpha$-sinucleína, contudo, os resultados da relação entre exposição a rotenona e o treinamento físico elevam significativamente esses níveis.

Desta maneira, sugere-se que a concentração de $1 \mathrm{mg} / \mathrm{kg} / \mathrm{dia}$ pode ser considerada como dose anterior ao aumento significativo da hiperposforilação de Tau e dos níveis de a-sinucleína em ratos Lewis idosos, exceto nas alterações encontradas que se devem aos efeitos da rotenona dependentes do treinamento físico. Sendo assim, ratos Lewis tratados com baixa dose de rotenona $(1 \mathrm{mg} / \mathrm{kg} / \mathrm{dia})$ parecem representar um modelo que antecede a agregação de proteína, considerando as repostas do hipocampo, possibilitando a análise de mecanismos do transporte intracelular, em especial das neurotrofinas e seus receptores.

\subsection{Quantificação dos níveis das isoformas de TrkB no hipocampo}

As neurotrofinas precisam se conectar aos seus receptores para que as cascatas de reações neurotróficas sejam iniciadas. Para tal, faz-se necessário que tanto as neurotrofinas como seus receptores estejam disponíveis.

Sabe-se que o TrkB, receptor de BDNF, existe em duas isoformas, a completa e a truncada. Verificou-se que a exposição a baixas doses de rotenona aumenta significativamente, triplicando, os valores da isoforma completa (145kDa) no hipocampo de ratos Lewis (Figura 18A).

Obteve-se um aumento de $205 \%$ na expressão de TrkB em sua isoforma completa $(145 \mathrm{kDa})$ para o G1 ROTsed em comparação ao G1 DMSOsed (Figura 18A).

Quanto aos efeitos do exercício, o valores obtidos indicam que o exercício físico forçado, por meio da corrida em esteira em intensidade moderada, aumenta a expressão da isoforma completa da TrkB em 4,5 vezes comparado ao controle sedentário (DMSOsed vs DMSOexe) (Figura 18A). 
Em contrapartida, o treinamento físico aliado à exposição à rotenona não altera os valores da expressão de TrkB (145kDa) para o G1 ROTexe se comparado à resposta da exposição à rotenona (ROTsed vs ROTexe), mas reduz de maneira significativa comparado aos efeitos do treinamento físico (DMSOexe vs ROTexe) (Figura 18A).

Para o animais do G2, os achados mostram que exposição à rotenona, mesmo após 6 semanas de treinamento reduz os níveis da isoforma completa de TrkB (73,58\%, G2 DMSOsed vs ROTsed), e a continuação do treinamento físico também a reduz significativamente em aproximadamente $41 \%$ (DMSOsed vs DMSOexe). Contudo, quando aliados treinamento físico e exposição a rotenona tem-se um aumento significativo superior a $5 \mathrm{x}$ comparado aos efeitos da exposição à rotenona (G2, ROTsed vs ROTexe) (Figura 18B).

Para a isoforma truncada (95kDa), no hipocampo dos animais do G1, a exposição à rotenona não alterou os níveis (DMSOsed vs ROTsed), bem como o treinamento físico isolado (DMSOsed vS DMSOexe). Contudo, quando aliados exposição à rotenona e treinamento físico, observou-se um aumento significativo superior a $2 x$ comparado tanto ao efeito apenas da rotenona, quanto ao efeito do treinamento físico (Figura 18C).

O mesmo ocorreu com as repostas da isoforma truncada no hipocampo do animais que compuseram o G2, sendo que não foram detectadas alterações significativas para nenhum dos seus subgrupos (Figura 18D). 


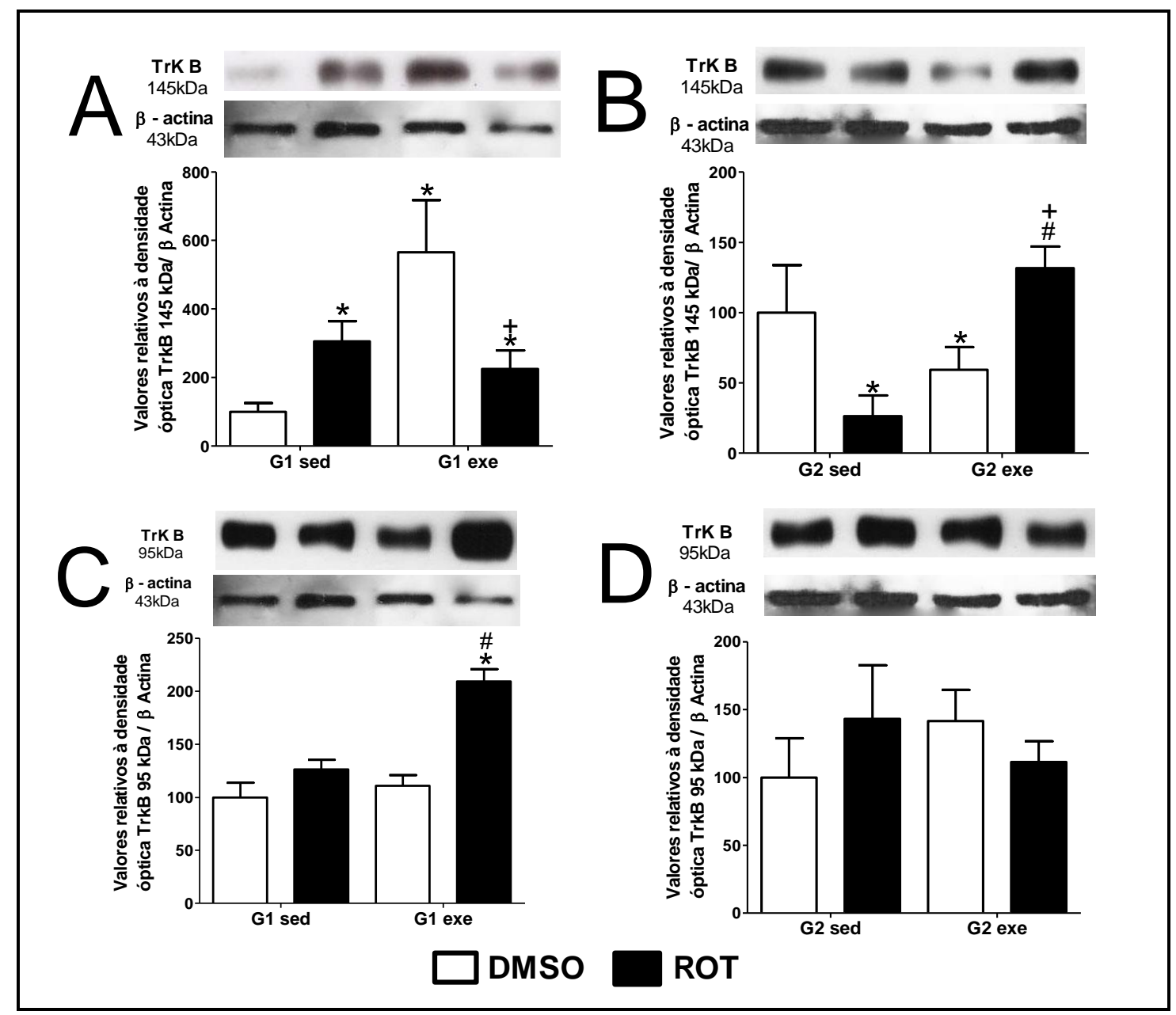

FIGURA 18 - Quantificação da expressão das isoformas completa (145kDa, AB) e truncada (95kDa,C-D) do TrKB, receptor de BDNF, no hipocampo de ratos idosos expostos a DMSO ou rotenona (ROT $1 \mathrm{mg} / \mathrm{kg} / \mathrm{dia}$ ) submetidos ao treinamento físico, conforme descrito para G1 (A e C) e G2 (B e D). Imagens representativas das bandas de Western Blot correspondentes a TrkB e B-actina (utilizada para normalização). Valores apresentados em porcentagem do controle. $(\mathrm{p}<0,05)$ * vs DMSOsed, \# vs ROTsed, + vs DMSOexe segundo a análise de variância (ANOVA) de duas vias seguido do pós-teste de Bonferroni. $(n=5)$.

Estes achados sugerem que o tanto a exposição à rotenona quanto o treinamento físico, aumentam os níveis de expressão da isoforma completa da TrKB, não alterando os níveis de isoforma truncada no hipocampo de ratos Lewis idosos. E que a combinação exposição a rotenona e treinamento físico forçado, com intensidade moderada, modula os níveis da isoforma TrkB completa de maneira dependente ao período em que são aplicados. Sendo: 
- aumentando-os quando aplicado posteriormente à exposição à ROT, no entanto, em valores menos expressivos que quando comparados tanto ao efeitos da ROT quanto do treinamento de maneira isolada;

- diminuindo-os quando aplicado anteriormente à exposição à ROT;

- mantendo-os quando aplicado anteriormente e durante a exposição a ROT, revertendo a diminuição causada tanto pela ROT quanto pelo treinamento de maneira isoladas.

Além disso, a isoforma truncada parece não ter seus níveis afetados pela exposição a ROT, bem como pelos efeitos do treinamento físico. E que a combinação ROT e treinamento altera somente os níveis de TrkB, em sua isoforma truncada no hipocampo de ratos Lewis, aumentado-os quando aplicados posteriormente à exposição a ROT.

\subsection{Níveis de proteínas do tráfego anterógrado de receptores TrKB} no hipocampo

De acordo com os resultados encontrados para os níveis do receptor TrKB, e sabendo que esses parecem ser regulados no hipocampo de ratos Lewis idosos tanto pela exposição à rotenona, quanto pelo treinamento físico, faz-se necessário analisar como está o tráfego intracelular desses receptores. Para tal, utilizou-se a análise indireta, por meio de western blot, do tráfego intracelular do receptor TrkB no hipocampo de ratos Lewis idosos, submetidos à exposição a rotenona e/ou treinamento físico.

Como descrito anteriormente o tráfego de receptores TrkB é realizado por um complexo de proteínas transportadoras e adaptadoras que se ligam às vesículas contendo os recepetores. Tais proteínas e suas alterações diante da exposição à rotenona e/ou treinamento físico serão descritas a seguir.

\subsubsection{Níveis da SLP-1 no hipocampo}

Dentre as proteínas tranportadoras dos receptores de TrkB, temos a proteína SLP-1, que se localiza na membrana da vesícula sináptica e funciona 
como reguladora da exocitose e endocitose, estando envolvida na liberação de neurotransmissores e inserção do receptor TrKB na membrana plasmática.

Os resultados demostram que a exposição a $1 \mathrm{mg} / \mathrm{kg} / \mathrm{dia}$ de rotenona promove uma diminuição significativa na expressão da SLP-1 em relação ao seu respectivo controle (G1, DMSOsed vs ROTsed) (FIGURA 19A). Também mostram que o treinamento físico recuperou os níveis de SLP-1 quando aplicado posteriormente à exposiçao à ROT (G1, ROTsed vs ROTexe) (Figura 19A).

Para os animais do G2, a exposição à ROT posteriormente a 6 semanas de treinamento físico não alterou os níveis de SLP-1 (G2, DMSOsed vs ROTsed) (Figura 19B). Já quando a exposição à rotenona ocorreu posteriomente a 6 semanas de treinamento físico, e conjutamente a mais 4 semanas de treinamento físico, houve aumento significativo dos níveis da SLP1 no hipocampo de ratos Lewis idosos (G2, ROTsed vs ROTexe) (Figura 19B).



FIGURA 19 - Quantificação da expressão da proteína semelhante a Sinaptotagmina1 (SLP-1, 65kDa) no hipocampo de ratos idosos expostos a DMSO ou rotenona (ROT $1 \mathrm{mg} / \mathrm{kg} / \mathrm{dia}$ ) submetidos ao treinamento físico, conforme descrito para G1 (A) e G2 (B). Imagens representativas das bandas de Western Blot correspondentes a SLP-1 e B-actina (utilizada para normalização). Valores apresentados em porcentagem do controle. $(p<0,05)$ * vs DMSOsed, \# vs ROTsed, segundo a análise de variância (ANOVA) de duas vias seguido do pós-teste de Bonferroni. $(n=5)$.

Assim sendo, pode-se, a partir dos resultados encontrados, sugerir que o treinamento físico recupera a diminuição causada pela exposição à rotenona, 
e que proteje das alterações nos níveis de SLP-1 no hipocampo de Ratos Lewis idosos quando aplicado anteriomente à exposição à rotenona.

\subsubsection{Níveis de Rab27B no hipocampo}

Outra proteína que constitui o complexo transportador de receptores de BDNF é a Rab27B. Esta regula a exocitose, bem como a inserção de receptores TrkB na membrana plasmática, juntamente com outras proteínas efetoras específicas de cada carga.

Os resultados demonstram que os níveis de expressão da Rab27B após exposição a rotenona diminuem significativamente em relação ao seu controle para os animais do G1 (G1 DMSOsed vs ROTsed) (FIGURA 20A). E que, estes níveis também estão diminuídos em resposta aos efeitos do treinamento físico (G1, DMSOsed vs DMSOexe). No entanto, quando o treinamento precede a exposição à rotenona, os níveis de Rab27-B não se alteram de maneira significativa quando comparados ao controle, e apresentam um aumento significativo em relação aos níveis resultantes dos efeitos da ROT (G1 ROTsed vs ROTexe) (Figura 20A).

Para os animais que compuseram o G2, obteve-se que a exposição a ROT posteriomente a 6 semanas de treinamento físico não altera os níveis de expressão da Rab27B (G2, DMSOsed vs ROTsed) (Figura 20B). Em contrapartida, a realiazação ininterrupta por 10 semanas de treinamento físico, 6 semanas iniciais e mais 4 semanas (com ou sem exposição a ROT), diminuiu de maneira signifcativa os níveis de expressão de Rab27B no hipocampo de ratos Lewis idosos (Figura 20B). 


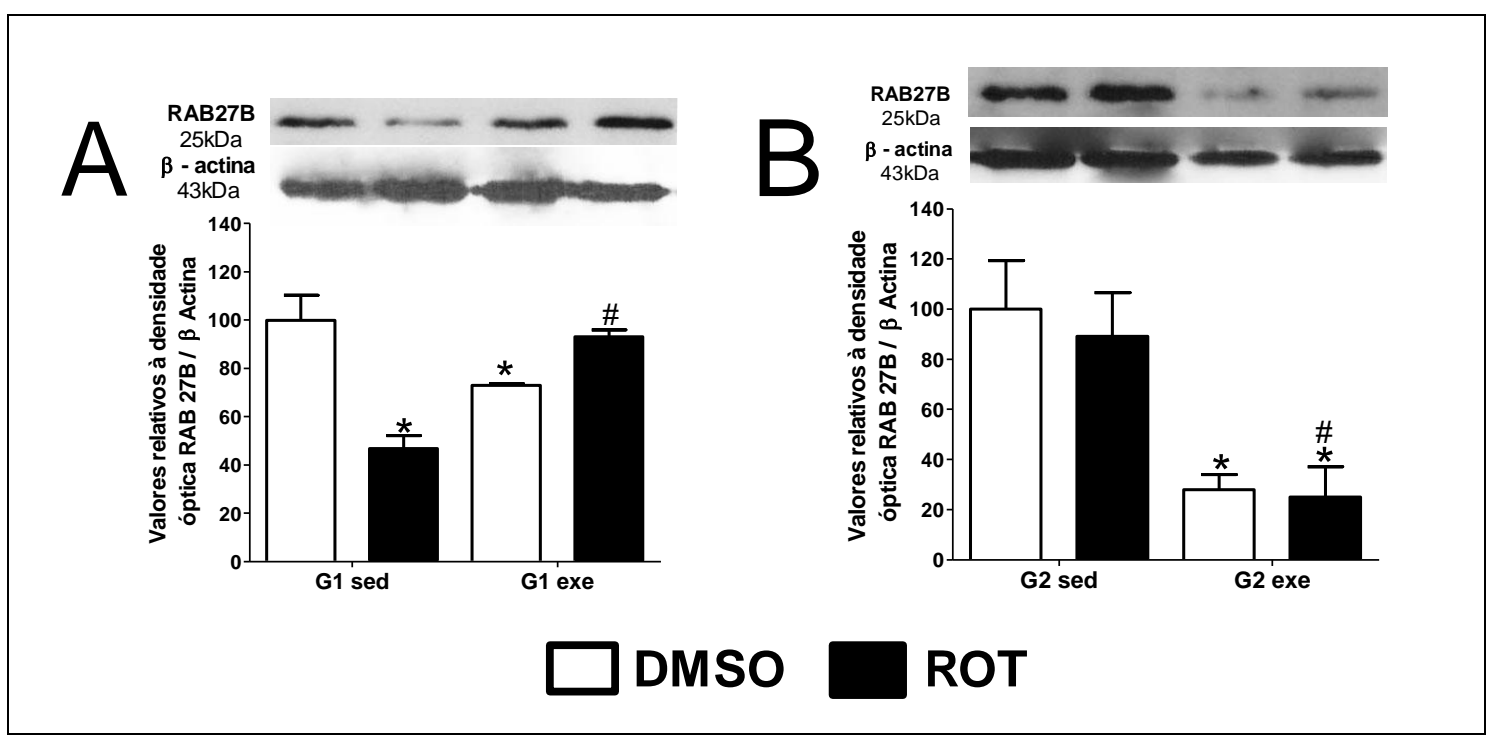

FIGURA 20 - Quantificação da expressão da RAB27B (25 kDa, A-B) no hipocampo de ratos idosos expostos a DMSO ou rotenona (ROT $1 \mathrm{mg} / \mathrm{kg} / \mathrm{dia}$ ) submetidos ao treinamento físico, conforme descrito para G1 (A) e G2 (B). Imagens representativas das bandas de Western Blot correspondentes a RAB27B e B-actina (utilizada para normalização). Valores apresentados em porcentagem do controle. $(p<0,05)$ * vs DMSOsed, \# vs ROTsed, segundo a análise de variância (ANOVA) de duas vias seguido do pós-teste de Bonferroni. $(n=5)$.

Estes resultados sugerem que a exposição à $1 \mathrm{mg} / \mathrm{kg} /$ dia de rotenona altera os níveis de RAB27B, diminuindo-os, sendo este recuperado pelo treinamento físico. Ainda que, o treinamento físico quando aplicado antes e durante à exposição à rotenona diminui expresivamente os níveis desta mesma proteína.

\subsubsection{Níveis da CRMP-2 no hipocampo}

Outra proteína relacionada ao tráfego do receptor TrKB analisada foi a CRMP-2, que se expressa predominantemente no sistema nervoso central durante o desenvolvimento e a formação dos axônios por meio da interação com os microtúbulos.

Os achados demonstram que a exposição à rotenona altera significativamente os níveis de CRMP-2 em comparação com seu respectivo controle, aumentando-o em 39\% (G1, DMSOsed vs ROTsed) (Figura 21A). E o 
treinamento físico também aumentou em 112\% (G1, DMSOsed vs DMSOexe), sendo mantido esse aumento (105\%) na presença da ROT (Figura 21A).

Quando os animais foram previamente treinados e posteriormemnte expostos a ROT, obteve-se um aumento de 103\% no níveis de CRMP-2 (G2, DMSOsed vs ROTsed) (Figura 21B). A continuidade do treinamento físico (G2 DMSOexe) bem como com a exposição a ROT (G2 ROTexe) também aumentam a CRMP-2 em 66\% e 44\%, respectivamente (Figura 21B). Vale ressaltar que a comparação entre os grupos expostos à rotenona mostrou uma diminuição de 30\% nos níveis de CRMP-2 após treinamento físico aplicado por 10 semanas do que quando o treinamento físico foi aplicado apenas anteriomente à exposição a $1 \mathrm{mg} / \mathrm{kg} /$ dia de rotenona (G2 ROTexe vs ROT sed) (Figura 21B).

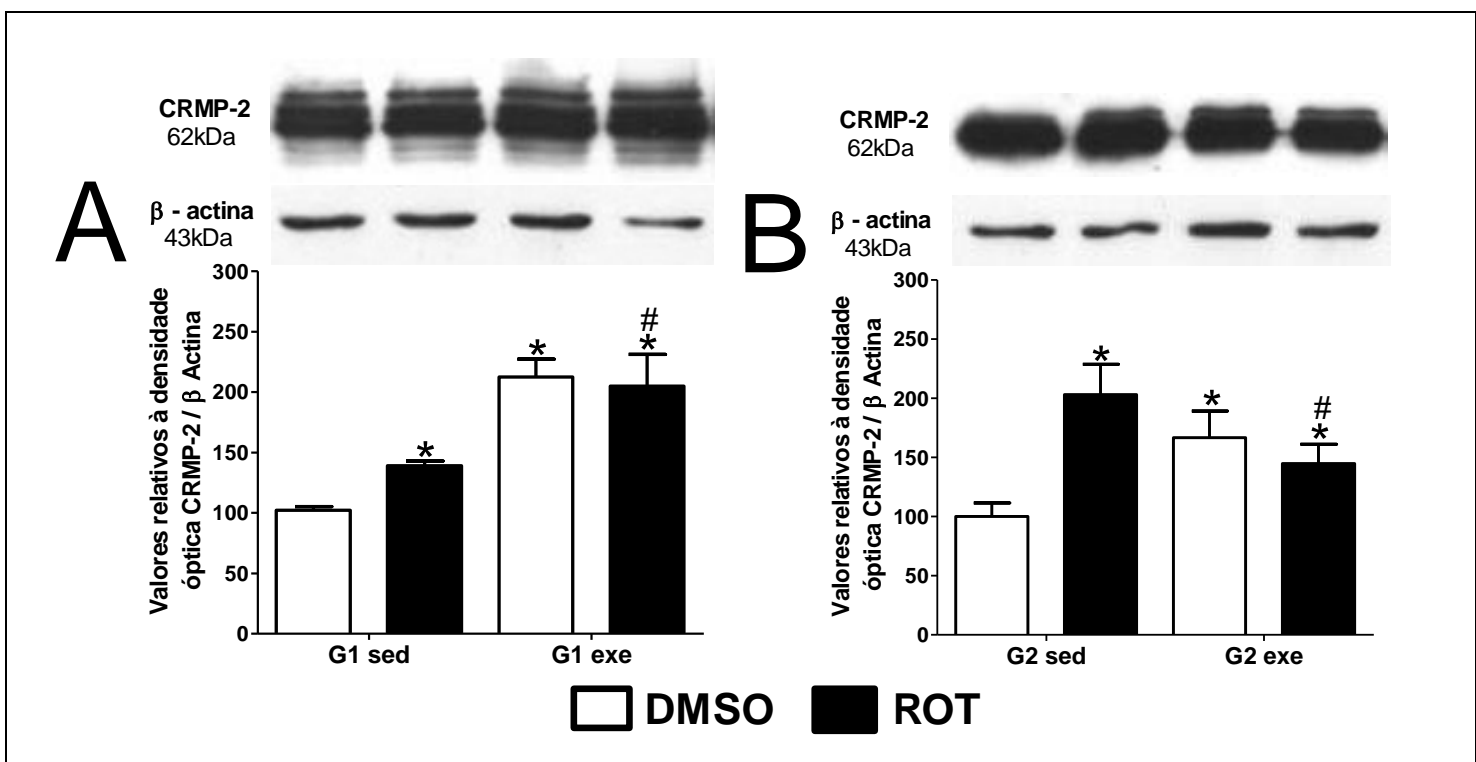

FIGURA 21 - Quantificação da expressão da CRMP-2 (62 kDa, A-B) no hipocampo de ratos idosos expostos a DMSO ou rotenona (ROT $1 \mathrm{mg} / \mathrm{kg} / \mathrm{dia}$ ) submetidos ao treinamento físico, conforme descrito para G1 (A) e G2 (B). Imagens representativas das bandas de Western Blot correspondentes a CRMP-2 e B-actina (utilizada para normalização). Valores apresentados em porcentagem do controle. $(p<0,05)$ * vs DMSOsed, \# vs ROTsed, segundo a análise de variância (ANOVA) de duas vias seguido do pós-teste de Bonferroni. $(n=5)$.

Desta forma, pode-se sugerir que a exposição à rotenona aumenta os níveis de expressão da proteína CRMP-2, e o treinamento físico age da mesma maneira. $\mathrm{O}$ treinamento físico aliado à exposição à rotenona também aumenta 
os níveis da CRMP-2, sendo este efeito minimizado quando a exposição à rotenona ocorre durante treinamento físico em animais já treinados por 6 semanas (G2).

\subsubsection{Níveis da Sortilina no hipocampo}

A análise da sortilina (SOR), proteína responsável por mediar a endocitose das formas precursoras de BDNF (proBDNF) e NGFB (proNGFB), e que também constitui o complexo transportador de receptor de TrKB, mostrou que não há alteração nos níveis de SOR em relação ao tratamento com rotenona, bem como pelo treinamento físico independente se ele foi aplicado antes, durante ou depois da exposição à ROT (Figura 22A e 22B). Pode-se assim sugerir, os níveis de SOR não são alterados nem pela exposição a rotenona bem como pelo treinamento físico, seja isolados ou em conjunto.

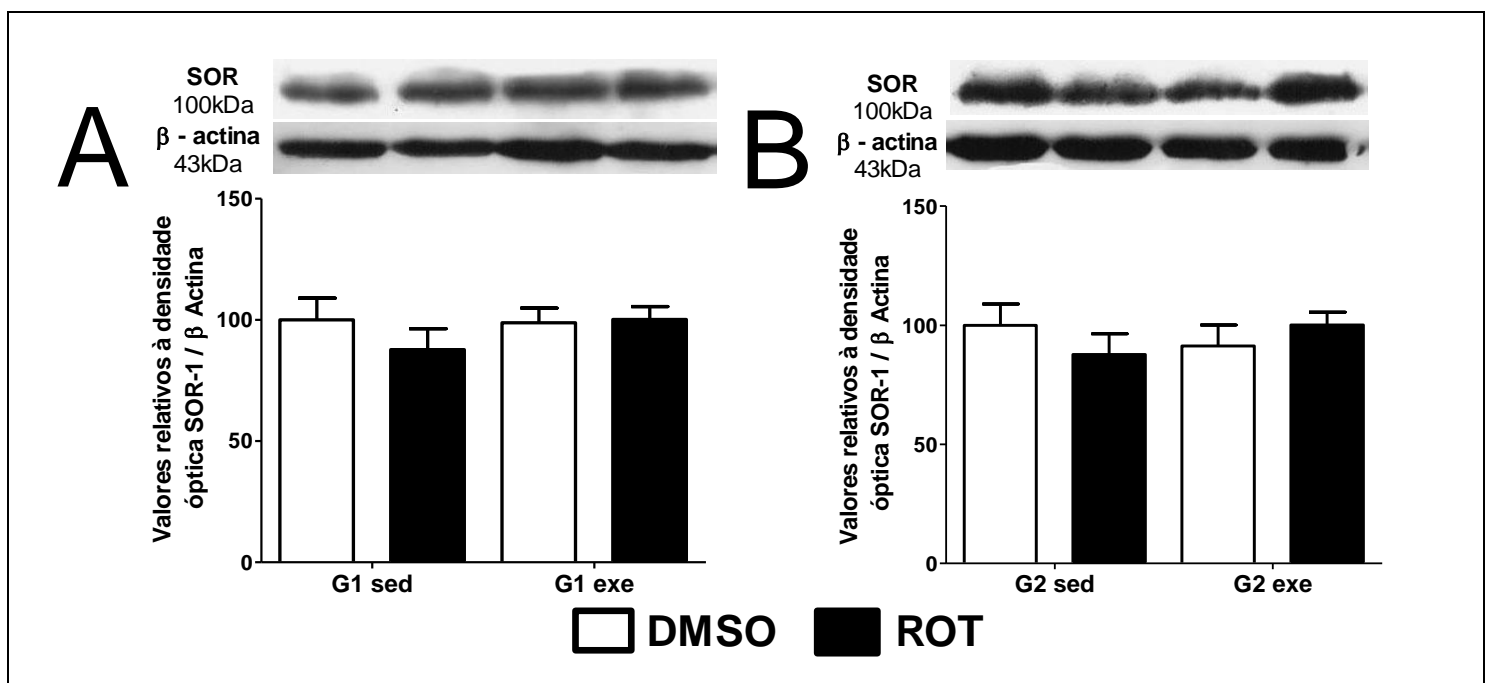

FIGURA 22 - Níveis da sortilina (100kDa, A-B) no hipocampo de ratos idosos expostos a DMSO ou rotenona (ROT $1 \mathrm{mg} / \mathrm{kg} / \mathrm{dia}$ ) submetidos ao treinamento físico do protocolo G1 (A e B) ou G2 (A e C). Imagens representativas das bandas de Western Blot correspondentes a SOR e B-actina (utilizada para normalização). Valores apresentados em porcentagem do controle. $(p<0,05)$ Segundo a análise de variância (ANOVA) de duas vias seguido do pós-teste de Bonferroni. $(n=5)$.

Desta maneira, pode sugerir a partir dos resultados encontrados no hipocampo a exposição à $1 \mathrm{mg} / \mathrm{kg} /$ dia de rotenona não altera os níveis de 
proteínas constituintes dos agregrados proteicos característicos da neurodegeneração.

E que, a rotenona aumenta os níveis de TrKB, de ambas isoformas, mesmo quando o período de exposição é seguido pelo treinamento físico. Vale ressaltar que, apenas 6 semanas de treinamento sem a presença de rotenona, eleva os níveis apenas da isoforma completa deste recepetor. O mesmo ocorre para treinamento realizado por 10 semanas consecutivas, sendo as ultimas semanas acompanhada pela exposição à rotenona. Contrariamente, os achados para a condição de treinamento anterior a exposição a rotenona, e apenas a realização do treinamento físico por 10 semanas, sem a presença de rotenona, diminuem os níveis da isoforma completa de TrKB.

Em relação as proteínas envolvidas no tráfego anterógrado do recepetor TrKB, pode-se sugerir que a proteína CRMP-2 está aumentada tanto em reposta à exposição à rotenona, bem como ao treinamento físico, mesmo em situações onde a rotenona e treinamento físico se interagem. A proteína SLP-1 foi alterada, sendo aumentada sua expressão, apenas quando o treinamento físico foi realizado por 10 semanas sendo as últimas 4 acompanhadas pela exposição à rotenona. A proteína RAB27B foi diminuída nas condições de treinamento físico sem a presença de rotenona, e na condição 10 semanas de treinamento com a exposição à rotenona no período final.

Finalizando, a sortilina não teve seus níveis alterados diante de exposição à rotenona, realização apenas do treinamento físico ou exposição a rotenona antes, durante e ou após a exposição a rotenona. A figura 23 ilustra o resumo dos resultados descritos anteriormente. 


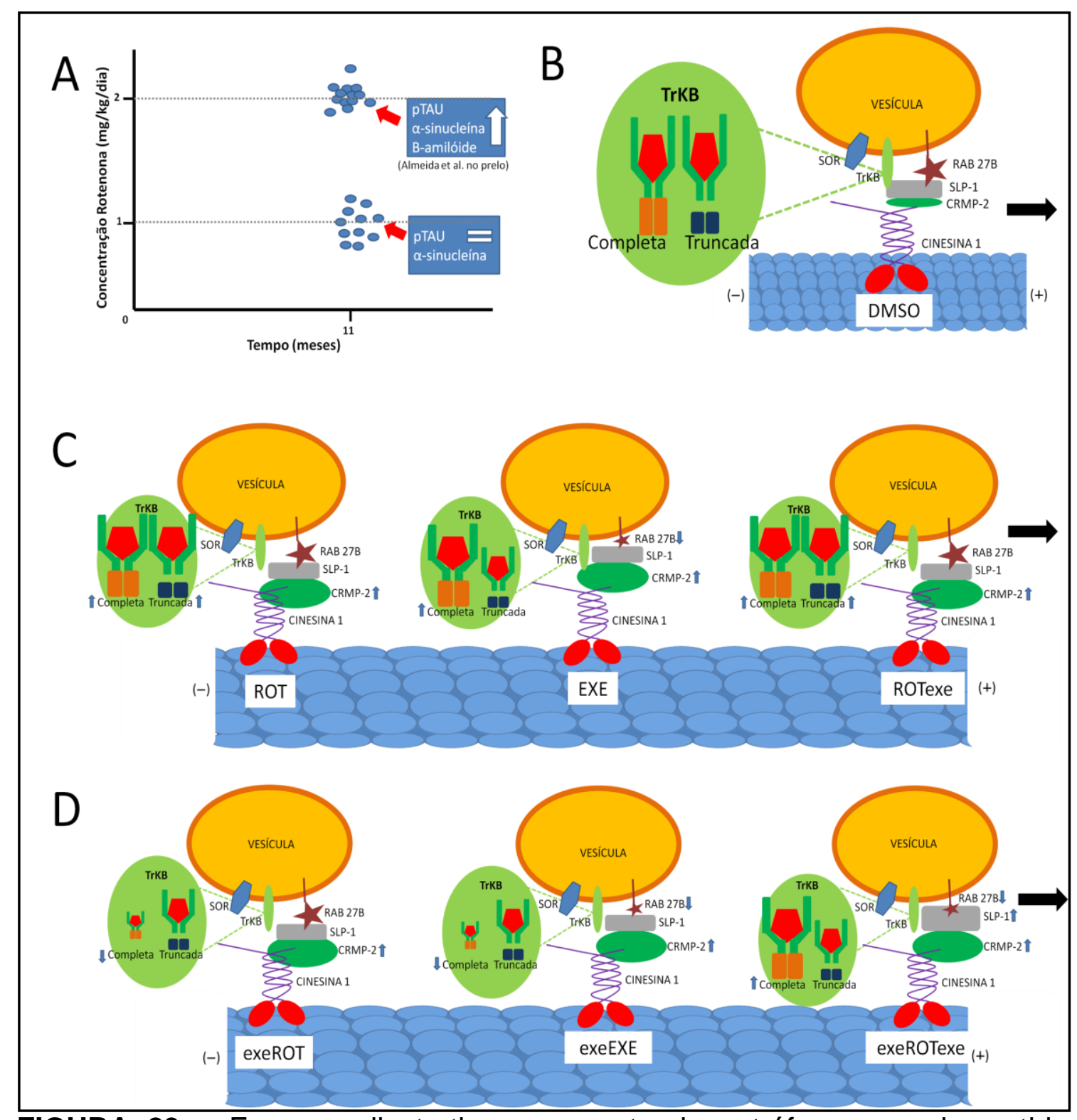

FIGURA 23 - Esquema ilustrativo representando o tráfego axonal, sentido anterógrado, do receptor TrkB no hipocampo de ratos Lewis idosos. Exposição a $1 \mathrm{mg} / \mathrm{kg} / \mathrm{dia}$ de rotenona não altera os níveis de tau hiperfosrilada e de alfasinucleína, diferentemente do que ocorre em concentrações superiores (A). Representação da estrutura do complexo transportador do receptor TrKB, e suas isoformas, no sentido anterógrado (B). Respostas na expressão de proteínas motoras do tráfego do receptor TrkB diante a exposição à rotenona (ROT), realização do treinamento físico moderado (EXE) e realização do treinamento físico posteriormente e durante a exposição à ROT (ROTexe) (C). Realização do treinamento físico por 6 semanas seguido de 4 semanas de sedentarismo conjuntamente a exposição à ROT (exeROT), 10 semanas de treinamento (exeEXE) e 10 semanas de treinamento sendo que as últimas 4 semanas foram acompanhadas pela exposição à ROT (exeROTexe) (D). 
4.7. Níveis de proteínas do tráfego retrógrado de receptores TrKB no hipocampo

\subsubsection{Níveis de expressão da EDH-4 no hipocampo}

A proteína EDH-4, também conhecida como Pincher ou PAST4, age em sentido contrário a SLP-1, Rab27B, CRMP-2 e SOR transportando o receptor TrkB retrogradamente.

Verificou-se que a exposição a $1 \mathrm{mg} / \mathrm{kg} / \mathrm{dia}$ de rotenona aumenta significativamente os níveis de expressão da proteína EDH-4, de maneira semelhante ao treinamento físico, mesmo quando este foi aplicado posteriormente a exposição à ROT (Figura 24A).

Obteve-se ainda os resultados de que a exposição à ROT precedida de 6 semanas de treinamento físico (G2 ROTsed) eleva os valores de EDH-4 (Figura 24B). Contudo, a realização de treinamento físico antes e durante a exposição à rotenona não alteram os níveis de expresssão de EDH-4 (Figura 24B). 


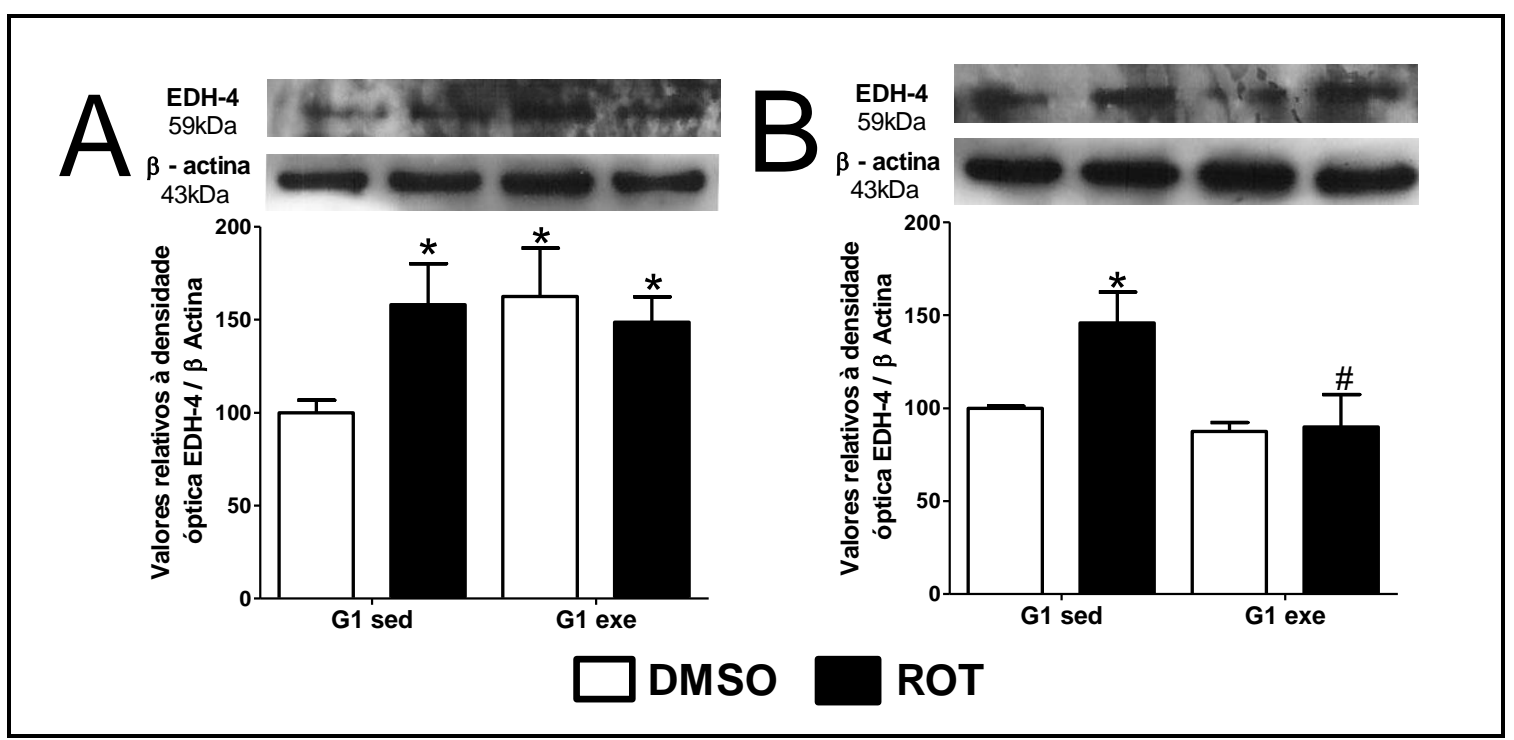

FIGURA 24 - Quantificação dos níveis da EDH-4 (59kDa, A-B) no hipocampo de ratos idosos expostos a DMSO ou rotenona (ROT $1 \mathrm{mg} / \mathrm{kg} / \mathrm{dia}$ ) submetidos ao treinamento físico do protocolo G1 (A e B) ou G2 (A e C). Imagens representativas das bandas de Western Blot correspondentes a EDH-4 e Bactina (utilizada para normalização). Valores apresentados em porcentagem do controle. $(p<0,05)$ * vs DMSOsed, \# vs ROTsed, segundo a análise de variância (ANOVA) de duas vias seguido do pós-teste de Bonferroni. $(n=5)$.

Pode-se sugerir que no hipocampo de ratos Lewis idosos a exposição a $1 \mathrm{mg} / \mathrm{kg} /$ dia de rotenona eleva os níveis de expressão da proteína EDH-4. O treinamento físico modula os níveis da EDH-4 apenas quando aplicado por 6 semanas. A associação entre treinamento físico e exposição à rotenona parece não influenciar os níveis de EDH-4. A figura 25 ilustra os resultados descritos anteriormente. 


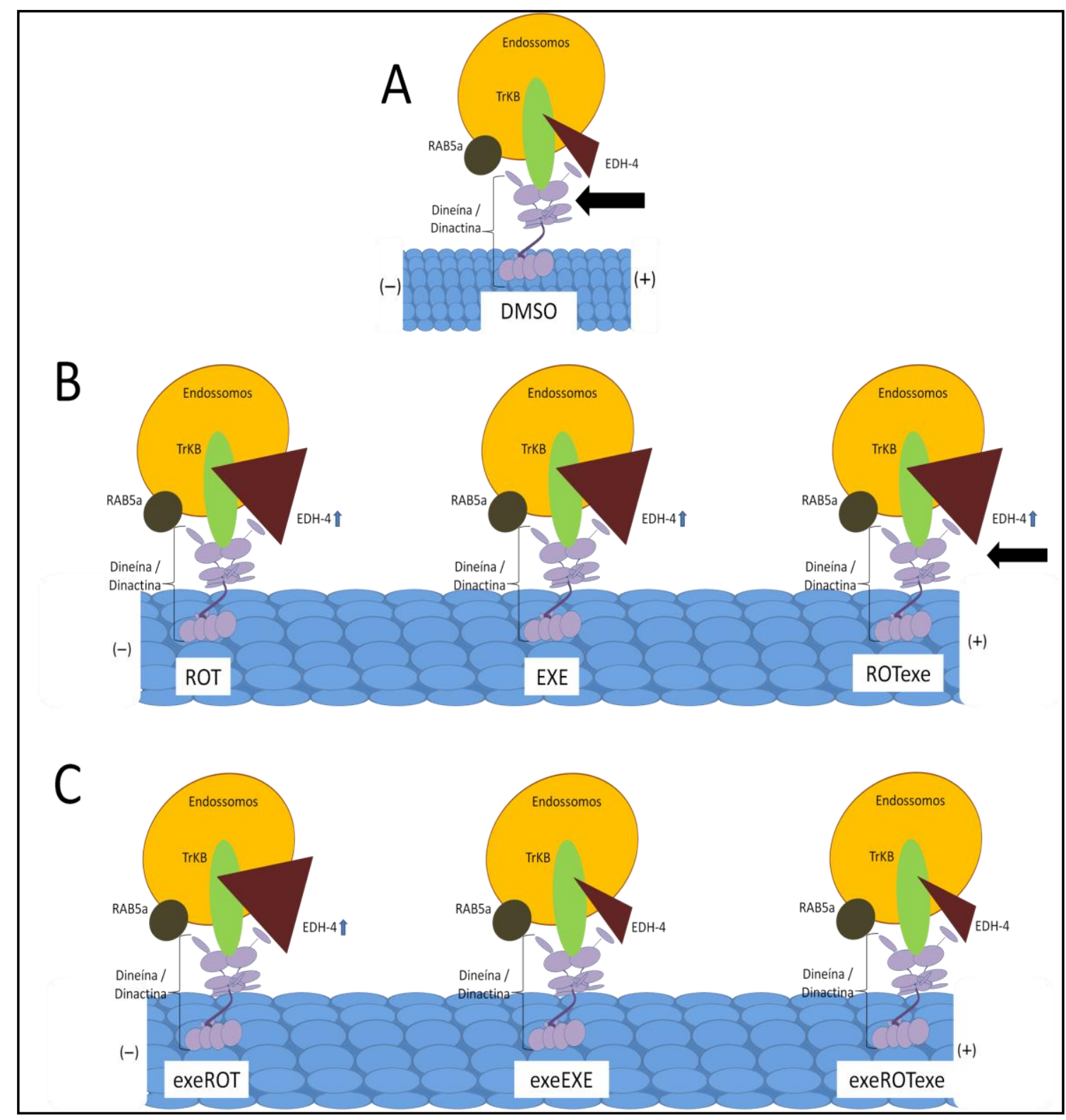

FIGURA 25 - Esquema ilustrativo representando o tráfego axonal, sentido retrógrado, do receptor TrkB no hipocampo de ratos Lewis idosos. Representação da estrutura do complexo transportador do receptor TrKB, no sentido retrógrado (A). Respostas na expressão de proteínas motoras do tráfego do receptor TrkB diante a exposição à rotenona (ROT), realização do treinamento físico moderado (EXE) e realização do treinamento físico posteriormente e durante a exposição à ROT (ROTexe) (B). Realização do treinamento físico por 6 semanas seguido de 4 semanas de sedentarismo conjuntamente a exposição a ROT (exeROT), 10 semanas de treinamento (exeEXE) e 10 semanas de treinamento sendo que as últimas 4 semanas foi acompanhada pela exposição a ROT (exeROTexe) (C ). 


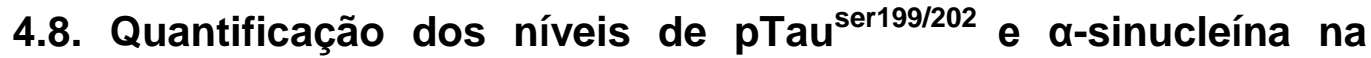 substância negra}

Assim como feito para o hipocampo, os níveis das proteínas pTAU ${ }^{\text {ser199/202 }}$ e a-sinucleína foram quantificados na substância negra de ratos Lewis idosos submetidos à exposição de $1 \mathrm{mg} / \mathrm{kg} / \mathrm{dia}$ de rotenona e ao treinamento físico forçado por meio da corrida em esteira e seus respectivos controles.

Obteve-se que a exposição à ROT não alterou os níveis da proteína pTAU ${ }^{\text {ser199/202 }}$ (G1, DMSOsed vs ROTsed), bem como o treinamento físico por 6 semanas (G1, DMSOsed vs DMSOexe). Além de não se alterar com o treinamento físico quando realizado juntamente à exposição à ROT (G1, ROTsed vs ROTexe) (Figura 26A). Os animais que compuseram o G2 também

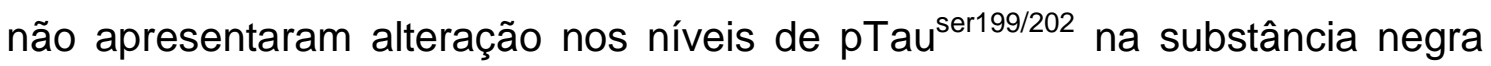
(Figura 26B).

Já os níveis de a-sinucleína elevaram-se significativamente, em 81\%, após exposição a $1 \mathrm{mg} / \mathrm{kg} /$ dia de rotenona (G1, DMSOsed vs ROTsed), da mesma maneira que o treinamento físico aumentou esses níveis em 83\% (G1, DMSOsed vs DMSOexe) (Figura 26C). Entretanto, quando a exposição à ROT foi realizada anteriormente ao treinamento físico, tanto o efeito da ROT quanto os efeitos do treinamento físico foram anulados, não havendo alteração nos níveis de a-sinucleína (G1, DMSOsed vs ROTexe) (Figura 26C).

Para os animais do G2, verificou-se aumento de $44 \%$ dos níveis de $\alpha$ sinucleína quando o treinamento físico foi realizado anteriomente à exposição à ROT (G2, DSMOsed vs ROTsed); na situação de 10 semanas de treinamento físico (6 semanas + 4 semanas) houve aumento de 74\% (G2, DMSOsed vs DMSOexe). Entretanto não houve alteração significativa quando o treinamento físico foi realizado antes e durante a exposição à ROT (G2, DMSOsed vs ROTexe) (Figura 26D). 


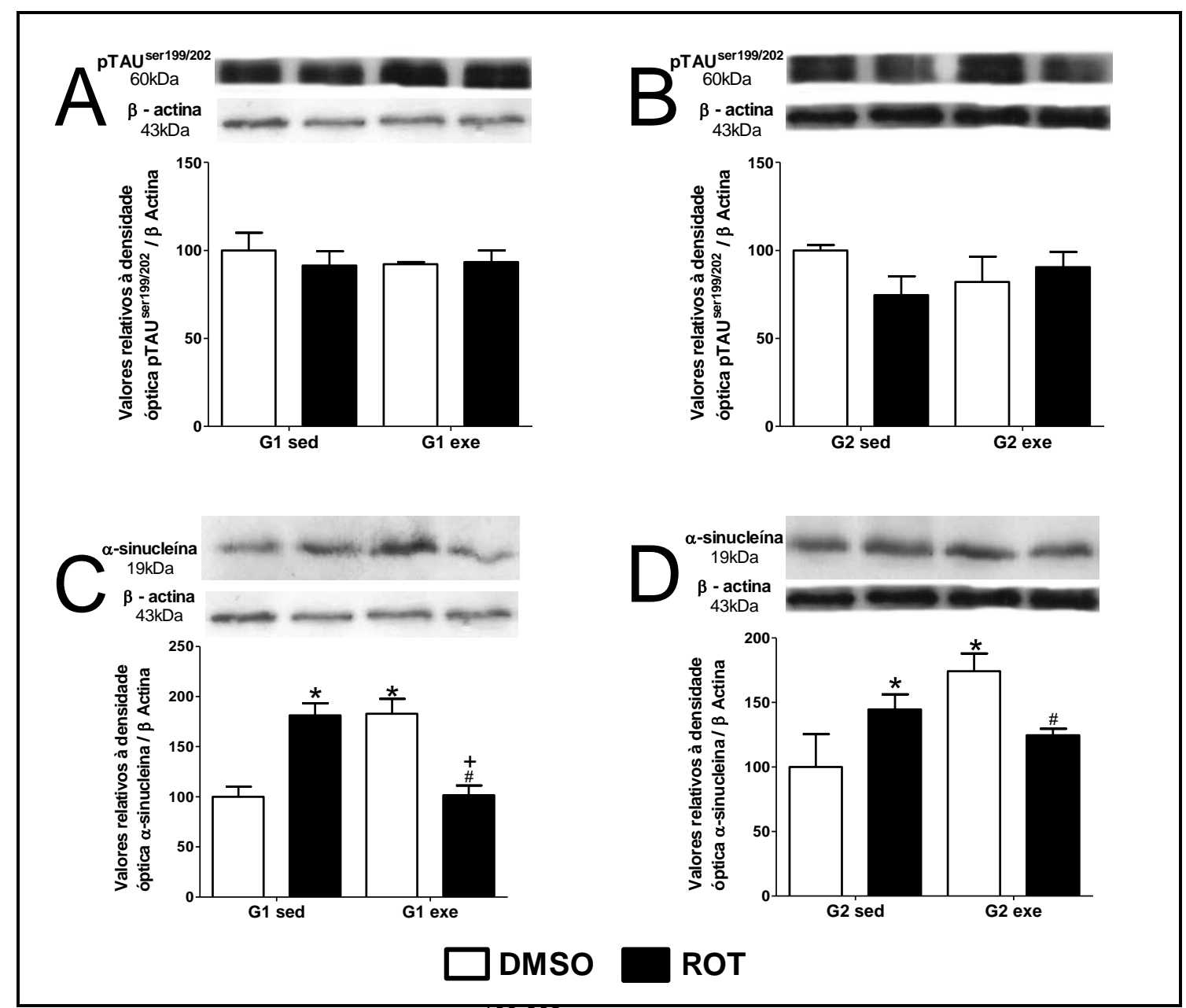

FIGURA 26 - Níveis de pTau ${ }^{\text {ser199-202 }}$ (60kDa, A-B) e a-sinucleína (19kDa, C-D) na substância negra de ratos idosos expostos a DMSO ou rotenona (ROT $1 \mathrm{mg} / \mathrm{kg} / \mathrm{dia}$ ) submetidos ao treinamento físico, conforme descrito para G1 (A e C) e G2 (B e D). Imagens representativas das bandas de Western Blot correspondentes a pTau ${ }^{\text {ser199-202, }}$ a-sinucleína e B-actina (utilizada para normalização). Valores apresentados em porcentagem do controle. $(p<0,05)$ * vs DMSOsed, \# vs DMSOexe, + VS ROTsed segundo a análise de variância (ANOVA) de duas vias seguido do pós-teste de Bonferroni. $(n=5)$.

Pode-se assim sugerir que na substância negra de ratos Lewis expostos

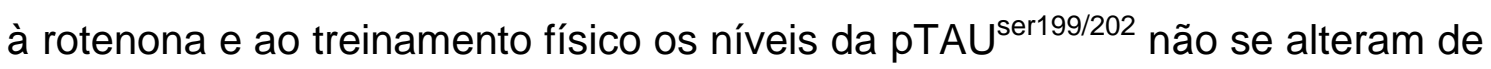
maneira independente da interação rotenona/treinamento. Em contrapartida, os níveis de a-sinucleína são modulados tanto pela exposição à ROT, quanto pelo treinamento físico, independentemente. Mas, quando em conjunto, o treinamento físico aplicado no mesmo período de exposição à ROT não há alteração dos níveis da a-sinucleína. 
4.9. Quantificação dos níveis das isoformas de TrkB na substância negra

Os resultados encontrados na substância negra mostraram que a expressão da TrkB diminui, 33\%, diante da exposição a 1mg/kg/dia de rotenona em comparação ao seu controle (G1, DMSOsed vs ROTsed) (Figura 27A).

Quanto aos efeitos do treinamento físico, não se observou alteração para o grupo DMSO na expressão da isoforma completa da TrkB (G1, DMSOsed vs DMSOexe) (Figura 27A). Entretanto, quando o treinamento físico foi aplicado posteriormente à exposição à ROT, os níveis deste receptor foram diminuídos tanto em relação ao controle (G1, DSMOsed vs ROTexe, 64\%), quanto em relação aos animais treinados (G1, DMSOexe vs ROTexe, 52\%) (Figura 27A).

Observou-se ainda que, mesmo diante do treinamento físico realizado precocemente à exposição à ROT, os níveis de expressão da isoforma completa de TrkB foram significantemente reduzidos (67\%) (G2, DMSOsed vs ROTsed). Da mesma forma, a continuidade do treinamento físico, na ausência de rotenona, também reduz de maneira significativa (31\%) os valores desta isoforma (G2, DMSOsed vs DMSOexe). Entretanto, quando o treinamento físico foi realizado antes (6 semanas) e durante as 4 semanas de exposição a ROT houve retomada dos níveis da isoforma completa de TrkB, tornando os esses valores significamente superiores (164\%) aos achados para o grupo que não treinou quando foram exposto à rotenona (G2, ROTsed vs ROTexe) (Figura 27B).

Considerando a isoforma truncada $(95 \mathrm{kDa})$, não houve alteração com exposição a $1 \mathrm{mg} / \mathrm{kg} / \mathrm{dia}$ de rotenona, bem como com o treinamento físico, aliado ou não à ROT, tanto para os animais do G1 quanto os pertencentes ao G2 (Figura 27C-D). 


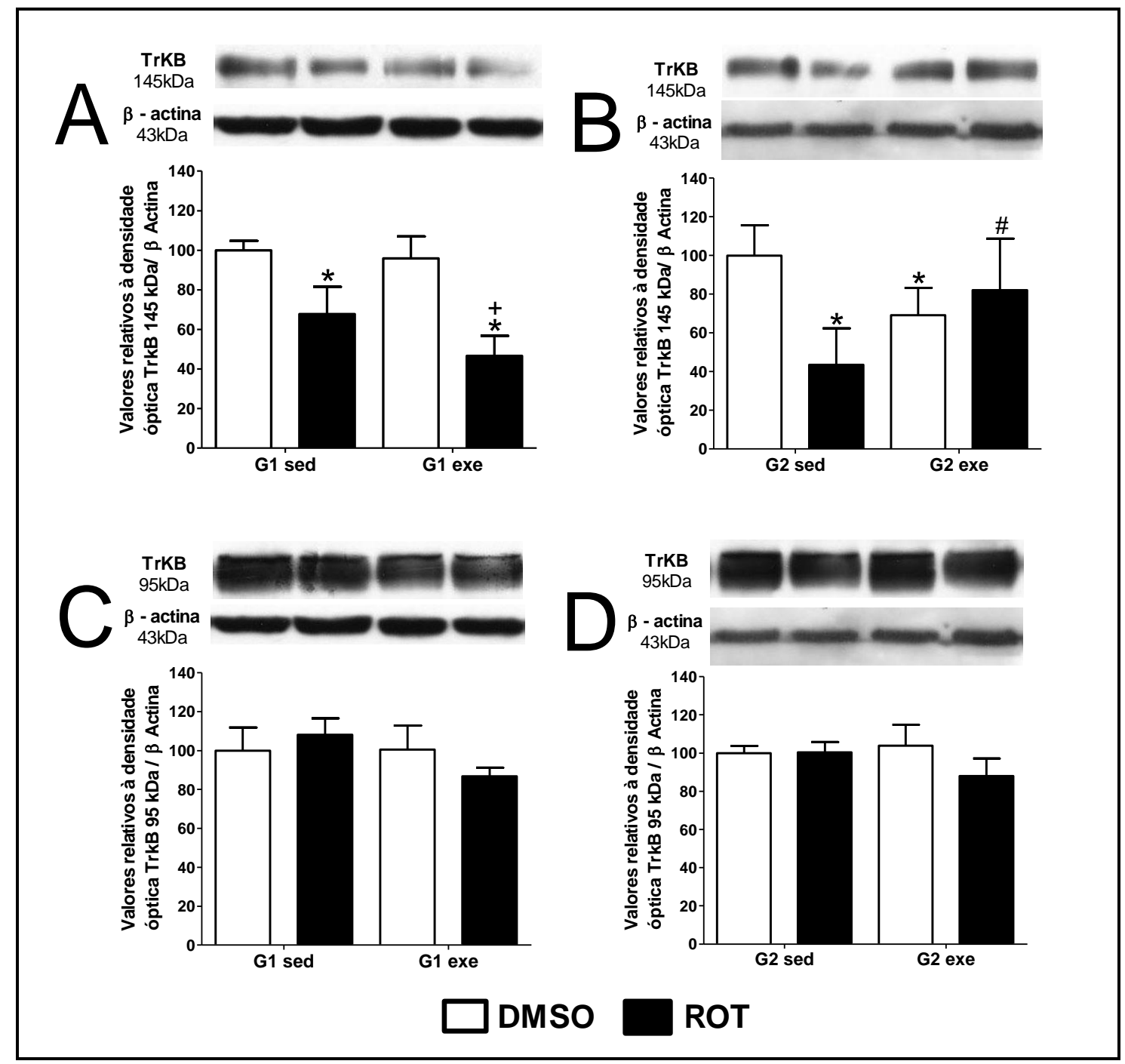

FIGURA 27 - Quantificação das isoformas completa (145kDa, A-B) e truncada (95kDa,C-D) do receptor TrkB, de BDNF, na substância negra de ratos idosos expostos a DMSO ou rotenona (ROT $1 \mathrm{mg} / \mathrm{kg} / \mathrm{dia}$ ) submetidos ao treinamento físico, conforme descrito para $\mathrm{G} 1$ ( $\mathrm{A}$ e $\mathrm{C}$ ) e $\mathrm{G} 2$ (B e D). Imagens representativas das bandas de Western Blot correspondentes a TrkB e B-actina (utilizada para normalização). Valores apresentados em porcentagem do controle. $(\mathrm{p}<0,05){ }^{*}$ vs DMSOsed, \# vs ROTsed, + vs DMSOexe segundo a análise de variância (ANOVA) de duas vias seguido do pós-teste de Bonferroni. $(\mathrm{n}=5)$.

Diante dos resultados obtidos, pode-se sugerir que a exposição à rotenona diminui os níveis da isoforma completa de TrkB, de maneira independente de ser aplicado antes ou após o treinamento físico. E o treinamento físico também reduz os níveis desta isoforma indepente da exposição à rotenona. Exceto, quando o treinamento físico é realizado antes e durante à exposição à rotenona, sendo que, neste caso, parece prevenir da perda dos níveis da isoforma completa de TrkB na substância negra. Já a 
isoforma truncada, não parece ser modulada nesta região, nem pela rotenona e nem pelo treinamento físico. Diante dos resultados obtidos, pode-se sugerir que a exposição à rotenona diminui os níveis da isoforma completa de TrkB, de maneira independente se aplicado antes ou após o treinamento físico. E o treinamento físico também reduz os níveis desta isoforma indepente da exposição à rotenona. Exceto quando o treinamento físico é reaizado antes e durante a exposição a rotenona, sendo que neste ele parece previnir a diminuição dos níveis da isoforma completa de TrkB na substância negra. Já a isoforma truncada, parece não ser modulada nesta região, nem pela rotenona e nem pelo treinamento físico.

\subsection{Níveis de proteínas do tráfego anterógrado de receptores TrkB} na substância negra

\subsubsection{Níveis da SLP-1 na substância negra}

$\mathrm{Na}$ substância negra, os resultados sugerem que a exposição a $1 \mathrm{mg} / \mathrm{kg} /$ dia de rotenona promove aumento significativo na expressão da proteína semelhante à SLP-1 em relação ao seu respectivo controle (G1, DMSOsed vs ROTsed), e que, o treinamento físico promove aumento semelhante a este (G1, DMSOsed vs DMSOexe), mesmo quando realizado posteriormente à exposição com rotenona (G1, ROTsed vs ROTexe) (Figura 28A).

Quando o treinamento físico precedeu a exposiçao à rotenona, na substância negra, verificou-se que os níveis de expressão da proteína semelhante a SLP-1 foi signitivamente reduzido a menos da metade (G2, DMSOsed vs ROTsed). Não foi verificada alteração nos níveis da SLP-1 quando o treinamento físico foi prolongado (10 semanas) sem a presença da ROT (G2, DMSOsed vs DMSOexe). Ainda, quando combinados no mesmo grupo exposição à ROT e ao EXE, verificou-se redução significante, a valores inferiores a metade, semelhante ao efeitos causados apenas ROT (G2, ROTsed vs ROTexe) (Figura 28B). 


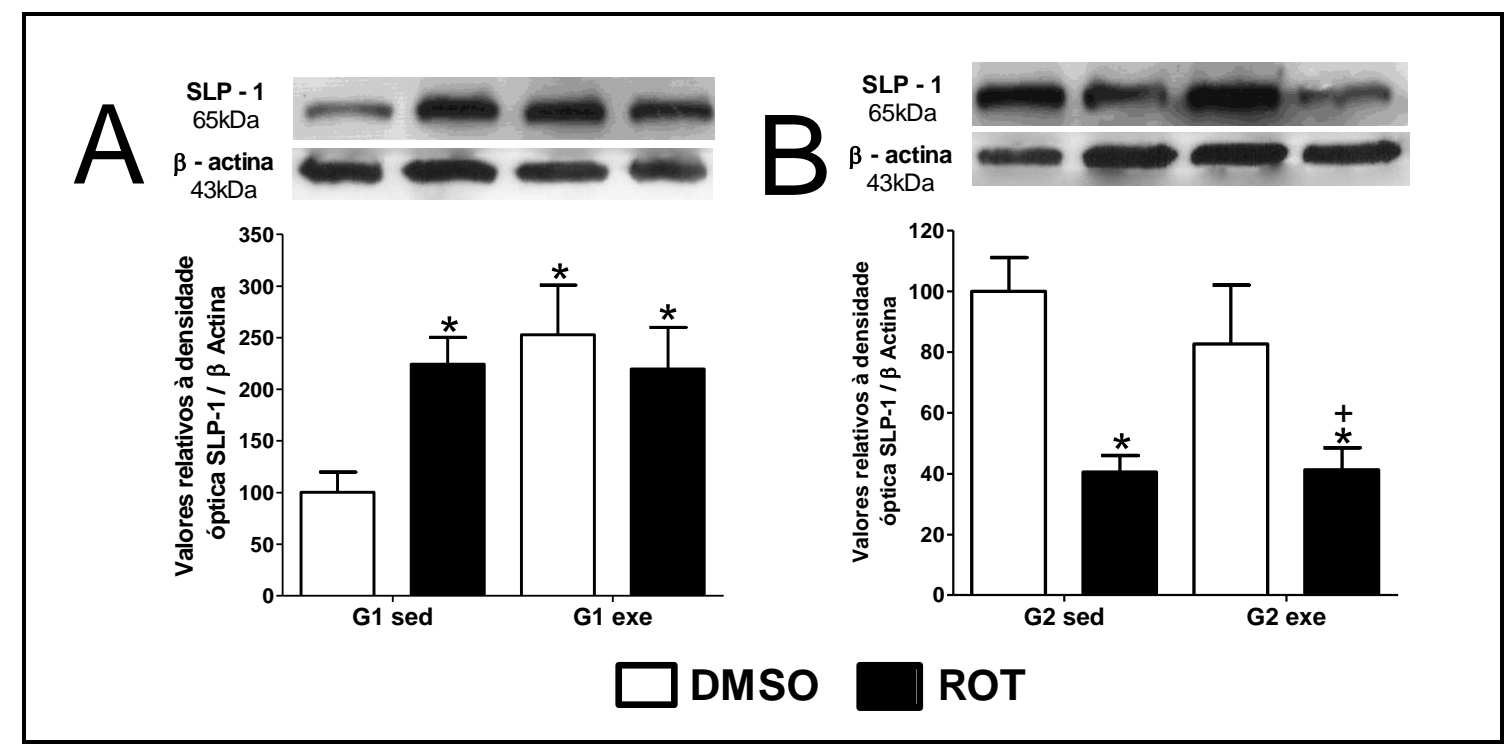

FIGURA 28 - Quantificação dos níveis da proteína semelhante a Sinaptotagmina1 (SLP-1, 65kDa) na substância negra de ratos idosos expostos a DMSO ou rotenona (ROT $1 \mathrm{mg} / \mathrm{kg} / \mathrm{dia}$ ) submetidos ao treinamento físico, conforme descrito para G1 (A) e G2 (B). Imagens representativas das bandas de Western Blot correspondentes a SLP-1 e B-actina (utilizada para normalização). Valores apresentados em porcentagem do controle. $(p<0,05)$ * vs DMSOsed, + vs DMSOexe, segundo a análise de variância (ANOVA) de duas vias seguido do pós-teste de Bonferroni. $(n=5)$.

Assim sendo, pode-se, a partir dos resultados encontrados, sugerir que na substância negra a exposição à rotenona eleva os níveis da SLP-1. O mesmo ocorre com o treinamento físico por 6 semanas posteriormente a exposição à ROT. Já quando o treinamento físico precede a exposição à ROT, os níveis de SLP-1 são reduzidos de forma independente da continuidade do treinamento físico.

\subsubsection{Níveis de Rab27B na substância negra}

A proteína Rab27B encontra-se aumentada em 2 vezes na substância negra após exposição à $1 \mathrm{mg} / \mathrm{kg} /$ dia de ROT (G1, DMSOsed vs ROTsed). $\mathrm{Na}$ mesma direção, o treinamento físico também aumentou significativamente os níveis de Rab27B (G1, DMSOsed vs DMSOexe), porém, quando o treinamento físico ocorreu posteriormente à exposição à ROT, essa elevação ocorreu em valores menos expressivos (1,5x), representando, uma menor elevação quando comparado apenas ao efeito da ROT (G1, ROTsed vs ROTexe) (Figura 29A). 
Quando observados os resultados obtidos para os animais previamente treinados por 6 semanas (G2), verificou-se que a exposição à rotenona sem a continuidade do treinamento (G2, DMSOsed vs ROTsed), ou com a continuidade do treinamento físico (G2, ROTsed vs ROTexe), e mesmo sem à ROT mas com continuidade do EXE diminuem significativamente os níveis de Rab27B na substância negra (G2, DMSOSed vs DMSOexe) (Figura 29B).

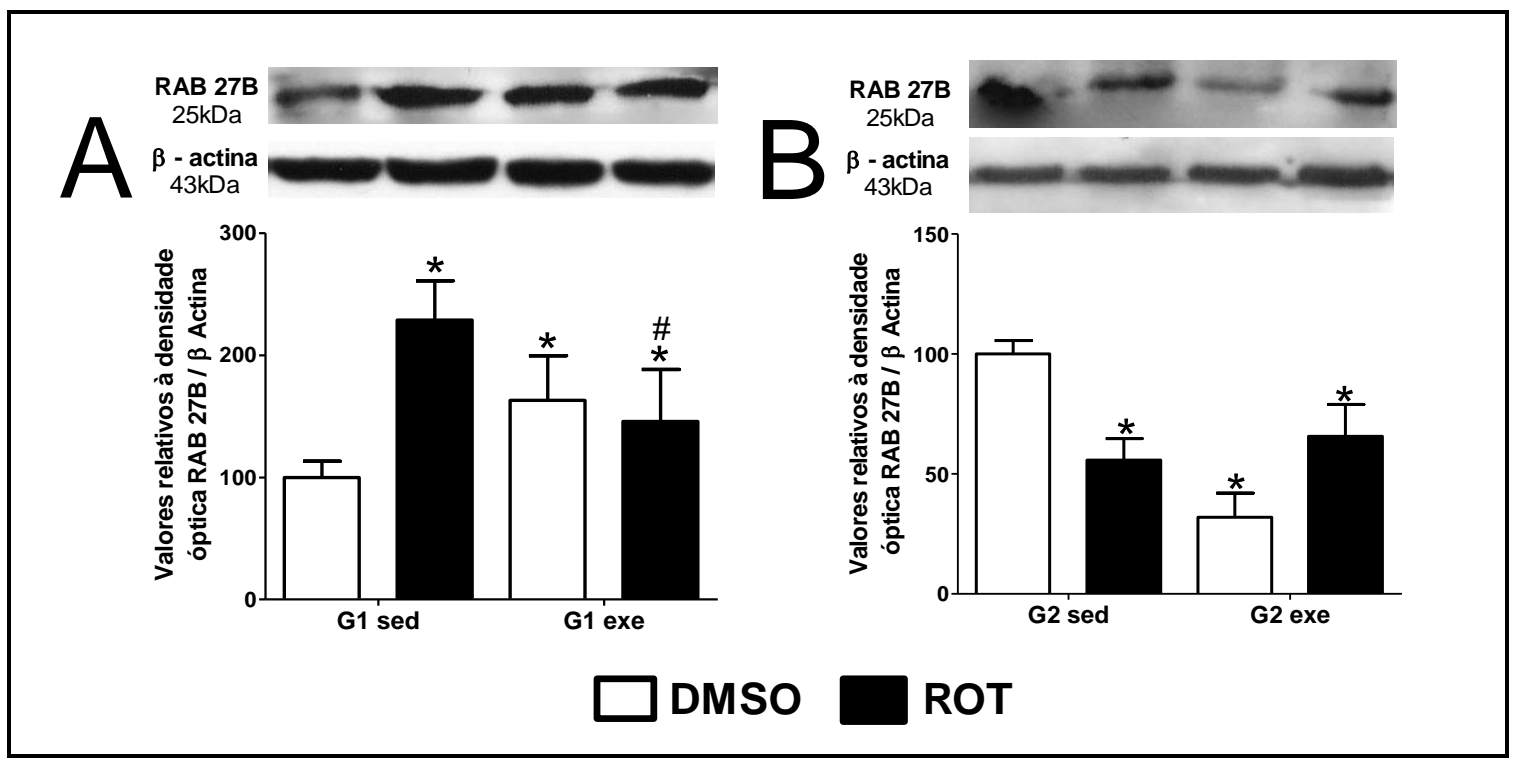

FIGURA 29 - Quantificação da expressão da Rab27B (25 kDa, A-B) na substância negra de ratos idosos expostos a DMSO ou rotenona (ROT $1 \mathrm{mg} / \mathrm{kg} / \mathrm{dia}$ ) submetidos ao treinamento físico, conforme descrito para G1 (A) e G2 (B). Imagens representativas das bandas de Western Blot correspondentes a Rab27B e B-actina (utilizada para normalização). Valores apresentados em porcentagem do controle. $(p<0,05)$ * vs DMSOsed, \# vs ROTsed, segundo a análise de variância (ANOVA) de duas vias seguido do pós-teste de Bonferroni. $(n=5)$.

Desta maneira, pode-se sugerir que a exposição à rotenona aumenta os níveis de Rab27B na substância negra de ratos Lewis idosos, e o treinamento físico parece minimizar esses efeito, podendo até mesmo reduzí-los quando realizado anteriormente e/ou durante a exposição à rotenona.

\subsubsection{Níveis da CRMP-2 na substância negra}

A exposição à rotenona altera significativamente os níveis de CRMP-2 na substância negra em comparação com seu respectivo controle (G1, 
DMSOsed vs ROTsed) bem como o treinamento físico (G1, DMSOsed vs DMSOexe). Ainda, esse aumento é mantido mesmo quando o EXE ocorre posteriormente à exposição à ROT (G1, ROTsed vs ROTexe) (Figura 30A).

Entretanto, para os animais do G2, na substância negra, os níveis de CRMP-2 não se alteram quando a exposição à ROT é precedida de 6 semanas de EXE (G2, DMSOsed vs ROTSed), porém na ausência de ROT e com a continuidade do EXE por mais 4 semanas verificou-se um aumento significativo (2,5x) (G2, DMSOsed vs DMSOexe). Tal aumento é anulado quando a ROT é aplicada conjuntamente às 4 útimas semanas de treinamento físico (G2, ROTsed vS ROTexe) (Figura 30B).

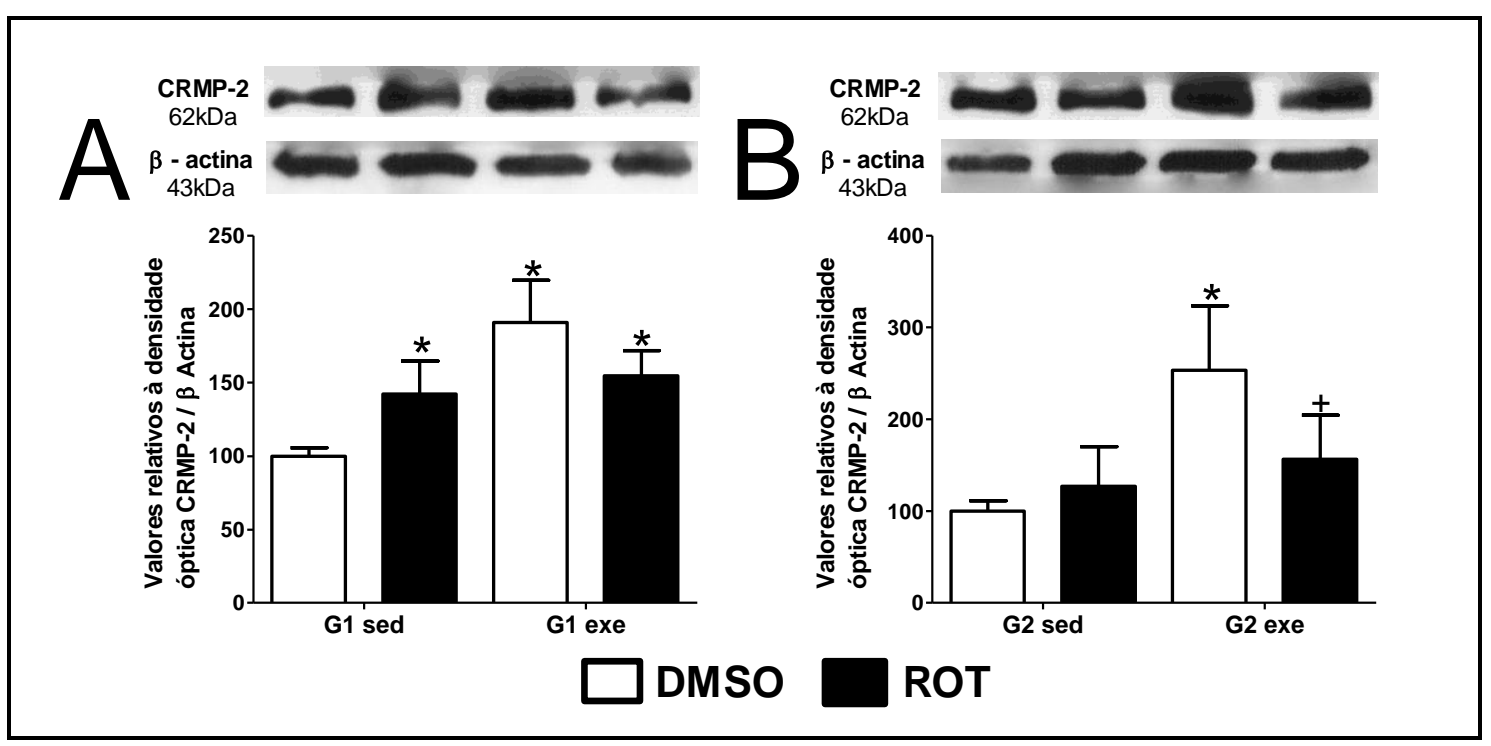

FIGURA 30 - Quantificação dos níveis da CRMP-2 (62 kDa, A-B) na substância negra de ratos idosos expostos a DMSO ou rotenona (ROT $1 \mathrm{mg} / \mathrm{kg} / \mathrm{dia}$ ) submetidos ao treinamento físico, conforme descrito para G1 (A) e G2 (B). Imagens representativas das bandas de Western Blot correspondentes a CRMP-2 e B-actina (utilizada para normalização). Valores apresentados em porcentagem do controle. $(p<0,05){ }^{*}$ vs DMSOsed, + VS DMSOexe segundo a análise de variância (ANOVA) de duas vias seguido do pós-teste de Bonferroni. $(n=5)$.

Assim sendo, pode-se sugerir que a exposição à rotenona eleva significativamente os níveis de expressão de CRMP-2, sendo este o mesmo efeito do treinamento físico. Contudo, quando o treinamento foi realizado somente anteriormente ou antes e durante a exposição à ROT a elevação da CRMP-2 tende a ser anulada ou minimizada, respectivamente. 
Diante dos resultados descritos, sugere-se que na substância negra a exposição à $1 \mathrm{mg} / \mathrm{kg} / \mathrm{dia}$ de rotenona não altera os níveis da pTAU, contudo eleva os níveis de $\alpha$-sinucleína.

Ainda, a rotenona diminui os níveis de TrkB, da isoforma completa, assim como o treinamento físico por 10 semanas consecutivas o faz. Também notou-se mesma resposta quando a exposição à rotenona ocorreu posteriormente ao treinamento físico.

Em relação as proteínas envolvidas no tráfego anterógrado do recepetor TrkB, pode-se sugerir que a proteína CRMP-2 está aumentada tanto em reposta a exposição à rotenona, bem como ao treinamento físico, mesmo em situações onde a rotenona e treinamento físico se interagem, exceto quando a exposição à rotenona procede ao treinamento físico, onde nota-se uma diminuição de seus em seus níveis. A proteína SLP-1 foi alterada, sendo aumentada sua expressão, decorrente da exposição a rotenona, bem como pelo treinamento físico de 6 semanas, aliado ou não à exposição de rotenona. Contudo, os níveis de SLP-1 são diminuídos quando se aplica o treinamento físico antes ou antes e durante a exposição à rotenona.

Para a proteína Rab27B nota-se aumento diante da exposição à rotenona, ao treinamento físico de 6 semanas e diante do mesmo período de treinamento antecedido pela exposição à rotenona. Em contrapartida, seus níveis foram diminuídos quando o treinamento anteceu a exposição à rotenona ou ocorreu por um período de 10 semanas. Os resultados estão representados na figura 31. 


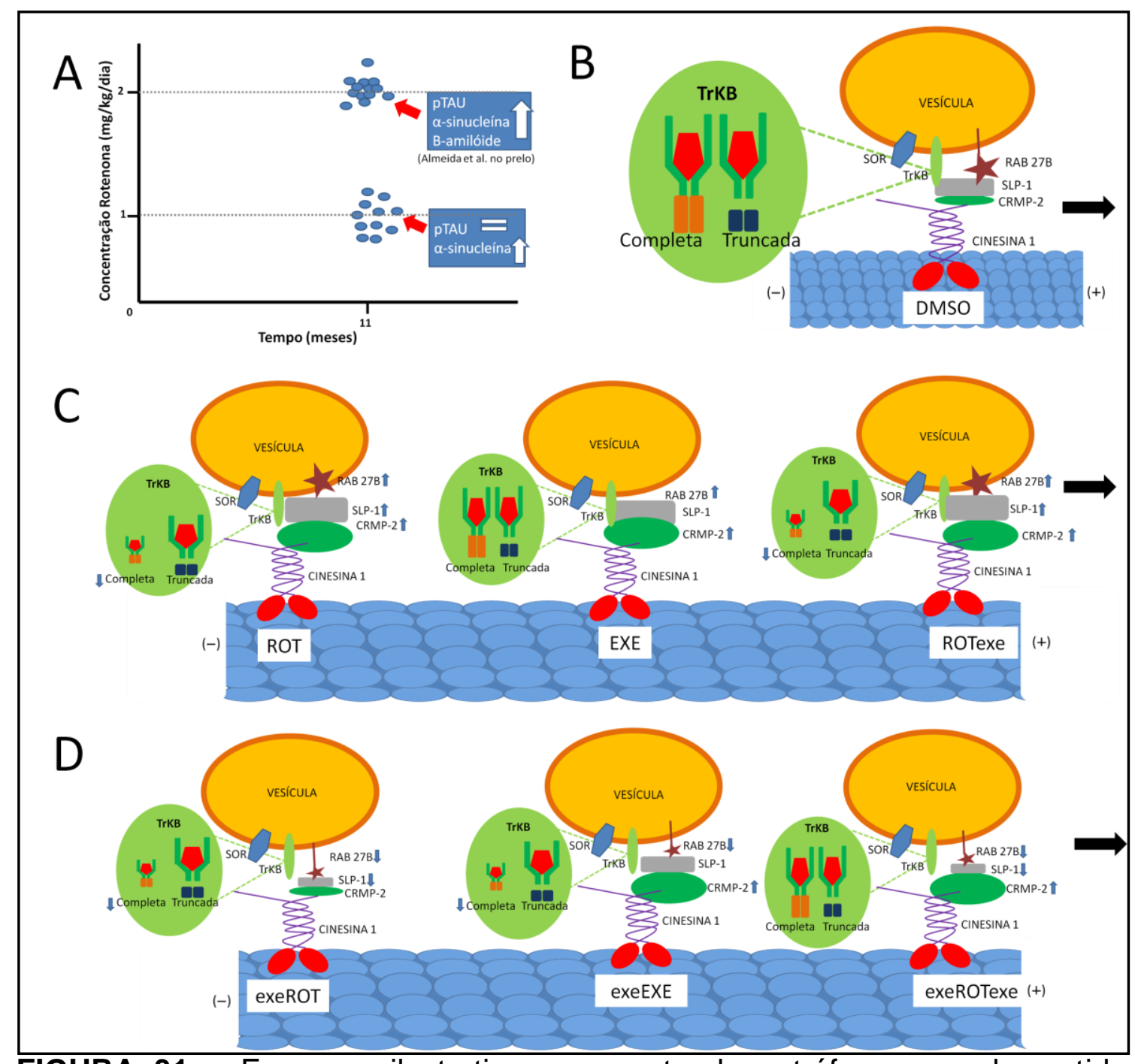

FIGURA 31 - Esquema ilustrativo representando o tráfego axonal, sentido anterógrado, do receptor TrkB na substância negra de ratos Lewis idosos. Exposição a $1 \mathrm{mg} / \mathrm{kg} /$ dia de rotenona não altera os níveis de tau hiperfoslirada, contudo eleva os níveis de alfa-sinucleína. Mesmo resultado encontrado por Almeida et al. (submetido) onde apesar do aumento dos níveis de $p$-tau verificou-se agregação apenas para a concentração de $2 \mathrm{mg} / \mathrm{kg} / \mathrm{dia}$ (A). Representação da estrutura do complexo transportador do receptor TrKB, e suas isoformas, no sentido anterógrado (B). Respostas na expressão de proteínas motoras do tráfego do receptor TrkB diante da exposição à rotenona $(R O T)$, realização do treinamento físico moderado (EXE) e realização do treinamento físico posteriormente e durante a exposição à ROT (ROTexe) (C). Realização do treinamento físico por 6 semanas seguido de 4 semanas de sedentarismo conjuntamente à exposição à ROT (exeROT), 10 semanas de treinamento (exeEXE) e 10 semanas de treinamento sendo que as últimas 4 semanas foram acompanhadas pela exposição à ROT (exeROTexe) (D). 


\subsection{Quantificação dos níveis a-sinucleína na medula cervical e torácica}

A exposição à $1 \mathrm{mg} / \mathrm{kg} /$ dia de rotenona, considerando a medula cervical, aumentou significativamente os níveis de a-sinucleína, superior a 2x vezes, considerando os níveis do controle (G1, DMSOsed VS ROTsed). Porém, o treinamento físico de 6 semanas, acompanhado ou não pela exposição à ROT, não alterou os níveis de a-sinucleína (G1, DMSOsed VS ROTsed; DMSOexe VS ROTexe). Vale ressaltar que, apesar do treinamento físico aliado à exposição à ROT não alterar os níveis de a-sinucleína comparado ao controle, este diminiu significativamente (65\%) os níveis quando comparados ao nível atingido exclusivamente pela exposição à ROT (Figura 32A).

Para os animais do grupo G2, verificou-se que a realização de treinamento físico por seis semanas seguido de exposição a ROT (G2, ROTsed) não altera os níveis de a-sinucleína. Em contrapartida, o treinamento físico por 10 semanas consecutivas (G2, DMSOexe) diminui significativamente os seus níveis (56\%). Ainda, para o grupo que realizou 10 semanas de treinamento físico, sendo as útimas 4 semanas aliadas a exposição à ROT (G2, ROTexe), aumenta significativamente os níveis de a-sinucleína comparado ao grupo treinamento físico sem rotenona (G2, DMSOexe VS ROTexe) (Figura 32B). 


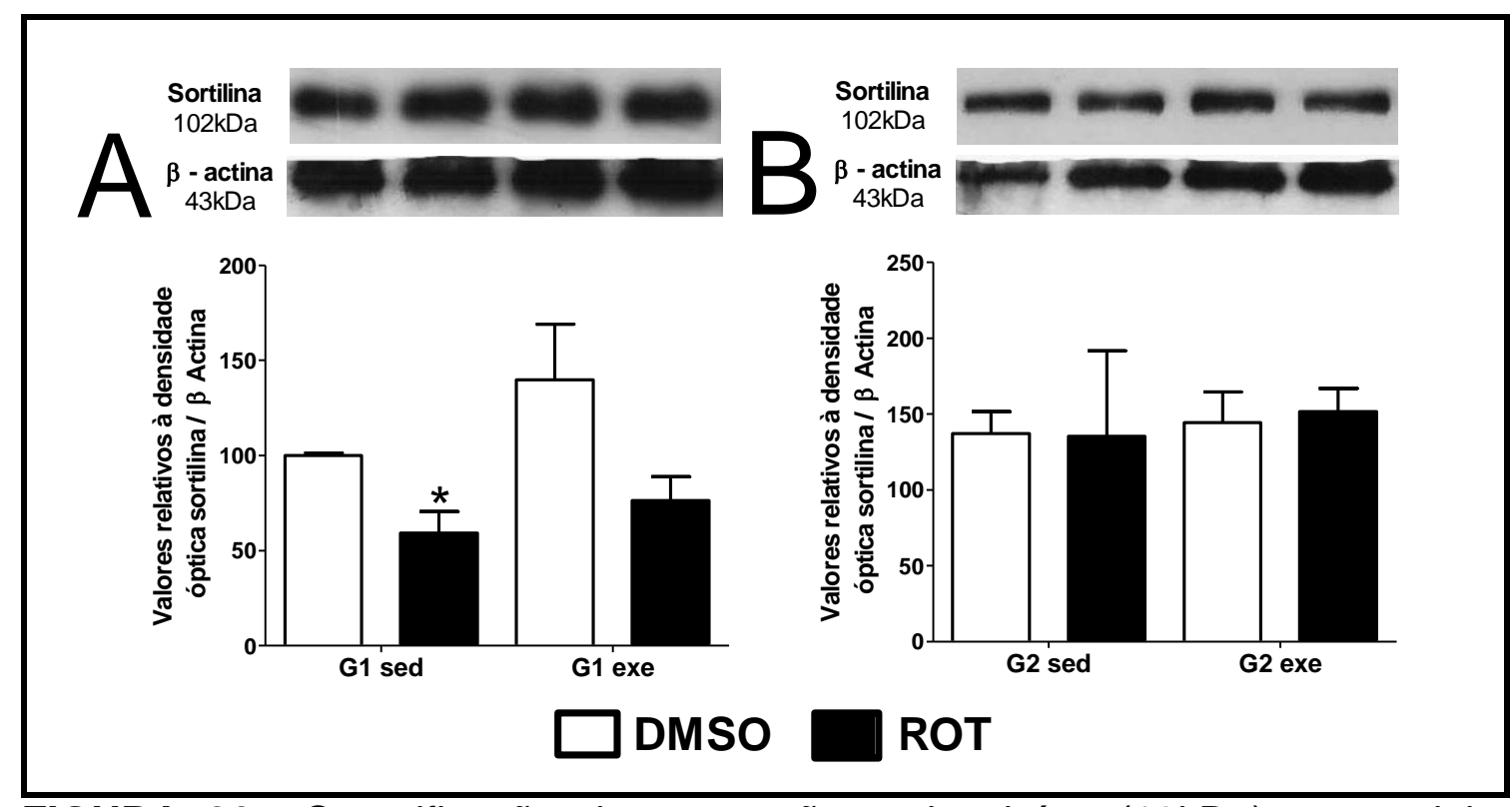

FIGURA 32- Quantificação da expressão a-sinucleína (19kDa) na medula cervical de ratos idosos expostos a DMSO ou rotenona (ROT $1 \mathrm{mg} / \mathrm{kg} / \mathrm{dia}$ ) submetidos ao treinamento físico, conforme descrito para G1 (A) e G2 (B). Imagens representativas das bandas de Western Blot correspondentes a $\alpha-$ sinucleína e ß-actina (utilizada para normalização). Valores apresentados em porcentagem do controle. $(p<0,05)$ * vs DMSOsed, \# vs ROTsed segundo a análise de variância (ANOVA) de duas vias seguido do pós-teste de Bonferroni. $(n=5)$.

Na medula torácica, vericou-se que os níveis de a-sinucleína não foram alterados com à exposição a $1 \mathrm{mg} / \mathrm{kg} / \mathrm{dia}$ de rotenona, bem como pela realização de 6 semanas de treinamento físico, aliado ou não, a ROT (Figura $33 A)$.

Quando analisado os resultados na medula torácica para o G2, verificouse que na presença de ROT não se obteve diminuição significativa dos níveis de a-sinucleína, porém pode-se sugerir que exista uma tendência de diminuição em seus níveis. Já na ausência de ROT, o grupo que realizou 10 semanas de treinamento físico consecutivas os níveis $\alpha$-sinucleína foram diminuídos (Figura 33B). 


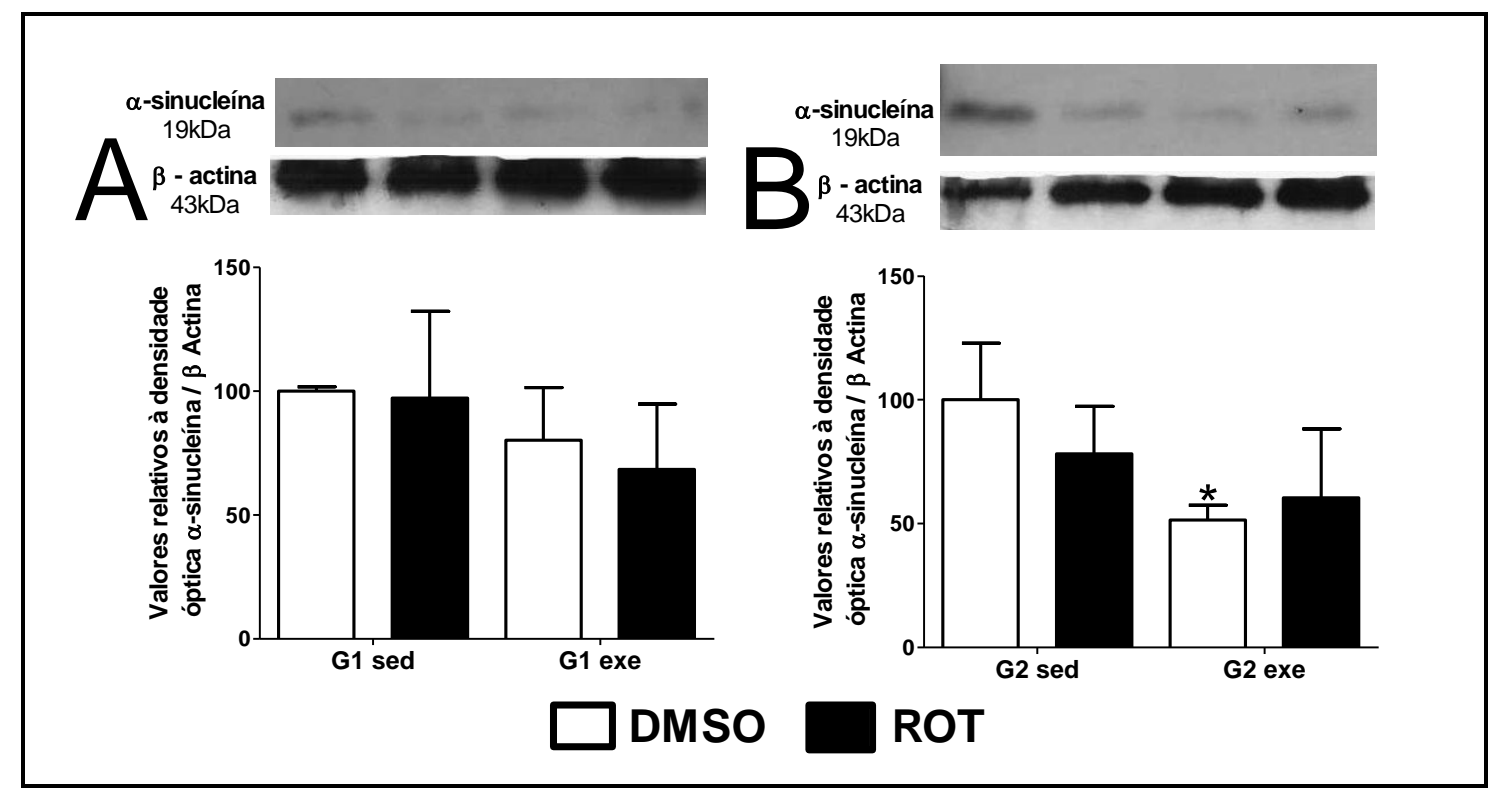

FIGURA 33 - Quantificação da expressão $\alpha$-sinucleína (19kDa) na medula torácica de ratos idosos expostos a DMSO ou rotenona (ROT $1 \mathrm{mg} / \mathrm{kg} / \mathrm{dia}$ ) submetidos ao treinamento físico, conforme descrito para G1 (A) e G2 (B). Imagens representativas das bandas de Western Blot correspondentes a $\alpha$ sinucleína e B-actina (utilizada para normalização). Valores apresentados em porcentagem do controle. $(p<0,05)$ * vs DMSOsed segundo a análise de variância (ANOVA) de duas vias seguido do pós-teste de Bonferroni. $(n=5)$.

Pode-se assim sugerir que na medula cervical os níveis de a-sinucleína são alterados pela exposição à rotenona, sendo estas revertidas pelo treinamento físico. Ainda, o treinamento físico quando realizado por 10 semanas na ausência de ROT diminui os níveis de a-sinucleína.

Considerando os achados na medula torácica, apenas o treinamento físico por 10 semanas consecutivas, sem a presença de rotenona diminuiu os níveis de a-sinucleína.

\subsection{Quantificação dos níveis de expressão das isoformas de TrkB} na medula cervical e torácica

Como mencionado anteriormente, o receptor TrkB pode ser identificado por duas isoformas, a completa e a truncada. Entretanto, na medula cervical e medula torácica não foi possível detectar a isoforma completa de TrkB, apenas a isoforma truncada (Figura 34). 


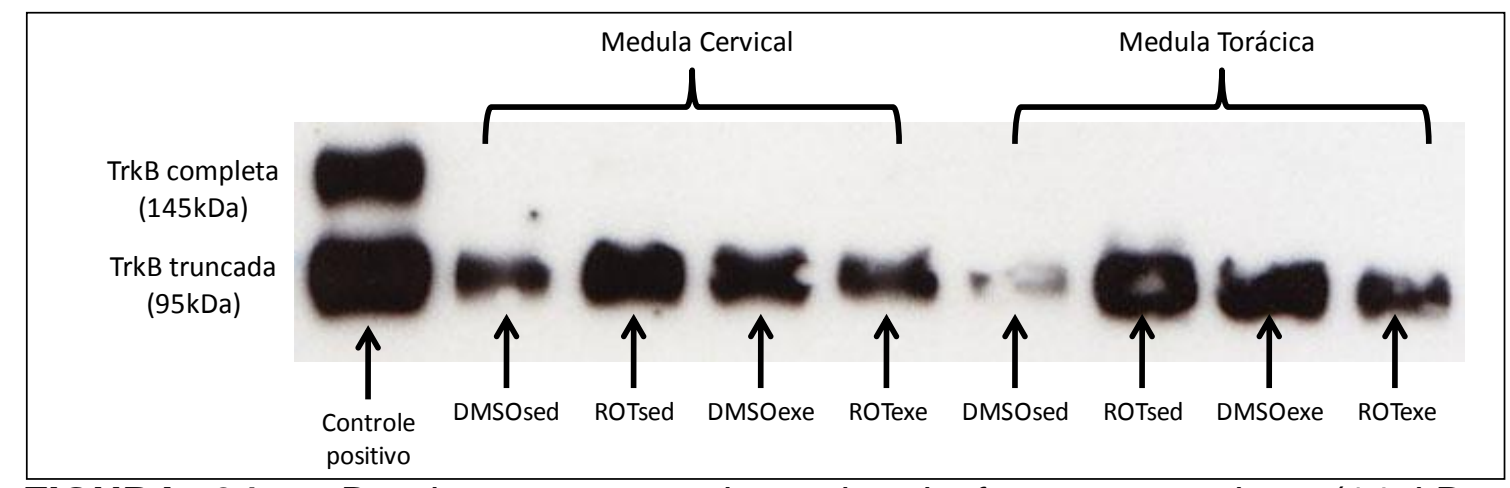

FIGURA 34 - Bandas representativas das isoformas completa (145kDa, apenas no controle positivo) e truncada (95kDa) do TrkB, receptor de BDNF, na medula cervical e medula torácica de ratos idosos expostos a DMSO ou rotenona (ROT $1 \mathrm{mg} / \mathrm{kg} / \mathrm{dia}$ ) submetidos ou não ao treinamento físico. O controle positivo correpondente a $30 \mu \mathrm{g}$ de proteínas do hipocampo de ratos idosos.

Desta maneira, somente os dados referentes à isoforma truncada do receptor TrkB para medula cervical e torácica foram quantificados.

Observou-se que a expressão TrkB truncada está significantemente aumentada após exposição a 1mg/kg/dia de ROT (G1, DMSOsed vs ROTsed), o mesmo ocorre em respota à 6 semanas de treinamento físico (G1, DMSOsed vs DMSOexe) na medula cervical. Já quando o treinamento físico foi realizado posteriormente à exposição à ROT obteve-se uma redução comparada aos níveis encontrados apenas com o treinamento físico (G1, DMSOexe vs ROTexe) (Figura 35A).

Ainda para a medula cervical, os animais que compunham o G2 não apresentam diferenças significativas em relação aos níveis da isoforma truncada TrkB quando a exposição à ROT foi precedida de treinamento físico (G2, DMSOsed vs ROTsed), precedida e acompanhada pelo treinamento físico durante a exposição a ROT (G2, ROTsed vs ROTexe), bem como somente o treinamento físico por dez semanas (G2, DMSOsed vs DMSOexe) (Figura 35B). 


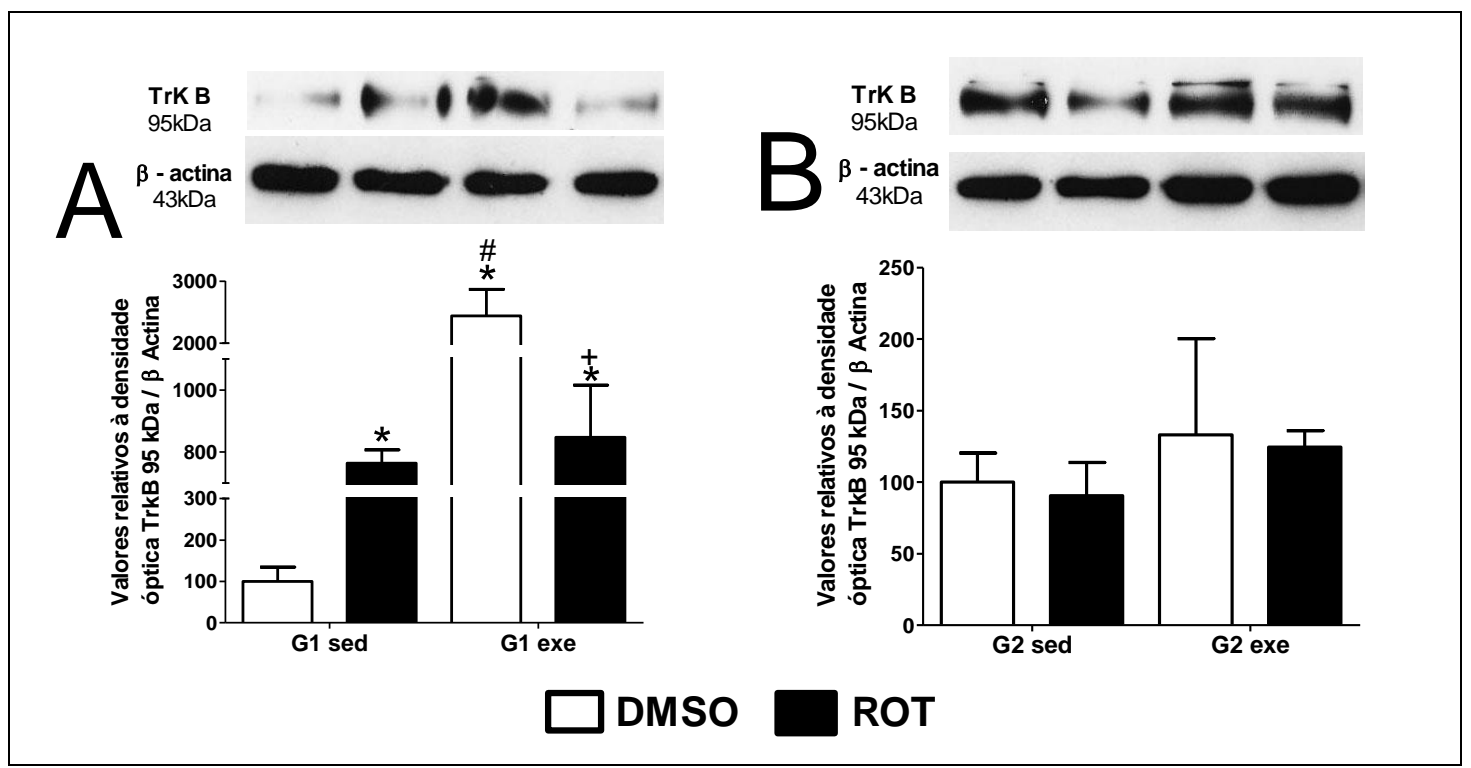

FIGURA 35 - Quantificação da expressão da isoforma truncada (95kDa) do TrkB, receptor de BDNF, na medula cervical de ratos idosos expostos a DMSO ou rotenona (ROT $1 \mathrm{mg} / \mathrm{kg} / \mathrm{dia}$ ) submetidos ao treinamento físico, conforme descrito para G1 (A) e G2 (B). Imagens representativas das bandas de Western Blot correspondentes a TrkB e ß-actina (utilizada para normalização). Valores apresentados em porcentagem do controle. $(p<0,05)$ * vs DMSOsed, \# vs ROTsed, + vs DMSOexe segundo a análise de variância (ANOVA) de duas vias seguido do pós-teste de Bonferroni. $(n=5)$.

Na medula torácica, os níveis da isoforma truncada de TrkB tem seus níveis elevados diante da exposição à ROT (G1, DMSOsed vs ROTsed). De maneira semelhante, o treinamento físico por seis semanas elevou significativamente os níveis desta isoforma (G1, DMSOsed vs DMSOexe). Porém, a exposição à ROT, anteriormente à realização do treinamento físico, diminui os níveis de expressão comparado ao grupo submetido somente ao EXE (G1, DMSOexe vs ROTexe) (Figura 36A).

Para os animais do G2, na medula torácica, verificou-se que a exposição à ROT precedida de 6 semanas de treinamento físico diminui significativamente os níveis da isoforma truncada de TrKB (G2, DMSOsed vs ROTsed). Em relação ao treinamento físico, esses níveis também estão diminuídos significativamente (G2, DMSOsed vs DMSOexe). Entretanto, quando a exposição de ROT acontece posteriormente à 6 semanas iniciais de treinamento físico e durante as 4 semanas finais, os níveis de isoforma truncada de TrkB são mantidos, recuperando a diminuição ocasionada tanto pela ROT quanto pelo EXE (Figura 36B). 


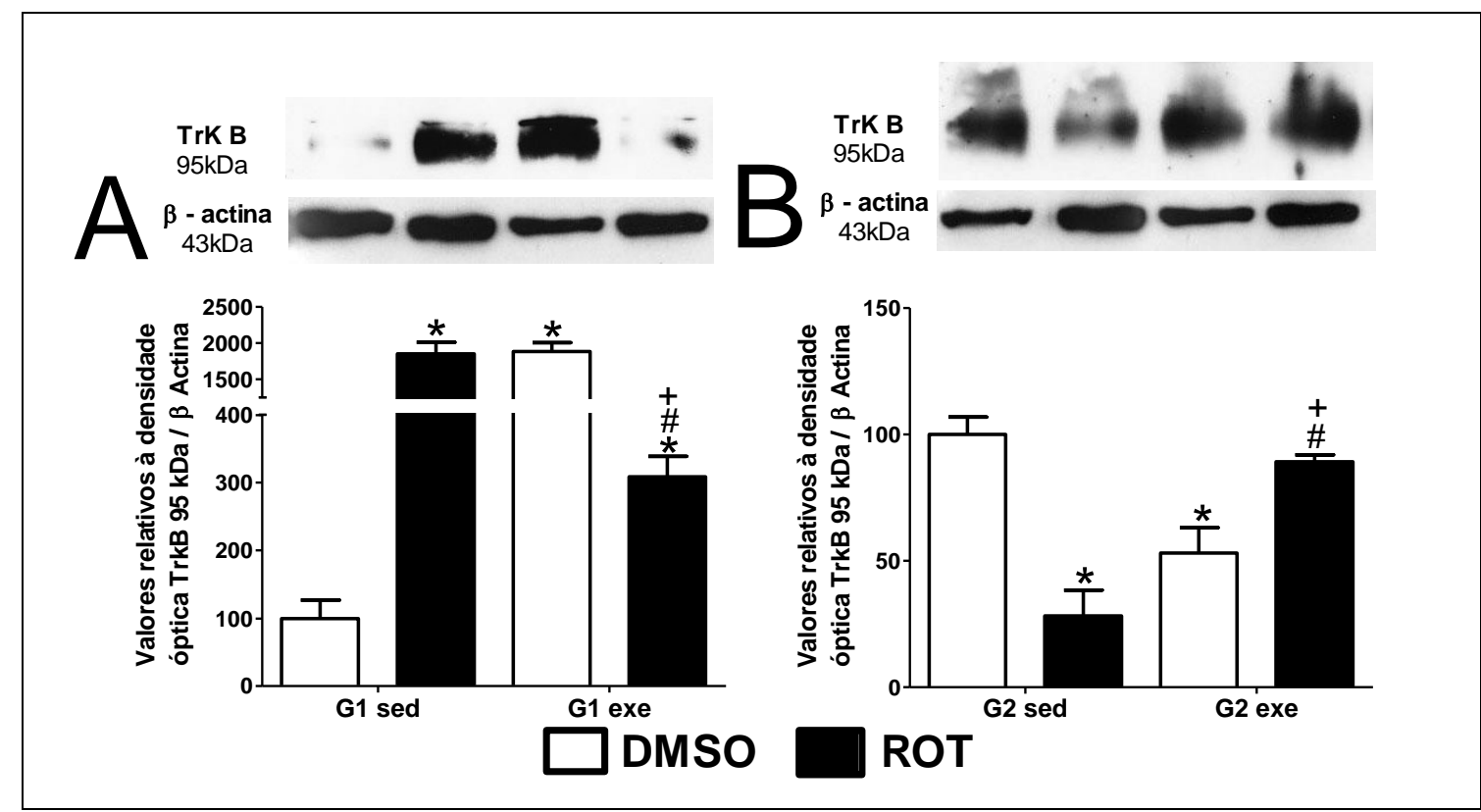

FIGURA 36 - Quantificação dos niveis da isoforma truncada (95kDa) do TrkB, receptor de BDNF, na medula torácica de ratos idosos expostos a DMSO ou rotenona (ROT $1 \mathrm{mg} / \mathrm{kg} / \mathrm{dia}$ ) submetidos ao treinamento físico, conforme descrito para G1 (A) e G2 (B). Imagens representativas das bandas de Western Blot correspondentes a TrkB e B-actina (utilizada para normalização). Valores apresentados em porcentagem do controle. $(p<0,05)$ * vs DMSOsed, \# vs ROTsed, + vs DMSOexe segundo a análise de variância (ANOVA) de duas vias seguido do pós-teste de Bonferroni. $(n=5)$.

Os resultados obtidos para a isoforma truncada de TrkB, tanto na medula cervical quanto na medula torácica, indicam que a exposição à rotenona ou ao treinamento físico aumentam os níveis de expressão deste receptor. Contudo, quando o treinamento físico e a rotenona são utilizados conjutamente verifica-se que a realização do treinamento posteriormente à exposição à ROT minimiza os efeitos de elevação na expressão da isoforma truncada. Ainda, somente na medula torácica, o treinamento físico realizado anteriormente à exposição à ROT dimininui os níveis do receptor TrkB. O treinamento por 6 semanas, seguido de exposição a ROT, e aliado a continuidade do treinamento físico houve preservação dos níveis deste receptor. 
4.13. Níveis de proteínas do tráfego anterógrado de receptores TrkB na medula cervical e torácica

\subsubsection{Níveis da SLP-1 na medula cervical e torácica}

Não foi possível detectar a expressão de SLP-1 na medula no cervical e na medula torácica, utilizando até $70 \mu \mathrm{g}$ de proteína em cada canaleta do gel de acrilamida, não sendo encontrada marcação da banda correspondente a essa proteína, de acordo com o mostrado na figura 37.

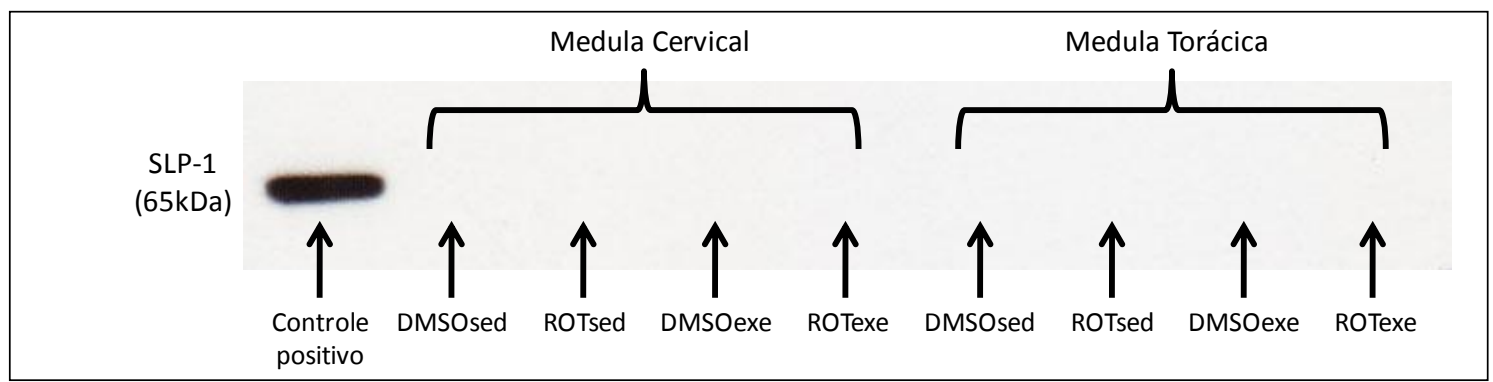

FIGURA 37 - Tentativa de identificação de bandas correspondentes à SLP-1 na medula cervical e medula torácica de ratos idosos expostos a DMSO ou rotenona (ROT $1 \mathrm{mg} / \mathrm{kg} / \mathrm{dia}$ ) submetidos ou não ao treinamento físico. Controle positivo correspondente a $30 \mu \mathrm{g}$ de proteínas do hipocampo de ratos idosos.

\subsubsection{Níveis da CRMP-2 na medula cervical e torácica}

Assim como para a SLP-1, a proteína CRMP-2 também não foi detectada na medula cervical por Western Blot (Figura 38).

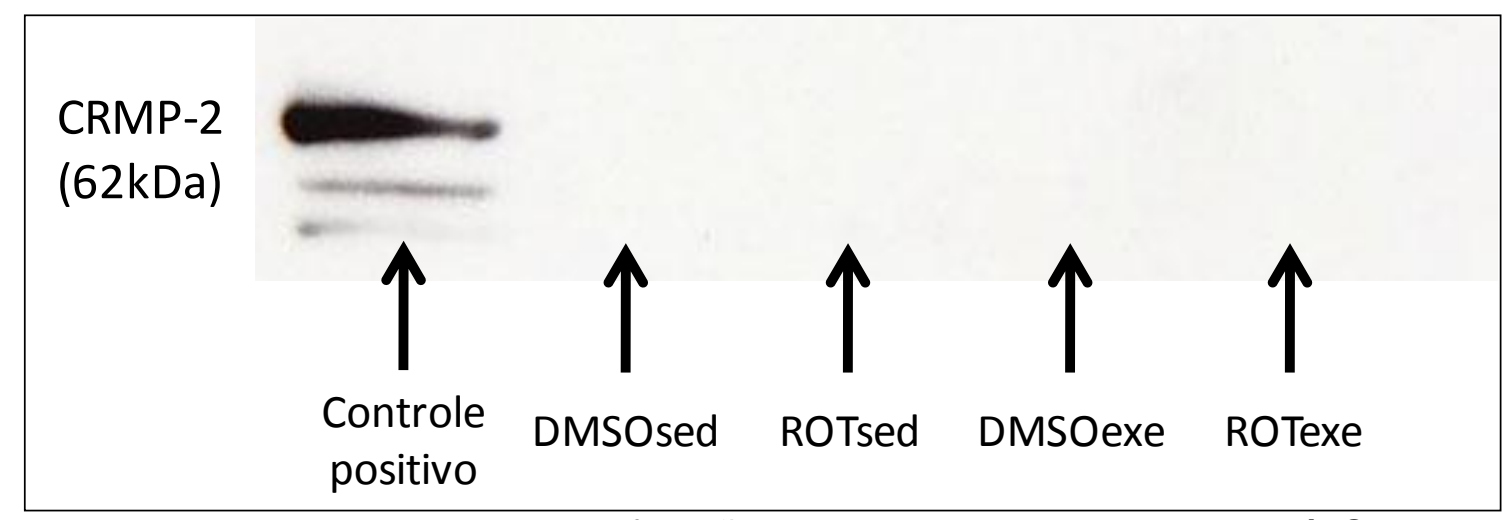

FIGURA 38 - Tentativa de identificação de bandas correspondentes à CRMP-2 na medula cervical de ratos idosos expostos a DMSO ou rotenona (ROT 
$1 \mathrm{mg} / \mathrm{kg} / \mathrm{dia}$ ) submetidos ou não ao treinamento físico. Controle positivo correspondente a $30 \mu \mathrm{g}$ de proteínas do hipocampo de ratos idosos.

Contudo, foi possível detectar a CRMP-2 na medula torácica. Observouse que a exposição à ROT diminuiu significativamente os níveis de CRMP-2 na medula torácica (G1, DMSOsed vs ROTsed). Em contrapartida, o treinamento físico aumenta de forma significativa esses níveis (G1, DSMOsed vs DMSOexe), alteração esta que não ocorre quando o período de treinamento é antecedido pela exposição a ROT, onde tem-se a manutenção dos níveis de CRMP-2 próximo aos valores do controle, sem alterações promovidas pela ROT ou pelo EXE (Figura 39A).

Já para os animais do $G 2$, não se verificou alterações nos níveis de CRMP-2 na medula cervical em nenhuma das condições, treinamento físico antes e/ou durante a exposição à ROT (Figura 39B).

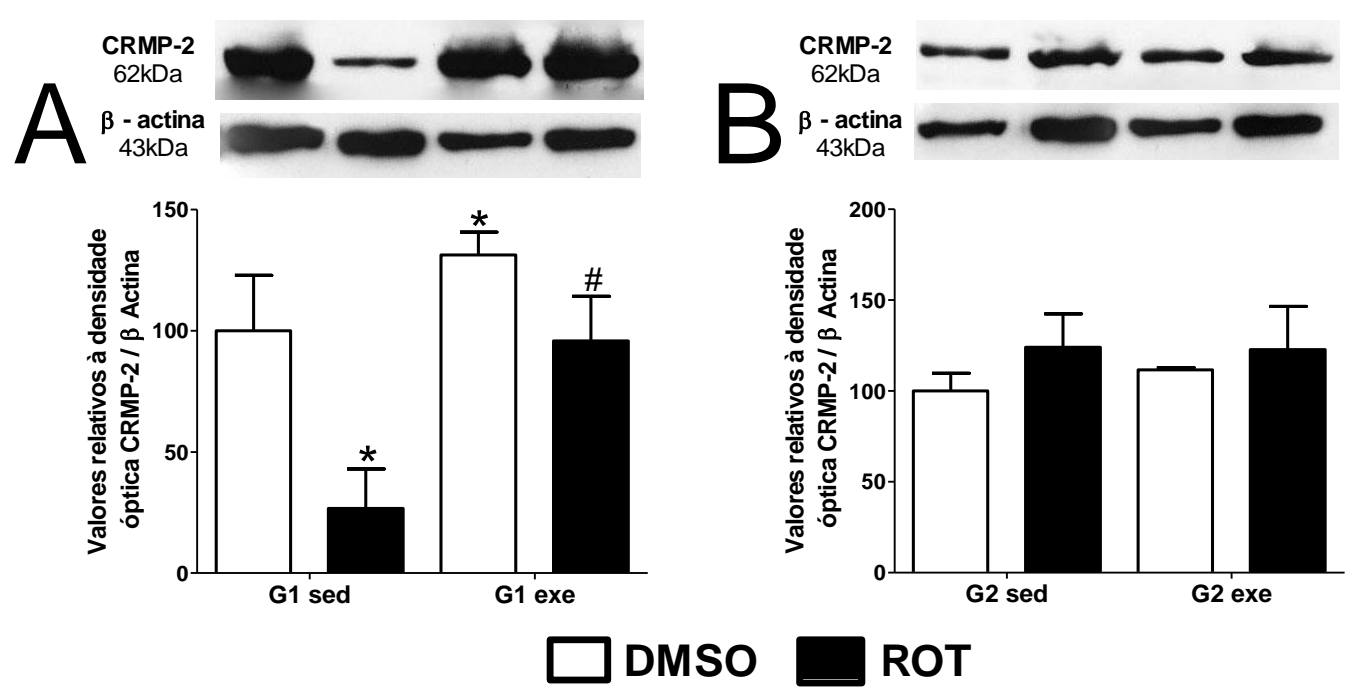

FIGURA 39 - Quantificação da expressão da CRMP-2 (62 kDa, A-B) na medula torácica de ratos idosos expostos a DMSO ou rotenona (ROT $1 \mathrm{mg} / \mathrm{kg} / \mathrm{dia}$ ) submetidos ao treinamento físico, conforme descrito para G1 (A) e G2 (B). Imagens representativas das bandas de Western Blot correspondentes a CRMP-2 e B-actina (utilizada para normalização). Valores apresentados em porcentagem do controle. $(p<0,05)$ * vs DMSOsed, \# vs ROTsed, segundo a análise de variância (ANOVA) de duas vias seguido do pós-teste de Bonferroni. $(n=5)$. 
Desta forma, pode-se sugerir que na medula torácica a rotenona diminui os níveis de CRMP-2, o quais são revertidos pelo treinamento físico quando realizado posteriormente à exposição à ROT.

\subsubsection{Níveis da Sortilina na medula cervical e torácica}

Quando analisados os níveis de Sortilina na medula cervical, não se verificou alterações com a exposição à ROT (G1, DMSOsed vs ROTsed), nem com o treinamento físico por 6 semanas (G1, DMSOsed vs DMSOexe). Mesmo resultado encontrado para quando o treinamento precede a exposição à ROT (G1, ROTsed vs ROTexe) (Figura 40A).

Por outro lado, na condição onde o treinamento físico foi aplicado por 10 semanas consecutivas, verificou-se, na medula cervical, um aumento significativo no níveis de SOR (G2, DMSOsed vs DMSOexe), sendo esta alteração minimizada, quando as últimas 4 semanas de treinamento físico foram acompanhadas pela exposição à ROT (G2, DMSOexe vs ROTexe) (Figura 40B).

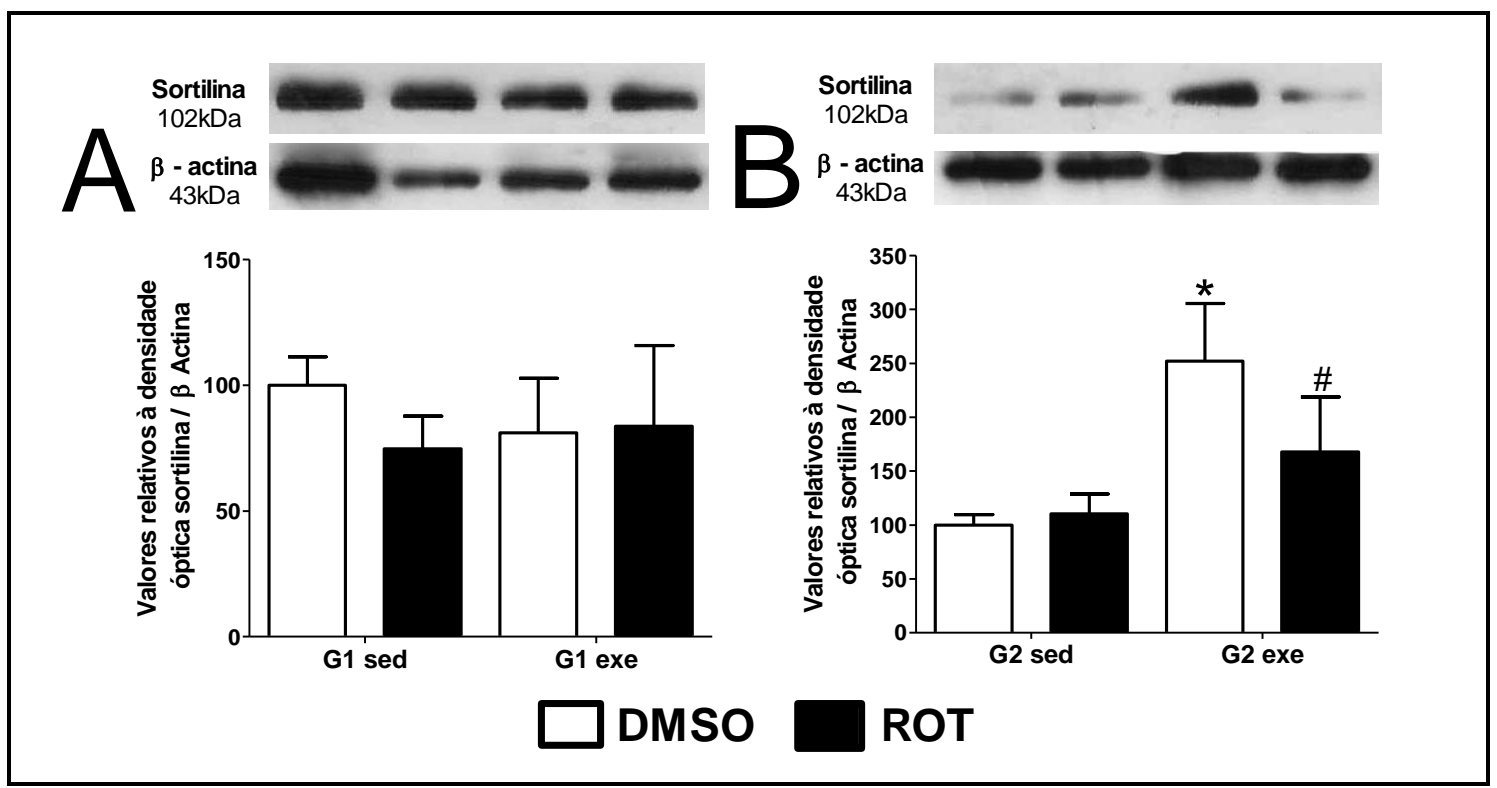

FIGURA 40 - Quantificação dos níveis da Sortilina (100kDa, A-B) na medula cervical de ratos idosos expostos a DMSO ou rotenona (ROT $1 \mathrm{mg} / \mathrm{kg} / \mathrm{dia}$ ) submetidos ao treinamento físico do protocolo G1 (A) ou G2 (B). Imagens representativas das bandas de Western Blot correspondentes a SOR e B-actina (utilizada para normalização). Valores apresentados em porcentagem do 
controle. $(p<0,05)$ * vs DMSOsed, \# vs ROTsed, segundo a análise de variância (ANOVA) de duas vias seguido do pós-teste de Bonferroni. $(n=5)$.

Já na medula torácica, verificou-se que os níveis de SOR foram reduzidos de maneira significativa posteriormente à exposição à ROT (G1, DMSOsed vs ROTsed), ao passo que o treinamento físico tende a aumentá-los (G1, DMSOsed vs DMSOexe). Porém, a expressão de SOR não se alterou quando a exposição à ROT antecedeu ao período de treinamento físico (Figura 41A).

Ainda acerca dos níveis de SOR na medula torácica, não se verificou alterações para os animais que compuseram o G2 independente do protocolo de exposição à ROT ou ao EXE (Figura 41B).

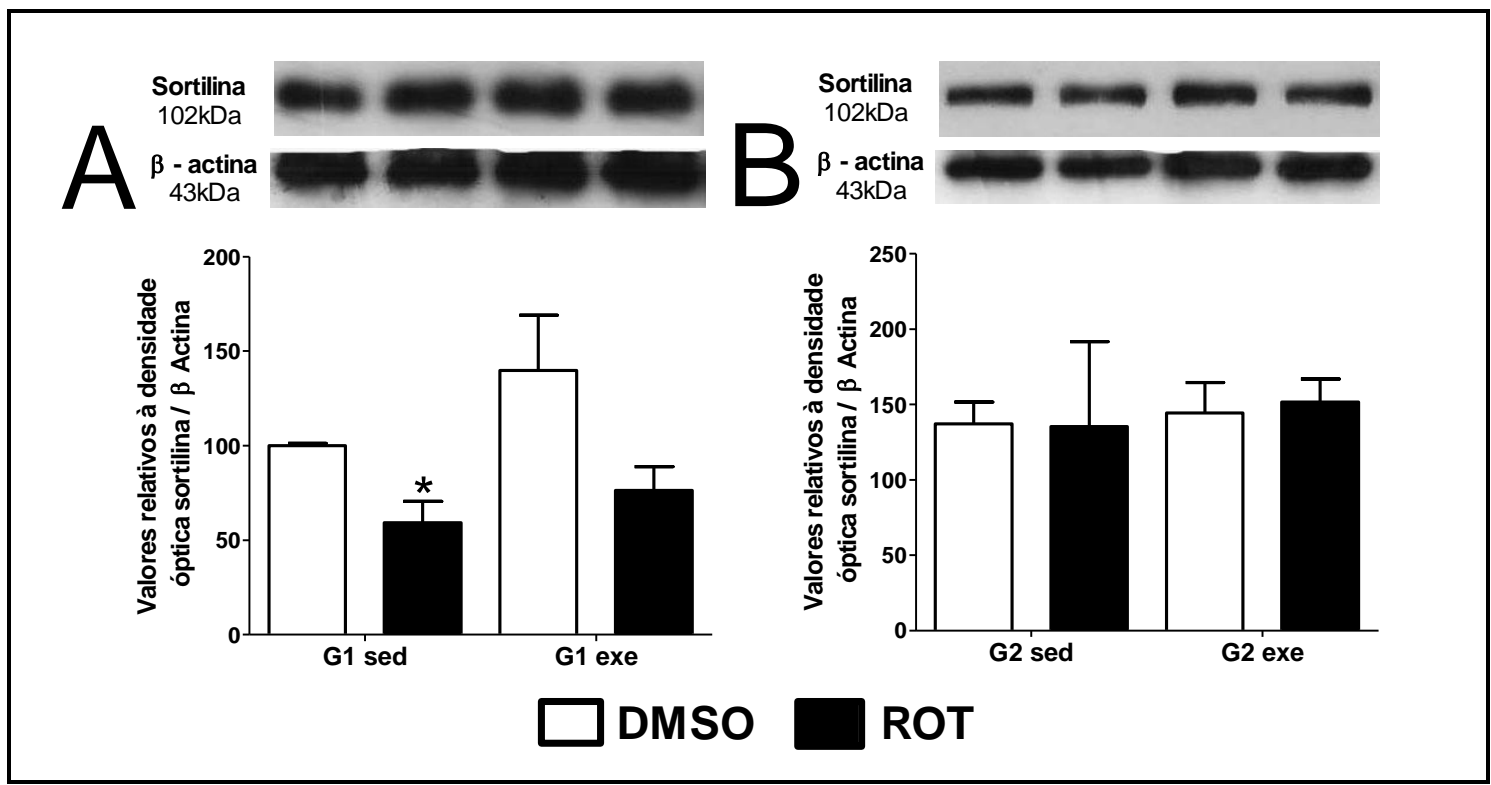

FIGURA 41 - Quantificação dos níveis da Sortilina (100kDa, A-B) na medula torácica de ratos idosos expostos a DMSO ou rotenona (ROT $1 \mathrm{mg} / \mathrm{kg} / \mathrm{dia}$ ) submetidos ao treinamento físico do protocolo G1 (A) ou G2 (B). Imagens representativas das bandas de Western Blot correspondentes a SOR e B-actina (utilizada para normalização). Valores apresentados em porcentagem do controle. $(p<0,05)$ * vs DMSOsed, segundo a análise de variância (ANOVA) de duas vias seguido do pós-teste de Bonferroni. $(n=5)$.

Pode-se assim sugerir que a exposição à rotenona modula os níveis de Sortilina somente na medula torácica, reduzindo-os, enquanto que o treinamento físico modula os níveis desta proteína na medula cervical somente quando é aplicado por longo período de tempo (10 semanas). 
Diante dos resultados descritos acima, sugere-se que na medula cervical à exposição à $1 \mathrm{mg} / \mathrm{kg} /$ dia de rotenona eleva os níveis de $\alpha$-sinucleína. $E, a$ rotenona eleva os níveis de TrkB, da isoforma truncada, assim como o treinamento físico por 6 semanas apicado conjuntamente ou não à exposição.

Em relação as proteínas envolvidas no tráfego anterógrado do recepetor TrkB, pode-se sugerir que na medula cervical onde somente os níveis da proteína sortilina foi mensurado, que apenas com 10 semanas de treinamento físico, indepentende se existe à exposição à rotenona nas últimas 4 semanas, eleva os níveis de maneira significativa. A figura 42 ilustra resumidamente esses resultados. 


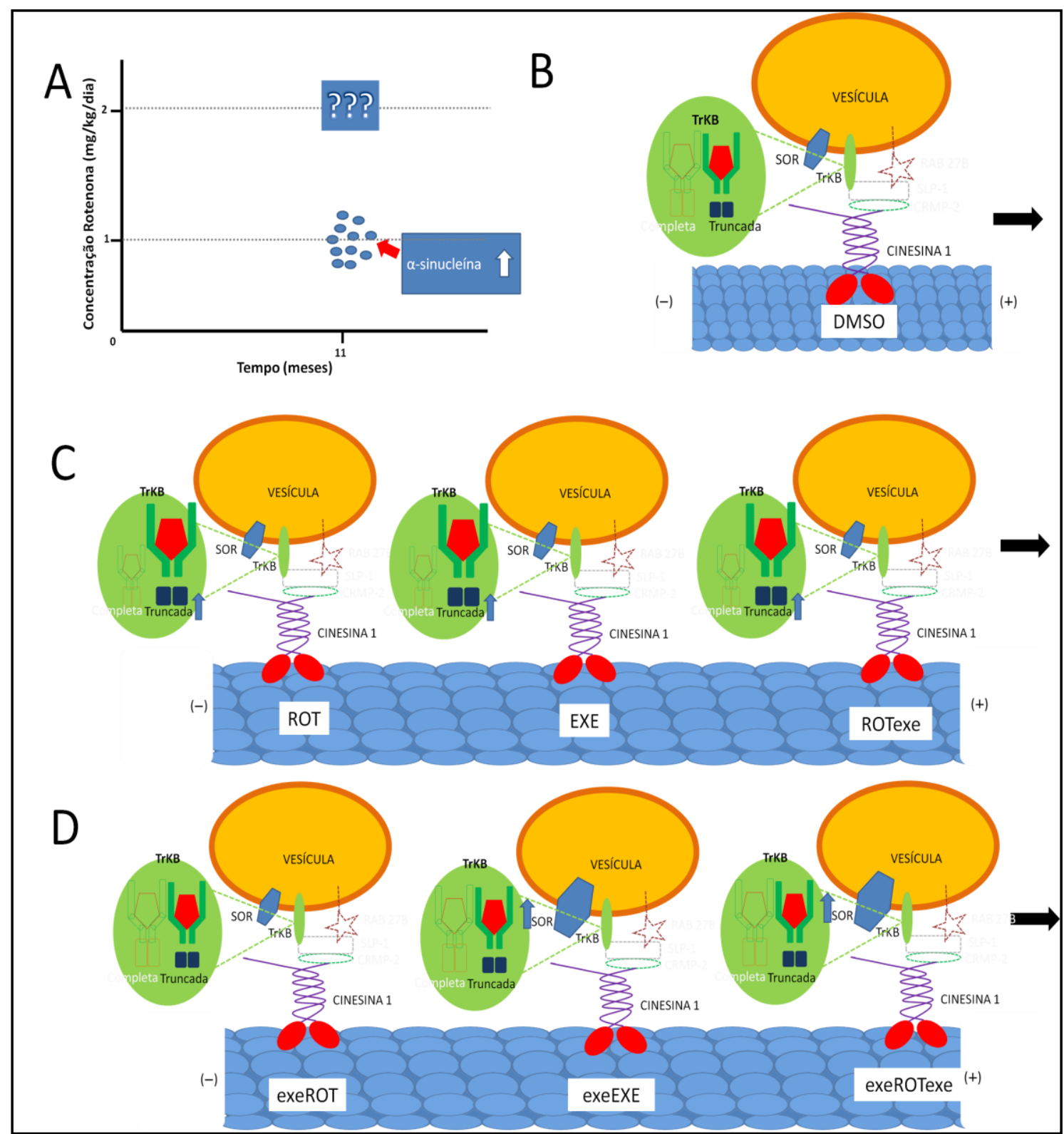

FIGURA 42 - Esquema ilustrativo representando o tráfego axonal, sentido anterógrado, do receptor TrkB na medula cervical de ratos Lewis idosos. Exposição a $1 \mathrm{mg} / \mathrm{kg} /$ dia de rotenona eleva os níveis de alfa-sinucleína $(A)$. Representação da estrutura do complexo transportador do receptor TrkB, e suas isoformas, no sentido anterógrado (B). Respostas na expressão de proteínas motoras do tráfego do receptor TrkB diante a exposição à rotenona (ROT), realização do treinamento físico moderado (EXE) e realização do treinamento físico posteriormente e durante a exposição à ROT (ROTexe) (C). Realização do treinamento físico por 6 semanas seguido de 4 semanas de sedentarismo conjuntamente à exposição à ROT (exeROT), 10 semanas de treinamento (exeEXE) e 10 semanas semanas de treinamento sendo que as últimas 4 semanas foram acompanhada pela exposição à ROT (exeROTexe) (D). As figuras demarcadas com linhas pontilhadas representam estruturas que não foram possíveis de serem detectadas via western blot. 
Para a medula torácica pode-se sugerir que a rotenona não altera os níveis de a-sinucleína, no entanto aumenta de maneira significativa os níveis da isoforma truncada do receptor TrkB. Níveis esses que são mantidos elevados com o treinamento físico de 6 semanas na apresença ou ausência de rotenona.

Considerando as proteínas envolvidas no tráfego anterógrado de TrkB, sugere-se que, dentre as proteínas que foram possíveis de serem detectadas, que os níveis de Sortilina são diminuídos diante à exposição à rotenona, e tem seus níveis recuperados pelo treinamento físico independentemente de quando este ocorre (antes, durante ou após). Ainda, os níveis de CRMP-2 são diminuídos diante a rotenona, e aumentados com treinamento físico de 6 semanas, contudo quando combinados (ROT+EXE) os níveis parecem não ser alterados em relação ao controle. De maneira ilustrativa a figura 43 resume esses achados. 


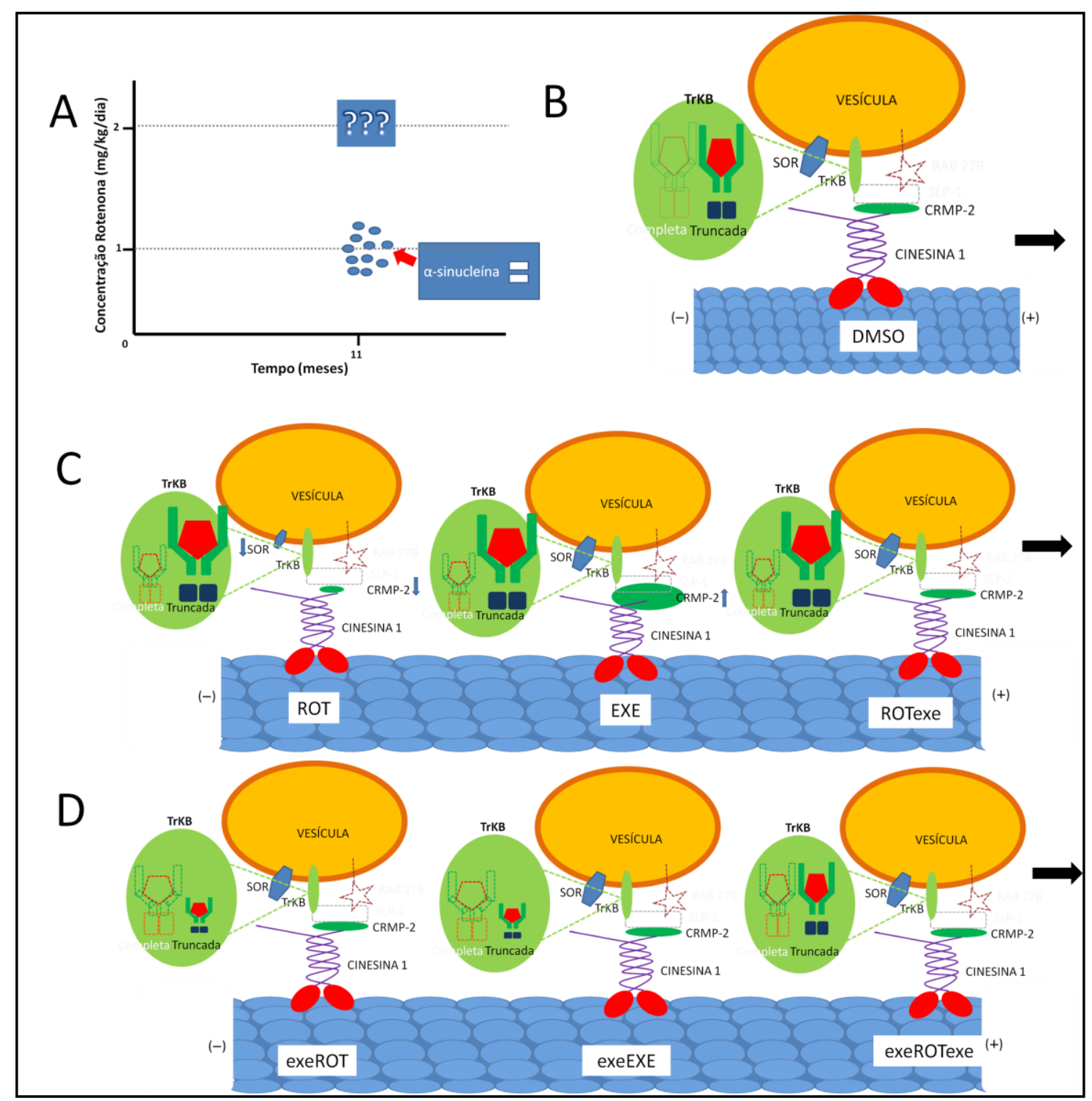

FIGURA 43 - Esquema ilustrativo representando o tráfego axonal, sentido anterógrado, do receptor TrkB na medula torácica de ratos Lewis idosos. Exposição a $1 \mathrm{mg} / \mathrm{kg} /$ dia de rotenona não altera os níveis de alfa-sinucleína $(A)$. Representação da estrutura do complexo transportador do receptor TrkB, e suas isoformas, no sentido anterógrado (B). Respostas na expressão de proteínas motoras do tráfego do receptor TrKB diante a exposição à rotenona (ROT), realização do treinamento físico moderado (EXE) e realização do treinamento físico posteriormente e durante a exposição à ROT (ROTexe) (C). Realização do treinamento físico por 6 semanas seguido de 4 semanas de sedentarismo conjuntamente à exposição à ROT (exeROT), 10 semanas de treinamento (exeEXE) e 10 semanas de treinamento sendo que as últimas 4 semanas acompanhada pela exposição à ROT (exeROTexe) (D). As figuras demarcadas com linhas pontilhadas representam estruturas que não foram possíveis de serem detectadas via western blot. 


\section{DISCUSSÃO}

\subsection{Tratamento com baixas doses de rotenona altera massa corporal de forma independente do treinamento físico}

No presente estudo foram encontradas diminuições para a massa corporal com a exposição a baixas doses de rotenona, de maneira independente do treinamento físico realizado antes, durante ou após efeito da droga.

A liberação subcutânea de rotenona tem sido caracterizada como modelos de doenças relacionadas à alfa-sinucleína ${ }^{128}$, podendo promover toxicidade sistêmica, incluindo perda de peso, em concentrações acima de $3 \mathrm{mg} / \mathrm{kg} / \mathrm{dia}^{129 ; 130}$.

Exposições superiores a $2 \mathrm{mg} / \mathrm{kg} /$ dia demonstram que a massa corporal diminuiu gradativamente nesses animais diferindo-se significativamente em relação ao grupo controle ${ }^{112 ; 131 ; 132}$.

No presente trabalho, foi encontrada diminuição da massa corporal, mesmo que em níveis mais baixos de exposição. Já os trabalhos acima citados, se diferenciam do presente trabalho em relação à dose de rotenona ao qual o animal foi exposto, visto que quanto maior a concentração de rotenona maiores as alterações de massa corporal, além de que, esses trabalhos que utilizaram ratos adultos, demonstraram uma possível maior sensibilidade em relação a rotenona.

Trabalhos utilizando exposições a concentrações mais baixas (1,5mg/kg/dia de rotenona) em ratos das linhagens Wistar adultos ${ }^{133}$ e Sprague Dawley ( 1 ano de idade) ${ }^{134}$ também verificaram a diminuição da massa corporal devido à rotenona.

A diminuição da massa corporal com exposição a rotenona, parece estar associada a uma disfunção gastrointestinal em resposta a deficiência de inibição funcional do sistema nervoso entérico. Nesse sentido, Drolet e colaboradores $^{135}$ e Greene e colaboradores ${ }^{136}$, verificaram que a exposição crônica a baixas doses rotenona parece afetar a função gastrointestinal, via 
disfunções ou mortes de células do sistema nervoso entérico, retardando a liberação gástrica relacionada à constipação.

Alterações gastrointestinais parecem preceder a agregração de proteínas e/ou perda de função motora, ou seja, as baixas concentrações de rotenona ao qual os animais foram expostos são capazes de alterar o funcionamento gastrointestinal, sem alteração da ingestão de alimento e água, sem fomação de agregados de alfa-sinucleína, mas com disfunções de organelas celulares, como as mitocôndrias ${ }^{135}$.

Em contrapartida, quando avaliados camundongos expostos a rotenona, Tasselli e colaboradores ${ }^{137}$ verificaram perda de neurônios dopaminérgicos na substância negra, sem alterações na massa corporal e na função gastrointestinal, mesmo relatando diferenças morfológicas no sistema nervoso entérico.

Recentemente, nosso grupo demonstrou não haver alterações significativas na massa corporal e na habilidade locomotora de ratos Lewis idosos após exposição à rotenona, em contrapartida, verificou-se alterações em proteínas de trafego intracelular em neurônios ${ }^{34}$. Resultados esses que se diferem dos aqui achados, possivelmente devido à diferença do presente trabalho ter o dobro de tempo de exposição à ROT comparado ao anterior.

Em relação ao treinamento, estudos utilizando ratos jovens Wistar (3-4 meses de idade) verificaram redução da massa corporal após protocolo de exercício por 13 semanas $^{138}$. Já em ratos idosos, também Wistar, o exercício físico moderado, não alterou a massa corporal ${ }^{139}$.

Para animais modelos de hipertensão o treinamento de 13 semanas em intensidade correspondente entre $50 \%$ e $60 \%$ da capacidade máxima não houve alteração de massa corporal ${ }^{140 ; 141 ; 142}$.

Esses estudos corroboram os achados do presente trabalho, visto que 0 treinamento físico moderado, por meio da corrida em esteira, não foi capaz de alterar a massa corporal de ratos Lewis, sendo que apenas o processo de envelhecimento parece ser o responsável pela perda gradativa de massa corporal. 


\subsection{Exercício físico moderado aumentou a capacidade física independente do tratamento}

O protocolo de exercício aplicado no presente estudo foi eficiente para alterar a capacidade física e variáveis do teste de capacidade máxima em ambos os grupos independente do tratamento.

A aplicação de exercícios físicos, de baixa intensidade, em ratos tem sido amplamente utilizada ${ }^{143 ; 144 ; 145}$ a fim de investigar os efeitos do exercício na prevenção da perda de memória ${ }^{146 ; 147 ; 148 ; 149 ; 150 ; 151}$, como atenuador dos efeitos da neurodegeneração ${ }^{152 ;}$ 153; 154 , nos mecanismos da hipertensão arterial ${ }^{123}$, dentre outros objetivos.

A comparação entre treinamento físico voluntário, de livre acesso a roda de corrida, e forçado revelou que ambos protocolos melhoram as respostas nos testes comportamentais de animais com déficits motores induzidos sem diferença entre os protocolos ${ }^{155}$.

Em ratos Lewis idosos, o treinamento de corrida em esteira também se mostrou eficaz contra artrite induzida ${ }^{156}$, atenuou o desenvolvimento e progressão, em ratos Lewis adultos, da Síndrome de Guillain-Barré ${ }^{16}$, e diminuiu significativamente a preferência pela cocaína em ratos Lewis jovens ${ }^{157}$.

Em estudo realizado com objetivo de identificar os efeitos do exercício físico, com intensidade moderada, foi demonstrado que corrida em esteira (50$60 \%$ da capacidade máxima individual) promove diminuição do estresse oxidativo no hipocampo ${ }^{158}$. Esta diminuição foi acompanhada pelo aumento da regulação de enzimas antioxidantes, como SOD-1, GPx, AMPK e PGC-1. Resultados semelhantes também foram descritos para o córtex pré-frontal, estriado e hipocampo ${ }^{159}$.

Protocolos de treinamentos que aplicam exercício físico forçado, de baixa a moderada intensidade, como a corrida em esteira, têm utilizado em sua maioria a duração de aproximadamente 13 semanas, visto que esse período proporciona alterações metabólicas e musculares ${ }^{140 ; 160 ; 161}$

O protocolo aplicado neste extudo foi adaptado a partir do utilizado por Amaral e colaboradores ${ }^{123}$ sendo que a familiarização dos animais foi por 
período de 15 dias, devido a idade do animais utilizados e suas deficiências. A duração foi de 6 semanas no grupo que realizou treinamento físico forçado, de intensidade baixa a moderada, apenas depois de um mês de exposição à ROT, G1, e de 10 semanas no grupo que realizou o exercício físico forçado, de intensidade baixa a moderada, 6 semanas seguidas da exposição à ROT simultaneamente a mais 4 semanas de treinamento, $\mathrm{G} 2$.

Dentre as maneiras de avaliar o protocolo de exercício físico utiliza-se o teste de capacidade máxima. Este teste permite determinar a capacidade máxima individual e distribuir ratos com desempenho semelhante aos diferentes protocolos de treinamento, e verificar os efeitos do tratamento e treinamento após aplicação do protocolo comparando ao estado inicial ${ }^{162}$.

Desta maneira, em animais jovens modelos de hipertensão 0 treinamento físico em intensidade semelhante a utilizada no presente estudo aumentou a distância atingida no teste de capacidade máxima individual de $120 \%$ a $140 \%$ após 13 semanas de treinamento, sendo possível ver alterações a partir da sexta semana de treinamento ${ }^{123}$. E mesmo alterações em relação a distância foram encontrados por Jordão e colaboradores ${ }^{163}$.

Quando analisada a velocidade atingida no teste já é possível observar alterações significativas após 6 semanas de treinamento ${ }^{141 ; 162 ; 164 ; 165}$

Quando comparadas as alterações obtidas no teste de capacidade máxima como variável fisiológica, por meio do consumo máximo de oxigênio, antes e após 13 semanas de treinamento, verificou-se efeito benéfico do exercício físico, sobre o sistema cardiovascular, em relação ao estado inicial e ao grupo sedentário. Vale ressaltar que o grupo sedentário teve seus valores referentes à capacidade máxima, diminuídos após 13 semanas ${ }^{140}$.

No presente estudo, o protocolo de treinamento aplicado foi eficiente para os grupos experimentais, visto que diferenças estatisticamente significativas foram encontradas para distância e tempo obtidos no teste de capacidade máxima individual em relação ao estado anterior ao protocolo de treinamento físico. 


\subsection{O protocolo de exercício físico elevou os níveis de atividade da enzima citrato-sintase no músculo sóleo e gastrocnêmio}

Observou-se que o treinamento físico elevou a atividade da enzima citrato sintase nos músculos sóleo e gastrocnêmio de ratos Lewis idosos, independente da duração do treinamento (6 ou 10 semanas) e da ordem em que foi aplicado (antes, durante e/ou depois do tratamento com rotenona).

A atividade da CS tem sido usada a fim de verificar alterações metabólicas no músculo em resposta ao treinamento ${ }^{152 ; 166 ; 167 ; 168}$. Com o intuito de avaliar a eficiência do treinamento aeróbio por 10 semanas a atividade da CS foi quantificada e constatou-se que o treinamento de ratos adultos promoveu aumento em relação ao grupo sedentário, sendo que estas alterações foram acompanhadas de melhorias das respostas ventilatórias, cardíacas e relacionadas a tolerância ao exercício ${ }^{169}$.

Em modelo de parkisonismo, a prática regular de exercício físico, por meio de corrida em esteira, aumentou significativamente a atividade da CS após quatro semanas de treinamento ${ }^{152}$.

A enzima citrato-sintase regula a produção de energia aeróbia catalisando a reação do oxaloacetato e acetilCoA para citrato no ciclo de Krebs $^{170}$. Sabendo que, no presente estudo foi utilizada a rotenona, um inibidor específico do complexo I da cadeia respiratória mitocondrial, pode-se atribuir o aumento da atividade da CS no G1 ROTsed, no músculo sóleo, como uma resposta "super-compensatória" da célula, resultante da diminuição da atividade do complexo I mitocondrial (NADH desidrogenase) que pode levar ao acúmulo de oxaloacetato, o que por maior oferta pode aumentar a atividade da enzima citrato sintase.

Já a diminuição da atividade da CS, no músculo gastrocnêmio, encontrada devido à exposição a rotenona (G1 ROTsed) pode ser atribuída a menor atividade aróbica deste, considerando que é um músculo misto, onde as porções de fibras vermelhas e fibras brancas são semelhantes.

Contudo, quando o treinamento físico antecedeu à exposição à rotenona (G2 ROTsed) a atividade da CS foi diminuída no músculo sóleo e não se alterou no músculo gastrocnêmio. Uma hipótese para esses achados é de que 
devido a maior participação do componente aeróbio a interrupção do treinamento físico por 4 semanas acompanhada dos efeitos causados pela rotenona na cadeia respiratória mitocondrial parece afetar de maneira mais acentuada o músculo sóleo.

Para confimar essas hipóteses seriam necessárias diferentes análises entre a cadeia respiratória mitocondrial, a atividade da CS, efeitos da rotenona e por fim os efeitos do treinamento físico. Porém, apesar de muito intrigante, tal via não foi aprofundada para se respeitar os objetivos deste trabalho.

Assim sendo, pode-se sugerir que o protocolo utilizado para 0 treinamento foi eficiente para garantir que os animais estivessem treinados, permitindo assim analisar as possíveis alterações no sistema nervoso central sobre o efeito do exercício físico sobre o trafégo de neurotrofinas e seus receptores.

\subsection{Exposição a baixas doses de rotenona como modelo anterior a} formação dos agregados proteicos

Sabendo que a agregação de proteínas parece ser um processo comum no desenvolvimento de doenças neurodegenerativas podendo levar a disfunções e mesmo a morte celular, compreender os processos iniciais da formação dessas inclusões celulares tem sido alvo de diversos grupos de pesquisas ${ }^{171 ; 172 ; 173 ; 174 ; 175 ; 176 .}$

Evidências sugerem que anteriormente à agregação proteica é possível verificar alterações no tráfego intracelular ${ }^{34 ; 177 ; 178}$, no tamanho, função e localização da mitocôndria, falhas nas sinapses ${ }^{179 ;}$;80, estresse oxidativo ${ }^{181}$, estresse do retículo endoplasmático e alteração das função do lisossomo ${ }^{182}$ podendo representar os estágios iniciais das doenças neurodegenerativas.

Embora inicialmente a exposição à rotenona tenha sido exclusivamente relacionada a doença de Parkinson ${ }^{183}$, atualmente ela tem sido considerada um modelo mais amplo de doenças neurodegenerativas, considerando seu potencial em promover, dentre outros eventos, a agregação proteica ${ }^{34 ;}$ 121; 184; 
185. E que, a relação agregação-rotenona é dependente da dose de exposição tanto em modelos in vitro ${ }^{186 ; 187 ; 188}$ quanto in vivo ${ }^{189}$.

Os achados do presente estudo corroboram os descritos acima, sendo demonstrado que a exposição a $1 \mathrm{mg} / \mathrm{kg} /$ dia de rotenona em ratos Lewis idosos por um ou dois meses não altera signifcativamente os níveis de pTau e asinucleína no hipocampo e medula torácica, vale ressaltar que não foi possível identificar os níveis de pTau na medula cervical e torácica. Os níveis de asinucleína encontraram-se elevados na substância negra e medula cervical, porém sem a presença de acúmulos proteicos, já que o padrão de bandas no gel de acrilamida não indicou agregação proteica.

\subsection{Aumento nos níveis de expressão da TrkB em resposta a exposição à rotenona e à prática de exercício físico.}

No presente estudo verificou-se que devido a exposição à rotenona, no hipocampo ocorre um aumento nos níveis de TrkB em sua isoforma completa, ao passo que na substância negra ocorre uma diminuição. Já a isoforma truncada não apresenta alterações em sua forma truncada após exposição à rotenona em comparação ao DMSO, tanto no hipocampo quanto na substância negra. E que na medula cervical e torácica apenas os níveis da isoforma truncada de TrkB foram mensurados, revelando aumento diante a exposição a rotenona em ambas as áreas.

Os receptores TrkB possuem diferentes isoformas da proteína, incluindo a sua isoforma completa do receptor de TrkB contendo o domínio de tirosinaquinase, e diferentes isoformas truncadas, que são mais curtas e não possuem a tirosina-quinase ${ }^{190}$. Entretanto, TrkB, isoforma truncada, ligam neurotrofinas com a mesma afinidade que receptores TrkB em sua isoforma completa, mesmo faltando o domínio intracelular de tirosina-quinase catalítico necessário para a transdução de sinais por meio de vias conhecidas ${ }^{191}$.

Recentemente, Carim-Todd e colaboradores ${ }^{192}$ analisaram a função do receptor TrkB (isoforma truncada) em camundongos. Eles relataram que a perda deste receptor não foi letal, o que significa que o principal papel de TrKB 
não está relacionado com a sobrevivência neuronal, embora outros receptores TrK podem compensar a perda da função do receptor de TrkB.

Tradicionalmente, o receptor de TrkB tem sido associado a vários aspectos da sobrevivência neuronal e, por essa razão, modelos knockdown de TrkB morrem durante o início de vida pós-natal ${ }^{193}$, fato que pode ter ocorrido devido esta fase representar o período de gliogênese, que ocorre em período semelhante à detecção da expressão do receptor $\operatorname{TrkB}^{194}$.

Quanto às funções dos receptores TrkB, estes estão envolvidos em processos de desenvolvimento, tais como a diferenciação, proliferação e apoptose $^{195}$, são essenciais para as conexões sinápticas ${ }^{196}$, e crescimento e desenvolvimento de novas sinapses ${ }^{197}$. Ainda, em modelo murino, TrkB truncado promove a proliferação de astrócitos ${ }^{198}$. Além disso, knockdown de TrkB diminuiu a proliferação de células precursoras embrionárias, enquanto superexpressão de BDNF promove a proliferação ${ }^{199}$.

Análises comparando indivíduos sadios, em estágios iniciais e estágios avançados da doença de Alzheimer verificaram, no hipocampo, aumento expressivo dos níveis de expressão de mRNA da TrkB no grupo sadio e em estágios iniciais da doença, sem alterações do mRNA do BDNF. Já para o grupo em estágio avançado, eles não observaram alterações para o mRNA da TrkB e, sim para o mRNA do BDNF. Esses dados sugerem que este aumento em inicial de TrkB se deve a uma resposta compensatória, com objetivo de prevenir o cognitivo utilizando toda sua reserva ${ }^{200}$.

Estes dados corroboram os achados do presente estudo onde foi encontrado aumento dos níveis de TrkB no hipocampo diante da exposição à rotenona, visto que a concentração de rotenona ao qual nossos animais foram expostos, $1 \mathrm{mg} / \mathrm{kg} / \mathrm{dia}$, precede a formação de agregados de proteínas marcadores de doenças neurodegenerativas.

Trabalhos anteriores de nosso grupo demonstraram alterações "in vivo" em proteínas motoras antes da formação de agregados, sem alterações comportamentais. Esses resultados são ainda confirmados "in vitro" onde foi verificada diminuição da mobilidade mitocondrial neste mesmo período ${ }^{34}$.

Recente pesquisa verificou que em cultura primária de neurônios corticais a exposição à rotenona no período de 6-36h diminuiu significativamente a 
expressão de TrkB ativa. Neste, a dose de rotenona utilizada foi capaz de aumentar os níveis de peróxido de hidrogênio $\left(\mathrm{H}_{2} \mathrm{O}_{2}\right)$, um marcador comumente utilizado para avaliar o estresse oxidativo ${ }^{201}$. Análise de cérebros humanos diagnosticados com a doença de Parkinson, encontrou diminuição significativa $a$ isoforma truncada de $\operatorname{TrkB}^{202}$. Da mesma forma que modelo utilizando MPTP revelou uma diminuição de aproximadamente $36 \%$ nos níveis de TrkB ${ }^{203}$.

Esses dados corroboram aos achados no presente trabalho na substância negra, onde houve diminuição nos níveis de expressão da TrkB, no entanto, nosso trabalho se difere dos acima citados pelo fato de que encontramos em nosso grupo que a dose de rotenona $(1 \mathrm{mg} / \mathrm{kg} / \mathrm{dia})$, anterior a agregação de proteínas, não altera os níveis de $\mathrm{H}_{2} \mathrm{O}_{2}$ no hipocampo e substância negra ${ }^{204}$.

Com objetivo de analisar a expressão dos receptores TrkB durante diferentes estágios do desenvolvimento, Bartkowska e colaboradores ${ }^{195}$ verificaram, por meio de análise utilizando gambás, que a expressão do receptor em TrkB, em sua isoforma completa, aumenta de forma progressiva até a fase adulta, sendo que a partir desta fase sua expressão começa a diminuir de forma contínua. Já para isoforma truncada, a expressão de TrkB, se comporta de maneira inversa. Curiosamente, em modelos murinos e primatas não humanos já estudados, TrkB truncado aumenta com o envelhecimento ${ }^{127}$; 205; 206; 207. Também foi observado aumento da expressão de mRNA para receptores TrkB truncados após lesão da medula espinal de ratos ${ }^{208}$.

Dados esses semelhantes aos aqui encontrados, onde se demonstrou elevação dos níveis de TrkB em sua isoforma truncada na medula cervical e torácica.

Os níveis sinápticos de $\operatorname{TrkA}, \operatorname{TrkB}, \operatorname{TrkC}$, mas não p75, estão diminuídos na doença de Alzheimer $(A D)$. Além disso, uma regulação negativa significativa de TrkA, TrkB, TrkC e expressão em neurônios colinérgicos individuais nos núcleos da base foi demonstrado durante a progressão da $A D^{209}$.

Além disso, a expressão de TrkB truncado, foi acompanhada pelo aumento no mRNA do receptor p75, relacionado a apoptose, após 8 semanas da lesão no Sistema Nervoso Central $(\mathrm{SNC})^{210}$. Estudos demonstram que a 
ligação de neurotrofinas ao receptor p75 levam à morte celular no sistema nervoso ${ }^{211 ; 212 ; 213}$ e a eliminação deste receptor previne a apoptose ${ }^{214}$. Nossos achados não observaram alterações na isoforma truncada de receptores TrkB quando expostos a $1 \mathrm{mg} / \mathrm{kg} / \mathrm{dia}$ em comparação ao controle no hipocampo e na substância negra, contudo estes estão aumentados nas áreas da medula espinhal. Vale ressaltar que nas áreas da medula não foi possível identificar os níveis da isoforma completa de TrkB.

Estudos têm mostrado que, enquanto o TrkB completo é essencial para a ativação da cascata de sinalização do BDNF, o TrkB truncado inibe esta via $^{215}$, pois ocorreria a heterodimerização com o TrkB completo, funcionando como um inibidor dominante negativo da sinalização de BDNF/TrkB ${ }^{216 ; 217}$; podendo ainda atuar como um receptor eliminador de BDNF $218 ; 219$.

Em relação aos efeitos do exercício físico forçado, por meio da corrida em esteira com intensidade moderada realizado por 6 semanas, este aumentou os níveis de expressão do receptor TrkB em sua isoforma completa apenas na substância negra. Em contrapartida, quando realizado por dez semanas, este diminuiu os níveis da isoforma completa tanto no hipocampo, quanto na substância negra. Considerando a isoforma truncada, 6 semanas de treinamento físico elevou os níveis na medula cervical e torácica, enquanto que dez semanas diminuiu este na medula torácica.

Considerando, a interação entre exposição à rotenona e o treinamento físico, obteve-se que quando o treinamento físico antecedeu a exposição a rotenona alterações apenas no hipocampo e na substância negra para o níveis da isoforma completa de TrkB, sendo aumento e diminuição, respectivamente. Já para a isoforma truncada, observou-se apenas aumento no hipocampo e na medula torácica. Quando o treinamento físico ocorreu anteriormente e durante a exposição à rotenona verificou-se apenas diminuição para isoforma completa no hipocampo e na substância negra, e na medula torácica para isorma truncada do receptor TrkB. E quando o treinamento físico ocorreu posteriormente e durante a exposição à rotenona obteve-se apenas elevação da isoforma completa no hipocampo.

Em modelo murino de Parkinson, Real e colaboradores ${ }^{220}$ verificaram os efeitos do treinamento físico, por meio da corrida em esteira, com e sem o 
bloqueio de receptores de BDNF. Assim sendo, eles verificaram que o exercício físico é capaz de restaurar o dano causado pelo parkisionismo, e que esse efeito parece ocorrer via interação BDNF/TrkB, pois quando bloqueado os receptores de BDNF os efeitos do treinamento foram minimizados.

Em modelo de lesão causado por irradiação, o exercício aplicado duas vezes ao dia por três semanas ativou a via de sinalização BDNF-pCREB e aumentou a expressão de BDNF e TrkB, o que se, correlaciona com os efeitos do exercício na neurogênese no hipocampo e atenuação dos danos em testes comportamentais ${ }^{221}$.

No presente trabalho podemos sugerir resumidamente que as alterações, nas isoformas completas e truncadas, de TrkB geradas pela rotenona são semelhantes as resultantes de 6 semanas de treinamento físico, exceto para na substância negra, onde observou-se diminuição apenas com a exposição à rotenona. Resultados semelhantes foram encontrados para os efeitos de 10 semanas de treinamento físico, no hipocampo onde se observou resposta contrária ao efeito da rotenona.

Aliados rotenona e treinamento físico, predominaram as alterações em sentido contrário ou a preservação dos níveis do controle aos efeitos da rotenona para os níveis de TrKB, considerando suas duas isoformas, para as três condições (treinamento antes, após e durante; e antes e durante exposição à rotenona), exceto para a isoforma completa no hipocampo e substância negra, e para isoforma truncada na medula torácica quando o treinamento foi aplicado posteriormente e durante a exposição à rotenona. Também não houve alteração ao obtido para a isoforma completa no hipocampo, e truncada na medula torácica, quando o treinamento físico antecedeu a rotenona, e na isoforma completa no hipocampo quando o treinamento físico ocorreu antes e durante o tempo de exposição à rotenona.

\subsection{Exposição a baixas doses de rotenona e a expressão de} proteínas envolvidas no tráfego de neurotrofinas e seus receptores

A ligação de neurotrofinas aos seus receptores Trk em terminais nervosos é essencial para a sobrevivência neuronal, diferenciação e 
plasticidade sináptica. Considerando que o corpo celular e os terminais nervosos são distantes, a eficiência da translocação sináptica e sinalização via Trk depende da eficiência também do transporte ${ }^{222}$.

Receptores Trk são produzidos no corpo celular, sendo transportados anterogradamente em vesículas exocíticas através dos microtúbulos, e, em seguida inseridos na membrana plasmática dos espinhos dendríticos e terminais sinápticos ${ }^{223}$. Quando inseridos e ativados pelas neurotrofinas, os receptores Trk iniciam sinais que culminam em desenvolvimento axonal e sobrevivência neuronal ${ }^{94 ; 223}$.

Além disso, depois de ativados os receptores Trk são autofosforilados e, por conseguinte, são endocitados no terminal axonal. Na sequência, as vesículas endocíticas contendo Trk são retrogradamente transportados para o corpo celular ${ }^{24 ; 225}$. Este transporte retrógrado é necessário, pois a sinalização de Trk exerce uma variedade de funções neuronais, como expressão gênica e processos tróficos ${ }^{223 ; 226 .}$

O transporte de vesículas é realizado por proteínas motoras específicas, que por um mecanismo ainda não bem descrito reconhecem e se ligam a carga para realizar o transporte via microtúbulo.

Alguns estudos têm se concentrado em descrever proteínas motoras específicas de carga e seus mecanismos de ação. Nesse sentido, pode-se destacar a proteína CRMP-2, crucial para a formação de axônios em neurônios do hipocampo $227 ; 228 ; 229$. Sabe-se que a superexpressão de CRMP-2 induz a formação de axônios, e a inibição da função CRMP-2 evita a formação do axônio ${ }^{228}$.

Arimura e colaboradores ${ }^{94}$, por meio de imunoprecipitação, relataram que os receptores TrkB interagem com a proteína CRMP-2, observando ainda que esta interage com a SLP-1, que é uma proteína efetora de Rab27, formando assim um complexo. Esses mesmos autores, ainda revelaram, por meio de análises de imagens, que o complexo SLP1/Rab27/CRMP-2 se colocaliza com os microtúbulos e com os receptores TrkB não fosforilados, indicando ser uma maquinaria de transporte anterógrado. 
Verificou-se que a ausência de uma dessas proteínas do complexo SLP1/Rab27/CRMP-2 prejudica o transporte anterógrado de TrkB. Já a deleção do complexo leva à interrupção do tráfego e acúmulo no corpo celular ${ }^{94}$.

No presente estudo, foi verificado que a exposição a $1 \mathrm{mg} / \mathrm{kg} / \mathrm{dia}$ de rotenona diminui os níveis de expressão das proteínas SLP-1 e Rab27B no hipocampo, entretanto, ela eleva os níveis de CRMP-2. Mesma elevação é encontrada SLP-1, Rab27B e CRMP-2 na substância negra. Já na medula espinhal, não se foi possível mensurar grande parte dessas proteínas, quando possível verifou-se apenas a diminuição dos níveis de CRMP-2 na medula torácica.

Parece existir mecanismos compensatórios para regular o transporte em momentos de estresse celular, de modo que a alteração na expressão em uma proteína que integra o complexo de transporte anterógrado de TrkB não acarrete em prejuízos celulares. Nesse contexto, a Sortilina pode surgir como um destes mecanismos, visto que ela pode atuar como um receptor suporte que facilita a formação do complexo entre receptores TrkB e SLP1/Rab27B/CRMP-2, e a cinesina-1, sendo uma alternativa, que pode ligar diretamente receptores Trk com outras proteínas motores de microtúbulos ${ }^{222}$.

A Sortilina é uma proteína altamente expressa no hipocampo e no córtex ${ }^{103 ; 230}$ onde pode funcionar como um receptor da superfície da célula para pró-neurotrofinas, neurotensina, e lipoproteínas ${ }^{231 ; 232}$. Mas a maioria da sortilina é expressa no interior de compartimentos intracelulares onde interage com as neurotrofinas ${ }^{105 ; 232 ; 233}$.

A cauda citoplasmática da Sortilina direciona o tráfego de BDNF para o terminal sináptico em neurônios, onde ele pode ser liberado em resposta à despolarização para modular a sobrevivência de células e de plasticidade sináptica ${ }^{234 ;}{ }^{235}$,sendo que na ausência desta esse mecanismo parece prejudicado $^{105}$.

No entanto, quando a Sortilina interage com as isoformas pró das neurotrofinas (como exemplo próBDNF) pode se conectar com o receptor p75 e desencadear cascatas apoptóticas ${ }^{236 ; 237}$.

Em relação ao tráfego anterógrado dos receptores TrkB, Vaegter e colaboradores ${ }^{222}$ relataram que a Sortilina se colocaliza com receptores TrkB. 
Vale ressaltar que apenas sua forma madura apresentou ligação com TrkB, já sua forma pró não apresenta as mesmas relações. Esses mesmos pesquisadores, relatam que em modelos sem expressão da proteína sortilina, o tráfego anterógrado de TrkB está prejudicado, sendo recuperado quando a mesma é superexpressa.

Apesar dos prejuízos gerados pela ausência ou deficiência na expressão de sortilina, em nosso trabalho, os níveis de sotilina foram alterados, sendo diminuídos apenas na medula torácica diante exposição à rotenona.

No sentido retrógado do transporte de neurotrofinas e seus receptores, apenas os níveis da proteína EDH-4 puderam ser mensurados e exclusivamente no hipocampo. Nossos achados, sugerem que a exposição à baixas doses de rotenona não altera os níveis de EDH-4 no hipocampo, assim como o treinamento físico por 6 semanas, aliado ou não à exposição a rotenona.

No presente estudo o treinamento físico de 6 semanas elevou no hipocampo os níveis de CRMP-2; na substância negra os níveis de SLP-1, CRMP-2 e Rab27B; e na medula torácica os níveis de CRMP-2. Sendo que, apenas os níveis de Rab27B no hipocampo fora diminuídos. Quando o tempo de treinamento foi alterado para 10 semanas, observou-se elevação no níveis de CRMP-2 no hipocampo e substância negra, e sortilina na medula torácica. Já a diminuição de níveis foi observada apenas para a Rab27B no hipocampo e susbtância negra.

Considerando os efeitos do treinamento físico e a exposição à rotenona no hipocampo obteve-se que os níveis de SLP-1 e Rab27B são preservados das alterações oriundas da rotenona quando o treinamento físico é aplicado por seis semanas antes ou após exposição. Ainda, os níveis de SLP-1 não apenas são preservados como tem seus níveis elevados, revertendo a diminuição causada pela exposição. Contudo, os níveis de CRMP-2 continuam elevados independente de quando e por quanto tempo o treinamento físico é aplicado. Já a Sortilina não é alterada em nenhuma das condições dos grupos experimentais, parecendo não ser sensível a rotenona e ao treinamento físico. Considerando ainda o hipocampo, os níveis de EDH-4 são mantidos elevados com o treinamento físico por 6 semanas, independente da fase em que foi 
aplicado, e são preservados quando treinamento foi realizado antes e durante a exposição à rotenona.

$\mathrm{Na}$ substância negra, o treinamento físico de 6 semanas quando aplicado posteriormente e durante a exposição à rotenona, não modifica as alterações causadas pelo efeito da droga. Em contrapartida, quando o treinamento físico foi aplicado anteriormente a exposição, este preserva os níveis de CRMP-2 e Rab27B, além de reverter a elevação dos níveis de SLP-1. Efeito que também ocorreu quando o treinamento físico foi aplicado por 10 semanas, sendo as 4 últimas semanas aliadas a exposição à rotenona, sendo revertido os efeitos de SLP-1 e Rab27B, contudo a elevação dos níveis de CRMP-2 são mantidos elevados.

Diante das dificuldades de indentificação do níveis destas proteínas na medula espinhal, pouco se pode descrever deste complexos transportadores na medula cervical e torácica. Porém, com o resultados obtidos pode-se sugerir que na medula cervical, os níveis da proteína Sortina, única detectada nesta área, somente foram elevados com 10 semanas de treinamento físico de maneira independente da exposição a rotenona.

Já na medula torácica, foi possível identificar tanto a Sortilina quanto a CRMP-2, sendo que os níveis de ambas proteínas foram preservados de maneira independente de quando aplicado o treinamento em relação a exposição à rotenona e por quanto tempo (seis ou dez semanas).

As tabelas abaixo (Tabela 4,5,6,7 e 8) resumem os achados neste trabalho. 
TABELA 4 - Resumo dos resultados encontrados para os níveis de TrkB no hipocampo, substância negra, medula cervical e torácica, diante exposição à rotenona ou submetido ao treinamento físico e seus respectivos controles.

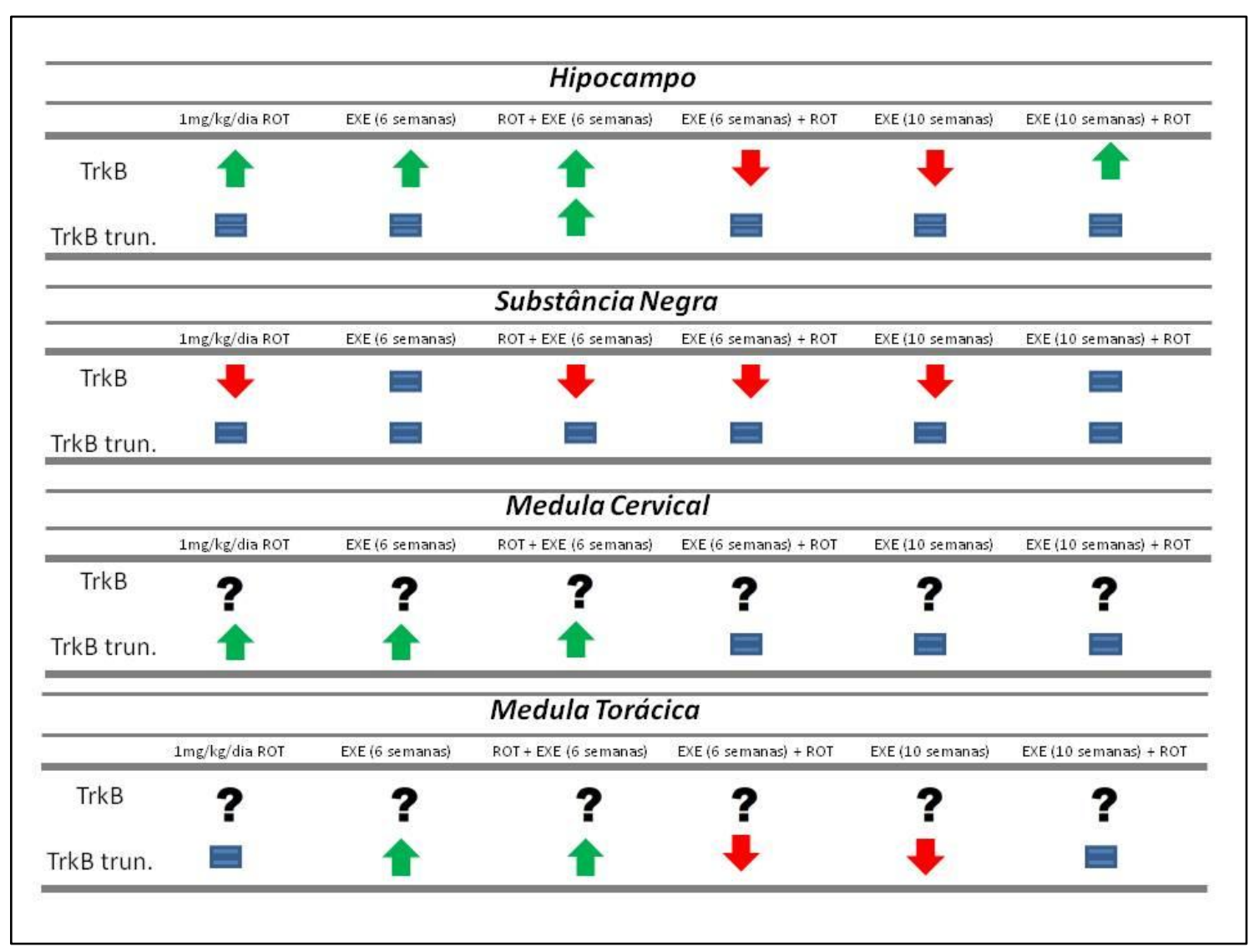


TABELA 5 - Resumo dos resultados encontrados para os níveis de proteínas do transporte anterógrado e retrógado TrkB no hipocampo diante exposição à rotenona ou submetido ao treinamento físico e seus respectivos controles.

\begin{tabular}{|c|c|c|c|c|c|c|}
\hline \multicolumn{7}{|c|}{ Hipocampo } \\
\hline & $1 \mathrm{mg} / \mathrm{kg} / \mathrm{dia}$ ROT & EXE(6 semanas) & ROT + EXE (6 semanas) & EXE (6 semanas) + ROT & EXE (10 semanas) & EXE (10 semanas) + ROT \\
\hline TrkB & 1 & 1 & 1 & $\checkmark$ & 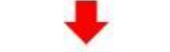 & 1 \\
\hline TrkB trun. & 물 & 回 & 1 & 뭄 & 뭄 & 回 \\
\hline \multicolumn{7}{|c|}{ Anterógrado } \\
\hline & $1 \mathrm{mg} / \mathrm{kg} /$ dia ROT & EXE (6 semanas) & ROT + EXE (6 semanas) & EXE (6 semanas) + ROT & EXE $(10$ semanas $)$ & EXE (10 semanas) + ROT \\
\hline SLP-1 & 7 & 回 & 目 & 目 & 回 & 回 \\
\hline Rab27B & & 7 & 回 & 回 & 7 & 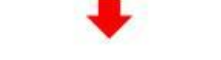 \\
\hline CRMP2 & 1 & 1 & 1 & 1 & 1 & 단 \\
\hline SOR & 回 & 目 & 目 & E & 回 & 回 \\
\hline \multicolumn{7}{|c|}{ Retrógrado } \\
\hline & $1 \mathrm{mg} / \mathrm{kg} / \mathrm{dia}$ ROT & EXE (6 semanas) & ROT + EXE (6 semanas) & EXE (6 semanas) + ROT & EXE (10 semanas) & EXE (10 semanas) + ROT \\
\hline Rab5 & $?$ & $?$ & $?$ & $?$ & $?$ & $?$ \\
\hline EDH-4 & 1 & 1 & 1 & 1 & ㅁ & 回 \\
\hline
\end{tabular}


TABELA 6 - Resumo dos resultados encontrados para os níveis de proteínas do transporte anterógrado de TrkB na substância negra diante exposição à rotenona ou submetido ao treinamento físico e seus respectivos controles.

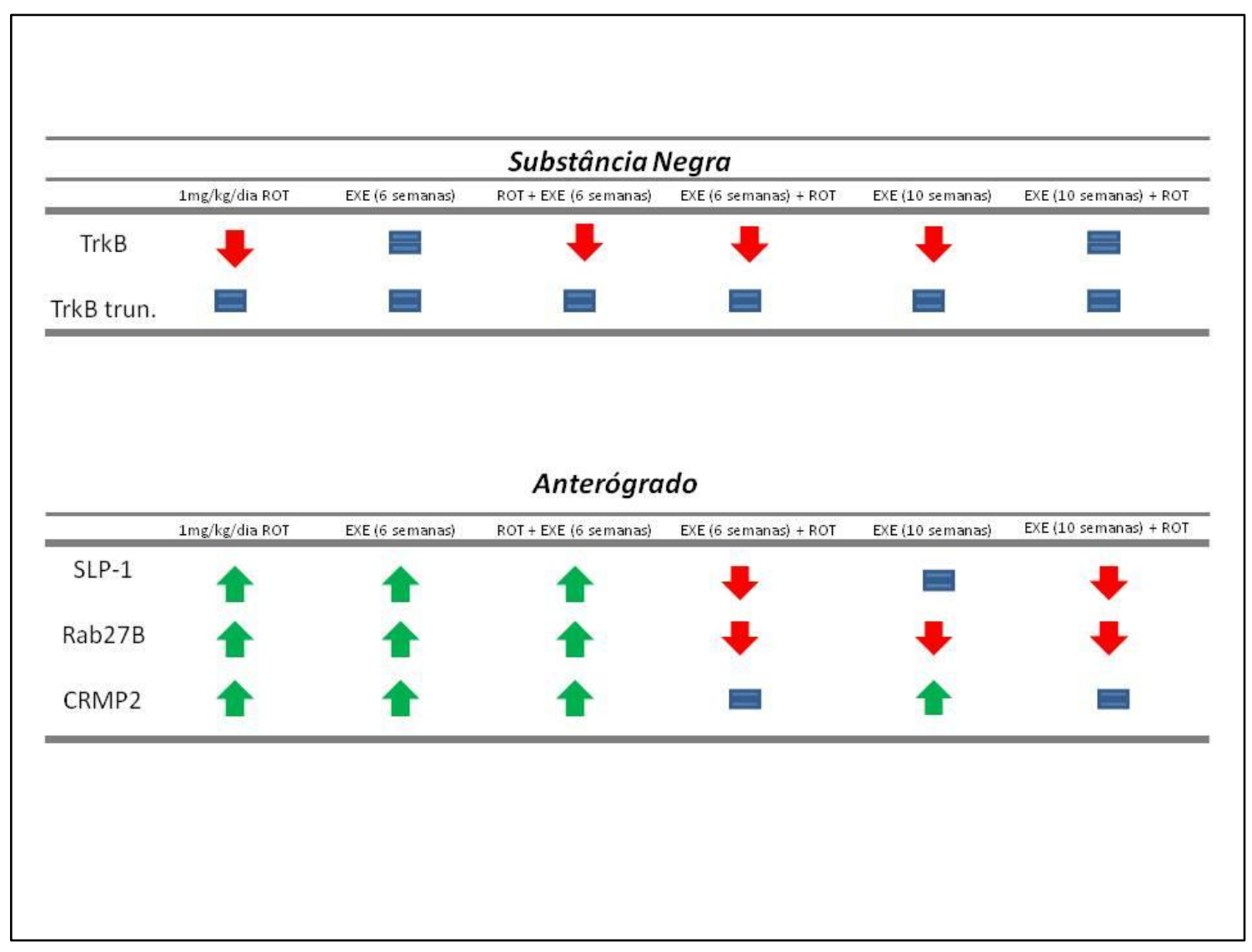


TABELA 7 - Resumo dos resultados encontrados para os níveis de proteínas do transporte anterógrado de TrkB na medula cervical diante exposição à rotenona ou submetido ao treinamento físico e seus respectivos controles.

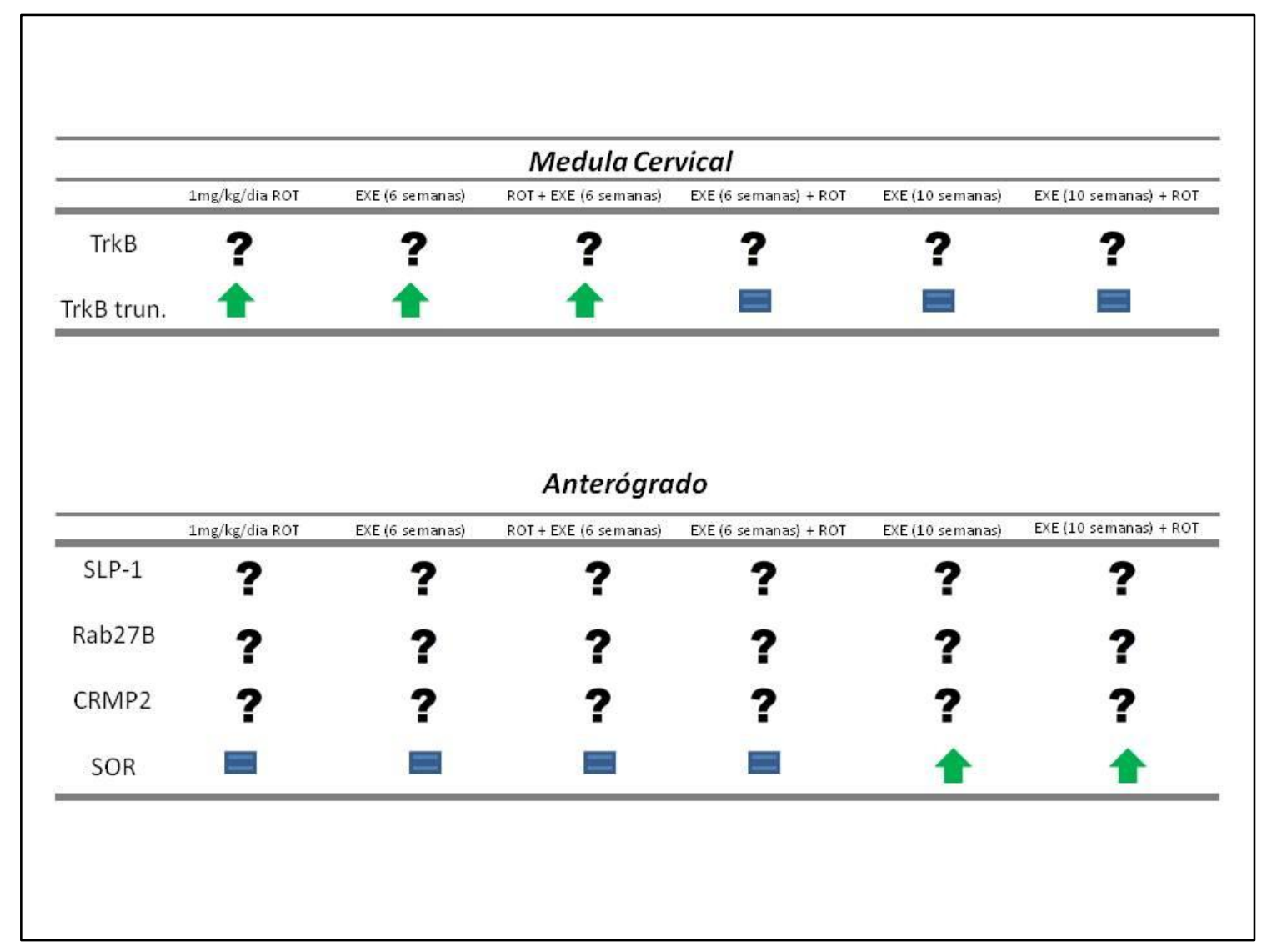


TABELA 8 - Resumo dos resultados encontrados para os níveis de proteínas do transporte anterógrado de TrkB na substância negra diante exposição à rotenona ou submetido ao treinamento físico e seus respectivos controles.

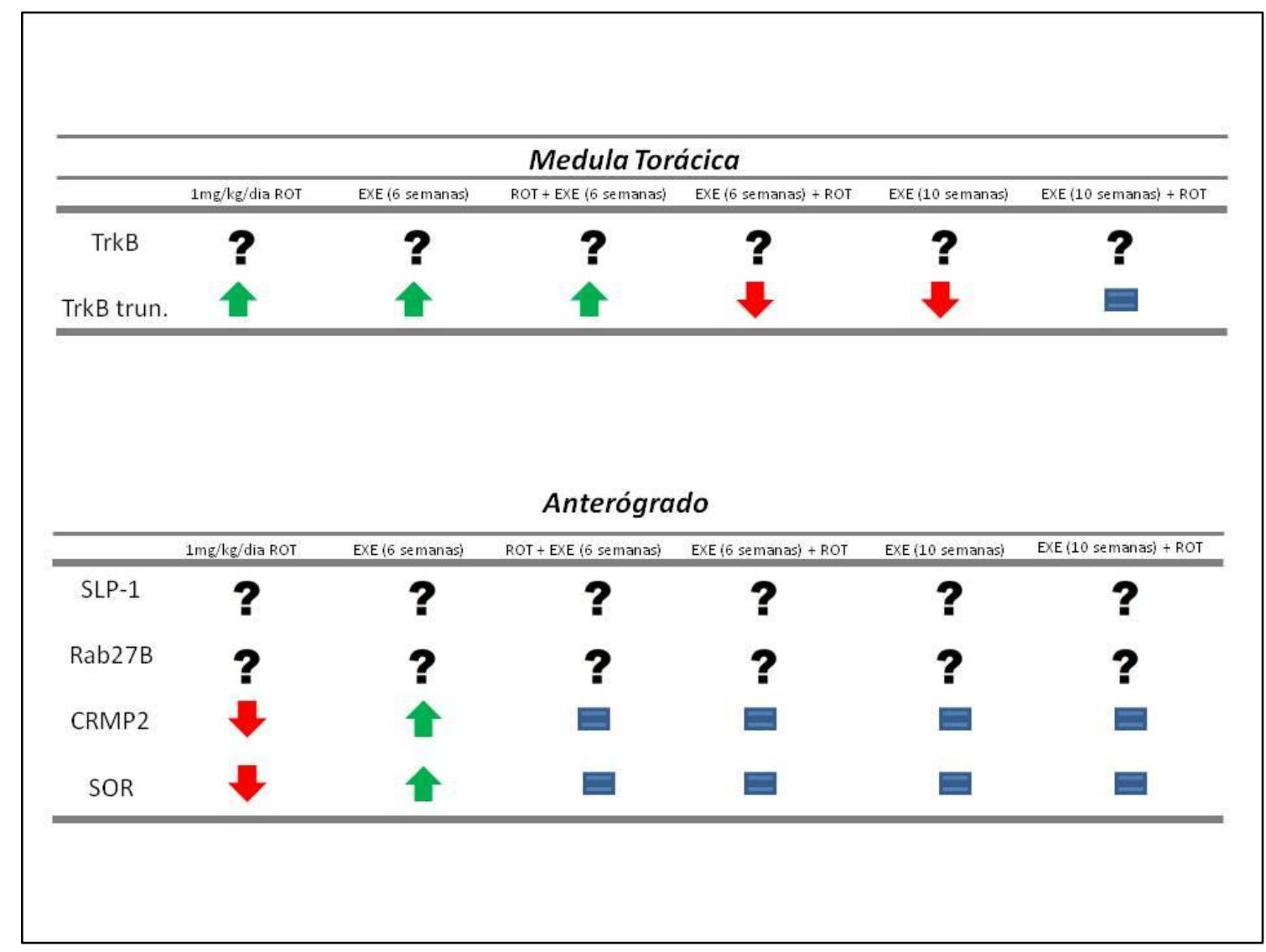

Apesar dos resultados aqui relatados apresentarem diversas alterações em proteinas relacionadas ao tráfego de neurotrofinas e seus receptores anteriormente ao processo de agregação proteica, faz-se necessária a análise direta do transporte, por meio de células vivas, para identificar se as alterações aqui descritas correspondem a reais alterações no sistema de transporte dessas vesículas contendo tanto os receptores como as neurotrifinas.

Também sugere-se que não somente o transporte, mas que as vias ativadas pela interação neurotrofinas/receptores sejam avaliadas e descritas bem como os processos resultantes desta, como por exemplo a neurogênese, em condições semelhantes ao presente estudo, sendo assim possível compreender os mecanismos da neurodegeneração bem como a aplicação do treinamento físico neste contexto neurogênico. 


\section{CONCLUSÃO}

De acordo com os resultados obtidos pode-se sugerir que o protocolo de exercício físico forçado, de baixa a moderada intensidade, além de identificar alterações na capacidade máxima individual proporcionada pelo exercício, promoveu mudanças metabólicas musculares relacionas ao exercício indicando efetividade ao término do treinamento.

Verificou-se ainda que a exposição subcutânea a baixas doses de rotenona, $1 \mathrm{mg} / \mathrm{kg} / \mathrm{dia}$, parece não elevar os níveis de proteínas a níveis de agregados.

Por fim, que o treinamento físico parece reverter ou prevenir de maneira geral os danos presente na neurodegeneração considerando as proteínas do tráfego de neurotrofinas e seus receptores, e ainda, que a magnitude e direção destas alterações esta diretamente relacionada ao tempo de treinamento físico, e o momento em que o mesmo foi aplicado, bem como, a área analisada. 


\section{REFERÊNCIAS BIBLIOGRÁFICAS}

$1 \quad$ U.N. Population Ageing and Development 2009.

2 UNIDAS, F. D. P. D. N. Relatório sobre a Situação da População Mundial 2011. 2011.

3 IBGE. "Número de idosos no Brasil vai quadruplicar até 2060". http://www.bbc.co.uk/portuguese/noticias/2013/08/130829 demografia ibge po pulacao brasil lgb.shtml: IBGE 2010.

4 ASSIS, E. L.; RABELO, H. T. Percepção da capacidade funcional de mulheres idosas praticantes de hidroginástica. . Movimentum - Revista Digital de Educação Física - Ipatinga, v. V.1, ago-dez 2006.

5 HERNANDES, E. S. C.; BARROS, J. F. Efeitos de um programa de atividades físicas e educacionais para idosos sobre o desempenho em testes de atividades da vida diária. R. Bras. Ci. e Mov., v. 12, n. 2, p. 43-50, 2004.

6 QIU, C.; KIVIPELTO, M.; VON STRAUSS, E. Epidemiology of Alzheimer's disease: occurrence, determinants, and strategies toward intervention. Dialogues Clin Neurosci, v. 11, n. 2, p. 111-28, 2009. ISSN 12948322 (Print)

1294-8322

(Linking).

Disponível

em:

http://www.ncbi.nlm.nih.gov/pubmed/19585947 >.

7 HERRERA E, C. P., NITRINI R. . Estudo epidemiológico populacional de demência na cidade de Catanduva, Estado de São Paulo, Brazil. . Rev Psiquiatr Clin, v. 25, p. 70-73, 1998.

$8 \quad$ Alzheimer's Association Alzheimer's Disease Facts and Figures, 2011. Disponível em: < http://www.alz.org/downloads/facts figures 2011.pdf $>$. Acesso em: 30/01/2014.

$9 \quad$ Alzheimer's Association. Alzheimer's Disease Facts and Figures, 2007. Disponível em:

$<$

https://www.alz.org/national/documents/report 2007factsandfigures.pdf $>$. Acesso em: 30/01/2014.

10 MAYEUX, R. Epidemiology of neurodegeneration. Annu Rev Neurosci, v. 26, p. 81-104, 2003. ISSN 0147-006X (Print) 
0147-006X

(Linking).

Disponível

em: $<$

http://www.ncbi.nlm.nih.gov/pubmed/12574495 >.

11 BARBOSA, M. T. et al. Parkinsonism and Parkinson's disease in the elderly: a community-based survey in Brazil (the Bambui study). Mov Disord, v. 21, n. 6, p. 800-8, Jun 2006. ISSN 0885-3185 (Print)

0885-3185 (Linking). Disponível em: <
http://www.ncbi.nlm.nih.gov/pubmed/16482566 > .

12 SELKOE, D. J. The deposition of amyloid proteins in the aging mammalian brain: implications for Alzheimer's disease. Ann Med, v. 21, n. 2, p. 73-6, 1989. ISSN 0785-3890 (Print)

0785-3890 (Linking). Disponível em: < http://www.ncbi.nlm.nih.gov/pubmed/2504258 >.

13 HARDY, J.; SELKOE, D. J. The amyloid hypothesis of Alzheimer's disease: progress and problems on the road to therapeutics. Science, v. 297, n. 5580, p. 353-6, Jul 19 2002. ISSN 1095-9203 (Electronic)

0036-8075 (Linking). Disponível em: < http://www.ncbi.nlm.nih.gov/pubmed/12130773 >.

14 GIBB, W. R.; LEES, A. J. The relevance of the Lewy body to the pathogenesis of idiopathic Parkinson's disease. J Neurol Neurosurg Psychiatry, v. 51, n. 6, p. 745-52, Jun 1988. ISSN 0022-3050 (Print). Disponível em: < http://www.ncbi.nlm.nih.gov/entrez/query.fcgi?cmd=Retrieve\&db=PubMed\&dopt $=$ Citation\&list uids $=2841426>$.

15 DAYAN, A. D. Quantitative histological studies on the aged human brain. I. Senile plaques and neurofibrillary tangles in "normal" patients. Acta Neuropathol, v. 16, n. 2, p. 85-94, 1970. ISSN 0001-6322 (Print)

0001-6322 (Linking). Disponível em: < http://www.ncbi.nlm.nih.gov/pubmed/4919692 >.

16 CALIK, M. W.; SHANKARAPPA, S. A.; STUBBS, E. B., JR. Forcedexercise attenuates experimental autoimmune neuritis. Neurochem Int, v. 61, n. 2, p. 141-5, Jul 2012. ISSN 1872-9754 (Electronic) 0197-0186 (Linking). Disponível em: < http://www.ncbi.nlm.nih.gov/pubmed/22569066 >.

17 TAKAHASHI, R. H. et al. Alzheimer beta-amyloid peptides: normal and abnormal localization. Histol Histopathol, v. 17, n. 1, p. 239-46, Jan 2002. ISSN 0213-3911 (Print) 
0213-3911

(Linking).

Disponível

em: $<$

http://www.ncbi.nlm.nih.gov/pubmed/11813874 >.

18 OHAMA, E.; IKUTA, F. Parkinson's disease: distribution of Lewy bodies and monoamine neuron system. Acta Neuropathol, v. 34, n. 4, p. 311-9, Apr 26 1976. ISSN 0001-6322 (Print)

0001-6322 (Linking). Disponível em: < http://www.ncbi.nlm.nih.gov/pubmed/179263 >.

19 OYANAGI, K. et al. Lewy bodies in the lower sacral parasympathetic neurons of a patient with Parkinson's disease. Acta Neuropathol, v. 80, n. 5, p. 558-9, 1990. ISSN 0001-6322 (Print)

0001-6322 (Linking). Disponível em: < http://www.ncbi.nlm.nih.gov/pubmed/2251914 >.

20 KAKITA, A. et al. Lewy bodies in the cerebellar dentate nucleus of a patient with Parkinson's disease. Pathol Int, v. 44, n. 12, p. 878-80, Dec 1994. ISSN 1320-5463 (Print)

1320-5463 (Linking). Disponível em: <
http://www.ncbi.nlm.nih.gov/pubmed/7866573 >.

21 WAKABAYASHI, K.; TAKAHASHI, H. Neuropathology of autonomic nervous system in Parkinson's disease. Eur Neurol, v. 38 Suppl 2, p. 2-7, 1997. ISSN 0014-3022 (Print)

0014-3022 (Linking). Disponível em: < http://www.ncbi.nlm.nih.gov/pubmed/9387796 >.

22 ALONSO ADEL, C. et al. Polymerization of hyperphosphorylated tau into filaments eliminates its inhibitory activity. Proc Natl Acad Sci U S A, v. 103, n. 23, p. 8864-9, Jun 6 2006. ISSN 0027-8424 (Print)

0027-8424 (Linking). Disponível em: < http://www.ncbi.nlm.nih.gov/pubmed/16735465 >.

23 GISPERT-SANCHEZ, S.; AUBURGER, G. The role of protein aggregates in neuronal pathology: guilty, innocent, or just trying to help? $\mathrm{J}$ Neural Transm Suppl, n. 70, p. 111-7, 2006. ISSN 0303-6995 (Print)

0303-6995 (Linking). Disponível em: < http://www.ncbi.nlm.nih.gov/pubmed/17017517 >.

24 CHURCHER, I. Tau therapeutic strategies for the treatment of Alzheimer's disease. Curr Top Med Chem, v. 6, n. 6, p. 579-95, 2006. ISSN 1568-0266 (Print) 
1568-0266

(Linking).

Disponível

em:

http://www.ncbi.nlm.nih.gov/entrez/query.fcgi?cmd=Retrieve\&db=PubMed\&dopt $=$ Citation\&list uids $=16712493>$.

25 EBNETH, A. et al. Overexpression of tau protein inhibits kinesindependent trafficking of vesicles, mitochondria, and endoplasmic reticulum: implications for Alzheimer's disease. J Cell Biol, v. 143, n. 3, p. 777-94, Nov 2 1998. ISSN 0021-9525 (Print). Disponível em: < http://www.ncbi.nlm.nih.gov/entrez/query.fcgi?cmd=Retrieve\&db=PubMed\&dopt $=$ Citation\&list uids $=9813097>$.

26 BENDISKE, J. et al. Intracellular deposition, microtubule destabilization, and transport failure: an "early" pathogenic cascade leading to synaptic decline. J Neuropathol Exp Neurol, v. 61, n. 7, p. 640-50, Jul 2002. ISSN 0022-3069 (Print).

Disponível em:

$<$ http://www.ncbi.nlm.nih.gov/entrez/query.fcgi?cmd=Retrieve\&db=PubMed\&dopt $=$ Citation\&list uids $=12125743>$.

27 PERLSON, E. et al. Retrograde axonal transport: pathways to cell death? Trends Neurosci, v. 33, n. 7, p. 335-44, Jul 2010. ISSN 1878-108X (Electronic)

0166-2236

(Linking).

Disponível

em:

http://www.ncbi.nlm.nih.gov/pubmed/20434225 >.

28 MILLECAMPS, S.; JULIEN, J. P. Axonal transport deficits and neurodegenerative diseases. Nat Rev Neurosci, v. 14, n. 3, p. 161-76, Mar 2013. ISSN 1471-0048 (Electronic)

1471-003X (Linking). Disponível em: < http://www.ncbi.nlm.nih.gov/pubmed/23361386 >.

29 PIGINO, G. et al. Alzheimer's presenilin 1 mutations impair kinesinbased axonal transport. J Neurosci, v. 23, n. 11, p. 4499-508, Jun 1 2003. ISSN 1529-2401 (Electronic)

0270-6474 (Linking). Disponível em: < http://www.ncbi.nlm.nih.gov/pubmed/12805290 >.

30 WAGNER, U. et al. Cellular phosphorylation of tau by GSK-3 beta influences tau binding to microtubules and microtubule organisation. J Cell Sci, v. 109 ( Pt 6), p. 1537-43, Jun 1996. ISSN $0021-9533$ (Print)

0021-9533 (Linking). Disponível em: < http://www.ncbi.nlm.nih.gov/pubmed/8799840 >. 
SEITZ, A. et al. Single-molecule investigation of the interference between kinesin, tau and MAP2c. EMBO J, v. 21, n. 18, p. 4896-905, Sep 16 2002. ISSN 0261-4189 (Print)

0261-4189 (Linking). Disponível em: < http://www.ncbi.nlm.nih.gov/pubmed/12234929 >.

32 LAPOINTE, N. E. et al. The amino terminus of tau inhibits kinesindependent axonal transport: implications for filament toxicity. J Neurosci Res, v. 87, n. 2, p. 440-51, Feb 2009. ISSN 1097-4547 (Electronic) 0360-4012 (Linking).
Disponível
em:
$<$ http://www.ncbi.nlm.nih.gov/pubmed/18798283 >.

33 MORFINI, G. A. et al. Pathogenic huntingtin inhibits fast axonal transport by activating JNK3 and phosphorylating kinesin. Nat Neurosci, v. 12, n. 7, p. 864-71, Jul 2009. ISSN 1546-1726 (Electronic)

1097-6256 (Linking). Disponível em: < http://www.ncbi.nlm.nih.gov/pubmed/19525941 >.

34 MELO, T. Q. et al. Rotenone-dependent changes of anterograde motor protein expression and mitochondrial mobility in brain areas related to neurodegenerative diseases. Cell Mol Neurobiol, v. 33, n. 3, p. 327-35, Apr 2013. ISSN 1573-6830 (Electronic)

0272-4340 (Linking). Disponível em: < http://www.ncbi.nlm.nih.gov/pubmed/23263842 >.

35 BIGAARD, J. et al. Waist circumference and body composition in relation to all-cause mortality in middle-aged men and women. Int $\mathrm{J}$ Obes (Lond), v. 29, n. 7, p. 778-84, Jul 2005. ISSN 0307-0565 (Print)

0307-0565 (Linking). Disponível em: < http://www.ncbi.nlm.nih.gov/pubmed/15917857 >.

36 HEITMANN, B. L. et al. Mortality associated with body fat, fat-free mass and body mass index among 60-year-old swedish men-a 22-year follow-up. The study of men born in 1913. Int J Obes Relat Metab Disord, v. 24, n. 1, p. 33-7, Jan 2000. ISSN 0307-0565 (Print)

0307-0565 (Linking). Disponível em: < http://www.ncbi.nlm.nih.gov/pubmed/10702748 >.

37 BARLOW, C. E. et al. Cardiorespiratory fitness is an independent predictor of hypertension incidence among initially normotensive healthy women. Am J Epidemiol, v. 163, n. 2, p. 142-50, Jan 15 2006. ISSN 0002-9262 (Print) 
0002-9262

(Linking).

Disponível

em: $<$

http://www.ncbi.nlm.nih.gov/pubmed/16293717 >.

38 BLAIR, S. N.; CHENG, Y.; HOLDER, J. S. Is physical activity or physical fitness more important in defining health benefits? Med Sci Sports Exerc, v. 33, n. 6 Suppl, p. S379-99; discussion S419-20, Jun 2001. ISSN 0195-9131 (Print) 0195-9131 (Linking). Disponível em: < http://www.ncbi.nlm.nih.gov/pubmed/11427763 >.

$39 \mathrm{CHURCH}, \mathrm{T}$. S. et al. Cardiorespiratory fitness and body mass index as predictors of cardiovascular disease mortality among men with diabetes. Arch Intern Med, v. 165, n. 18, p. 2114-20, Oct 10 2005. ISSN 0003-9926 (Print) 0003-9926 (Linking). Disponível em: < http://www.ncbi.nlm.nih.gov/pubmed/16217001 >.

40 GALE, C. R. et al. Grip strength, body composition, and mortality. Int J Epidemiol, v. 36, n. 1, p. 228-35, Feb 2007. ISSN 0300-5771 (Print) 0300-5771 (Linking). Disponível em: < http://www.ncbi.nlm.nih.gov/pubmed/17056604 >.

41 JURCA, R. et al. Association of muscular strength with incidence of metabolic syndrome in men. Med Sci Sports Exerc, v. 37, n. 11, p. 1849-55, Nov 2005. ISSN 0195-9131 (Print)

0195-9131 (Linking). Disponível em: < http://www.ncbi.nlm.nih.gov/pubmed/16286852 >.

42 NEWMAN, A. B. et al. Strength, but not muscle mass, is associated with mortality in the health, aging and body composition study cohort. J Gerontol A Biol Sci Med Sci, v. 61, n. 1, p. 72-7, Jan 2006. ISSN 1079-5006 (Print) 1079-5006 (Linking). Disponível em: < http://www.ncbi.nlm.nih.gov/pubmed/16456196 >.

43 POLLOCK, M. L. et al. AHA Science Advisory. Resistance exercise in individuals with and without cardiovascular disease: benefits, rationale, safety, and prescription: An advisory from the Committee on Exercise, Rehabilitation, and Prevention, Council on Clinical Cardiology, American Heart Association; Position paper endorsed by the American College of Sports Medicine. Circulation, v. 101, n. 7, p. 828-33, Feb 22 2000. ISSN 1524-4539 (Electronic) 0009-7322 (Linking). Disponível em: < http://www.ncbi.nlm.nih.gov/pubmed/10683360 >.

44 SLENTZ, C. A. et al. Inactivity, exercise training and detraining, and plasma lipoproteins. STRRIDE: a randomized, controlled study of exercise 
intensity and amount. J Appl Physiol (1985), v. 103, n. 2, p. 432-42, Aug 2007. ISSN 8750-7587 (Print)

0161-7567 (Linking). Disponível em: < http://www.ncbi.nlm.nih.gov/pubmed/17395756 >.

45 LEE, D. C. et al. Comparisons of leisure-time physical activity and cardiorespiratory fitness as predictors of all-cause mortality in men and women. Br J Sports Med, v. 45, n. 6, p. 504-10, May 2011. ISSN 1473-0480 (Electronic) 0306-3674 (Linking). Disponível em: < http://www.ncbi.nlm.nih.gov/pubmed/20418526 >.

46 MCAULEY, P. et al. Cardiorespiratory fitness and mortality in diabetic men with and without cardiovascular disease. Diabetes Res Clin Pract, v. 85, n. 3, p. e30-3, Sep 2009. ISSN 1872-8227 (Electronic) 0168-8227 (Linking). Disponível http://www.ncbi.nlm.nih.gov/pubmed/19524317 >.

47 MYERS, J. et al. Exercise capacity and mortality among men referred for exercise testing. N Engl J Med, v. 346, n. 11, p. 793-801, Mar 14 2002. ISSN 1533-4406 (Electronic)

0028-4793 (Linking). Disponível em: < http://www.ncbi.nlm.nih.gov/pubmed/11893790 >.

48 SUI, X.; LAMONTE, M. J.; BLAIR, S. N. Cardiorespiratory fitness and risk of nonfatal cardiovascular disease in women and men with hypertension. Am $\mathrm{J}$ Hypertens, v. 20, n. 6, p. 608-15, Jun 2007. ISSN 0895-7061 (Print) 0895-7061 (Linking). Disponível em: < http://www.ncbi.nlm.nih.gov/pubmed/17531916 >.

$49 \quad$ JIA, L. L. et al. Exercise training attenuates hypertension and cardiac hypertrophy by modulating neurotransmitters and cytokines in hypothalamic paraventricular nucleus. PLoS One, v. 9, n. 1, p. e85481, Jan 10 2014. ISSN 1932-6203 (Electronic)

1932-6203 (Linking). Disponível em: < http://www.ncbi.nlm.nih.gov/pubmed/24482680 > .

50 BABU, A. S.; PADMAKUMAR, R.; MAIYA, A. G. A review of ongoing trials in exercise based rehabilitation for pulmonary arterial hypertension. Indian J Med Res, v. 137, n. 5, p. 900-6, May 2013. ISSN 0971-5916 (Print)

0971-5916 (Linking). Disponível em: < http://www.ncbi.nlm.nih.gov/pubmed/23760374 >. 

and Therapy: Experimental Findings and Molecular Mechanisms. Biomed Res Int, v. 2013, p. 805217, 2013. ISSN 2314-6141 (Electronic). Disponível em: < http://www.ncbi.nlm.nih.gov/pubmed/24455726 >.

52 WOOD, R. J.; O'NEILL, E. C. Resistance Training in Type II Diabetes Mellitus: Impact on Areas of Metabolic Dysfunction in Skeletal Muscle and Potential Impact on Bone. J Nutr Metab, v. 2012, p. 268197, 2012. ISSN 20900732 (Electronic)

2090-0724 (Linking). Disponível em: < http://www.ncbi.nlm.nih.gov/pubmed/22474580 >.

53 SAKURAI, T. et al. The Effects of Exercise Training on Obesity-Induced Dysregulated Expression of Adipokines in White Adipose Tissue. Int $\mathrm{J}$ Endocrinol, v. 2013, p. 801743, 2013. ISSN 1687-8337 (Print)

1687-8337 (Linking). Disponível em: < http://www.ncbi.nlm.nih.gov/pubmed/24369466 >.

54 SAKURAI, T. et al. Preventive and improvement effects of exercise training and supplement intake in white adipose tissues on obesity and lifestylerelated diseases. Environ Health Prev Med, v. 17, n. 5, p. 348-56, Sep 2012. ISSN 1347-4715 (Electronic)

1342-078X (Linking). Disponível em: < http://www.ncbi.nlm.nih.gov/pubmed/22362099 >.

55 PALOMBARO, K. M. et al. Effectiveness of exercise for managing osteoporosis in women postmenopause. Phys Ther, v. 93, n. 8, p. 1021-5, Aug 2013. ISSN 1538-6724 (Electronic)
0031-9023
(Linking).
Disponível
em: $\quad<$

http://www.ncbi.nlm.nih.gov/pubmed/23704034 >.

56 DE KAM, D. et al. Exercise interventions to reduce fall-related fractures and their risk factors in individuals with low bone density: a systematic review of randomized controlled trials. Osteoporos Int, v. 20, n. 12, p. 2111-25, Dec 2009. ISSN 1433-2965 (Electronic)

0937-941X (Linking). Disponível em: < http://www.ncbi.nlm.nih.gov/pubmed/19421702 >.

$57 \quad$ BASSETT, D. R., JR. et al. Validity of four motion sensors in measuring moderate intensity physical activity. Med Sci Sports Exerc, v. 32, n. 9 Suppl, p. S471-80, Sep 2000. ISSN 0195-9131 (Print)

0195-9131 (Linking). Disponível em: < http://www.ncbi.nlm.nih.gov/pubmed/10993417 >. 
PITKALA, K. et al. Efficacy of physical exercise intervention on mobility and physical functioning in older people with dementia: a systematic review. Exp Gerontol, v. 48, n. 1, p. 85-93, Jan 2013. ISSN 1873-6815 (Electronic) 0531-5565 (Linking). Disponível em: < http://www.ncbi.nlm.nih.gov/pubmed/22960590 >.

59 POTTER, R. et al. A systematic review of the effects of physical activity on physical functioning, quality of life and depression in older people with dementia. Int J Geriatr Psychiatry, v. 26, n. 10, p. 1000-11, Oct 2011. ISSN 1099-1166 (Electronic)

0885-6230 (Linking). Disponível em: < http://www.ncbi.nlm.nih.gov/pubmed/21905096 > .

60 LITTBRAND, H.; STENVALL, M.; ROSENDAHL, E. Applicability and effects of physical exercise on physical and cognitive functions and activities of daily living among people with dementia: a systematic review. Am J Phys Med Rehabil, v. 90, n. 6, p. 495-518, Jun 2011. ISSN 1537-7385 (Electronic)

0894-9115 (Linking). Disponível em: < http://www.ncbi.nlm.nih.gov/pubmed/21430516 >.

61 COlBERT, L. H.; HOOTMAN, J. M.; MACERA, C. A. Physical activityrelated injuries in walkers and runners in the aerobics center longitudinal study. Clin J Sport Med, v. 10, n. 4, p. 259-63, Oct 2000. ISSN 1050-642X (Print) 1050-642X (Linking). Disponível em: < http://www.ncbi.nlm.nih.gov/pubmed/11086751 >.

62 OELAND, A. M. et al. Impact of exercise on patients with depression and anxiety. Nord J Psychiatry, v. 64, n. 3, p. 210-7, May 4 2010. ISSN 1502-4725 (Electronic)

0803-9488 (Linking). Disponível em: < http://www.ncbi.nlm.nih.gov/pubmed/20100135 >.

63 THOMPSON, P. D. et al. Exercise and physical activity in the prevention and treatment of atherosclerotic cardiovascular disease: a statement from the Council on Clinical Cardiology (Subcommittee on Exercise, Rehabilitation, and Prevention) and the Council on Nutrition, Physical Activity, and Metabolism (Subcommittee on Physical Activity). Circulation, v. 107, n. 24, p. 3109-16, Jun 24 2003. ISSN 1524-4539 (Electronic)

0009-7322 (Linking). Disponível em: < http://www.ncbi.nlm.nih.gov/pubmed/12821592 > 

status. Med Sci Sports Exerc, v. 33, n. 6 Suppl, p. S622-34; discussion S640-1, Jun 2001. ISSN 0195-9131 (Print)

0195-9131 (Linking). Disponível em: < http://www.ncbi.nlm.nih.gov/pubmed/11427787 >.

65 GARBER, C. E. et al. American College of Sports Medicine position stand. Quantity and quality of exercise for developing and maintaining cardiorespiratory, musculoskeletal, and neuromotor fitness in apparently healthy adults: guidance for prescribing exercise. Med Sci Sports Exerc, v. 43, n. 7, p. 1334-59, Jul 2011. ISSN 1530-0315 (Electronic)
0195-9131
(Linking).
Disponível
em:

http://www.ncbi.nlm.nih.gov/pubmed/21694556 > .

66 CHODZKO-ZAJKO, W. J. et al. American College of Sports Medicine position stand. Exercise and physical activity for older adults. Med Sci Sports Exerc, v. 41, n. 7, p. 1510-30, Jul 2009. ISSN 1530-0315 (Electronic)

0195-9131 (Linking). Disponível em: < http://www.ncbi.nlm.nih.gov/pubmed/19516148 >.

67 DUNN, A. L. et al. Exercise treatment for depression: efficacy and dose response. Am J Prev Med, v. 28, n. 1, p. 1-8, Jan 2005. ISSN 0749-3797 (Print) 0749-3797 (Linking). Disponível em: < http://www.ncbi.nlm.nih.gov/pubmed/15626549 >.

68 GILLISON, F. B. et al. The effects of exercise interventions on quality of life in clinical and healthy populations; a meta-analysis. Soc Sci Med, v. 68, n. 9, p. 1700-10, May 2009. ISSN 1873-5347 (Electronic)

0277-9536 (Linking). Disponível em: <
http://www.ncbi.nlm.nih.gov/pubmed/19297065 >.

69 PATEL, B. P.; HAMADEH, M. J. Nutritional and exercise-based interventions in the treatment of amyotrophic lateral sclerosis. Clin Nutr, v. 28, n. 6, p. 604-17, Dec 2009. ISSN 1532-1983 (Electronic)

0261-5614 (Linking). Disponível em: < http://www.ncbi.nlm.nih.gov/pubmed/19782443 >.

70 PLOUGHMAN, M. Exercise is brain food: the effects of physical activity on cognitive function. Dev Neurorehabil, v. 11, n. 3, p. 236-40, Jul 2008. ISSN 1751-8431 (Electronic)
1751-8423
(Linking).
Disponível
em:

http://www.ncbi.nlm.nih.gov/pubmed/18781504 >. 
KRAMER, A. F. et al. Ageing, fitness and neurocognitive function. Nature, v. 400, n. 6743, p. 418-9, Jul 29 1999. ISSN 0028-0836 (Print)

0028-0836 (Linking). Disponível em: < http://www.ncbi.nlm.nih.gov/pubmed/10440369 >.

$72 \mathrm{KUBESCH}$, S. et al. Aerobic endurance exercise improves executive functions in depressed patients. J Clin Psychiatry, v. 64, n. 9, p. 1005-12, Sep 2003. ISSN 0160-6689 (Print)

0160-6689 (Linking). Disponível em: < http://www.ncbi.nlm.nih.gov/pubmed/14628975 >.

73 MCMORRIS, T. et al. A test of the catecholamines hypothesis for an acute exercise-cognition interaction. Pharmacol Biochem Behav, v. 89, n. 1, p. 106-15, Mar 2008. ISSN 0091-3057 (Print)

0091-3057

(Linking).

Disponível

em:

$<$

http://www.ncbi.nlm.nih.gov/pubmed/18164752 >.

$74 \quad \mathrm{KINNI}, \mathrm{H}$. et al. Cerebral metabolism after forced or voluntary physical exercise. Brain Res, v. 1388, p. 48-55, May 4 2011. ISSN 1872-6240 (Electronic)

0006-8993

(Linking).

Disponível

em:

$<$

http://www.ncbi.nlm.nih.gov/pubmed/21396919 >.

75 GRAFF-RADFORD, N. R. Can aerobic exercise protect against dementia? Alzheimers Res Ther, v. 3, n. 1, p. 6, 2011. ISSN 1758-9193 (Electronic). Disponível em: < http://www.ncbi.nlm.nih.gov/pubmed/21392412 >.

76 ERICKSON, K. I.; MILLER, D. L.; ROECKLEIN, K. A. The aging hippocampus: interactions between exercise, depression, and BDNF. Neuroscientist, v. 18, n. 1, p. 82-97, Feb 2012. ISSN 1089-4098 (Electronic)

1073-8584 (Linking). Disponível em: < http://www.ncbi.nlm.nih.gov/pubmed/21531985 >.

77 MOLTENI, R.; YING, Z.; GOMEZ-PINILLA, F. Differential effects of acute and chronic exercise on plasticity-related genes in the rat hippocampus revealed by microarray. Eur J Neurosci, v. 16, n. 6, p. 1107-16, Sep 2002. ISSN 0953-816X (Print)

0953-816X

(Linking).

Disponível

em:

http://www.ncbi.nlm.nih.gov/pubmed/12383240 >.

78 BENRAISS, A. et al. Adenoviral brain-derived neurotrophic factor induces both neostriatal and olfactory neuronal recruitment from endogenous 
progenitor cells in the adult forebrain. J Neurosci, v. 21, n. 17, p. 6718-31, Sep 1 2001. ISSN 1529-2401 (Electronic)

0270-6474 (Linking). Disponível em: < http://www.ncbi.nlm.nih.gov/pubmed/11517261 >.

$79 \mathrm{CHAO}, \mathrm{M}$. V. Neurotrophins and their receptors: a convergence point for many signalling pathways. Nat Rev Neurosci, v. 4, n. 4, p. 299-309, Apr 2003. ISSN 1471-003X (Print)

1471-003X (Linking). Disponível em: < http://www.ncbi.nlm.nih.gov/pubmed/12671646 >.

80 VICARIO-ABEJON, C. et al. Neurotrophins induce formation of functional excitatory and inhibitory synapses between cultured hippocampal neurons. J Neurosci, v. 18, n. 18, p. 7256-71, Sep 15 1998. ISSN 0270-6474 (Print)

0270-6474 (Linking). Disponível em: < http://www.ncbi.nlm.nih.gov/pubmed/9736647 >.

$81 \mathrm{JI}$, Y. et al. Cyclic AMP controls BDNF-induced TrkB phosphorylation and dendritic spine formation in mature hippocampal neurons. Nat Neurosci, v. 8, n. 2, p. 164-72, Feb 2005. ISSN 1097-6256 (Print)

1097-6256 (Linking). Disponível em: <
http://www.ncbi.nlm.nih.gov/pubmed/15665879 >

$82 \mathrm{MU}$, J. S. et al. Deprivation of endogenous brain-derived neurotrophic factor results in impairment of spatial learning and memory in adult rats. Brain Res, v. 835, n. 2, p. 259-65, Jul 24 1999. ISSN 0006-8993 (Print)

0006-8993 (Linking). Disponível em: < http://www.ncbi.nlm.nih.gov/pubmed/10415381 >.

83 LEE, J. G. et al. Decreased serum brain-derived neurotrophic factor levels in elderly korean with dementia. Psychiatry Investig, v. 6, n. 4, p. 299305, Dec 2009. ISSN 1976-3026 (Electronic)
1738-3684
(Linking).
Disponível
em:

http://www.ncbi.nlm.nih.gov/pubmed/20140129 > .

84 DIOGENES, M. J. et al. Influence of age on BDNF modulation of hippocampal synaptic transmission: interplay with adenosine A2A receptors. Hippocampus, v. 17, n. 7, p. 577-85, 2007. ISSN 1050-9631 (Print) 1050-9631 (Linking). Disponível em: < http://www.ncbi.nlm.nih.gov/pubmed/17421024 >. 
WEBSTER, M. J. et al. BDNF and trkB mRNA expression in the hippocampus and temporal cortex during the human lifespan. Gene Expr Patterns, v. 6, n. 8, p. 941-51, Oct 2006. ISSN 1567-133X (Print)

1567-133X (Linking). Disponível em: < http://www.ncbi.nlm.nih.gov/pubmed/16713371 >.

86 CROLL, S. D. et al. Expression of BDNF and trkB as a function of age and cognitive performance. Brain Res, v. 812, n. 1-2, p. 200-8, Nov 231998. ISSN 0006-8993 (Print)

0006-8993 (Linking). Disponível em: < http://www.ncbi.nlm.nih.gov/pubmed/9813325 >.

87 LUELLEN, B. A. et al. Reduced brain-derived neurotrophic factor is associated with a loss of serotonergic innervation in the hippocampus of aging mice. Genes Brain Behav, v. 6, n. 5, p. 482-90, Jul 2007. ISSN 1601-1848 (Print)

1601-183X (Linking). Disponível em: < http://www.ncbi.nlm.nih.gov/pubmed/17156118 >.

88 ERICKSON, K. I. et al. Exercise training increases size of hippocampus and improves memory. Proc Natl Acad Sci U S A, v. 108, n. 7, p. 3017-22, Feb 15 2011. ISSN 1091-6490 (Electronic)

0027-8424 (Linking). Disponível em: < http://www.ncbi.nlm.nih.gov/pubmed/21282661 >.

89 OGONOVSZKY, $\mathrm{H}$. et al. The effects of moderate-, strenuous- and overtraining on oxidative stress markers, DNA repair, and memory, in rat brain. Neurochem Int, v. 46, n. 8, p. 635-40, Jun 2005. ISSN 0197-0186 (Print)

0197-0186 (Linking). Disponível em: < http://www.ncbi.nlm.nih.gov/pubmed/15863241 >.

90 MARAIS, L.; STEIN, D. J.; DANIELS, W. M. Exercise increases BDNF levels in the striatum and decreases depressive-like behavior in chronically stressed rats. Metab Brain Dis, v. 24, n. 4, p. 587-97, Dec 2009. ISSN 15737365 (Electronic)

0885-7490 (Linking). Disponível em: < http://www.ncbi.nlm.nih.gov/pubmed/19844781 >.

91 CARRO, E. et al. Circulating insulin-like growth factor I mediates the protective effects of physical exercise against brain insults of different etiology and anatomy. J Neurosci, v. 21, n. 15, p. 5678-84, Aug 1 2001. ISSN 15292401 (Electronic) 
0270-6474

(Linking).

Disponível

em: $<$

http://www.ncbi.nlm.nih.gov/pubmed/11466439 >.

92 PLOUGHMAN, M. et al. Exercise intensity influences the temporal profile of growth factors involved in neuronal plasticity following focal ischemia. Brain Res, v. 1150, p. 207-16, May 30 2007. ISSN 0006-8993 (Print) 0006-8993 (Linking). Disponível em: http://www.ncbi.nlm.nih.gov/pubmed/17382914 >.

93 STENMARK, H. Rab GTPases as coordinators of vesicle traffic. Nat Rev Mol Cell Biol, v. 10, n. 8, p. 513-25, Aug 2009. ISSN 1471-0080 (Electronic) 1471-0072 (Linking). Disponível em: < http://www.ncbi.nlm.nih.gov/pubmed/19603039 >.

94 ARIMURA, N. et al. Anterograde transport of TrkB in axons is mediated by direct interaction with SIp1 and Rab27. Dev Cell, v. 16, n. 5, p. 675-86, May 2009. ISSN 1878-1551 (Electronic)

1534-5807 (Linking). Disponível em: < http://www.ncbi.nlm.nih.gov/pubmed/19460344 >.

95 MAJAVA, V. et al. Crystal and solution structure, stability and posttranslational modifications of collapsin response mediator protein 2. FEBS J, v. 275, n. 18, p. 4583-96, Sep 2008. ISSN 1742-464X (Print)
$1742-464 X$
(Linking).
Disponível
em:

http://www.ncbi.nlm.nih.gov/pubmed/18699782 >.

96 KANNINEN, K. et al. Glycosylation changes in Alzheimer's disease as revealed by a proteomic approach. Neurosci Lett, v. 367, n. 2, p. 235-40, Sep 2 2004. ISSN 0304-3940 (Print)

0304-3940 (Linking). Disponível em: < http://www.ncbi.nlm.nih.gov/pubmed/15331161 >.

97 GU, Y.; HAMAJIMA, N.; IHARA, Y. Neurofibrillary tangle-associated collapsin response mediator protein-2 (CRMP-2) is highly phosphorylated on Thr-509, Ser-518, and Ser-522. Biochemistry, v. 39, n. 15, p. 4267-75, Apr 18 2000. ISSN 0006-2960 (Print)

0006-2960 (Linking). Disponível em: < http://www.ncbi.nlm.nih.gov/pubmed/10757975 >.

98 YANG, M. et al. Precursor of brain-derived neurotrophic factor (proBDNF) forms a complex with Huntingtin-associated protein-1 (HAP1) and sortilin that modulates proBDNF trafficking, degradation, and processing. J Biol Chem, v. 286, n. 18, p. 16272-84, May 6 2011. ISSN 1083-351X (Electronic) 
0021-9258

(Linking).

Disponível

em: $<$

http://www.ncbi.nlm.nih.gov/pubmed/21357693 >.

99 TWELVETREES, A. E. et al. Delivery of GABAARs to synapses is mediated by HAP1-KIF5 and disrupted by mutant huntingtin. Neuron, v. 65, n. 1, p. 53-65, Jan 14 2010. ISSN 1097-4199 (Electronic)

0896-6273 (Linking). Disponível em: <
http://www.ncbi.nlm.nih.gov/pubmed/20152113 >.

100 KITTLER, J. T. et al. Huntingtin-associated protein 1 regulates inhibitory synaptic transmission by modulating gamma-aminobutyric acid type $A$ receptor membrane trafficking. Proc Natl Acad Sci U S A, v. 101, n. 34, p. 12736-41, Aug 24 2004. ISSN 0027-8424 (Print)

0027-8424 (Linking). Disponível em: < http://www.ncbi.nlm.nih.gov/pubmed/15310851 >.

101 RONG, J. et al. Regulation of intracellular trafficking of huntingtinassociated protein-1 is critical for TrkA protein levels and neurite outgrowth. $J$ Neurosci, v. 26, n. 22, p. 6019-30, May 31 2006. ISSN 1529-2401 (Electronic) 0270-6474 (Linking). Disponível em: < http://www.ncbi.nlm.nih.gov/pubmed/16738245 >.

102 WU, L. L.; ZHOU, X. F. Huntingtin associated protein 1 and its functions. Cell Adh Migr, v. 3, n. 1, p. 71-6, Jan-Mar 2009. ISSN 1933-6926 (Electronic) 1933-6918 (Linking). Disponível em: < http://www.ncbi.nlm.nih.gov/pubmed/19262167 >.

103 SARRET, P. et al. Distribution of NTS3 receptor/sortilin mRNA and protein in the rat central nervous system. J Comp Neurol, v. 461, n. 4, p. 483505, Jul 7 2003. ISSN 0021-9967 (Print)

0021-9967 (Linking). Disponível em: < http://www.ncbi.nlm.nih.gov/pubmed/12746864 >.

104 NIELSEN, M. S. et al. The sortilin cytoplasmic tail conveys Golgiendosome transport and binds the VHS domain of the GGA2 sorting protein. EMBO J, v. 20, n. 9, p. 2180-90, May 1 2001. ISSN 0261-4189 (Print)

0261-4189 (Linking). Disponível em: < http://www.ncbi.nlm.nih.gov/pubmed/11331584 >.

105 CHEN, Z. Y. et al. Sortilin controls intracellular sorting of brain-derived neurotrophic factor to the regulated secretory pathway. J Neurosci, v. 25, n. 26, p. 6156-66, Jun 29 2005. ISSN 1529-2401 (Electronic) 
0270-6474

(Linking).

Disponível

em: $<$

http://www.ncbi.nlm.nih.gov/pubmed/15987945 >.

106 LOU, $\mathrm{H}$. et al. Sorting and activity-dependent secretion of BDNF require interaction of a specific motif with the sorting receptor carboxypeptidase e. Neuron, v. 45, n. 2, p. 245-55, Jan 20 2005. ISSN 0896-6273 (Print) 0896-6273 (Linking). Disponível em: http://www.ncbi.nlm.nih.gov/pubmed/15664176 > .

107 VALDEZ, G. et al. Pincher-mediated macroendocytosis underlies retrograde signaling by neurotrophin receptors. J Neurosci, v. 25, n. 21, p. 5236-47, May 25 2005. ISSN 1529-2401 (Electronic)

0270-6474 (Linking). Disponível

em: $\quad<$

http://www.ncbi.nlm.nih.gov/pubmed/15917464 >.

108 ZWEIFEL, L. S.; KURUVILLA, R.; GINTY, D. D. Functions and mechanisms of retrograde neurotrophin signalling. Nat Rev Neurosci, v. 6, n. 8, p. 615-25, Aug 2005. ISSN 1471-003X (Print)

1471-003X (Linking). Disponível em: < http://www.ncbi.nlm.nih.gov/pubmed/16062170 >.

109 PHILIPPIDOU, P. et al. Trk retrograde signaling requires persistent, Pincher-directed endosomes. Proc Natl Acad Sci U S A, v. 108, n. 2, p. 852-7, Jan 11 2011. ISSN 1091-6490 (Electronic)

0027-8424 (Linking). Disponível em: < http://www.ncbi.nlm.nih.gov/pubmed/21187387 >.

110 VON BARTHELD, C. S.; ALTICK, A. L. Multivesicular bodies in neurons: distribution, protein content, and trafficking functions. Prog Neurobiol, v. 93, n. 3, p. 313-40, Mar 2011. ISSN 1873-5118 (Electronic)

0301-0082 (Linking). Disponível em: < http://www.ncbi.nlm.nih.gov/pubmed/21216273 >.

111 HIROKAWA, N.; NIWA, S.; TANAKA, Y. Molecular motors in neurons: transport mechanisms and roles in brain function, development, and disease. Neuron, v. 68, n. 4, p. 610-38, Nov 18 2010. ISSN 1097-4199 (Electronic) 0896-6273 (Linking). Disponível http://www.ncbi.nlm.nih.gov/pubmed/21092854 >.

112 SHERER, T. B. et al. Subcutaneous rotenone exposure causes highly selective dopaminergic degeneration and alpha-synuclein aggregation. Exp Neurol, v. 179, n. 1, p. 9-16, Jan 2003. ISSN 0014-4886 (Print) 
0014-4886

(Linking).

Disponível

em: $<$

http://www.ncbi.nlm.nih.gov/pubmed/12504863 >.

113 HOGLINGER, G. U. et al. The mitochondrial complex I inhibitor rotenone triggers a cerebral tauopathy. J Neurochem, v. 95, n. 4, p. 930-9, Nov 2005. ISSN 0022-3042 (Print)

0022-3042 (Linking). Disponível em: <
http://www.ncbi.nlm.nih.gov/pubmed/16219024 >.

114 FENG, Y. et al. alpha-Synuclein redistributed and aggregated in rotenone-induced Parkinson's disease rats. Neurosci Bull, v. 22, n. 5, p. 288-93, Sep 2006. ISSN 1673-7067 (Print)

1995-8218 (Linking). Disponível em: < http://www.ncbi.nlm.nih.gov/pubmed/17690729 >.

115 DUKES, A. A.; KORWEK, K. M.; HASTINGS, T. G. The effect of endogenous dopamine in rotenone-induced toxicity in PC12 cells. Antioxid Redox Signal, v. 7, n. 5-6, p. 630-8, May-Jun 2005. ISSN 1523-0864 (Print)

1523-0864 (Linking). Disponível em: < http://www.ncbi.nlm.nih.gov/pubmed/15890007 >.

116 HUANG, J. et al. Involvement of glyceraldehyde-3-phosphate dehydrogenase in rotenone-induced cell apoptosis: relevance to protein misfolding and aggregation. Brain Res, v. 1279, p. 1-8, Jul 7 2009. ISSN 18726240 (Electronic)

0006-8993 (Linking). Disponível em: < http://www.ncbi.nlm.nih.gov/pubmed/19445904 >.

$117 \mathrm{CHOU}, \mathrm{A}$. P. et al. Mechanisms of rotenone-induced proteasome inhibition. Neurotoxicology, v. 31, n. 4, p. 367-72, Aug 2010. ISSN 1872-9711 (Electronic)

0161-813X (Linking). Disponível em: < http://www.ncbi.nlm.nih.gov/pubmed/20417232 >.

118 CHOI, W. S.; PALMITER, R. D.; XIA, Z. Loss of mitochondrial complex I activity potentiates dopamine neuron death induced by microtubule dysfunction in a Parkinson's disease model. J Cell Biol, v. 192, n. 5, p. 873-82, Mar 72011. ISSN 1540-8140 (Electronic)

0021-9525 (Linking). Disponível em: < http://www.ncbi.nlm.nih.gov/pubmed/21383081 >.

119 DIAZ-CORRALES, F. J. et al. Rotenone induces aggregation of gammatubulin protein and subsequent disorganization of the centrosome: relevance to 
formation of inclusion bodies and neurodegeneration. Neuroscience, v. 133, n. 1, p. 117-35, 2005. ISSN 0306-4522 (Print)

0306-4522

(Linking).

Disponível

em:

$<$

http://www.ncbi.nlm.nih.gov/pubmed/15893636 > .

120 ULLRICH, C.; HUMPEL, C. Rotenone induces cell death of cholinergic neurons in an organotypic co-culture brain slice model. Neurochem Res, v. 34, n. 12, p. 2147-53, Dec 2009. ISSN 1573-6903 (Electronic)

0364-3190 (Linking). Disponível em: < http://www.ncbi.nlm.nih.gov/pubmed/19495971 >.

121 CHAVES, R. S. et al. Protein aggregation containing beta-amyloid, alpha-synuclein and hyperphosphorylated tau in cultured cells of hippocampus, substantia nigra and locus coeruleus after rotenone exposure. BMC Neurosci, v. 11, p. 144, 2010. ISSN 1471-2202 (Electronic)

1471-2202 (Linking). Disponível em: < http://www.ncbi.nlm.nih.gov/pubmed/21067569 > .

122 PHINNEY, A. L. et al. Enhanced sensitivity of dopaminergic neurons to rotenone-induced toxicity with aging. Parkinsonism Relat Disord, v. 12, n. 4, p. 228-38, May 2006. ISSN 1353-8020 (Print)
1353-8020
(Linking).
Disponível
em:

http://www.ncbi.nlm.nih.gov/pubmed/16488175 >.

AMARAL, S. L. et al. Time course of training-induced microcirculatory changes and of vegf expression in skeletal muscles of spontaneously hypertensive female rats. Braz J Med Biol Res, v. 41, n. 5, p. 424-31, May 2008. ISSN 1414-431X (Electronic)

0100-879X (Linking). Disponível em: < http://www.ncbi.nlm.nih.gov/pubmed/18545815 >.

124 PAXINOS, G.; WATSON, C. The Rat Brain in Sterotaxic Coordinates. Academic Press, 2007. 456

125 BRADFORD, M. M. A rapid and sensitive method for the quantitation of microgram quantities of protein utilizing the principle of protein-dye binding. Anal Biochem, v. 72, p. 248-54, May 7 1976. ISSN 0003-2697 (Print)

0003-2697 (Linking). Disponível em: < http://www.ncbi.nlm.nih.gov/pubmed/942051 >.

SRERE, P. A. Citrate synthase. 1969. 
ALLENDOERFER, K. L. et al. Regulation of neurotrophin receptors during the maturation of the mammalian visual system. J Neurosci, v. 14, n. $3 \mathrm{Pt}$ 2, p. 1795-811, Mar 1994. ISSN 0270-6474 (Print)

0270-6474 (Linking). Disponível em: <
http://www.ncbi.nlm.nih.gov/pubmed/8126572 >.

128 SHERER, T. B. et al. Mechanism of toxicity in rotenone models of Parkinson's disease. J Neurosci, v. 23, n. 34, p. 10756-64, Nov 26 2003. ISSN 1529-2401 (Electronic)
0270-6474
(Linking).
Disponível
em:
$<$

http://www.ncbi.nlm.nih.gov/pubmed/14645467 >.

129 ALAM, M.; SCHMIDT, W. J. Mitochondrial complex I inhibition depletes plasma testosterone in the rotenone model of Parkinson's disease. Physiol Behav, v. 83, n. 3, p. 395-400, Dec 15 2004. ISSN 0031-9384 (Print)

0031-9384 (Linking). Disponível em: < http://www.ncbi.nlm.nih.gov/pubmed/15581661 >.

130 THAKUR, P.; NEHRU, B. Modulatory effects of sodium salicylate on the factors affecting protein aggregation during rotenone induced Parkinson's disease pathology. Neurochem Int, v. 75, p. 1-10, Sep 2014. ISSN 1872-9754 (Electronic)

0197-0186 (Linking). Disponível em: < http://www.ncbi.nlm.nih.gov/pubmed/24852355 >.

131 NEHRU, B. et al. Behavioral alterations in rotenone model of Parkinson's disease: attenuation by co-treatment of centrophenoxine. Brain Res, v. 1201, p. 122-7, Mar 27 2008. ISSN 0006-8993 (Print)

0006-8993 (Linking). Disponível em: < http://www.ncbi.nlm.nih.gov/pubmed/18308296 >.

132 CANNON, J. R. et al. A highly reproducible rotenone model of Parkinson's disease. Neurobiol Dis, v. 34, n. 2, p. 279-90, May 2009. ISSN 1095-953X (Electronic)

0969-9961 (Linking). Disponível em: < http://www.ncbi.nlm.nih.gov/pubmed/19385059 >.

133 ABDELSALAM, R. M.; SAFAR, M. M. Neuroprotective effects of vildagliptin in rat rotenone Parkinson's disease model: role of RAGE-NFkappaB and Nrf2-antioxidant signaling pathways. J Neurochem, Mar 5 2015. ISSN 1471-4159 (Electronic)

0022-3042 (Linking). Disponível em: < http://www.ncbi.nlm.nih.gov/pubmed/25752913 >. 

Parkinson's disease induced by rotenone. Exp Ther Med, v. 9, n. 2, p. 553-558, Feb 2015. ISSN 1792-0981 (Print)

1792-0981 (Linking).

Disponível

em: http://www.ncbi.nlm.nih.gov/pubmed/25574233 >.

135 DROLET, R. E. et al. Chronic rotenone exposure reproduces Parkinson's disease gastrointestinal neuropathology. Neurobiol Dis, v. 36, n. 1, p. 96-102, Oct 2009. ISSN 1095-953X (Electronic)

0969-9961 (Linking). Disponível em: <
http://www.ncbi.nlm.nih.gov/pubmed/19595768 >.

136 GREENE, J. G.; NOORIAN, A. R.; SRINIVASAN, S. Delayed gastric emptying and enteric nervous system dysfunction in the rotenone model of Parkinson's disease. Exp Neurol, v. 218, n. 1, p. 154-61, Jul 2009. ISSN 10902430 (Electronic)

0014-4886 (Linking). Disponível em: < http://www.ncbi.nlm.nih.gov/pubmed/19409896 > .

137 TASSELLI, M. et al. Effects of oral administration of rotenone on gastrointestinal functions in mice. Neurogastroenterol Motil, v. 25, n. 3, p. e18393, Mar 2013. ISSN 1365-2982 (Electronic)
$1350-1925$
(Linking).
Disponível
em:

http://www.ncbi.nlm.nih.gov/pubmed/23281940 >

138 AGUIAR, A. S., JR. et al. Short bouts of mild-intensity physical exercise improve spatial learning and memory in aging rats: involvement of hippocampal plasticity via AKT, CREB and BDNF signaling. Mech Ageing Dev, v. 132, n. $11-$ 12, p. 560-7, Nov-Dec 2011. ISSN 1872-6216 (Electronic)
0047-6374
(Linking).
Disponível
em:

http://www.ncbi.nlm.nih.gov/pubmed/21983475 >.

139 PASINI, E. et al. Effects of treadmill exercise and training frequency on anabolic signaling pathways in the skeletal muscle of aged rats. Exp Gerontol, v. 47, n. 1, p. 23-8, Jan 2012. ISSN 1873-6815 (Electronic) 0531-5565 (Linking).
Disponível
em: $<$ http://www.ncbi.nlm.nih.gov/pubmed/22015326 > .

140 COIMBRA, R. et al. Is gender crucial for cardiovascular adjustments induced by exercise training in female spontaneously hypertensive rats? Hypertension, v. 52, n. 3, p. 514-21, Sep 2008. ISSN 1524-4563 (Electronic) 
0194-911X

(Linking).

Disponível

em: $<$

http://www.ncbi.nlm.nih.gov/pubmed/18695147 >.

141 CERONI, A. et al. Chronic absence of baroreceptor inputs prevents training-induced cardiovascular adjustments in normotensive and spontaneously hypertensive rats. Exp Physiol, v. 94, n. 6, p. 630-40, Jun 2009. ISSN 1469-445X (Electronic)

0958-0670

(Linking).

Disponível

em:

$<$

http://www.ncbi.nlm.nih.gov/pubmed/19251981 >.

142 MELO, R. M.; MARTINHO, E., JR.; MICHELINI, L. C. Training-induced, pressure-lowering effect in SHR: wide effects on circulatory profile of exercised and nonexercised muscles. Hypertension, v. 42, n. 4, p. 851-7, Oct 2003. ISSN 1524-4563 (Electronic)

0194-911X

(Linking).

Disponível

em:

$<$

http://www.ncbi.nlm.nih.gov/pubmed/12913057 >.

143 KLETZIEN, $H$. et al. Differential Effects of Targeted Tongue Exercise and Treadmill Running on Aging Tongue Muscle Structure and Contractile Properties. J Appl Physiol, Dec 20 2012. ISSN 1522-1601 (Electronic)

0161-7567 (Linking). Disponível em: < http://www.ncbi.nlm.nih.gov/pubmed/23264540 >.

144 COPP, S. W. et al. Acute ascorbic acid and hindlimb skeletal muscle blood flow distribution in old rats: rest and exercise. Can J Physiol Pharmacol, v. 90, n. 11, p. 1498-505, Nov 2012. ISSN 1205-7541 (Electronic)

0008-4212 (Linking). Disponível em: < http://www.ncbi.nlm.nih.gov/pubmed/23181277 >.

145 BEHNKE, B. J. et al. Effects of aging and exercise training on skeletal muscle blood flow and resistance artery morphology. J Appl Physiol, v. 113, n. 11, p. 1699-708, Dec 1 2012. ISSN 1522-1601 (Electronic)

0161-7567 (Linking). Disponível em: < http://www.ncbi.nlm.nih.gov/pubmed/23042906 >.

146 REISI, P. et al. Effects of treadmill running on spatial learning and memory in streptozotocin-induced diabetic rats. Neurosci Lett, v. 455, n. 2, p. 79-83, May 15 2009. ISSN 1872-7972 (Electronic)
0304-3940
(Linking).
Disponível
em:

http://www.ncbi.nlm.nih.gov/pubmed/19368850 >.

147 GRIESBACH, G. S.; HOVDA, D. A.; GOMEZ-PINILLA, F. Exerciseinduced improvement in cognitive performance after traumatic brain injury in 
rats is dependent on BDNF activation. Brain Res, v. 1288, p. 105-15, Sep 8 2009. ISSN 1872-6240 (Electronic)

0006-8993 (Linking). Disponível em: < http://www.ncbi.nlm.nih.gov/pubmed/19555673 >.

148 BEN, J. et al. Running exercise effects on spatial and avoidance tasks in ovariectomized rats. Neurobiol Learn Mem, v. 94, n. 3, p. 312-7, Oct 2010. ISSN 1095-9564 (Electronic)

1074-7427 (Linking). Disponível em: < http://www.ncbi.nlm.nih.gov/pubmed/20659572 >.

149 HOVEIDA, R. et al. Treadmill running improves spatial memory in an animal model of Alzheimer's disease. Behav Brain Res, v. 216, n. 1, p. 270-4, Jan 1 2011. ISSN 1872-7549 (Electronic)

0166-4328 (Linking). Disponível em: < http://www.ncbi.nlm.nih.gov/pubmed/20709113 >.

$150 \mathrm{KIM}, \mathrm{S}$. E. et al. Treadmill exercise prevents aging-induced failure of memory through an increase in neurogenesis and suppression of apoptosis in rat hippocampus. Exp Gerontol, v. 45, n. 5, p. 357-65, May 2010. ISSN 18736815 (Electronic)

0531-5565 (Linking). Disponível em: < http://www.ncbi.nlm.nih.gov/pubmed/20156544 >.

151 CASSILHAS, R. C. et al. Spatial memory is improved by aerobic and resistance exercise through divergent molecular mechanisms. Neuroscience, v. 202, p. 309-17, Jan 27 2012. ISSN 1873-7544 (Electronic)

0306-4522 (Linking). Disponível em: < http://www.ncbi.nlm.nih.gov/pubmed/22155655 >.

152 AL-JARRAH, M. et al. Endurance exercise promotes cardiorespiratory rehabilitation without neurorestoration in the chronic mouse model of parkinsonism with severe neurodegeneration. Neuroscience, v. 149, n. 1, p. 2837, Oct 12 2007. ISSN 0306-4522 (Print)

0306-4522 (Linking). Disponível em: < http://www.ncbi.nlm.nih.gov/pubmed/17869432 >.

153 PIETRELLI, A. et al. Aerobic exercise prevents age-dependent cognitive decline and reduces anxiety-related behaviors in middle-aged and old rats. Neuroscience, v. 202, p. 252-66, Jan 27 2012. ISSN 1873-7544 (Electronic)
0306-4522
(Linking).
Disponível
em:

http://www.ncbi.nlm.nih.gov/pubmed/22183054 >. 

aged transgenic mouse model of Alzheimer's disease. Neurosci Res, v. 69, n. 2, p. 161-73, Feb 2011. ISSN 1872-8111 (Electronic)

0168-0102 (Linking). Disponível em: < http://www.ncbi.nlm.nih.gov/pubmed/20969897 >.

155 AGUIAR, A. S., JR. et al. Physical exercise improves motor and shortterm social memory deficits in reserpinized rats. Brain Res Bull, v. 79, n. 6, p. 452-7, Aug 14 2009. ISSN 1873-2747 (Electronic)
0361-9230
(Linking).
Disponível
em:
$<$

http://www.ncbi.nlm.nih.gov/pubmed/19463920 >.

156 FERRY, A.; LE PAGE, C.; RIEU, M. Sex as a determining factor in the effect of exercise on in vivo autoimmune response adjuvant arthritis. $J$ Appl Physiol, v. 76, n. 3, p. 1172-5, Mar 1994. ISSN 8750-7587 (Print)

0161-7567 (Linking). Disponível em: < http://www.ncbi.nlm.nih.gov/pubmed/8005860 >.

157 THANOS, P. K. et al. Chronic forced exercise during adolescence decreases cocaine conditioned place preference in Lewis rats. Behav Brain Res, v. 215, n. 1, p. 77-82, Dec 20 2010. ISSN 1872-7549 (Electronic)

0166-4328 (Linking). Disponível em: < http://www.ncbi.nlm.nih.gov/pubmed/20615434 >.

158 MAROSI, K. et al. Long-term exercise treatment reduces oxidative stress in the hippocampus of aging rats. Neuroscience, v. 226, p. 21-8, Dec 13 2012. ISSN 1873-7544 (Electronic)

0306-4522 (Linking). Disponível em: < http://www.ncbi.nlm.nih.gov/pubmed/22982624 >.

159 AKSU, I. et al. Effect of acute and chronic exercise on oxidantantioxidant equilibrium in rat hippocampus, prefrontal cortex and striatum. Neurosci Lett, v. 452, n. 3, p. 281-5, Mar 20 2009. ISSN 1872-7972 (Electronic) 0304-3940 (Linking). Disponível em: < http://www.ncbi.nlm.nih.gov/pubmed/18817845 >.

160 NEGRAO, C. E. et al. Vagal function impairment after exercise training. J Appl Physiol, v. 72, n. 5, p. 1749-53, May 1992. ISSN 8750-7587 (Print) 0161-7567 (Linking). Disponível em: < http://www.ncbi.nlm.nih.gov/pubmed/1601782 >.

161 HIGA-TANIGUCHI, K. T. et al. Exercise training-induced remodeling of paraventricular nucleus (nor)adrenergic innervation in normotensive and 
hypertensive rats. Am J Physiol Regul Integr Comp Physiol, v. 292, n. 4, p. R1717-27, Apr 2007. ISSN 0363-6119 (Print)

0363-6119 (Linking). Disponível em: < http://www.ncbi.nlm.nih.gov/pubmed/17218443 >.

162 CRUZ, J. C. et al. Peripheral chemoreceptors mediate training-induced plasticity in paraventricular nucleus pre-autonomic oxytocinergic neurons. Exp Physiol, v. 98, n. 2, p. 386-96, Feb 2013. ISSN 1469-445X (Electronic)

0958-0670 (Linking). Disponível em: < http://www.ncbi.nlm.nih.gov/pubmed/22872656 >.

163 JORDAO, M. T. et al. Exercise training restores hypertension-induced changes in the elastic tissue of the thoracic aorta. J Vasc Res, v. 48, n. 6, p. 513-24, 2011. ISSN 1423-0135 (Electronic)

1018-1172 (Linking). Disponível em: < http://www.ncbi.nlm.nih.gov/pubmed/21829037 >.

164 CAVALLERI, M. T. et al. Afferent signaling drives oxytocinergic preautonomic neurons and mediates training-induced plasticity. Am J Physiol Regul Integr Comp Physiol, v. 301, n. 4, p. R958-66, Oct 2011. ISSN 15221490 (Electronic)

0363-6119 (Linking). Disponível em: < http://www.ncbi.nlm.nih.gov/pubmed/21795633 >.

165 FELIX, J. V.; MICHELINI, L. C. Training-induced pressure fall in spontaneously hypertensive rats is associated with reduced angiotensinogen mRNA expression within the nucleus tractus solitarii. Hypertension, v. 50, n. 4, p. 780-5, Oct 2007. ISSN 1524-4563 (Electronic)

0194-911X (Linking). Disponível em: <
http://www.ncbi.nlm.nih.gov/pubmed/17646572 >.

166 HOLLOSZY, J. O. et al. Mitochondrial citric acid cycle and related enzymes: adaptive response to exercise. Biochem Biophys Res Commun, v. 40, n. 6, p. 1368-73, Sep 30 1970. ISSN 0006-291X (Print)

0006-291X (Linking). Disponível em: < http://www.ncbi.nlm.nih.gov/pubmed/4327015 >.

167 LEEK, B. T. et al. Effect of acute exercise on citrate synthase activity in untrained and trained human skeletal muscle. Am J Physiol Regul Integr Comp Physiol, v. 280, n. 2, p. R441-7, Feb 2001. ISSN 0363-6119 (Print)

0363-6119 (Linking). Disponível em: < http://www.ncbi.nlm.nih.gov/pubmed/11208573 >. 
SPINA, R. J. et al. Mitochondrial enzymes increase in muscle in response to 7-10 days of cycle exercise. J Appl Physiol (1985), v. 80, n. 6, p. 2250-4, Jun 1996. ISSN 8750-7587 (Print)

0161-7567

(Linking).

Disponível

em:

$<$

http://www.ncbi.nlm.nih.gov/pubmed/8806937 >.

169 FERNANDES, T. et al. AEROBIC EXERCISE TRAINING CORRECTS CAPILLARY RAREFACTION AND ALTERATIONS IN PROPORTIONS OF THE MUSCLE FIBERS TYPES IN SPONTANEOUSLY HYPERTENSIVE RATS. Rev Bras Med Esporte, v. 18, n. 4, jul/ago 20122012.

170 SIU, P. M. et al. Citrate synthase expression and enzyme activity after endurance training in cardiac and skeletal muscles. J Appl Physiol (1985), v. 94, n. 2, p. 555-60, Feb 2003. ISSN 8750-7587 (Print)

0161-7567

(Linking).

Disponível

em:

$<$

http://www.ncbi.nlm.nih.gov/pubmed/12531911 >.

$171 \mathrm{FLACH}, \mathrm{K}$. et al. Tau oligomers impair artificial membrane integrity and cellular viability. J Biol Chem, Nov 5 2012. ISSN 1083-351X (Electronic)

0021-9258 (Linking). Disponível em: < http://www.ncbi.nlm.nih.gov/entrez/query.fcgi?cmd=Retrieve\&db=PubMed\&dopt $=$ Citation\&list uids $=23129775$ > .

172 HOOVER, B. R. et al. Tau Mislocalization to Dendritic Spines Mediates Synaptic Dysfunction Independently of Neurodegeneration. Neuron, v. 68, n. 6, p. 1067-1081, 2010. Disponível em: < http://www.sciencedirect.com/science/article/pii/S0896627310009724 >.

173 CHUNG, C.-W. et al. Proapoptotic Effects of Tau Cleavage Product Generated by Caspase-3. Neurobiol Dis, v. 8, n. 1, p. 162-172, 2001. Disponível em:

http://www.sciencedirect.com/science/article/pii/S0969996100903358 >.

174 LASAGNA-REEVES, C. A. et al. Preparation and Characterization of Neurotoxic Tau Oligomers. Biochemistry, v. 49, n. 47, p. 10039-10041, 2012/11/18 2010. Disponível em: < http://dx.doi.org/10.1021/bi1016233 >.

175 RIEMER, J.; KINS, S. Axonal Transport and Mitochondrial Dysfunction in Alzheimer's Disease. Neurodegener Dis, Sep 28 2012. ISSN 1660-2862 (Electronic)

1660-2854 (Linking). Disponível em: < http://www.ncbi.nlm.nih.gov/pubmed/23037012 >. 

mitochondria in cell and animal models of Parkinson's disease. J Neurochem, Apr 26 2012. ISSN 1471-4159 (Electronic)

0022-3042 (Linking). Disponível em: < http://www.ncbi.nlm.nih.gov/pubmed/22537068 >.

177 MELO, T. Q. et al. Rotenone-Dependent Changes of Anterograde Motor Protein Expression and Mitochondrial Mobility in Brain Areas Related to Neurodegenerative Diseases. Cell Mol Neurobiol, Dec 22 2012. ISSN 15736830 (Electronic)

(Linking).

Disponível

em: $<$ http://www.ncbi.nlm.nih.gov/pubmed/23263842 >.

178 TANG, Y. et al. Early and selective impairments in axonal transport kinetics of synaptic cargoes induced by soluble amyloid beta-protein oligomers. Traffic, v. 13, n. 5, p. 681-93, May 2012. ISSN 1600-0854 (Electronic) 1398-9219
(Linking).
Disponível
em:

http://www.ncbi.nlm.nih.gov/pubmed/22309053 >.

179 HERAS-SANDOVAL, D.; FERRERA, P.; ARIAS, C. Amyloid-beta protein modulates insulin signaling in presynaptic terminals. Neurochem Res, v. 37, n. 9, p. 1879-85, Sep 2012. ISSN 1573-6903 (Electronic)

0364-3190 (Linking). Disponível em: <
http://www.ncbi.nlm.nih.gov/pubmed/22638775 > .

180 GAUGLER, M. N. et al. Nigrostriatal overabundance of alpha-synuclein leads to decreased vesicle density and deficits in dopamine release that correlate with reduced motor activity. Acta Neuropathol, v. 123, n. 5, p. 653-69, May 2012. ISSN 1432-0533 (Electronic)

0001-6322 (Linking). Disponível em: < http://www.ncbi.nlm.nih.gov/pubmed/22361813 > .

181 FANG, C.; BOURDETTE, D.; BANKER, G. Oxidative stress inhibits axonal transport: implications for neurodegenerative diseases. Mol Neurodegener, v. 7, p. 29, 2012. ISSN 1750-1326 (Electronic)

1750-1326 (Linking). Disponível em: < http://www.ncbi.nlm.nih.gov/pubmed/22709375 >.

182 UMEDA, T. et al. Intraneuronal amyloid beta oligomers cause cell death via endoplasmic reticulum stress, endosomal/lysosomal leakage, and mitochondrial dysfunction in vivo. J Neurosci Res, v. 89, n. 7, p. 1031-42, Jul 2011. ISSN 1097-4547 (Electronic) 
0360-4012

(Linking).

Disponível

em: $<$

http://www.ncbi.nlm.nih.gov/pubmed/21488093 >.

183 HIRSCH, E. C. et al. Animal models of Parkinson's disease in rodents induced by toxins: an update. J Neural Transm Suppl, n. 65, p. 89-100, 2003. ISSN 0303-6995 (Print)

0303-6995 (Linking). Disponível em: < http://www.ncbi.nlm.nih.gov/pubmed/12946051 >.

184 XIONG, N. et al. Mitochondrial complex I inhibitor rotenone-induced toxicity and its potential mechanisms in Parkinson's disease models. Crit Rev Toxicol, v. 42, n. 7, p. 613-32, Aug 2012. ISSN 1547-6898 (Electronic)

1040-8444 (Linking). Disponível em: < http://www.ncbi.nlm.nih.gov/pubmed/22574684 >.

185 BLESA, J. et al. Classic and new animal models of Parkinson's disease. J Biomed Biotechnol, v. 2012, p. 845618, 2012. ISSN 1110-7251 (Electronic) 1110-7243 (Linking). Disponível em: < http://www.ncbi.nlm.nih.gov/pubmed/22536024 >.

186 ISAACS, $A$. M. et al. Acceleration of amyloid beta-peptide aggregation by physiological concentrations of calcium. J Biol Chem, v. 281, n. 38, p. 2791623, Sep 22 2006. ISSN 0021-9258 (Print)

0021-9258 (Linking). Disponível em: < http://www.ncbi.nlm.nih.gov/pubmed/16870617 >.

187 LEUNER, K. et al. Mitochondrion-Derived Reactive Oxygen Species Lead to Enhanced Amyloid Beta Formation. Antioxidants \& Redox Signaling, v. 16, n. 12, p. 1421-1433, Jun 2012. ISSN 1523-0864. Disponível em: < <Go to ISI>://000303047100005 >.

188 SWARNKAR, S. et al. Rotenone-induced apoptosis and role of calcium: a study on Neuro-2a cells. Arch Toxicol, Apr 24 2012. ISSN 1432-0738 (Electronic)

0340-5761 (Linking). Disponível em: < http://www.ncbi.nlm.nih.gov/pubmed/22526376 > .

189 ALMEIDA, M. F. D. et al. Protein aggregation and carbonylation in hippocampus, locus coeruleus and substantia nigra of aged rats exposed to low and moderate doses of rotenone. Neuroscience Research, In press 2015.

190 LUBERG, K. et al. Human TrkB gene: novel alternative transcripts, protein isoforms and expression pattern in the prefrontal cerebral cortex during 
postnatal development. J Neurochem, v. 113, n. 4, p. 952-64, May 2010. ISSN 1471-4159 (Electronic)

0022-3042 (Linking). Disponível em: < http://www.ncbi.nlm.nih.gov/pubmed/20193039 >.

191 MIDDLEMAS, D. S.; LINDBERG, R. A.; HUNTER, T. trkB, a neural receptor protein-tyrosine kinase: evidence for a full-length and two truncated receptors. Mol Cell Biol, v. 11, n. 1, p. 143-53, Jan 1991. ISSN 0270-7306 (Print)

0270-7306 (Linking). Disponível em: < http://www.ncbi.nlm.nih.gov/pubmed/1846020 >.

192 CARIM-TODD, L. et al. Endogenous truncated TrkB.T1 receptor regulates neuronal complexity and TrkB kinase receptor function in vivo. J Neurosci, v. 29, n. 3, p. 678-85, Jan 21 2009. ISSN 1529-2401 (Electronic) 0270-6474 (Linking). Disponível em: < http://www.ncbi.nlm.nih.gov/pubmed/19158294 >.

193 KLEIN, R. et al. Targeted disruption of the trkB neurotrophin receptor gene results in nervous system lesions and neonatal death. Cell, v. 75, n. 1, p. 113-22, Oct 8 1993. ISSN 0092-8674 (Print)

0092-8674 (Linking). Disponível em: < http://www.ncbi.nlm.nih.gov/pubmed/8402890 >.

194 PUZZOLO, E.; MALLAMACI, A. Cortico-cerebral histogenesis in the opossum Monodelphis domestica: generation of a hexalaminar neocortex in the absence of a basal proliferative compartment. Neural Dev, v. 5, p. 8, 2010. ISSN 1749-8104 (Electronic)

1749-8104 (Linking). Disponível em: < http://www.ncbi.nlm.nih.gov/pubmed/20302607 >.

195 BARTKOWSKA, K. et al. Distribution and function of TrkB receptors in the developing brain of the opossum Monodelphis domestica. Dev Neurobiol, Jan 20 2014. ISSN 1932-846X (Electronic)

1932-8451 (Linking). Disponível em: < http://www.ncbi.nlm.nih.gov/pubmed/24443161 >.

196 LEIN, E. S.; SHATZ, C. J. Rapid regulation of brain-derived neurotrophic factor mRNA within eye-specific circuits during ocular dominance column formation. J Neurosci, v. 20, n. 4, p. 1470-83, Feb 15 2000. ISSN 0270-6474 (Print)

0270-6474 (Linking). Disponível em: < http://www.ncbi.nlm.nih.gov/pubmed/10662837 >. 
KANEKO, M. et al. Dendritic BDNF synthesis is required for late-phase spine maturation and recovery of cortical responses following sensory deprivation. J Neurosci, v. 32, n. 14, p. 4790-802, Apr 4 2012. ISSN 1529-2401 (Electronic)

0270-6474

(Linking).

Disponível

em: $<$ http://www.ncbi.nlm.nih.gov/pubmed/22492034 >.

198 CHENG, A. et al. Truncated tyrosine kinase B brain-derived neurotrophic factor receptor directs cortical neural stem cells to a glial cell fate by a novel signaling mechanism. J Neurochem, v. 100, n. 6, p. 1515-30, Mar 2007. ISSN 0022-3042 (Print)

0022-3042 (Linking). Disponível em: < http://www.ncbi.nlm.nih.gov/pubmed/17286628 >.

199 BARTKOWSKA, K. et al. Trk signaling regulates neural precursor cell proliferation and differentiation during cortical development. Development, $v$. 134, n. 24, p. 4369-80, Dec 2007. ISSN 0950-1991 (Print)

0950-1991 (Linking). Disponível em: < http://www.ncbi.nlm.nih.gov/pubmed/18003743 >.

$200 \mathrm{KAO}, \mathrm{P}$. F. et al. Increased expression of TrkB and Capzb2 accompanies preserved cognitive status in early Alzheimer disease pathology. $\mathrm{J}$ Neuropathol Exp Neurol, v. 71, n. 7, p. 654-64, Jul 2012. ISSN 1554-6578 (Electronic)

0022-3069

(Linking). Disponível

em:

http://www.ncbi.nlm.nih.gov/pubmed/22710966 > .

201 ZHU, M.; LU, C.; LI, W. Transient exposure to echinacoside is sufficient to activate Trk signaling and protect neuronal cells from rotenone. J Neurochem, v. 124, n. 4, p. 571-80, Feb 2013. ISSN 1471-4159 (Electronic)

0022-3042 (Linking). Disponível em: < http://www.ncbi.nlm.nih.gov/pubmed/23189969 >.

202 FENNER, M. E.; ACHIM, C. L.; FENNER, B. M. Expression of full-length and truncated trkB in human striatum and substantia nigra neurons: implications for Parkinson's disease. J Mol Histol, v. 45, n. 3, p. 349-61, Jun 2014. ISSN 1567-2387 (Electronic)

1567-2379 (Linking). Disponível em: < http://www.ncbi.nlm.nih.gov/pubmed/24374887 >.

203 DING, Y. X. et al. The TrkB-positive dopaminergic neurons are less sensitive to MPTP insult in the substantia nigra of adult C57/BL mice. 
Neurochem Res, v. 36, n. 10, p. 1759-66, Oct 2011. ISSN 1573-6903 (Electronic)

0364-3190

(Linking).

Disponível

em:

$<$

http://www.ncbi.nlm.nih.gov/pubmed/21562748 >.

204 SILVA, C. M. D. Autofagocitose e estresse oxidativo no sistema nervoso central de ratos idosos submetidos ao exercício físico moderado. 2015. 113 Faculdade de Medicina Universidade de São Paulo, São Paulo.

205 FRYER, R. H. et al. Developmental and mature expression of full-length and truncated TrkB receptors in the rat forebrain. J Comp Neurol, v. 374, n. 1, p. 21-40, Oct 7 1996. ISSN 0021-9967 (Print)

0021-9967 (Linking). Disponível em: < http://www.ncbi.nlm.nih.gov/pubmed/8891944 >.

206 OHIRA, K.; SHIMIZU, K.; HAYASHI, M. Change of expression of fulllength and truncated TrkBs in the developing monkey central nervous system. Brain Res Dev Brain Res, v. 112, n. 1, p. 21-9, Jan 11 1999. ISSN 0165-3806 (Print)

0165-3806 (Linking). Disponível em: < http://www.ncbi.nlm.nih.gov/pubmed/9974156 >.

207 SILHOL, M. et al. Age-related changes in brain-derived neurotrophic factor and tyrosine kinase receptor isoforms in the hippocampus and hypothalamus in male rats. Neuroscience, v. 132, n. 3, p. 613-24, 2005. ISSN 0306-4522 (Print)

0306-4522 (Linking). Disponível em: < http://www.ncbi.nlm.nih.gov/pubmed/15837123 >.

208 FRISEN, J. et al. Characterization of glial trkB receptors: differential response to injury in the central and peripheral nervous systems. Proc Natl Acad Sci U S A, v. 90, n. 11, p. 4971-5, Jun 1 1993. ISSN 0027-8424 (Print)

0027-8424 (Linking). Disponível em: < http://www.ncbi.nlm.nih.gov/pubmed/8389459 >

209 GINSBERG, S. D. et al. Down regulation of trk but not p75NTR gene expression in single cholinergic basal forebrain neurons mark the progression of Alzheimer's disease. J Neurochem, v. 97, n. 2, p. 475-87, Apr 2006. ISSN 00223042 (Print)

0022-3042 (Linking). Disponível em: < http://www.ncbi.nlm.nih.gov/pubmed/16539663 > . 
ROSTAMI, E. et al. Alteration in BDNF and its receptors, full-length and truncated TrkB and p75(NTR) following penetrating traumatic brain injury. Brain Res, v. 1542, p. 195-205, Jan 13 2014. ISSN 1872-6240 (Electronic)

0006-8993

(Linking).

Disponível

em:

http://www.ncbi.nlm.nih.gov/pubmed/24192075 >.

211 FRADE, J. M.; RODRIGUEZ-TEBAR, A.; BARDE, Y. A. Induction of cell death by endogenous nerve growth factor through its p75 receptor. Nature, v. 383, n. 6596, p. 166-8, Sep 12 1996. ISSN 0028-0836 (Print)

0028-0836 (Linking). Disponível em: < http://www.ncbi.nlm.nih.gov/pubmed/8774880 >

212 HUANG, E. J.; REICHARDT, L. F. Neurotrophins: roles in neuronal development and function. Annu Rev Neurosci, v. 24, p. 677-736, 2001. ISSN 0147-006X (Print)

0147-006X (Linking). Disponível em: < http://www.ncbi.nlm.nih.gov/pubmed/11520916 >.

213 SHULGA, A. et al. The loop diuretic bumetanide blocks posttraumatic p75NTR upregulation and rescues injured neurons. J Neurosci, v. 32, n. 5, p. 1757-70, Feb 1 2012. ISSN 1529-2401 (Electronic)
0270-6474
(Linking).
Disponível
em:

http://www.ncbi.nlm.nih.gov/pubmed/22302815 >.

214 NAUMANN, T. et al. Complete deletion of the neurotrophin receptor p75NTR leads to long-lasting increases in the number of basal forebrain cholinergic neurons. J Neurosci, v. 22, n. 7, p. 2409-18, Apr 1 2002. ISSN 15292401 (Electronic)

0270-6474 (Linking). Disponível em: < http://www.ncbi.nlm.nih.gov/pubmed/11923404 >.

215 EIDE, F. F. et al. Naturally occurring truncated trkB receptors have dominant inhibitory effects on brain-derived neurotrophic factor signaling. J Neurosci, v. 16, n. 10, p. 3123-9, May 15 1996. ISSN 0270-6474 (Print)

0270-6474 (Linking). Disponível em: < http://www.ncbi.nlm.nih.gov/pubmed/8627351 >.

216 DRAKE, C. T.; MILNER, T. A.; PATTERSON, S. L. Ultrastructural localization of full-length trkB immunoreactivity in rat hippocampus suggests multiple roles in modulating activity-dependent synaptic plasticity. J Neurosci, v. 19, n. 18, p. 8009-26, Sep 15 1999. ISSN 1529-2401 (Electronic)

0270-6474 (Linking).

Disponível

em:

http://www.ncbi.nlm.nih.gov/pubmed/10479701 >. 

of trkB.TK+-mediated cell survival. Biochem Biophys Res Commun, v. 280, n. 5, p. 1352-8, Feb 9 2001. ISSN 0006-291X (Print)

0006-291X (Linking). Disponível em: <
http://www.ncbi.nlm.nih.gov/pubmed/11162678 >.

218 BIFFO, S. et al. Selective binding and internalisation by truncated receptors restrict the availability of BDNF during development. Development, v. 121, n. 8, p. 2461-70, Aug 1995. ISSN 0950-1991 (Print)

0950-1991 (Linking). Disponível em: < http://www.ncbi.nlm.nih.gov/pubmed/7671810 >.

219 KLEIN, R. et al. The trkB tyrosine protein kinase gene codes for a second neurogenic receptor that lacks the catalytic kinase domain. Cell, v. 61, n. 4, p. 647-56, May 18 1990. ISSN 0092-8674 (Print)

0092-8674 (Linking). Disponível em: <
http://www.ncbi.nlm.nih.gov/pubmed/2160854 >.

220 REAL, C. C. et al. BDNF receptor blockade hinders the beneficial effects of exercise in a rat model of Parkinson's disease. Neuroscience, v. 237, p. 11829, May 1 2013. ISSN 1873-7544 (Electronic)

0306-4522 (Linking). Disponível em: < http://www.ncbi.nlm.nih.gov/pubmed/23396085 >.

$221 \mathrm{JI}, \mathrm{J} . \mathrm{F}$. et al. Forced running exercise attenuates hippocampal neurogenesis impairment and the neurocognitive deficits induced by wholebrain irradiation via the BDNF-mediated pathway. Biochem Biophys Res Commun, v. 443, n. 2, p. 646-51, Jan 10 2014. ISSN 1090-2104 (Electronic)

0006-291X (Linking). Disponível em: < http://www.ncbi.nlm.nih.gov/pubmed/24333433 >.

222 VAEGTER, C. B. et al. Sortilin associates with Trk receptors to enhance anterograde transport and neurotrophin signaling. Nat Neurosci, v. 14, n. 1, p. 54-61, Jan 2011. ISSN 1546-1726 (Electronic)

1097-6256 (Linking). Disponível em: < http://www.ncbi.nlm.nih.gov/pubmed/21102451 >.

223 SEGAL, R. A. Selectivity in neurotrophin signaling: theme and variations. Annu Rev Neurosci, v. 26, p. 299-330, 2003. ISSN 0147-006X (Print)

0147-006X (Linking). Disponível em: < http://www.ncbi.nlm.nih.gov/pubmed/12598680 >. 

during, and after synapse formation between cortical neurons. J Neurosci, v. 26, n. 44, p. 11487-500, Nov 1 2006. ISSN 1529-2401 (Electronic)

0270-6474 (Linking).

Disponível em: $<$ http://www.ncbi.nlm.nih.gov/pubmed/17079678 >.

225 DEINHARDT, K. et al. Rab5 and Rab7 control endocytic sorting along the axonal retrograde transport pathway. Neuron, v. 52, n. 2, p. 293-305, Oct 19 2006. ISSN 0896-6273 (Print)

0896-6273 (Linking). Disponível em: < http://www.ncbi.nlm.nih.gov/pubmed/17046692 >.

226 GLEBOVA, N. O.; GINTY, D. D. Growth and survival signals controlling sympathetic nervous system development. Annu Rev Neurosci, v. 28, p. 191 222, 2005. ISSN 0147-006X (Print)

0147-006X (Linking). Disponível em: < http://www.ncbi.nlm.nih.gov/pubmed/16022594 >.

227 FUKATA, Y. et al. CRMP-2 binds to tubulin heterodimers to promote microtubule assembly. Nat Cell Biol, v. 4, n. 8, p. 583-91, Aug 2002. ISSN 1465-7392 (Print)

1465-7392 (Linking). Disponível em: <
http://www.ncbi.nlm.nih.gov/pubmed/12134159 >.

228 INAGAKI, N. et al. CRMP-2 induces axons in cultured hippocampal neurons. Nat Neurosci, v. 4, n. 8, p. 781-2, Aug 2001. ISSN 1097-6256 (Print)

1097-6256 (Linking). Disponível em: < http://www.ncbi.nlm.nih.gov/pubmed/11477421 >.

229 NISHIMURA, T. et al. CRMP-2 regulates polarized Numb-mediated endocytosis for axon growth. Nat Cell Biol, v. 5, n. 9, p. 819-26, Sep 2003. ISSN 1465-7392 (Print)

1465-7392 (Linking). Disponível em: < http://www.ncbi.nlm.nih.gov/pubmed/12942088 >.

230 PETERSEN, C. M. et al. Molecular identification of a novel candidate sorting receptor purified from human brain by receptor-associated protein affinity chromatography. J Biol Chem, v. 272, n. 6, p. 3599-605, Feb 71997. ISSN 0021-9258 (Print)

0021-9258 (Linking). Disponível em: < http://www.ncbi.nlm.nih.gov/pubmed/9013611 >. 
MAZELLA, J. et al. The 100-kDa neurotensin receptor is gp95/sortilin, a non-G-protein-coupled receptor. J Biol Chem, v. 273, n. 41, p. 26273-6, Oct 9 1998. ISSN 0021-9258 (Print)

0021-9258 (Linking).

Disponível

em:

http://www.ncbi.nlm.nih.gov/pubmed/9756851 >.

232 NIELSEN, M. S. et al. Sortilin/neurotensin receptor-3 binds and mediates degradation of lipoprotein lipase. J Biol Chem, v. 274, n. 13, p. 88326, Mar 26 1999. ISSN 0021-9258 (Print)

0021-9258

(Linking).

Disponível

em:

$<$

http://www.ncbi.nlm.nih.gov/pubmed/10085125 >.

LEFRANCOIS, $S$. et al. The lysosomal trafficking of sphingolipid activator proteins (SAPs) is mediated by sortilin. EMBO J, v. 22, n. 24, p. 64307, Dec 15 2003. ISSN 0261-4189 (Print)

0261-4189

(Linking).

Disponível

em:

http://www.ncbi.nlm.nih.gov/pubmed/14657016 >.

234 PATTERSON, S. L. et al. Recombinant BDNF rescues deficits in basal synaptic transmission and hippocampal LTP in BDNF knockout mice. Neuron, v. 16, n. 6, p. 1137-45, Jun 1996. ISSN 0896-6273 (Print) 0896-6273
(Linking).
Disponível
em:

http://www.ncbi.nlm.nih.gov/pubmed/8663990 >

235 PANG, P. T. et al. Cleavage of proBDNF by tPA/plasmin is essential for long-term hippocampal plasticity. Science, v. 306, n. 5695, p. 487-91, Oct 15 2004. ISSN 1095-9203 (Electronic)

0036-8075 (Linking). Disponível em: < http://www.ncbi.nlm.nih.gov/pubmed/15486301 >.

236 LEE, R. et al. Regulation of cell survival by secreted proneurotrophins. Science, v. 294, n. 5548, p. 1945-8, Nov 30 2001. ISSN 0036-8075 (Print)

0036-8075 (Linking). Disponível em: < http://www.ncbi.nlm.nih.gov/pubmed/11729324 >.

237 TENG, H. K. et al. ProBDNF induces neuronal apoptosis via activation of a receptor complex of p75NTR and sortilin. J Neurosci, v. 25, n. 22, p. 5455-63, Jun 1 2005. ISSN 1529-2401 (Electronic)

0270-6474

(Linking).

Disponível

em:

http://www.ncbi.nlm.nih.gov/pubmed/15930396 >. 
ANEXOS 
ANEXO 1

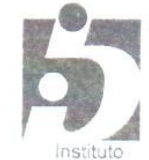

de Biocienncias

OF.CEUA/IB/050/201 1

Ref. 2011.1.863.41.9

São Paulo. 26 de setembro de 2011

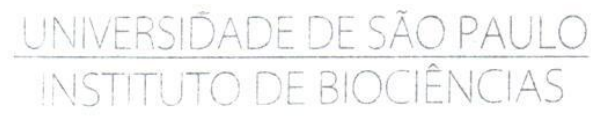

Prezada Senhora

Dirijo-me a V. Sa para informar que a Comissão de Ética em Uso de Animais do IB (CEUA), em reunião realizada nesta data, APROVOU o Projeto "Efeitos da atividade física espontânea sobre o tráfego de neurotrofinas e seus receptores no sistema nervoso central de ratos idosos" - Protocolo 138/2011, de sua responsabilidade (Colaboradora: Michael Fernandes de Almeida)

\footnotetext{
Atenciosamente

Profa. Dra. Mariz Vainzof

Coordenadora da Comissão de Ética no

Uso de Animais do IB (CEUA)
}

Ilma. Sra.

Profa. Dra. MERARI DE FÁTIMA RAMIRES FERRARI

Departamento de Genética e Biologia Evolutiva do IBUSP. 


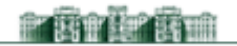 \\ MEDICINA \\ TSP \\ COMITÊ DE ÉTICA EM PESQUISA}

\section{CIÊNCIA}

O Comitê de Ética em Pesquisa da Faculdade de Medicina da Universidade de São Paulo, em 03 de Abril de 2013, TOMOU CIÊNCIA do(s) documento(s) abaixo mencionado(s) no Protocolo de Pesquisa $n^{\circ}$ 451/11, intitulado: "EFEITOS DA ATIVIDADE FísICA ESPONTÂNEA SOBRE O TRÁFEGO DE NEUROTROFINAS E SEUS RECEPTORES NO SISTEMA NERVOSO CENTRAL DE RATOS IDOSOS." apresentado pelo PROGRAMA DE FISIOPATOLOGIA EXPERIMENTAL.

- Alteração no tífulo do projeto para: Éeitos do exercício físico moderado sobre o tráfego de neurotrofinas e seus receptores no sistema nervoso central de ratos idosos.

Pesquisador (a) Responsável: Merari de Fátima Ramires Ferrari

CEP-FMUSP, 04 de Abril de 2013.

PClavems.

Prof. Dr. Roger Chammas Coordenador

Comitê de Ética em Pesquisa 


\title{
ANEXO 3
}

\author{
Elsevier Editorial System(tm) for Neuroscience Research \\ Manuscript Draft
}

Manuscript Number: NSR-D-15-00201

Title: Protein aggregation and carbonylation in hippocampus, locus coeruleus and substantia nigra of aged rats exposed to low and moderate doses of rotenone

Article Type: Research Report

Section/Category: Neuroscience of Disease

Keywords: neurodegeneration, protein aggregates, protein carbonyls

Corresponding Author: Ms. Michael Fernandes de Almeida,

Corresponding Author's Institution: University of Sao Paulo

First Author: Michael Fernandes de Almeida

Order of Authors: Michael Fernandes de Almeida; Carolliny M da Silva, Master`s student; Aline M D`unhão; Merari F Ramires Ferrari , Professor

Manuscript Region of Origin: BRAZIL

Abstract: Protein aggregates are often present during the course of neurodegeneration, however it is patent that cell physiology may be impaired well before early stages of aggregation and this may be more important than protein inclusions themselves for cell death. Considering this, the present study aims to examine the effects of low doses of rotenone on tau hyperphosphorylation, beta-amyloid formation, alpha-synuclein expression and oxidative stress in the brain of aged Lewis rats. Aged rats were exposed to 1 or $2 \mathrm{mg} / \mathrm{kg} /$ day of rotenone delivered subcutaneously through mini-pumps, during one month, the hippocampus, substantia nigra and locus coeruleus were extracted and analyzed by immunocytochemistry, western blotting and protein carbonylation assays. Results demonstrated that rotenone at $2 \mathrm{mg} / \mathrm{kg} /$ day promoted increase in amyloid-beta peptide, hyperphosphorylation of tau and alpha-synuclein expression. However, rotenone at $1 \mathrm{mg} / \mathrm{kg} /$ day did not alter protein levels in brain regions analyzed. In conclusion, the present study demonstrated that low dose of rotenone $(1 \mathrm{mg} / \mathrm{kg} /$ day), did not trigger increase in tau hyperphosphorylation, beta-amyloid formation, alphasynuclein expression levels and oxidative stress in the brain of aged rats, validating the use of this model to study cellular processes of protein aggregation. 